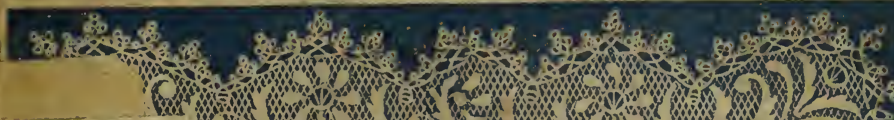

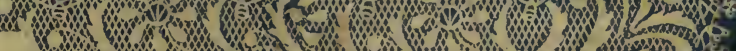

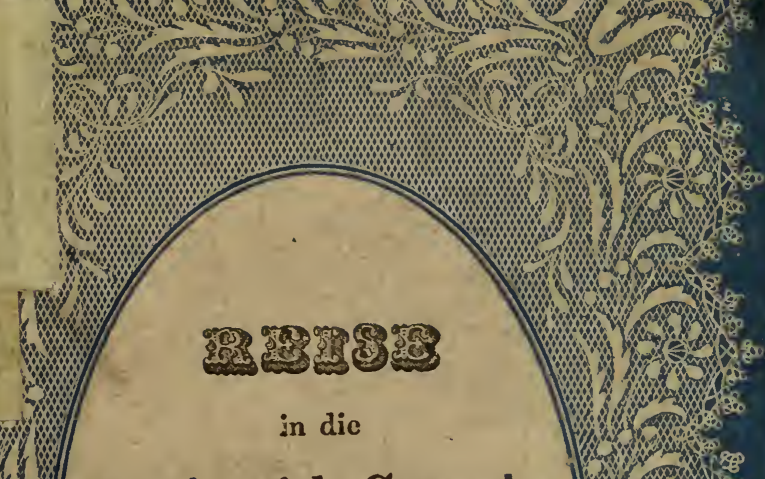

Geros

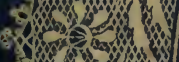

Eivoris

is

ais

Bive

-

Aequinoctial - Gegenden

neuen Continents.

8200 -

Dive

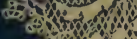

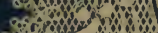

98. 000 -

9:0

$08 \times ?$ ? $3=1$

ail 1000

coing

if ond and

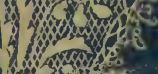

neuen Continents.

\& 10000

o. 0.0

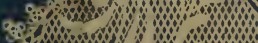

cosos

Viertes Bändchen.

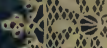

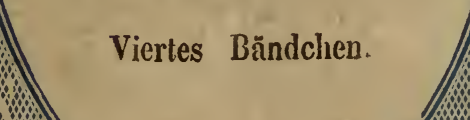

a. 10.020 in 2018 12000000 260 100 $00 \%$

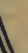

Ais.

\&

8.

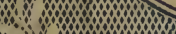
100000000

O.

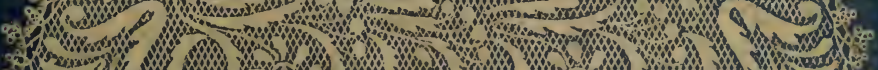

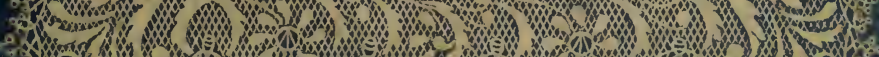

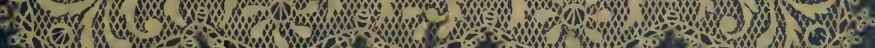

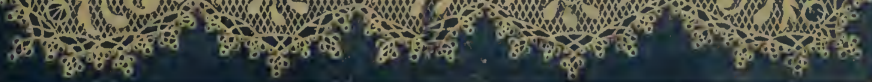



Digitized by the Internet Archive in 2013 




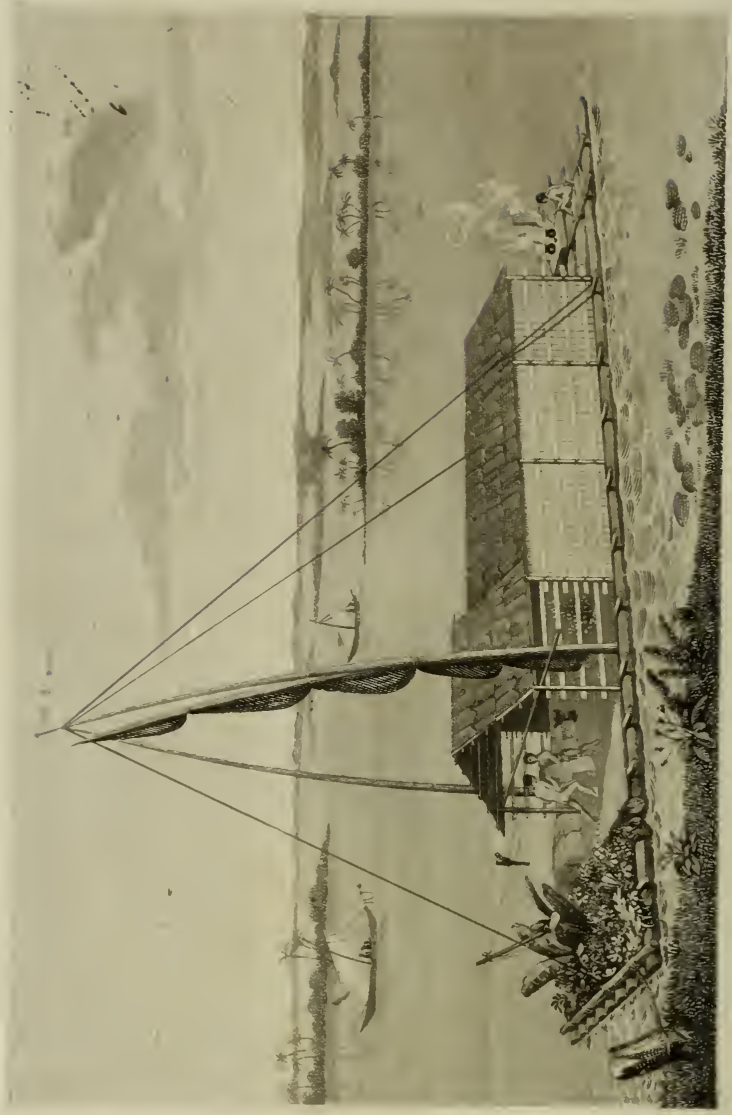

2 
Des

Freiherrn Alexander von Humboldt und Aimé Bonpland
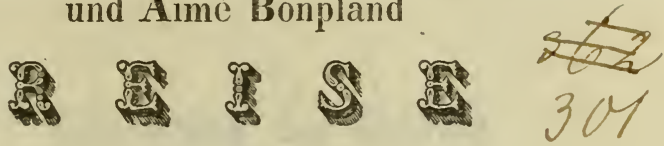

in die

Aequinoctial-Gegenden des

\title{
neuen Continemts,
}

\author{
für die
}

reifere Fugend zuer belehrenden: Olnterkaltung be a r beitet

von

G. A. Wimmer.

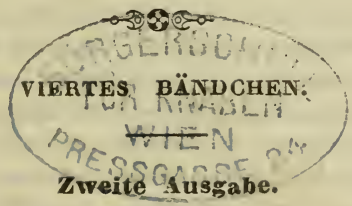

Mit $\mathrm{Hupfern}$ und Charten.

VIEN.

Gedruckt und im Yerlage bei Carl Gerold.

1844. 


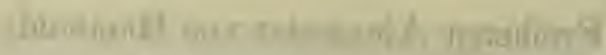

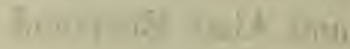

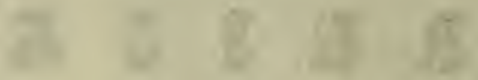

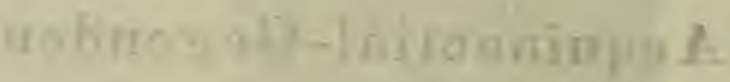
1

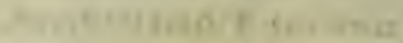

$$
\text { wo } \quad y
$$

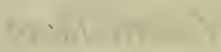

$4 x+8=$

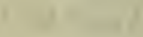

$x+1$
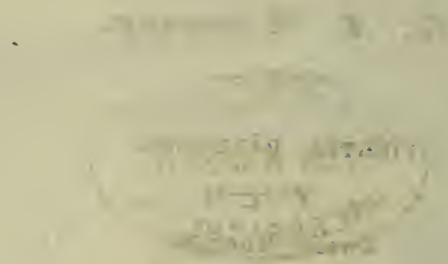

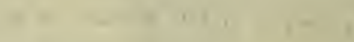

nes

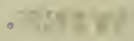

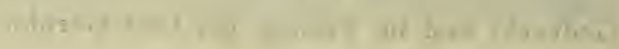

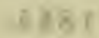




\title{
Erklärung der Kupfer
}

\author{
des
}

\section{$r$ i e r t e n $B$ ä $n$ d c h e n s,}

svelche theils zur Zierde, hauptsächlich aber zur Versinulichung der vorkommenden Gegenstände beigegeben worden.

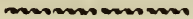 \\ I. \\ Das Flofs von-Guayaquil. (Titelkupfer.)}

$D_{\text {ieses schöne Kupfer ist darum beigegeben, um den jungen }}$ Lesern so einen recht erfreulichen Blick in die südliche Welt thun zu lassen, und die ganze Pracht einer tropischen Landschaft ror ihnen zu entfalten. Dieses Flors ist eines von deuen, deren sich dret Peruaner seit den ältesten Zeiten bedienen, um an den Küsten des Südmeeres und an der Mündung des Flusses Guayaquil ihre Transporte zu verrichten. $\Delta$ uf dem Vordertheile ist ein Haufe des verschiedensten Pflanzen und Früchte der Tropenwelt zusammengehäuft : Ananas, Bananen, Passionsblumen u. s. w. Sie gewähren einen heitern Anblick. Die Flofse selbst bestehen aus 8 bis $9 \mathrm{Bal}$ ken ron sehr leichtem Holze, sind dem Anschen nach schwerfällig aber doch sehr leicht zu.regieren. Man bedient sich ihres $2 \mathrm{um}$ Fischfange wie zum Waarentransporte. Die Leute, welche auf diesem. Flofse beschäftigt sind, erinnern durch ihre leichte Klei- 
dung, dafs ihre Blicke auf Palmeninseln zu ruhen gowohnt sind Diese Inseln stellen sich auch im Hintergrunde malcrisch gruppirt dar.

\section{II.}

\section{Briefpost der Provinz Jaen de Braccamoros.}

Dieses schöne Blatt soll meinen jungen Lesern die Lebenswcise der Menschen jener Länder vor Augen bringen, in denen der Mensch bis jetzt noch kcineswegs als Gebietcr, sondern mchr als ein geduldeter Gast aufgetreten ist. Keine Poststrafsen durchschneiden jene Wildnisse, und nur mit Mühe bahnt sich der Wilde den Weg durch das verwachsene Gesträuch. Selbst den wilden Vierfüfsern sind manche Striche unzugänglich, wie wir bei Gelegenheit der Reise auf dem Apure gesehen haben. Zwischen Peru und der Provinz Jaen de Braccamoros am Amazonenstrome liegt eine grofse waldige Strecke, welche keine andere, als eine Wasserstrafse hat. Der Courir, welcher ron einer Proviuz zur andern die Briefe zu besorgen hat, schwimmt auf den Flüssen; zuerst im Guancabamba und aus diesem in den Amazonenstrom. Die Briefe, welche ihm anvertraut sind, hat er bald in ein Tuch, bald in den Gürtel (Guayuco) eingeschlagen und um den Kopf gewunden. Eben da steckt auch die Manchette, ein grofses Messer, das jeder Indianer besitzt, um sich sowohl zu vertheidigen, als hauptsächlich einen Weg durch die Wildnifs zu bahneu.

Der Courir von Truxillo wird daher im Lande der schwimmende Bote genannt. Unsere Tafel seigt ihn schwimmend, ein Stück Holz unterm Arme und auch wie er sich bereitet, die Bricfe eine supacken und sich in den Flufs za werfen. Um im Schwimmen nicht zu ermüden, nimmt er ein Stück leichtes $\mathrm{Holz}$ von einem Bombay oder einer Ochroma zu sich; an reifsenden Stellen und Wasserfällen steigt er aus, und geht die Strecke zu Lande, wirft sich aber wieder in's Wasser, sobald er heine Gefahr mehr sieht. Auch braucht er keine Lebensmittel mit sich zu nehmen, denn ex findet in den häufigen Hütten und Pflanzungen längs den Ufern gastfreie Aufnahme. 
Manchmal nimmt er, der Kurzweile wegen, noch einen Ge. fährten mit sich. Die Flüsse, welche sich oberhalb Pongo de Magasi mit dem Amazonenstrome vereinigen, haben glücklicher Weise keine Krokodille. Auch die Indianerhorden jener Gegenden reisen auf dieselbe Manier, wie der Courir von Peru. Hat er in Tomependa nach vollbrachter Botschaft ausgeruht, so kehrt er durch den Paramo del Pareton oder tiber den wilden Weg, der durch die Dörfer San Felipe und Sagique und die Chinawälder führt, nach Peru zurück.

\section{IiI.}

Der Grundrifs der Stałt und des Hafens von Havannah. 



\section{R e i s e}

in die

A equinoctial-Gegenden

des

neuen Continents. 


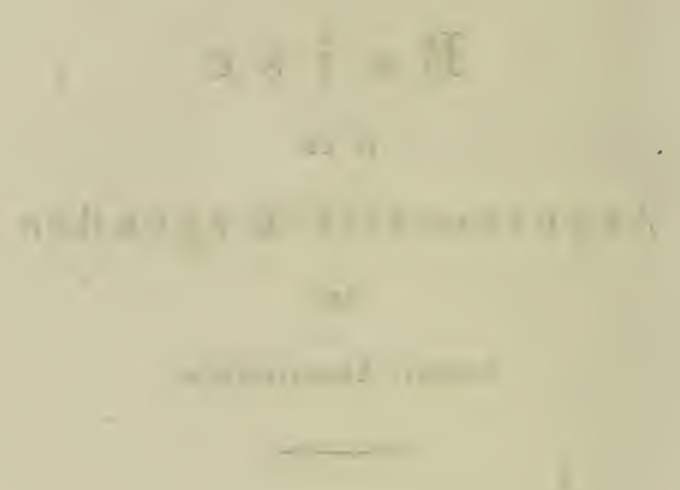




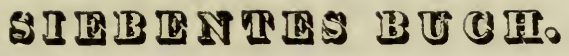




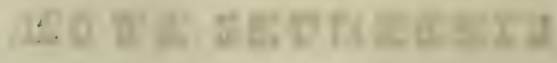

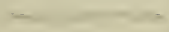




\section{Eilftes Kapitel.}

Töpfer- Waare der Indianer. - Die Landschaft bis zu den schwarzen Wassern.

Der Missionär führte nun die Reisenden in eine Hütte der Indianer, wo dieselben eben beschäftigt waren, Töpfe und grofse Gefäfse aus Thon zu brennen. Dieser Gewerbzweig ist den verschiedenen Stämmen der Maypuresfamilie eigenthümlich und wird seit unendlichen Zeiten von ilınen getrieben Die Neigung für dieses Erzeugnifs scheint vormals über beide $\Lambda$ merika's ausgedehnt gewesen zu seyn. Überall, wo man nachgräbt, selbst in den tiefsten Wäldern, trifft man Bruchstücke von bemalter Tüpferarbeit an. Auffallend ist dabei die Ähnlichkeit ihrer Verzicrungen. Es scheint, als ob sie alle nach demselben Mustergleichsam instinktmälsig verfertigt worden wären. Vor den Augen der Reisenden wurden dieselben Figuren und Verzierungen auf dic Gefälse gemalt, welche sie später auf den TodtenUrnen in der Höhle von Ataruipe wahrnahmen. Es sind Bilder von Krokodillen, Affen und einem ele. phantenähnlichen vierfüfsigem Thiere, welches jedoch auch ein Tapir seyn kann, dann Grecken und Meandriten. Am gewandtesten fübren die Maypures Bilder aus von geraden, verschiedentlich vereinbar- 
ten Linien, denen ähnlich, die man aucb auf den Gefäfsen Grofs-Griechenlands und so vicler alter Völiker aller Gegenden antrifte.

Der Thon zu diesen Gefäfsen wird durch öfteres Waschen gereiniget, dann in Form eines Cylinders gelinetet, wo sodann mit der Hand die gröfsten Gefäfse verfertigt werden. Das Töpferrad ist hier so unbekannt, wie auf der Halbinsel Araya. Dic Färbestoffe sind Eisen- und Mlangan-Oxyde, vorzüglich gelbe und rothe Ocherarten, die in den Höh. lungen des Sandsteins vorkommen. Zuweilen wird auch Chica angewandt, nachdem die Töpferwaare bei ganz gelindem Feucr gebrannt worden ist. Diese Malerei wird mit dem Algorobo-Firnisse überzogen, welcher das durchsichtige Harz der Hymenea Courlaril ist. Die grofsen Gefälse zur Aufbewahrung der Chiza heifsen Chiamacu, die lileinen Gefäfse heissen MIucra.

Sehr merkwürdig ist, dafs man in Tordamerika, westwärts der Aleghany-Berge, beim Aufgraben des Bodens sehr oft neben Scherben aus Töpferwaaren, Geräthschaften aus Kupfer gefunden hat. Dieses mufs befremden in einer Gegend, wo ror Ankunft der Europäer der Gebrauch der Metalle noch unbekannt war. In Südamerika wird die nämliche Töpferwaare in den Einöden angetroffen, neben ilir finden sich aber Haken aus Neplrit und harten Steinen, die künstlich durchbolırt sind, nie aber lat man metallische Werkzeuge oder Verzierungen gefunden. In jencn Gegenden Nordamerika's findet 
man auch Matern ohne Mörtel, Schanzen und Tumulus; in Südamerika nirgend aber ein Denkmal eines civilisirten Volks, welches dem Zahne der Zeit Widerstand geleistet hätte, obschon man in die härte. sten Felsen Figuren eingehauen findet. Woher diese Verschiedenheit zwischen den Völkern der nördlichen und südlichen Gegenden?

Heut zu Tage geht die von den Mönclıen eingeführte Cultur wieder rückwärts. Die Tiger haben die Ziegen gefressen, das Hornvieh ist wieder um. gekommen, und nur die Schweine konnten der Vertilgung durch wilde Thiere widerstehen. Mit Vergnügen trafen sie um die Hütten der Indianer Aras an, die, wie unsere Haustauben, auf das Feld flicgen. Es ist dies eine der schönsten und gröfsten Papageien. Art, die in Südamerika angetroffen wird. Er heifst hier Cahuei. Scine Länge beträgt, mit Einschlufs des Schweifes, 2 Fufs 3 Zoll, und sein schweres und zälies Fleisch wird häufig gegessen. Diese Aras, deren Federn in den lebhaftesten Farben von Purpur, Blau und Gelb g!änzen, sind eine grofse Zierde der amerikanischen Hühnerhöfe, und stehen den Pfauen, Goldfasanen, Pauxis und Aleltors niclit nach. Diese Gewohnheit, Aras statt Hühner aufzuziehen, fand schon Columbus auf den Antillen berrschend.

Um das kleine Dorf von Maypures her wäclıst ein prachtvoller Bauın, der über $60 \mathrm{Fufs}$ Höle hat, und den die Colonisten Frutta de Burro nennen. Es ist dieses eine neue Art der Unona. Ihre Äste ste- 
hen gerade und erheben sich pyramidenförmig, fast wie bei der Pappel von Missisippi, die man falsch italienische Pappel nennt. Dieser Baum trägt einc aromatische Frucht, deren Aufgufs ein wirksames, fiebertilgendes Mittel ist. Man zieht hier überhaupt gewürzhafte Mittel den zusammenziehenden gegen das Fieber vor, und selbst da, wo der wohlthätige Chinarindenbaum einheimisch ist, sucht man aus Vorurt beil andere Mittel zur Hebung des Fiebers auf.

Maypures liegt unter $8^{\circ}, 13^{\prime} 32^{\prime \prime} \mathrm{N}$. Br. und $70^{\circ}$, $37^{\prime} 33^{\prime \prime}$ Ö.L. Diese astronomischen Beobachtungen waren jedoeh über alle Begriffe mühsam, denn nirgends hatte sich die Mosquitos. Wolke dichter gezeigt. Sie bildete eine dicke, etliche Fufs hohe Schiehte, welche noeh dichter wurde, wenn man die Lichter zu den Instrumenten brachte, um die Grade abzulesen. Meistens verlassen die Einwohner das Dorf des Abends, um in den Catarakten zu schlafen, wo die Insekten nicht so häufig sind; andere unterhalten unter ihren Hängematten Feuer, und räuchern sich im eigentlichsten Sinne. Der Thermometer stand am Tage auf $30^{\circ}$ und des Nachts auf $27^{\circ}$ bis $29^{\circ}$.

Nach dritthalbtägigem Aufenthalt in Maypures bestiegen sie am 21. April von neuem ihre Pirogue. Obwohl sie in den Raudales stark beschädigt worden ist, fand man sie doch noch geeignet, die Reise auszuhalten.

Sobald die grofsen Wasserfälle zurückgelegt sind, befindet man sich gleichsam in einer neuen Welt, 
und man glaubt die Grenze überschritten zu haben, welche die Natur zwisehen lultivirten Küistenländern und den wilden noch unbekannten Gegenden des innern Küstenlandes aufgeführt hat. Ostwärts in blaulicher Ferne stellte sirh zum letzten Male die hohe Bergliette von Cunavami dar. Ihr langer, wagerechter Kamm erinnert an die Gestalt des Brigantin, in der Nähe von Cumana; sic läuft aber in einem stumpfen Gipfel aus. Der Pik von Calitamini heifst er, er glänzt beim Untergange der Sonne wie vom röthlichen Feuer. Der Anblick ist alle Tage der nämliche. Niemand hat sich noch je diesem Berge genähert, der nicht über 600 Toisen hoch ist. Herr von Humboldt vermuthet, es sey dieser Glanz ds: Wiederschein, welcher von grofsen Talkplatten herrührt, oder von Gneifs, der in Glim. merschiefer übergeht. Die ganze Gegend enthält Granitfelsen, auf welchen hin und wieder ein thon. artiger Sandstein rulit.

Auf dem Wege von der Mission nach dem Platze der Einschiffung fanden sie einen Stamm der Hevea, welcher Federharz liefert, und dann eine schöne buntgefärbte Froschart. Der Bauch war gelb, Rücken und Kopf schön dunkel purpurfarb, ein einziger schmaler und weifser Streif ging von der Spitze der Schnautze über den ganzen Körper bis an die Hinterfüfse. Es war eine zwei Zoll lange Froschart, der Rana Tinctoria verwandt, deren Blut (wic man erzählt) in die Haut der Papageien, an Stellen, wo ihnen die Federn ausgerupft wurden, eingerie. 
ben, buntscheckige, gelbe oder rothe Federn wachsen macht. Am Wege zeigten die Indianer Spuren von Wagenrädern, als eine in diesem Lande allerdings merkwürdige Erscheinung. Sie sprachen, wie von cinem unbekannten Geschöpfe, von den Thieren mit grofsen Höruern, welche zur Zeit des Grenzzuges die Fahrzenge durch das Thal von Keri, vom Rio Toparo zum hio Cameji zogen, um die Catarakten zu ungehen und die Mühe des Waarenabladens zu crsparen. Die Indianer von Maypures würden heut zu Tage eben so über einen Ochsen erstaunen, wie dic Römer über den Elephanten des Pyrrhus, den sic lucanische Ochsen nannten, erstaunten. Durch einen Canal, der im Keri-Thale die kleinen Flüsse Cameri und Toparo vereinigte, liönnte das Raudal umfahren werden. Er dürfte nicht länger als 1360 oder 2850 Toisen seyn, je nachdem man entweder in der Nähe der Quellen oder der Mündungen beide Flüsse vereinigte.

Nachdem sie noch das bei hohem Wasserstande gefährliche Raudal von Cameji durchfahren hatten, fanden sic den Flufs spiegelglatt. Sic bivouakirten auf cinem felsigen Eilande, das erst anfing mit Gebüsch zu überwachsen. Es liegt unter $5^{\circ}, 4^{\prime} 31^{\prime \prime}$ N. Br. und $70^{\circ}, 37^{\circ}$ W. L. Die Mosquitos waren unzählbar, wie der Sand am Meere. Folgenden Tag war der Morgen feucht, und die Luft, wie immer, ruhig, kein Blatt rauschte. In der Entfernung von sechs Meilen von der Piedra Raton, wo sie übernachtet hatten, fuhren sie östlich bei der Ausmündung des 


\section{$-11$}

Rio Sipapo vorbei, und hernach westlich vor der Mündung des Rio Wichada. In der Nähe der letzteren bilden Felsen eine kleine Cascade. Der Rio Sipapo kommt aus einer beträchtlichen Bergkette her, die eine Felsmauer bilden, welche malerische Ansichten darbietet. Bei Sonnenaufgang ertheile ihm der dicke Pflanzenwuchs das in's Braune spie. lende dunkelgrüne Colorit, das den Landschaften mit lederartigen Blättern eigenthümlich ist. Breite und starke Schatten stellen sich in der nahen Ebene dar, und stechen so gegen das helle über dem Boden, in der Luft und auf der Meeresfläche verbrei. tete Licht ab.

Hinter diesen Bergen von Sipapo hatte Cruzero, das mächtige Haupt der Guaypunabis, geraume Zeit seinen Aufenthalt genommen, nachdem er mit seiner Íriegerhorde die Ebenen zwischen den Rio Inirida verlassen hatte. Die Indianer versicherten, es werde das Vehuco der Maimure in den Waldungen des Sipapo in Menge angetroffen. Diese Lianenpflanze ist den Eingebornen sehr wichtig, indem sie daraus Körbe verfertigen und Matten flechten. Die Wälder von Sipapo sind noch völlig unbekannt, und die Missionäre versetzen das Volk der Rayas dorthin, welche den Mund in der Gegend des Nabels haben. Ein Indianer in Carichana versicherte, öfter Menschenfleisch gespeist zu haben, und behauptete, er habe die kopflosen Menschen mit eigenen Augen gesehen. (Das konnte er übrigens leicht behaupten, denn waren die, welche ihm glaubten, nicht kopf. 
los?) Dieses ungereimte Mährchen verbreitete sich bis in die Llannos, wo der Zweifel am Daseyn der Rayas-Indianer zuweilen übel aufgenommen wird. Denn zur Leichtgläubigkeit gesellt sich unter allen Zonen Unduldsamkeit, und man könnte auf die Ver. muthung gerathen, die Erdichtungen der alten Erdbeschreiber scheinen aus einer Halbkugel in die andere übergegangen, wenn nicht bekannt wäre, dafs die seltsamsten Erzeugnisse der Phantasie, gleich den Werken der Natur, überall eine gewisse Ähnlichkeit in Form und Aussehen darbieten.

An der Mündung des Rio Vichada gingen sie an's Land, um die Pflanzen der Gegend zu untersuchen. Der Wald war hier etwas lichter und zerstreute Felsblöcke lagen umher. Die Landschaft ist sehr malerisch durch diese Felsen und den mannigfaltigen Pflanzenwuchs. Herr Bonpland fand hier mehrere Stämme des Laurus. Cinnamomoides, sine sehr aromatische Zimmtbaunart, die am Orinoko unter den Namen Varimacu und Canelilla bekannt ist. Dieses köstliche Gewächs wird auch im Thale Rio Caura, so wie in der Nähe von Esmeralda und ostwärts von den grofsen Catarakten angetroffen. Der Jesuit Francisco de Olmo scheint der erste gewesen zu seyn, welcher die Canelilla im Lande der Piaroas bei den Quellen des Cataniapo entdeckt hatte. Diese gewürzhaften Rinden und Früchte, der Zimmt, die Muskatnufs, der Myrtus-Pimenta und der Laurus pulcheri würden wichtige Handelsartikel geworden seyn, wenn zur Zeit der Entdeckung Amerika's 
Europa bereits an die Gewürze und Aroma's Indiens gewöhnt gewesen wäre. Der amerikanische Zimmt ist jedoch so aromatisch nicht, als der Zimmt von Ceylon. Jeder Erdtheil hat ihm eigenthümliche Erzeugnisse und Gewächse. Es kann diese Verschiedenheit nicht aus physikalischen Gründen erklärt werden. Und die Ursachen, warum Afrika keine Laurineen, die neue Welt keine Heidekräuter hat, warum diese Thiere, die hier unter einer gewissen Breite vorkommen, in derselben Bréite in einem andern Welttheile nicht vorhanden sind? geliören zu den Geheimnissen der Natur, die sie sich auch bisher nicht abfragen lassen, und welche auch die Naturphilosophie nicht so leicht ergründen dürfte.

Die Reisenden fuliren nun bei verschiedenen Flufsmündungen vorbei, als beim Rio Bichada, dessen Quellen und Lauf ziemlich unbekannt sind, und der ein beträchtlicher Flufs ist; dann beim Canno Pirajavi, dann noch bei einem kleinen Flusse, endlich übernachteten sie bei der Mündung des Rio Zama. Die Luft war schön und heiter, aber trotz der schwarzen Gewässer des Zama, plagten sie die Mosquitos jämmerlich.

Die aúsgebreitete Landschaft zwischen dem Meta, dem Vichada oder Bichada und dem Guaviare ist völlig unbekannt, man glaubt sie werde von den wilden Indianern bewohnt, die zum Stamme der Chiricoas gehören, und welche zum Glück keine Kähne verfertigen. Vormals, so lange die Cariben und ihre Feinde, die Kabren, diese Gegenden mit 
ihren Flöfsen durchzogen, wäre es unvorsichtig gewesen, in der Mündung eines von Westen liommenden Flusses zu übernachten. Jetzt aber, seit die kleinen Niederlassungen die unabhängigen Indianer von den Gestaden des Ober.Orinoko vertrieben haben, ist die Landschaft $\mathrm{zu}$ so einer vollkommenen Einöde geworden, dafs von Carichana bis Javita und von Esmeralda bis San Fernando de A tabapo, auf einer Schiffahrt von 180 Meilen, kein einziges Fahrzeug zu sehen ist.

\section{Zwölftes Ka pitel.}

Die schwarzen Gewässer. - San Fernando de Atabapo.

Wenn ein Reisender den Orinoko hinauffährt, und an die Mündung des Rio Zama gelangt, so begegnet er hier einer Naturerscheinung, die zwar nicht so auffallend und Bewunderung erregend, wie ein Wasserfall oder ein hoher Berg ist, aber darum nicht weniger die ganze Aufmerksamkeit der Naturforscher in Anspruch nimmt. Es sind dieses die sogenannten schwarzen Gewässer. Der Zama, der Matareni, der Atabapo, Tuamini, Temi, Guainia fülıren aquas negras, das will so viel sagen: ihre Gewässer, in grofsen Massen betrachtet, stellen sich braun, wie Caffee, oder schwarzgriinlich dar. Sie sind jedoch darum nicht minder hell und rein, wenn man sie z. B. in ein Glas schöpft, und dabei sehr gute wohlschmeckende Gewässer. Wir haben un- 


\section{$-15$}

sern jungen Lesern schon oben berichtet, dafs die Krokodille und Mosquitos die schwarzen Gewässer meiden, und nur die Zaeundos sich daselbst aufhalten. Das Volk behauptet, dafs die schivarzen Wasser reine Ufer haben, wogegen die wcifsen Gewässer, wie wir schon oben vielfach sahen, schwarz färben, und wirklich waren auch die vun Herrn von Humboldt besuchten Ufer des Rio Negro glänzend weifs, wo sie aus Granit und Quarzmassen be. standen. Im Glase ist das Wasser des Mataveni, eines schwarzen Flusses, weifs, des vom Atabapo behält eine braunliche Schattirung. Setzt die Oberfläche der schwarzen Flïsse ein Wind in Bewegung, so erscheint sie, wie die der Schweizerseen, in einem lieblichen Wiesengrün. Im Schatten ist der Atabapo, der Guainia oder Rio Negro und der Zama schwarzbraun, wie Caffeesatz. Diese Naturerscheinung ist in Südamerika so auffallend, dafs die Indianer überall die Gewässer in schwarze und weifse eintheilen. Die schwarzen Wässer werfen die Sternbilder mit bewundernswerther Klarheit zurück, dafs sie zum künstlichen Horizont benützt werden lïnnten.

Es fragt sich nun, welches ist die Farbe des Wassers in der Natur überhaupt? Und dann, woher rührt die verschiedene Färbung derselben insbesondere? Diese Fragen sind aber eben so leicht aufzuwerfen, als sie schwer oder vielleicht gar nicht zu lösen sind. Man hat vergebens gesucht, die durchgehenden oder sich brechenden Strahlen des Lichts 


\section{$-16$}

in Anschlag zu bringen, man erbält aus der Optik keine Antwort auf obige Fragen. Aber auch die Chemie bat bisher noch immer ausweichend geantwortet. Berühmte Naturforscher, welche die meisten Wasser der Gletscher und die aus den mit ewigem Schnee bedeckten Bergen herkommen, wo der Boden keinerlei Pflanzenüberbleibsel enthält, untersucht haben, sind der Meinung, die eigenthüm. liche Farbe des Wassers dürfte blau oder grün seyn. In der That ist auch nichts erwiesen, dafs das Wasser, seiner Natur nach, weifs sey, und dafs man allezeit einen färbenden Grundstoff annehmen müsse, wenn die Wasserspiegel gefärbt erscheinen. Wenn in den gefärbten Gewässern auch solche Farbenstoffe vorhanden sind, so sind sie wenigstens in so geringer Quantität da, dafs sie sich jeder chemischen Untersuchung entziehen.

Der Ocean ist in verschiedenen Weltgegenden verschieden gefärbt. Man hat wohl schon öfters behauptet, die Farbe des Wassers rühre von der des Himmels her, der sich in demselben spiegelt, und sogar vom schivarzen Meere, seine Farbe rühre vom schwarzen Grunde her, auf dem es fluthet. Dies sind jedoch Mährchen, und so viel ist entschieden, dafs wirklich verschiedenen Gewässern verschiedene Farben eigenthümlich sind.

Schon die Alten haben die blauen Wässer von Thermopytä, die rothen von Japho und die schwarzen vom Astyra, Lesbos gegenüber, unterschieden. Die Rhone nächst Genf zeigt eine auffallend blaue 


\section{- $17-$}

Farbe; die Schneewasser der Schweizeralpen geben öfter in smaragdgrüne Farbe über. Verschiedene Seen in Savoyen und Peru haben ein bräunliches, beinahe schwarzes Colorit, und die verschiedenartigen Bergseen der Karpathen sind bekannt.

In dem grofsen Flufssysteme, welches unsere Reisenden durchwanderten, bleiben die schwarzen Wasser besonders auf den Aequatorialstreif beschränkt, der zwischen dem fünften Grade nördlich bis zum zweiten Grade südlich sich ausdehnt. Es zeigt sich jedoch auf diesem Erdstriche eine so auffallende Mischung schwarzer und weifser Wasser, dafs auch aus der Lage derselben unter dem Aequator kein Resultat gezogen werden kann. Der Cassiquiare, ein Arm des Orinoko, der sich in den Rio Negro ergiefst, hat weifse Farbe. Von zwei nur wenig von einander entfernt liegenden Zuflüssen des Cassiquiare, der Siapa und der Pacimony, ist der eine weifs und der andere schwarz.

Fragt man die Indianer nach der Ursache der Färbung, so antworten sie, indem sic die Frage auf eine andere Art wiederbolen. Die Missionäre sagen: die Wasser färben sich, indem sie über die Wurzeln der Sassaparille hinfliefsen. Diese Pflanzen sind nun wirklich häüfig an den schwarzen Flüssen, und ihre eingeweichten Wurzeln liefern einen braunen und schleimigen Stoff, allein man findet dieselben Smilax-Büsche auch an den weifsen Flüssen. In den sumpfigen Wäldern, wo die Pirogue zum Ric Pimichin getragen werden mufste, durchwateten die 
Feisenden bald weifse, bald schwarze Flüssc. Es ist auch kein Flufs bekannt, der nahe bei seinem Ursprunge wcifs und hernach schwarz gefärbt wäre.

Herr von Humboldt meint : es sey eine Nischung ron Kohlenstoff und Wasserstoff, ein Pflanzen-Ex. traktivstoff, welcher die Wasser des Zama, Metaveni Guainia schivarz färbe. Er legt jedoch dicse Meinung zweifelnd hin, weil die Wasser des Rio Negro durch's Sieden niclıt braun werden.

Mcrkwürdig ist insbesondere noch, dafs die Erscheinung der schwarzen Wasser, von der man glauben könnte, sie gehöre der niedrigen Region der heifsen Zone ausschliefslich an, auch auf den Plateaus der Anden, obgleich nur selten, vorkommt. Han bedient sich ihrer dort vorzugsweise zum Trinken und schreibt ihre Farbe gleichfails der Sassapa. rille zu.

Aus allem diesen gelit hervor, dafs die Erscheinung der weifsen und schwarzen Wasser zu denen gehört, die man noch nicht zu crklären wcifs, und so möge denn zu den obigen Hypothesen noch folgende kommen, die, so gut oder schlecht sie ist, dem Bearbeiter selbst angehört. Die Farbe des Wassers, wenn es rein ist, ist allezeit namenlos, d.h. es ist die Farbe der reinen Luft, so dafs ein breitcr, dichter Wasserstrahl in der reincn Luft nicht wahrge. nommen werden könnte. Die verschiedenen Farben rühren von Gasarten her, welche sich auf chemischem Wege aus der Verbindung verschiedener Körper mit dem Wasser entwickeln und mit letzterem sich 
verbiuden. Die dunkeln, in die beiden Farben gelb und schwarz sich einschattirenden Farben, kommen aus dem Boden, wo die Quellen entspringen und iliren Lauf haben, aber auch aus gerbestofflialtigen Pflanzenfilzen, durch welche das Wasser sickert. Die lichten, dem Weifs und Grün angehörenden Farben, kommen aus animalischen und vegetabilischen Stoffen, die keinen Gerbestoff enthaiten. Als feine Gasarten haben sie sich zwar bis jetzt der Untersuchung entzogen, besonders in schwarzen Gewässern, sie werden es jedoch nicht immer, und der Fleifs der Naturforscher wird auch dieses Räthsel mit der Zcit Jösen.

Um drei Uhr Morgens fuhren sie von der Mïndung des Zama ab. Der Strom war von beiden Seiten mit dichter Waldung besetzt. Dic östlichen Berge entfernten sich immer weiter. Sie kamen nun vor der Mündung des Rio Mataveni vorbei und $z u$ ciner. Insel von der seltsamsten Gestalt. Wie ein Koffer steht ein gewiegter Granitwürfel aus dem Was. ser empor, die Missionäre nennen ihn el Castillito. Die Nacht über verweilten sie bei dem Felsen Aricagua. Eine zahllose Menge Fledermäuse kau hervor und umschwärmte die Hängematten. In trocknen Jahren vermehrt sich ihre Menge aufserordentlich.

Am 24. April langten sie Nachmittags um vier Uhr bei den Hütten und kleinen Pflanzungen der Indianer an, die nach San Fernando gehören, nach. dem sie noch mehrere Einmündungen in den Orinoko 


\section{$-20-$}

vorbeigekommen waren. Die guten Leute wollten sie bei sich behalten; sie fuhren aber vorüber, und bei dunkler Nacht in den Rio Guaviare, und langten um Mitternacht in San Fernando de Atabapo an.

Fast ohne es zu merken, hatten sie in der Nacht die Gewässer des Orinoko verlassen, und befanden sich am andern Morgen beinabe in einem andern Lande. Sie standen an einem Flusse, den sie kaum dem Namen nach gekannt hatten, und welcher sie an die Grenze Brasiliens führen sollte.

\section{Dreizehntes Kapitel.}

Neuer Reiseplan. - San Fernando de Atabapo. - Fahrt auf dem Guaviare in den Atabapo, - St. Balthasar.

Den neuen Reiseplan oder vielmehr die Marścliroute, die sic nun zu nelimen hatten, beschrieb ihnen der Vorsteher der Missionen, der zu San Fernando wohnte, folgendermafsen : 》Ihr werdet zuerst den Atabapo hinauffahren, hernach den Temi und zuletzt den Tamini. Wenn die Gewalt der Strömung der schwarzen Wasser das Weiterkommen unmöglich macht, wird man euch alsdann aufser dem Strombette durch Wälder, die ihr überschwemmt antreffet, weiter bringen. In diesen Wüsten, zwischen dem Orinoko und dem Rio Negro, sind einzig nur zwei Mönche angesiedelt; aber in Javita wird man euch Mittel an die Hand geben, um eure Piro. gue vier Tagereisen weit, über Land, zum Canno 


\section{$-21$}

Pimichin zu schleppen. Hommt sie unverselirt an, so mögt ihr alsdann ungehindert den Rio Negro von N. W. gegen S. O. hinunterfahren bis zum Fort San Carlos, nachher fahrt ihr den Cassiquiare von Süd gegen Nord auf, und nach Abflufs eines Monats kommt ilur dann den Ober-Orinoko herab, von Osten gegen Westen fahrend, nach San Fernando zurück.* Dieser Plan wurde denn aucl, von unsern Freunden in zwei und dreifsig Tagen ausgeführt, wiewolıl nicht ohne Schwierigkeit und Besclswerde.

Der Missionär von San Fernando fülurt den Titel cines Präsidenten der Missionen vom Orinoko. Sechs und zwanzig Ordensmänner, die an den Ufern des Rio Negro, Cassiquiare, Atabapo und des Orinoko angesiedelt sind, stehen unter seinen Befehlen, und er selbst wieder unter denen des Guardians von Neu-Barcellona. Sein Dorf zeigle etwas mehr Wohlstand, als die, welche unsere Freunde bisher ange. troffen hatten, doch stieg die Zahl der Bewohner nicht über 226. Auch diese Mission soll gleich nach. ihrer Stiftung volkreicher gewesen scyn. Dennoch könnte dieser Ort einmal sehr wichtig werden.

San Fernando de Atabapo liegt nicht weit rom Zusammenflusse dreier grofser Ströme des Orinoko, des Guaviare und des Atabapo. Wird einst an dicsen drei Strömen der Verhelır lebhaft, so wird die Stadt, welche an dem Zusammenflusse dieser Gewässer liegt, der Stapelort der Schiffe, die Niederlage der Waaren und der eigentliche Ort der Sittigung werden. Früher hausten hier eine Menge 
Stämme, als mit sich selbst streitende, feindselige Völker. Die Jesuiten, um ihre Niederlassungen zu sichern, zogen inelurere Häuptlinge in ihr Interesse, die alsdanı wieder die feindlichen Stämme belıämpften, und so wurde die Gegend entvölkert, was noch mehr durch die Menschenjagden geschah, nach je. nem Grenzzuge, welchen Solano unternommen hatte. Viele Indianer wurden auch von andern Indianern an die Holländer und Portugiesen als Sclaven verkauft. Die Phönizier und Karthaginenser bolten vor. mals in Europa Selaven. Jetzt übt Europa hinwieder Bedrückung aus, theils gegen die Länder, aus dencn es seine wissenschaftliche Bildung erhalten hat, theils über jene, welchen es dieselbe fast un. freiwillig mit den Erzeugnissen seines Íunstfleifses zuführt.

Dieses sind die Verbältnisse der Länder, wo dic überwundenen Völkerschaften nach und nach erlöschen, und keine andere Spur zurücklassen, als einige Wörter, welche sich in die Sprache der Überwinder cinmischen. Am Ober-Orinoko sind früler die Cabren und Cariben, am Rio Negro die Mare. pizanos und Manitivitanos mächtige Völkerscliaften gewesen. Der lange Widerstand, welchen die $\mathrm{Ca}$ bren den Cariben geleistet, war ihnen seit 1720 ge. fährlich geworden. Sie hatten ihre Feinde zuerst in der Nähe der Mündung des Rio Caura geschlagen. Auf der Flucht fand ein grofser Theil der Cariben seinen Untergang, zwischen den Rapides von Torno und der Hülleninsel Isla de Infierno. Die Gefange- 


\section{$-23$}

sen wurden aufgefressen, und mit jener grausamen Verschlagenheit, die den Wilden beider Amerika's eigen ist, war nur ein einziger Caribe ain Leben gelassen, der einen Baum besteigen mufste, um Zeuge des abscheulichen Vorgangs zu seyn, und den Überwundenen Kunde zu' bringen. Allein der Sieg des Tep, Häuptlings der Cabren, war von kurzer Dauer. Die Cariben kehrten in so grofser Anzahl zurück, dafs nur wenige Cabren übrig blieben.

Am Ober - Orinoko fülrten auch zwei Häuptlinge, Cocuy und Cuseru, mit der gröfsten Erbitterung Kírieg gegen einander, als Solano mit dem denk. würdigen Grenzzuge an der Mündung des Guaviare eintraf. Der crstere stand zur Seite der Portugiesen, der letztere hielt es mit den Jesuiten, und benachrichtigte sie allezeit, wenn die Manitivitaner einen Einfall in die Missionen vorbatten. Cuseru ging nur erst wenige Tage vor seinem Tode zum Christenthume über, aber in den Gefechten trug er ein Crucifix an seiner linken Hüfte befestigt, welches er von den Jesuiten-Vätern empfangen hatte, und wodurch er unverwundbar zu seyn glaubte. Von der Wildheic seines Charakters mag Folgendes zeugen. Er hatte die Tochter eines andern Häuptlings vom Rio Temi zum Weibe. In einem Anfalle von Unwillen gegen den Schwiegervater, erklärte er seiner Frau, er ziehe aus, um mit ihm einen Kiampt zu bestehen. Die Frau erinnerte ilın an die aufserordentliche Stärke und Entschlossenheit des Vaters, Cuseru aber, obne ein Wort zu sprechen, stöfst ihr 
einen giftigen Pfeil in die Brust. Im Jahre 1756 erregte die Ankunft Solano's mit einer kleinen Truppe Spanier bei ihm Verdacht. Er war im Begriffe sich mit den Spaniern in einen Kampf einzulassen, als ihm die Jesuiten -Väter vorstellten, dafs es gerathener sey für jhn, mit den Christen den Frieden zu erhalten. Cuseru wurde nun zur Tafel des spa. nischen Generals geladen, und durch schöne Ver. heifsungen für den Untergang seiner Feinde gewon. nen. Der König wurde nun Dorfmeier, und liefs sich's gefallen, in der neuen Mission von San Fernando de Atabapo mit den Seinigen sich anzusiedeln. Dieses ist gewöhnlich das traurige Ende der Häuptlinge, welche von den Reisenden und Missionarien so freigebig Könige genannt werden. Pater Gili erzählt : " ich hatte in meiner Mission fünf Königleins (Regecillos) der Tamanaken, der Avarigoten, der Parecas, der Quaquas und der Méépures. In der Kirehe liefs ich dieselben alle auf die nämliche Bank sitzen; aber der erste Platz ward dem Könige der Tamanaken, Monasti, zu Theil, weil dieser mir bei der Gründung des Dorfes behülflieh gewesen war. Er schien auf diese Auszeichnung nicht wenig stolz zu scyn. N Nicht allezeit sind jedoch abgesetzte Könige so leicht zufrieden zu stellen.

Als Cuseru die spanischen Truppen dureh die Cataralten zichen sah, rieth er dem Solano, mit der Gründung der Niederlassung an den Ufern des A tabapo noch ein Jahr abzuwarten, und verkündigte ihm alles Unglüek im Voraus, das hernach wirklieh 
eintraf. "Lafst mich mit meinen Leuten arbeiten und das Land urbar machen; ich will Manioc pflan. zen, damit ihr nachher für so viele Leute Speise findet." Solano war aber ungeduldig, weiter zu kommen, verachtete diesen königlichen Rath. Die neuen Bewohner von San Fernando mufsten grofsen Mangel leiden, und die Fieber rafften einen grofsen Theil derselben leicht dahin. Noch sind in San Fernando Überbleibsel alter Cultur vorhanden. Jeder Indianer besitzt eine Cacaopflanzung, die vom fünften Jahre an häufigen Ertrag liefern, aber auch früher, als in den Thälern von Aragua, Früchte zu tragen aufhören. Die Bohnen sind zwar etwas kleiner, aber von vortrefflichem Gehalte. Die Almuda, deren zwölf eine Fanega ausmachen, liostet in San Fernando vier Franken, an den Küsten aber wenigstens zwanzig bis fünf und zwanzig. Die ganze Mission liefert aber kaum 8o Fanegas des Jahres, und weil, der alten verderblichen Sitte gemäfs, der Handel mit Cacao dem Missionär allein zugehört, so fühlen die Indianer gar keine Neigung, die Bäume zu vermehren, die ibnen gar keinen Vortheil bringen. Um San Fernando sind gute Viehweiden in den Savanen, aber die Reisenden fanden kaum noch acht Kühe von denen, welche der Grenzzug hingebracht hatte. Die Indianer sind um etwas gebildeter, als in den andern Missionen, und sogar ein Schmied vom einheimischen Stamme war vorhanden.

Der Landschaft von San Fernando gewährt die Bibl. naturh. Reisen. IV. 
Pirijao-Palme ein eigenthümliches Aussehen. The mit Stacheln besetzter Stamm wird über 60 Fufs boch. Die Blätter sind gefiedert, ausnchmend zart, wellenförmig und gegen die Spitze gekräuselt. Die Erüchte des Baumes sind aufserordentlich. Jeder Zweig trägt deren 50 bis 80 . Ihre Farbe ist erst gelb, und wenn sie reifen, purpurroth. Sie sind zwei bis drei Zoll grofs und durch fehlgeschlagene. Befrucbtung meist ohne Kern. Unter den achtrig. bis neunzig Palmarten, die der neuen Welt eigen. thümlich angehören, findet sich keine von so grofser Fruchtbarkeit. Die Frucht des Pirijao enthält einen Stoff, der gelb, wie das Innere von einem Eie, etwas zuckerhaltig und sehr nahrhaft ist. Sie wird, wic dic Pisangfrucht oder Erdäpfel, entweder gesotten oder in Asche gebraten gegessen, und ist chen so gesund als schmackhaft. Die Indianer, so wie die Missionäre, werden nicht satt im Lobe dieser köstlichen Palme, die man Pfirsichpalme nen. nen könnte, und die süflich von A tabapo überall an. gebaut wird. Mlan erinnert sich hier der $\ddot{A} u f s e r u n g$ Linnée's: »der Mensch wohnend unter den Tropen, lebt von Palmen, ein Palmenesser; siedelnd aufser denselben auf stiefmütterlicher Erde wird er ein Flcischfresser.* Untersucht man die Vorräthe in den Hütten der Indianer, so überzeugt man sich, dafs ihre Nahrung den gröfsten Theil des Jahres hindurch aus den Früchten der Palmen besteht. Jeder Baum trägt jährlich nur ein Mal Früchte, aber bis auf drei Zweige, und also 5o bis 200. 


\section{$-\quad 27$}

San Fernando de Atabapo, San Carlos und San Francesco Solano sind die bedeutendsten Niederlas. sungen am Ober-Orinoko. In San Fernando, wie in den benacbbarten Missionen, sind gutgebaute Pfarrhäuser, mit Schlingpflanzen bewachsen und mit Gärten umgeben. Die schönste Zierde dieser Pflanzungen waren aber die Pirijao. Palmen. Der Pater Präfekt machte auf einem Spaziergange eine lebhafte Schilderung von seinen Streifzügen zum Rio Guaviare. Er versicherte : diese zur Gewinnung von Seelen unternommenen Reisen seyen den Indianern der Mission so erwünscht, dafs Jedermann, Weiber und Greise sogar, daran Theil nehmen wollen. Unter dem Vorwande, die aus den Missionen entflohenen zu verfolgen, werden acht - und zehnjährige Kinder entführt, und an die Indianer der Mission als Leibeigene vertheilt.

Sobald man in's Flufsbett des Atabapo gelangt ist, verändert sich alles, die Beschaffenheit der At. mosphäre, die Farbe des Wassers und die Gestalt der am Ufer wachsenden Bäume. Den Tag über wird man nicht so sehr von den Mosquitos gequält. Die langbeinigen Schnaken werden zur Nachtzeit sehr selten und jenseits San Fernando verschwinden sie ganz. Das Wasser ist rein, und nicht stin. kend, wie das erdige und mit Krokodillen-Aas infieirte Wasser des Orinoko. Aufser der grofsen Reinheit ist das schwarze Wasser auch um zwei bis drei Grad kühler. Die Abwesenheit der Krokodille er. laubt zu baden; das Wasser ist so rein, dafs man 


\section{$-28$}

auf zwanzig bis dreifsig Fufs Ticfe die Fische sehen kann. Der Grund ist ein weifser, glänzender Quarzund Granitsand. Die unvergleichlich schöıen Ufer prangen mit gefiederten Palmen und spiegeln sich im klaren Flusse, und ihr Bild in diesem reinem Wasser ist eben so kräftig und schön gefärbt, wie sie selbst.

Der Rio Guaviare ist breiter, als der Atabapo, er führt weifses Wasser, und gleicht durch seine Vögel, seine Mosquitos und Krokodille ganz dem Orinoko.

Vom Ursprunge des Orinoko hegen die Indianer heut zu Tage noch eine ganz andere Ansicht, als die Erdbeschreiber. Sie behaupten: der Orinoko entspringe aus zwei Flüssen, dem Rio Guaviare und dem Rio Paragua. Dieser letztere Name wird dem Ober. Orinoko von San Fernando und San Barbara bis Esmeralda gegeben. Diesemnach halten sie den Cassiquiare für einen Arm, nicht des Orinoko, sondern des Rio Paragua. Übrigens sind lier die Namen sehr gleichgültig, wenn man nur sonst genaue Kenntnifs von dem Laufe der Flüsse hat, und nicht, wie vor dieser Reise des Herrn von Humboldt geschehen ist, Flüsse durch Bergketten von einan. der abschneidet, die zusammenhängen und ein $\mathrm{S}_{y}$ stem bilden. Würde man jedoch den Guaviare als den eigentlichen Orinoko annehmen, und den Rio Paragua als einen Zuflufs betrachten, so würde der Orinoko durch eine Richtung von Südwest nach Nordost einen natürlicheren Lauf darstellen. Auch 


\section{$-29$}

ist der Geschmack des Wassers aus dem Rio Gua. viare dem des Orinoko bei den grofsen Catarakten ähnlich, das des Rio Paragua hingegen ist reiner und von besserem Geschmacke. Die Indianer wissen die Wässer an Geschmacke recht gut zu unterscheiden. „Bringt nur die Wässer von drei oder vier grofsen Flüssen dieses Landes, sprach ein alter Indianer der Mission ain Javita, so will ich euch aus dem Geschmacke derselben mit Zuverläfsigkeit sagen, wo die Wässer her sind, ob sie einem schwarzen oder weifsem Flusse, dem Orinolio oder dem Atabapo, dem Paragua oder dem Guaviare angehören.« Die Delphine und Krokodille werden im Guaviare, wie im Unter-Orinoko, in gleicher Zahl und Gröfse angetroffen, hingegen mangeln sie gänzlich im Rio Paragua. Dieses sind allerdings merkwürdige Verschiedenheiten in Hinsicht auf die Natur der Gewässer und die Vertheilung der Thierarten. Die Indianer berufen sich darauf, um den Reisenden zu beweisen, dafs der Ober-Orinoko, ostwärts von San Fernando, ein eigenthümlicher sich in den Orinoko ergiefsender Strom sey, und der walıre Ursprung des letzteren in den Quellen des Guaviare gesucht werden müsse. San Fernando liegt unter $4^{\circ}, 2^{\prime} 48^{\prime \prime}$ N. B. und $70^{\circ}, 30^{\prime} 46^{\prime \prime}$ W. L. Der Strom gewährt überall einen eigenthümlichen Anblick. Seine acht bis zehn Fufs hohen Ufer sind mit Gebüschen überdeckt, die die Oberfäche des Wassers berühren, und das Ufer verbergen. Zahlreiche Krokodille sind von der Stelle an, wo man den Orinoko verläfst, bis 
zur Mlission von San Fernando sichtbar, und ihre Gegenwart deutet an, dafs dieser Theil dem Guaviare und nicht dem Atabapo angehört. Im eigentlichen Bette dieses Flusses, oberhalb San Fernando, gibt es keine Krokodille melhr. Man trifft daselbst Bava's und unschädliche Süfswasser-Delphine, aber weder Krokodille noch Seekühe an. Vergeblich sucht man hier die Chiguire, Araguaten oder grossen Brüllaffen, den Zamuro und den gehaubten Fasan. Dafür ist aber leider sehr häufig die grofse Wasserschlange, deren Aussehen der Boa gleich lommt, und den badenden Indianern oft sehr gefährlich wird. Die Reisenden sahen derselben glcich in den ersten Tagen mehrere um die Pirogue schwimmen, deren Länge zwölf bis vierzehn Fufs betrug. Die Jaguare an diesen Ufern sind grofs und wohlgenährt, aber nicht so kühn, wie die am Orinoko.

Sie übernachteten in einer Hütte von Guapasoso; gegen Morgen fing es zu regnen an. Es war den Reisenden auffallend, hier keine Brüllaffen zu hören, und sie schlossen daraus, dafs diese Wälder ungleich weniger Thiere, als die des Orinoko beherbergen. Um den Kalın spielten Delphine, die hier in einer Entfernung von 320 Meilen von der Mündung des Orinoko beinerkenswerth sind. Gegen Mittag kamen sie bei dem unter dem Namen Piedra del Tigre bekannten Granit - Hügel vorbei. Dieser einzelne, sechzig Fufs hohe Felsstock, ist in der Gegend weit und breit bekannt. Zwischen dem $4^{\circ}$ und $5^{\circ}$ der Breite erreicht man das mittägige Ende jener 


\section{- 5i}

Catarakten- Kette, welche Herr von Humboldt ảic Íette von Parime zu nennen vorschlägt. Die ganze von dieser hette bis zum Amazonenstrome sich aus. dehnende Landschaft, durchzogen vom Rio Atabapo, Rio Negro und Cassiqquiare nebst vielen andern Flüssen, bildet eine ungeheure, theils mit Waldung, theils mit Graswuchs bedeckte Ebene. Wie feste Schlüsser stehen hin und wieder einzelne Felsstücke auf ibr empor.

Bei Tagesanbruch kamen sie am 28. April bei la Piedra und dem Falle von Guarinuma vorbei. Er. sterer ist ein nackter Fels mit Flechten bedeckt. Als sic bei dem Raudale vorbei waren, sahen sie am gegenüberstehenden Ufer mitten unter indianischen Pflanzen einen Riesenstamm einer Ceibe oder Häscbaum. Sie landeten, um ihn zu messen. Er hatte 14 bis 15 Fufs Durchmesser und 120 Fufs Höhe.

Am 29. war die Luft küller. Zacundos waren keine vorhanden; der Himmel jedoch bedeckt und sternlos. Die starke Strömung liefs sie nur langsam vorwärts kommen, und da sie auch, um Pflanzen am Ufer zu suchen, verweilt hatten, kamen sie erst in der Nacht bei der Nission San Barbara an, oder wie sie die Mönche nennen, la divina Pastora de Balthasar de Atabapo. Sie wurden von dem catalonischen Missionär auf das Freundlichste empfangen. Er war ein munterer, liebenswürdiger Mann, der sich mit der seiner Nation eigenthümlichen Thätigkeit in dieser Wildnifs einen schönen Garten gepflanzt, worin der europäische Feigenbaum, die 
Persea, der Citronenbaum dem Manioc zur Seite stand. Das Dorf war mit einer Regelmäfsigkeit angelegt, welche man bei den Brüdergemeinden antrifft. Die Pflanzungen der Indianer waren sorgfältiger, als anderswo bearbeitet. Hier bekamen unscre Freunde auch zum ersten Male jene schwam. mige und weifse Substanz zu Gesicht, die sie später unter dem Namen Dapicho bekannt gemacht baben. Sie bemerkten sogleick, dafs sie dem Federharze glich, weil aber die Landeseingebornen durch Zeichen zu verstehen gaben, dafs es unter der Erde gefunden werde, so waren sie bis zur Ankunft in der Mission von Javita zu glauben geneigt, es dürfte ein fossiles Caoutchouc (Federharz, Gummi elasticum) seyn. In der Hütie des Missionärs war ein beim Feuer sitzender Indianer beschäftigt, schwarzes Federharz aus dem Dapicho zu verfertigen. Er hatte mehrere Stücke an Holzstäbe angespiefst, die cr, wie Flcisch, röstete. Das Dapicho schwärzt sich in dem Verhältnisse, als es weich und elastisch wird. Der harzige, aromatische Geruch, womit die Hütte erfüllt war, schien anzudeuten, dafs diese Färbung die Wirkung der Zersetzung eines wasserstoffigen Brennstoffes sey, und dafs der Kohlenstoff zum Vorschein komme, nach Mafigabe, wie der Wasserstoff bei mäfsiger Hitze verbrennt. Der Indianer klopfte die erweichte und schwarz gewordene Masse mit einer Keule aus Brasilienholz, hierauf knetete er sie in Kugeln von drei bis vier Zoll Durchmesser und liefs sie kalt werden. Diese Ku- 


\section{- .33}

geln gleichen völlig dem im Handel vorkommenden Federharz, nur bleibt die Oberfläche etwas klebrig. Sie werden in den Missionen von Uruana und Encaramada zum Ballspiele gebraucht, und man mufs gestehen, dafs solche Kugeln, ihrer Dauer und Elasticität wegen, sich trefflich dazu eignen. Wie majestätisch mufs sich nicht ein solcher Ball in die Luft erheben und wie herrlich von dem Rücken ab. prallen! Man gebraucht hier dieses Dapicho auch statt der Korkstöpseln, und als solche leisten sie viel vortrefflichere Dienste, als die Korkstöpsel. Der Missionär zeigte ihnen auch vor dem Versamm. lungshause (Casa de los solteros) eine Trommel, die aus einem hölzernen hoblen Cylinder, 2 Fufs lang und 18 Zoll dick, bestand. Die Trommel wurde mit grofsen Dapicho - Massen, deren man sich als Trommelschlägel bediente, geschlagen. Sie hatte Öffnun. gen, die zur Veränderung des Tones mit der Hand willkürlich geschlossen werden konnten, und sie war zwischen zwei dünnen Stützen im Freien befestigt. Die Wilden lieben eine Janitscharen-Musik. Die Trommel und die Botutos oder Trompeten aus gebrannter Erde, worin eine drei bis vier Fufs lange Röhre mit ehernen Bauchungen zusammenhängt, sind bei den Indianern vortreffliche Instrumente, wenn die Musik auf sie wirken soll.

San Balthasar liegt unter $3^{\circ}, 14^{\prime} 2^{\prime \prime}$ N. B. und $7^{\circ}, 14^{\prime} 21^{\prime \prime}$ W.L. Sie folgten am 3o. April noch cine Zeitlang dem Atabapo entlang, fuluren dann aber in den Rio Temi ein. 


\section{- 34}

\section{Vierzehntes Kapitel.}

Fahrt auf dem Rio Temi. - Der Fels der Mratter. - Reise nach Javita.

Vor der Einfahrt in den Rio Temi zog ein an sich unbedeutender Gegenstand, der aber durch cine schaudervolle Begebenheit cin Denkmal des europäischen Fanatismus und blutdürstiger Grausam. keit geworden ist, die Aufmerksamlseit unserer gefühlvollen Reisenden auf sich. Es ist dieses ein am westlichen Ufer befindlicher Granithügel, er heifst: der Fels der Guabiba-Indianerinn, oder auch der Fels der Mutter (Piedra de Madre). Wenn der Mensch in diesen Einöden kaum eine Spur seines Daseyns zurückläfst, so ist es für den Europäer doppelt besclämend, wenn ein Felsstück seine Verkehrtheit aufbewahrt, und die Tugend der Vilden sammt der Barbarei des Gebildeten überliefert.

Dic Ursache der Benennung ist folgende. Der Vorfahr des gegenwärtigen Missionärs von San Fernando hatte seine Indianer an das Gestade des Rio Guaviare, in der grausamen Absicht, die eben so der Religion, wie den Gesetzen Spanien's entgegen war, geführt, um Seelen zu erobern. Sic kamen in eine Hütte der Guahiba-Indianer, und trafen daselbst eine Mutter dieses Stammes nebst drei Kindern an, wovon zwei noch unmündig waren. Die Familie war eben mit Bereitung von Manioc-Mehl beschäftigt. Jeder Widerstand wäre vergebens gewesen. Der Vater war auf Fischfang abwesend und 


\section{$-35-$}

die Mutter suchte mit ihren Kindern zu entfliehen. Kaum hatte sie die Savane erreiclit, als sie sich von den Indiancrn der Mission, welche auf die Menschenjagd gehen, wie die Weifsen auf die Negerjagd in Afrika, angehalten uud umringt sah. Mutter und Kinder wurden nun geknebelt und an's Ufer geschleppt. Der Ordensmann hatte, in seinem Falırzeuge sitzend, den Ausgang des Unternehmens, an dessen Gefahren er keinen Theil nalim, abgewartet. Hätte die Mutter heftigern Widerstand geleistet, so hätten die Indianer sie getödtet. Sie halten bei solchen Gelegenheiten alles für erlaubt, und gehen be. sonders auf Íinder los, um sie in der Mission als Sclaven der Christen zu betrachten. In der IIoffnung, die Mutter würde keinen Landweg in ihre Heimath finden, brachte man sie in die Mission San Fernando. Allein die Entfernung von demjenigen Kinde, welches den Vater am Tage des Überfalls begleitet hatte, brachte d̉as Weib zur höchsten Verzweiflung. Sie wollte die in der Gewalt des Mis. sionärs befindlichen Kinder zu den Ihrigen zurückbringen, und sie entfloh defshalb mehrmals mit ihnen aus dem Dorfe San Fernando. Die Indianer holten sie jedoch jedesmal wieder ein, und nachdem sic unbarmherzig mit Peitschenlieben gezüchtigt worden war, fafste der Missionär den grausamen Entschlufs, die Mutter von den zwei mil ihr eingebrachten Kindern zu trennen. Sic ward den Atabapo hinauf in die Missionen am Rio Negro geführt. Locker gebunden safs sie im Vordertheile des Fahrzeugs. 


\section{$-\quad 30$}

Unbekannt mit dem Schicksale, das man ihr bestimmt hatte, schlofs sie aus der Richtung der Sonne, dafs sie sich immer weiter von ihrer Hütte und ihrem Geburtslande entferne. Es gelang ihr, die Bande zu lösen; sie stürzte sich in's Wasser, und schwamm dem linken Ufer des Atabapo zu. Die Strömung trieb sie an die Felsenbank, die ihren Namen fübrt, und ein ewiges Denkmal der Helden. kraft und Tugend einer Mutter ist. Sie stieg daselbst an's Land, und flüchtete sich in den Wald. Aber der Missionär liefs seine Indianer ebenfalls landen, und sie im Walde aufsuchen. Am Abende ward sie zurückgebracht, - auf die Piedra de la Madre hingestreckt, und mit jenen Riemen aus Lamantinfell, welche in dieser Landschaft als Peitschen gebraucht werden, und womit die Alcalden jederzeit versehen sind, grausam gepeitscht. Mit starken Schlingen von Mavacure band man ihr die Hände auf den Rücken, und schleppte die unglückliche Frau in die Mission von Javita.

Sie ward hier in eines der Häuser gebracht, dic man Casa del Rey nennt, und zur Aufnalime der Fremden dienen. Die Regenzeit war eingetreten, die Nacht stochfinster. Wälder, welche bis dahin für undurchdringlich gehalten wurden, trennen die Mission Javita von derjenigen von San Fernando auf 25 Meilen in gerader Richtung. Flüsse sind die einzigen Strafsen, die man gebrauchen kann. Niemand hatte je den Versuch gemacht, von einem Dorfe zum andern, wenn ihre Entfernung auch nur 
wenige Stunden betrug, zu Lande zu gelangen. Alles dieses kann eine Mutter, die von ihrem Kinde getrennt wird, niclit abschrecken. Ihre Kinder sind in San Fernando de A tabapo; sie mufs wieder dorthin kommen, dieselben aus fremder Gewalt befreien, und ihrem Vater an die Gestade des Guaviare zurück führen. Niemand hütet, durch Entfernung sicher gemacht, das Weib. Weil ihre Arme bluteten, hatten, ohne Vorwissen des Missionärs und der Alcalden, die Indianer von Javita sie nur locker gebunden. Mit den Zälnen gelang ihr's, ihre Bande zu lösen. Sie war in der Nacht verschwunden, und am vierten Morgen ward sie in der Mission von San Fernando in der Näle der Hütte gesehen, wo ihre Kinder sich befanden. "Was dieses Weib ausgeführt hat, beinerkte der Missionär, der diese Gc. schichte erðählte, hätte der kräftigste Indianer zu unternehmen sich nicht gewagt. « Sie durchwanderte Wälder, in einer Jahreszeit, wo der Himmel beständig mit Wolken bedeckt ist, und die Sonne nur wenige Minuten sichtbar wird. Ist sie etwa dem Laufe der Gewässer gefolgt? Allein die Überschwemmungen der Flüsse nöthigten sie, sich von dem Uferzu entfernen, und ihren Weg mitten durcls den Wald zu nebmen, wo die Bewegung der Wässer beinahe unmerklich ist. Wie oft mufste sie durch jene stachlichten Schlingpflanzen, welche ein Gitter. werk um die Bäume schlingen, aufgehalten werden: Wie oft mufste sie schwimmend über die Flüsse setzen, welche sich in den $\Lambda$ tabapo ergiefsen! 


\section{$-\quad 38$}

Das unglückliche Weib ward gefragt: womit sie sich die vier Tage hindurch genährt habe? Ihre Antwort war: sic habe, durch Anstrengung erschöpft, keine andere Nahrung gefunden, als jene grofsen, schwarzen Amcisen, die Vachacos heifsen, und in langen Reihen die Bäume ersteigen, an denen sie ihre harzigen Nester befestigen.

Herr von Humboldt wünschte von dem Missionär zu erfahren, ob ihr endlich das Glück des ruhigen Beisammenseins mit ihren Kindern zu Theil geworden sey? Dieser weigerte sich die Frage zu beantworten, aber auf der Fückkehr vom Rio Negro vernahmen unsere Reisenden, dafs man der Indianerinn nicht ein Mal Zeit liefs, ihre Wunden zu heilen, dafs sie nochmals von ihren Kindern getrennt, und in eine der Missionen am Ober - Orinoko gesandt ward, wo sie durcl Weigerung aller Nahrung, wie die Wilden im grofsen Unglücke zu thun pflegen, sich den Tod gab.

Dieses ist das schöne Beispiel von Mutterliebe, dessen Denkmal der Fels der Mutter ist, und das eine Mutter gab, die zu einem von lange her verleumdeten Menschenstamme gehörte. Mutterliebe über alles !

Der Rio Temi richtet scinen Lauf von Süden nach Norden. Er ist 80 bis 90 Toisen breit, und hiefse in jedem andern Lande ein Strom. Die Landschaft besteht aus einem Walde, der den völlig flachen Boden deckt. Aus ihm ragt hervor die schöne, oben erwähnte Pfirsichpalme und die Mauritia mit stach. 


\section{- 39}

lichtem Stamme. Diese Mauritia aculeata wird von den Indianern Juria oder Cauvaja genannt. Die fächerförmigen Blätter sind der Erde zugekehrt, jedes Blatt zeigt, vermuthlich in Folge einer Krankheit, blaue und gelbe Kreise. Diese pfauenschweifartig gefärbten Blätter stehen auf niedrigen ungemein dichten Stämmen. Die Stacheln sind sehr holzig, kurz, unten breit, ähnlich denen der $\Lambda$ lkazien. Diese Palme wächst am Temi und Atabapo in Gruppen, von 12 bis 15 Stämmen, die jedoch einander so nahe stehen, als hätten sie nur eine Wurzel; durch Wuchs, Gestalt und die geringe Zahl der Blätter g!eicht sie den Fächerpalmen und Chamaerops des alten Festlan. des. Sie bemerkten einige Stämme olne alle Früchte, und andere, die sehr viele Früchte trugen, welches eine Palme mit getrennten Geschlechtern anzurleu. ten scheint.

$\mathrm{Da}$ das Land hier vollkommen eben ist, so ist auch der Wald überall, wo der Flufs sich krümmt, auf eine halbe Mcile und mehr noch überschwemmt. Um die Krümmungen zu vermeiden, und dic Schifffahrt abzukürzen, bedient man sich ganz besonderer Mittel. Die Indianer verliefsen das Flufsbett, und fuliren quer waldein auf einer Art Canal, der vier bis fünf Fufs breit ist. Diese Canäle werden, so wie unsere Fufssteige, gebildet, wenn man die Krümmungen der Heerstrafse verlälst, um auf kür. zerem Wege gerade durch den Wald zu kommen. Da jedoch hier wenig gereist wird, so verwachsen sich diese Pfade oft wieder, und man wird dann 
aufgehalten. Es steht daher immer auf einer sol. chen Fahrt ein Indianer mit einer Machette im Vordertheile des Bootes, um diesen Pflanzenivuchs zu zerstören, und die Pirogue in dem oft nicht eine halbe Elle tiefen Canal flott zu erhalten. Im dich. testen Walde wurden sie durch ein ungewöhnliches Rauschen überrascht, und als sie gegen das Buschwerk anschlugen, kam eine Bande Süfswasser-Delphine zum Vorschein, die vier Fufs Länge hatten, und umzingelten das Fahrzeug. Diese Thiere waren unter einem alten Ceiba verborgen gewesen, und flohen jetzt nach allen Seiten, indem sie jene Wasser - und Luftstrahlen ausspieen, von denen sie in allen Sprachen den Namen Spritzer führen. Dieser Anblick ist in doppelter Hinsicht seltsam. Ein Mal ist es wahrlich sebr spafshaft, mitten im Walde Delphine zu jagen, und dann ist die Entfernung von drei bis vierhundert Meilen von der Mündung des Orinoko für das Daseyn dieser Wasserthiere eben. falls sehr seltsam, indem die Delphine doch eigent. lich eine dem Meere angehörige Form bilden.

Mit vieler Mühe gelangten sie um fünf Uhr wieder in das eigentliche Flufsbett zurïck. Einige Minuten zuvor waren sie zivischen zwei Baunstämmen fast sitzen geblieben, und bald darauf an eine Stelle gekommen, wo sich die Canälc kreuzten, und man nicht wufste, welchen man einschlagen sollte. Übrigens machten sie auch hier eine für die Pflanzen. geographie wichtige Bemerkung. Sie sahen nämlich auch hier nirgends jene baumartigen Farrenkräuter, 


\section{$-41$}

sie bemerkten überhaupt, dafs dieselben vom $5^{\circ}$ an gegen den Aequator zu allmählich abnehmen. Sie gehören einem minder heifsen Lílima an, und kommen meisten's nur auf einer Höhe von $3 o 0$ Toisen vor. Sie scheinen daher die Aequatorial - Niederungen zu flichen.

Am 1. Mai wurde die Fahrt nach einer finstern Nacht durch den Wald wieder fortgesetzt, um die Strömung zu vermeiden. Bald darauf fuhren sie aus dem Temi in den Tamini über, und langten um eilf Uhr in der Mission Javita an. Von den Spritzern erschreckt, fiel aus dem Bote ein Saguin-Äffchen in's Wasser, und es kostete Mühe, ihn zu retten. In Javita war nun der Ort, wo sie Mittel finden sollten, um ihre Pirogue zu Land in den Rio Negro transportiren za lassen.

Glücklicher Weise fanden sie in der Mission Ja= vita einen sehr vernünftigen und überaus gefälligen Mönch, was um so angenehmer war, als sie genöthigt waren, fünf Tage in der Wolınung des Missionärs zu bleiben. So viel Zeit war nämlich erforderlich, um das Schiffchen auf dem Landwege (Portage) von Pimichin zu transportiren. Diese Zeit über wurde zu Spaziergängen benutzt, und um ihre Hände von einem Übel zu heilen, das sie seit zwei Tagen empfanden. Das Übel bestand in einem fürchterlichen Jucken der Finger und Gelenke. Der Missionär be. sah ihre Hände, und sagte ihnen sogleiclı, dafs es Aradores (Ackerbauern) wären, die sich unter der Haut eingegraben hätten. Mit dem Mikroskope konn. 
ten sie aber nichts, als parallele Furchen von weis. ser Farbe erkennen; die Gestalt derselben hat auch zu der Benennung Anlafs gegeben. Es ward nun eine Mulattin gerufen, die in der Mission das Amt eines Doktors inne hatte, und dic sich der Bekanntschaft aller der kleinen Thiere rühmte, welche die Haut des Menschen durchwühlen. Sie versprach auch sogleich, die Insekten alle nach einandar heraus zu holen. Zu dem Ende erwärmte sie an der Lampe ein sehr hartes, spitziges Stückchen Holz, und drang damit in die Furchen, die in der Haut sichtbar waren. Nach langem Suchen erliärte sie gravitätisch, und mit einer Miene, wie kaum ein europäischer Quacksalber vermocht hätte: » wir haben cinen Arador gefunden." Sie zog nun einen kleinen, runden Sack hervor, der wahrscheinlich der Eiersack des Insektes war. Sie holte auf diese Wcise drei oder vier Aradores hervor; allein hätten alle auf diese Weise herausgeholt werden sollen, so würde schwer. lich ein Monat zugereicht haben, denn die Hände waren voll dieser Milben. Die Reisenden hatten daher weder Zeit noch Geduld zu einer solchen Operation. Tags darauf wurden sie jedoch gründlich und überraschend schnell geheilt. Ein Indianer brachte einen Ziveig von einem Strauche, welcher Uzao heifst, und kleine sehr lederartige und glänzende Cassiablätter hat. Von der Rinde dieses Strauches bereitete er einen Aufgufs, der eine bläuliche Farbe und den Geschmack des Süfsholzes hatte, und aufgerührt viel Schaum gab. Das einfache Wa. 
sthen mit diesem Uzao - Wasser hob die Plage der Aradores völlig. Leider konnte man damals weder die Blüthe noch die Frucht des Uzao-Gewächses erhalten, welches zur Familie der Schotengewächse zu gehören scheint. Übrigens hatte sie der Schaden klug gemacht, und sie führten nun auf dem ganzen Wege Uzao - Zweige im Kalıne mit sich, welche am Gestade des Pimichin in Menge wachsen. Möchte man doch auch, ruft hier Herr von Humboldt aus, se schnelle und sichere Mittel gegen die Mosquitos und Zacundos erfunden haben! - Wir hätten es dell armen Freunden vom Ierzen gegönnt.

Vor dem Grenzzuge des Solano wurde diese ganze Landschaft von den Portugiesen besessen, die hier meistens das Handwerk der Secleneroberung in diesen Wäldern trieben, in der That aber die Indianer einfingen, um sie als Sclaven an die Brasilier zu verkaufen. Solano trieb sie jedoch nach Brasilien zurück, und machte sich den Iäuptling Javita zum Freunde, mit dem auch die Mission Javita gegründet wurde. Javita war noch an Leben, als Herr von Humboldt in der Mission verweilte. Er war ein an Geist und Körper gleich ausgezeichneter Indianer. Er wufste sich mit Leichtigkeit in der spanischen Sprache auszudrïcken, und hat auf die benachbarten Völkerschaften Einflufs behalten. Er begleitete die Fremden allezeit auf ihren botanischen Wanderungen, erzählte da vieles, und die Missionäre setzten in seine Wahrhaftigkeit festes Vertrauen. Er hatte in seiner Jugend alle Stämme zwischen dem 
Ober-Orinoko und dem Rio Negro Menschenfleiseh speisen gesehen. Er sagte aber, diese Sitte sey nur Wirkung der Rachsucht, und sie fressen nur gefangeue Feinde. Auch ist ihnen die Sitte der Scythen und Massageten, nach welcher sie aus Achtung den Leichnam der verstorbenen Feinde speisen, ganz fremd. Auf San Domingo würde jedoch ein Wilder der Achtung gegen seine Verwandten zu ermangeln geglaubt haben, wenn er in sein Getränke nicht etwas vom Körper des Verstorbenen beigemischt liätte. Die Menschen sind doch seltsame Narren! und wie ein Morgenländer sagt: vor allen Thieren seltsam in ihren Sitten und ausschweifend in ihren Teigungen.

\section{Fünfzehntes Kapitel.}

\section{Javita. - Reise an den Rio Negro.}

Das Klima der Mission Javita zeichnet sich durch seine Feuchtigkeit aus. In diesen waldigen Aequatorial-Gegenden bekommt man die Sonne nur selten $z u$ sehen, sobald man den $3^{\circ}$ Breite überschritten hat. Nur selten kann man Sterne beobachten, es regnet fast das ganze Jahr hindurch, und immer ist der Himmel bedeckt. Da im ungeheuren Walde von Guiana die Brise beinahe gar nicht weht, so werden die nassen und von Wasserdünsten gesättigten Luftschichten niemals durch andere trockne er. setzt, und es findet eine beinahe ununterbrochene 


\section{$-45$}

Wechschvirkung der Auslünstung und Niederschläge Statt. Der Missionär bezeugte, oft vier bis fünf Monate ununterbrochen Regen erfahren zu haben. Herr von Humboldt mafs am 1. Mai das in fünfStunden gefallene Wasser, es betrug ein und zwanzig Linien, und am 3. Mai sogar vierzehn Linicn in drei Stunden, und zwar nicht während eines Schlag.regens, sondern bei gewöhnlichem Regen. In Paris fallen sogar in den regnerischsten Monaten, März, Juli und September, nur 28 Linien Wasser. Aus vielen Beobachtungen, die Herr von Humboldt an. stellte, ergab sich : dafs gewöhnlich in einer Stunde Zeit qwei und drei Mal weniger Wasser auf dem Rücken der Anden, als in diesen Ebenen, die beinahe mit dem Oceane wagerecht sind, fällt. Es regnet in den Bergen öftermal, aher es fällt weni. ger Wasser in derselben Zeit. Ain Rio Negro, in Haroa und San Carlos ist der Itimmel merklich heiterer, als zu Javita und an den Ufern des Temi. Die Temperatur ist hier lühler, als zu Maypures, und wärmer, als am Rio Negro.

Vom 29. April bis zum 12. Mai war kein Stern im Meridiane zu sehen, obwohl ganze Näehte durchwacht wurden, um die Ortsbreite zu bestimmen. Nur am 4. Mai war die Sonne einige Minuten sichtbar, und gab die Länge des Orts zu $70^{\circ}, 22^{\prime}$.

Die 160 Indianer der Mission gehören zu verschiedenen Stämmen, und beschäftigen sich mit dem Baue von Canots. Zu diesem Ende werden grofse Stämme des Sassafras, theils durch Feuer, theils 


\section{$-40-$}

durch die Axt ausgehöhlt. Die Höhe dieser Bäume beträgt über $100 \mathrm{Fufs}$. Sein $\mathrm{Holz}$ ist gell, harzig; im Wasser fast unzerstörbar und hat einen angeneh. men Geruch. Die Arbeit kann man in Javita, San Fernando und vorzüglich in Esmeralda sehen, wo die meisten Piroguen verfertigt werden, weil die umliegenden Gegenden die gröfsten Sassafrasstämme darbieten. Man bezahlt für eine Pirogue, nach halben Toisen oder Varas, zu einen Piaster, so dafs eine Pirogue von 48 Fufs 16 Piaster kostet; aber die Ausrïstung, die Nägel und die Bekleidung, wodurch der Raum vergröfsert wird, verdoppelt die Kosten.

Der Wald bietet hier eine grofse Mannigfaltigkeit von Riesenbäumen dar. Ocotea, eigentliche Laurus, die Persea, die nie unter 10 Toisen angetroffen wird, die Amasonea-Arborea, das Retini. phyllum secundiflorum, die Curvana, der Jacio, der Jacifate, dessen Holz blutroth ist, der Guamufate, mit schönen 7 bis 8 Zoll langen Blättern, das Colo. phyllum, die Amyris - Cavnana und der Mani. Diese Gewächse haben alle über 100 bis $110 \mathrm{Fufs}$ Höhe; da sie jedoch erst gegen die Gipfel hin Äste treiben, so ist es sehr schwer, sich ihre Blüthen und Blätter zu verschaffen. Die Blüthen liegen wohl öfter unter den Bäumen zerstreut, weil aber die verschiedenen Arten unter einander gruppirt und mit Schlingpflanzen überwachsen sind, so läfst sich nicht allezeit mit Gewifsheit angeben, welcher Pflanze eigentlich die Blüthen angehören. $\mathrm{Zu}$ botanisiren ist hier sehr 
schwer, was man seit Monaten sammelt und durch lünstliche Wärme trocknet, geht in der grofsen Nässe wieder zu Grunde. Die Indianer nannten die Bäume nach ihrer Art, indem sie dieselben durch das Kauen des Holzes unterschieden. Sie wufsten die Blätter besser, als die Blumen und Frïchte zu unterschieiden.

Es bietet sich bei der Betrachtung des Gewächsreiches dic Bemerkung dar, dafs verschiedene chemische Eigenschaften der Pflanzen sich in verschicdenen Familien und Erdstrichen gleichsam ersetzen. Mehrere Palmarten liefern den Bewohnern der Aequinoctial - Länder das Öhl, welches in der gemälsigten Zone die Olive darbietet. Was den gemälsigten Erdstrichen die Zapfenbäume sind, das sind den heifsen Ländern die Terebinthen und Guttiferen. In den Wäldern der beifsen Ebenen gibt es weder Fichten, noch Tuja, noch Taxodium, nicht einmal einen Podocarpus; dafür liefert aber die Moronobea von Javita und die Amyris Harze, Balsame und aromatische Gummiarten. Diese Gummi und Harze werden in Javita häufig gesammeīt, wo sie cinen Gegenstand des IIandels bilden. Das berühmteste dieser Harze ist das Mani, von dem man Massen sieht, die mehrere Zentner im Gewichte halten, und dem Colophonium und Mastix gleich sehen. Der gröfste Theil kommt von einer Art Amyris her, die Mararo heifst. Es ist ein starkriechendes, schneeweifses Harz, welehes da, wo es mit dem innern Theile alter Rinden zusammenhängt, gelb wird. 
Sic bcsuchten während des Aufenthalts in Javita tägliclı den Wald, um den Fortgang der Pirogue zu selien. Drei und zwanzig Indianer waren beschäftigt, dieselbe über Baumäste, die in gemefsner Entfernung als Rollhölzer gebrauclit wurden, fortzuscbleppen. Ein kleiner Kahn wird in anderthalb Tagen aus dem Tuamini in den Pimichin übergesetzt; aber diese Pirogue war sehr grofs, und weil sie 7.am zweiten Male die Fahrt durch die Catarakten machen mufste, so mufste man dic zu starke Reibung des Bodens zu vermeiden suchen. Die Fahrt auf der erst seit 1795 angelegten Strafse dauerte also vier Tage. Diese Strafse beträgt 17,180 Varas. Die eine Hälfte der Arbeit liegt den Indianern von Javita, die andere denen von Maroa, Davipe und San Carlos ob.

In diesem Walde gelang es auch Herrn von Humboldt und seinen Gefährten endlich das angeblich fossile Federharz (Caoutchouc), welchem die Indianer den Namen Dapicho geben, zu erhalten. Der alte Capitän Javita führte sie an das Ufer eines kleinen Flusses, welcher sich in den Tuamini ergiefst. Er zeigte, dafs, um die Substanz zu sammeln, man in einen sumpfigen Boden, bei zwei bis drei Fufs Tiefe, zwischen den Wurzeln zweier unter dem Namen Jacio und Curvana bekannten Bäume nach. graben mufs. Der erste ist die Hevea, welche das Federharz, von Cayenne in den Handel liefert; der zweite hat gefiederte Blätter, sein Saft ist milchig, aber sehr dünn und beinahe gar nicht klebrig. Der 
Dapicho scheint das Produkt einer Ergiefsung des Saftes aus den Wurzeln, und diese Ergielsung vieder eine Folge des hohen Alters der Stämme und ihrer innern Fäulnifs zu seyn. Indem sich nämlich Splint und Rinde spaltet, geschieht natürlich, was der Mensch künstlich zu bewerkstelligen, sucht, dafs der Saft Gelegenheit findet, sich zu einer Masse zu sammeln. Herr von Humboldt glaubt, dafs diese Ergiefsung durch die Endtheile der längsten Wurzeln geschehe; denn or hat Stücke von zwei Fufs Länge und vier Zoll Dicke auf acht Fufs Entfernung vom Stamme gefunden. Die Substanz ist weifs, korkartig, brüchig und gleicht durch ihre über ein. ander liegenden Blätter und wellenförmigen Ränder dem Feuerschwamm. Ob es wohl bis jetzt nur in Javita gegraben wurde, so dürfte es dennoch in alken feuchten Wäldern von Guiana zu finden seyn, wo man sich die Mühe nälıme, in den Gegenden, wo Heveen vorkommen, nach denselben zu graben. Gegenwärtig kommt im Handel ein weifsgelblicbes Caoutchouc vor, welches sich vom Dapicho dadurch unterscheidet, dafs es weder trocken, wie Kork, noch zerreibbar, sondern mehr elastisch, glänzend und seifenartig ist. Dieses wird in Ostindien bercitet, und dünstet einen thierischen Geruch aus. Im Königreiche Neu-Granada sind glückliche Versuche gemacht worden, aus Federharz Stiefeln und Schuhe, ohne Nath, zu verfertigen. Die Omaguas am Amazonenflusse sind diejenigen Leute, welche in Ame. rika das Federharz am besten zu bearbeiten wissen.

Bibl. naturh. Reisen. IV. 
Es waren vier Tage vorüber, und noch war díe Pirogue nicht im Hafen von Pimichin. Die Reisenden wurden ungeduldig, aber der Missionär, Pater Cereso, tröstete sie mit folgenden Worten: „Ihr leidet keinen Mangel in meiner Mission. Ihr habt Pisang und Friichte, des Nachts stechen Euch keine Mosquitos, und je länger Ihr bleibet, desto eher möget Ihr auch die Gestirne meines Landes zu sehen bekommen. Wenn Eucr Falirzeug auf dem Transporte zerschlagen wird, so geben wir Euch ein neues, und mir wird das Vergnügen zu Theil, ein paar Wochen, con gente blanca $y$ de razon, mit weifsen und vernünftigen Leuten zu verleben.is So grofs auch die Ungeduld war, mul'sten sie sich bescheiden. Der Missionär entschädigte sie durch sein Wohlwollen und Nachrichten über die wilden Stämme. Sie leben in kleinen Horden, sind gegen einand: $r$ eben so mifstrauisch, haben keine andere Religion, als die Verehrung der Naturkräfte. Das gute Grundwesen und das büse Grundwesen wird auch hier unterschieden. Mit den Kirchen und Bildern können sie sich nicht leicht befreunden. Der Missionär erzählte: vdiese guten Leute lieben nur Umgänge im Freien. Als ich jüngst das Fest meines Kirchenpatrons des Dorfs, des heiligen Antonius feierte, wohnten die Indianer von Trinida der Messe bei. Euer Gott, sagten sie zu mir, bleibt in seinem Hause verschlossen, als ob er alt und schwach wäre; der unsrige wobnt im Walde, auf den Feldern, auf den Bergen von Sipapu, woher der Regen lommt." 


\section{$-51$}

Einige alte Indianer behaupten von göttlichen Dingen mehr zu wissen, als die andern. Sic sind es, denen das Botudo, die heilige Trompete, vertraut ist, von der oben die Rede war, dafs sie unter Palmen geblasen wird. Um in die Geheimnisse des Botudo eingeweiht zu werden, dazu gehört Sittenreinheit, und dafs man unverehlicht geblieben sey. Die Eingeweihten unterziehen sich Geifselungen, dann $\mathrm{Fa}$ sten und anderem lästigen Aberglauben melir. Die Zahl dieser Trompeten ist nicht grofs; die von Al. ters her berühmteste befindet sich auf einem Hügel nahe beim Zusammenflusse des Tomo und Guainia. Man behauptet, sie werde auf 10 Meilen weit gehört. Sie ist der Gegenstand der Verehrung mehrerer Völkerschaften. Zuweilen bläst sie der grofse Geist selbst. Es gibt Ungläubige, die jedoch ihren Unglauben nicht laut werden lassen. Weiber dürfen die Wundertrompete nicht beschauen. Der Missionär erzählte : dafs er 1798 so glücklich gewesen sey, ein junges Mädchen zu retten, das von einem eifersüchtigen und boshaften Lichhaber bcschuldiget ward, aus Neugierde die Indianer begleitet zu haben, welclse das Botudo in den Pilanzungen erschallen liefsen. Üffentlich hätte man sie zwar nicht genordet, aber wer vermochte sie vor dem Schwärmereifer der Eingebornen in einem Lande zu schützen, wo Vergiftungen so leicht sind? Sie entdeekte diese Besorgnisse dem Missionär, der sie in eine Mission am Unter-Orinoko bringen liefs. 


\section{$-52$}

So hat der Fanatismus auch in diesen Wildnissen scine Henker!

Am 4. Nai braclite man einen Indianer in die Mis. sion, der von eincr Schlange gebissen war. Dic Micania quaco, jenes Schlinggewächse, welches Mutis berühmt gemacht hat, und welches ein Gegengift gegen den Schlangenbifs enthält, war hier noch unbekannt. Es liefen vielc Indiancr nach der Hütte, und der Kranke wurde mit einem Aufgusse des Raiz de Mato gcheilt. Herr von Humboldt konnte von dieser nützlichen Pflanze wcder Blüthe noch Frucht sehen, und sie also auch nicht bestimmen. Sie half ïbrigens. Der Gebissene war ein starker Mann, und befand sich, als er gebracht wurde, sehr ïbel. Er war bewufstlos zur Erde gestürzt; Ekcl, Schwindel, Blutandrang zum liopfe folgten auf die Ohnmacht; dennoch ward er wieder hergestellt.

Am 5. Mai war endlich die Pirogue im Canno de Pimichin eingctroffen, und die Reisenden macliten sich auf den Weg, um dahin zu gclangen. Sie mufsten viele kleine Flüsse durchwaten, und hatten, der häufigen Schlangen wcgen, grofse Vorsicht nöthig. In dem feuchten Schlamme sahen sie die Fufsstapfen eincr klcinen Bärenart, die hier häufig ist. Sie unterscheidet sich an Gröfse von den Ursus americanus. Die Missionäre nennen ihn Osso cornicero, zum Unterschicde vom Osso palmero oder dem grossen Tamamdua (myrmecophaga jubata) und dem Osso lormigero oder Ameisenbär (fourmilles amandua); gegen dicse Thiere, deren Fleisch eine gute Speise 


\section{- 53}

ist, vertheidigen sich die zwei erstern, indem sie sich auf die Hinterfüfse stellen. Sic fanden einige lichte und an Pflanzen reiche Stellen im Walde, wo sie neue Arten der Coffea und Galega.Piscatorum entdeckten, deren sich die Indianer zur Betäubung der Fische bedienen, endlich auch die in diesen Gegenden unter dem Namen Vejuco de Wavacure bekannte Schlingpflanze, von der das berüchtigte Gift, Curare, herrülırt. Wir werden weiter unten noch von diesem Gifte sprechen.

Dic Bäume im Walde von Pimichin behalten ihre Höhe von 80 bis $120 \mathrm{Fufs}$. Gegen Abend trafen sie auf einem kleinen Meierhofe ein, der zunäclıst dem Landungsplatze von Pimichin lag. Man zeigte ihnen am VVege ein Kreuz, wo ein armer Kapuziner-Missionär von den Wespen getödtet worden ist. Dic Wespen von Javịta dürfen niclıt mit jenen Engelchen auf der Silla von Caracas verwecliselt werden. Sic sind nicht so gutartig, und in der heifsen Zone sind alle giftigen Inscktenstiche gefährlicher, als in der gemäfsigten. Übrigens dürfte wohl zu dem Tode des armen Mönchis das feuchte Klima und die Er. schöpfung eben so viel, als dia Wespen beigetragen haben.

Der Hafen oder vielmelir Landungsplatz von Pimichin ist von kleinen Cacaopflanzungen umgeben, und auch hier sind diese kräftigen Bäume überall mit Blüthen und Früchten beladen. Sic fangen im vierten Jahre schon zu tragen an. Wo der Boden nicht sumpfig ist, ist er überall sandig und durch 
wegs überaus fruchtbar. Da hier der Cacaobaum einlicimisch ist, und dic feuchte Luft des Orinoko ihm viel besser zusagt, als die immer trockner wer. dende zu Caracas, so ist es Schade, dafs dieser liostbare Zweig der Colonial-Wirthschaft nicht besser betrieben wird. Die Missionen allein liönnten jähr. lich 50,000 Fanegas in den Handel liefern, dic in Europa seclis Millionen Franken werth seyn würden.

Hicr wächst auch die Igua, welche mit dem Alendron von Mariquitar und der Juvia vom Amazonenstrome die köstlichsten Mandeln Südamerila's lie. fert. Diese Wälder sind voll vegetabilischer Wun. der, und jeder Schritt zeigt die Natur in neuer Ilerr. lichkeit.

Sic verweilten die Nacht über in einer IIütte, die leer stand, und worin noch die Fischerwerkzeuge, Töpferwaaren, Palmmatten und alles Haus. geräthe der sorglosen Indianer war. Um die Hïtte war ein grofser Vorrath des Mani, jenes woblricchenden Harzes, dessen wir schon oben erwähnt haben, und das hier zunn Betheeren der Schiffe gebraucht wird. Doch sogleich konnte die Hütte nicht in Besitz genommen werden, die Indianer inufsten erst die Schlangen daraus vertreiben, welche sich da einquartiert hatten. Zwei wurden getödtet. Sie waren schön, aber giftig, am Bauche weifs, auf dem Rücken aber braun und roth gefleckt. Nan war dic Nacht über nicht aulser Sorgen, da man die Hängc. matten nicht aufmachen konnte, und wirklich, als einer der Bedienten des Morgens sein Jaguarfell auf- 
liob, entdeckte er, dafs er lieineswegs allein geschlafen habe, denn eine grofse Schlange krock hervor. Sie suchen die Wärme, diese Thiere. Am Magdalenenstrome war sogar eine solche Schlange in das Betteiner unserer Reisenden gekrochen, ohne ihn zu beschädigen. Herr von Humboldt meint, wenn die Nattern und Kllappersehlangen so geneigt wären, den Menschen anzugreifen, ais man glaubt, so unufs. ten mehrce Gegenden Amerika’s, z. B. diese Wälder, unbewohnt bleiben.

Am 6. Mai ward endlich bei Sonnenaufgang die Pirogue wieder bestiegen. Der Boden der Pirogue war wohl dünner geworden, dennoch glaubte man mit ihr eine Falurt an 300 Meilen den Rio Negro hinab, den Cassiquiare linauf und wieder vom Orinoko bis Angostura herab machen zu können. Der Pimichin heifst hier ein Bach, hat aber die Gröfse der Seine bei Paris, den Tuillerien gegenüber. Er ist sehr stark an seinen Ufern hewachsen, so dals nur ein Canal für die Schiffahrt bleibt, welche durch die vielen hrümmungen sehr verlängert wird. Nachdem sie auf diesem Flüfschen fünf Stunden hinab. geschifft hatten, gelangten sie in den hio Negro.

Sechs und dreifsig Tage waren sie nun in einem engen Kahne eingeschlossen, unter den Beschwerden, dic wir naclı einander aufgezählt haben, herab. geschiff, um in den Rio Negro zu gelangen. Sie fuhren auf Flüssen, die den lírokodillen und In. sekten auzugehören schienen; durch Landschaften, welche ein Erbgut der Affen, der Schlangen, der 


\section{- $50-$}

haubrögel, der Tapire, der Pakari und der Jaguare sind, und wo des Menschen Oberherrschaft nicht anerkannt vird, der sich hier in Nichts zu verlieren scheint. Ein Soldat, der ein verständiger Mensch war, hatte mit ihnen an dem Ufer des Flusses ïbernachtet, er hatte von den Sternen und von allen Naturgegenständen mit ihnen gesprochen, und schlofs also: „Was die Menschen betrifft, so glaube ich, es gibt deren dort eben gerade so wenig, als ihr solche auf dem Landwege von Javita nach dem Cassiquiare gefunden habt. Ich glaube in den Sternen, so wie hier, eine mit hohem Grase und mit einem Walde bewachsene Ebene zu sehen, durch die kein Strom fliefst.« 


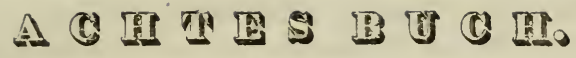

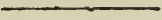





\section{Erstes Kapitel.}

Fahrt auf den hio Negro. - Der Teufelstanz. - heise bis zur Mission Franzesco Solano.

Der Rio Negro würde ein Strom ersten Ran. ges in jedem andern Welttheile seyn, hier aber, wo der Amazonen-Strom in ihm nur cinen Zuflufs er. kennt, gehört er zum zweiten Range. Seit dreihundert Jahren war er der Zankapfel zwischen der spanischen und portugiesischen Regierung, da ihn jede zu behaupten sich bemühte, und die Portugiesen durch seinen Besitz einen gebahnten Weg in das innere Guyanas gehabt haben iürden. Die Völker, welche in Europa Nachbarn sind, wurden es auf eine seltsame Weise und beinahe in demselben Ver. hältnisse in Amerika. Aus dieser seltsamen Nach. barschaft entstanden Grenzstreitiglieiten, welche so lange fortdauerten, bis neue Verhältnisse eintraten, und in Amerika sich Staaten bildeten, die, wenn sic ihren cigenen Vortheil einsehen, gewifs etwas anders zu thun finden werden, als sich um einige Quadratmeilen Wildnifs die Hälse zu brechen.

Übrigens betritt man mit dem Rio Negro ein neues Flufssystem. Man hat die Theilungsgräte oder Wasserscheide (divortia aquarum) überschritten, und alle die Flüssc ergiefsen ibre Wässer nun nicht mehr 


\section{$-60$}

in den Orinoko, sondern in den Amazonenstrom. Beide Systeme werden dureh die berülımte Gabeltheilung des Orinoko, deren ein Arm der Cassiquiare ist, verbunden. Die dem zweiten Bändehen beigefügte Charte wird meinen Lesern ein Bild von den Wasserverzweigungen darstellen.

Sobald unsere Reisenden aus dem Pimiehin in den Rio Negro gekommen waren, sahen sie auch sogleieh die Mlission von Maroa. Dieses Dorf ist von 150 Indianern bewohnt, und hat ein überrasehend nettes Aussehen von Gedeihen und Wohlstand. Sie lauften hier etliche sehöne Arten lebendiger Tukans (piapoco), eines kühnen Vogels, der, wie unsere Raben, viel Verstand entwiekelt. Sie kamen bicrauf bei den Mündungen der Flüsse Aquio und Tomo vorbei. Letzterer begünstigt die geheimen Verbindungen mit den Portugiesen. Der Tomo nähert sich in seinem Laufe dem Rio Guaicia, und die Mission von Tomo erhält darlureb zuweilen einen Zuwachs von Indianer - Flüehtlingen vom Unter - Guainia. Der Missionär Zea crzählte bei dieser Gelegenheit, wie die Indianer von Tomo und Maroa einst in einen grofsen Aufstand geriethen, als sie gezwungen werden sollten, den berïehtigten Teufelstanz vorzunehmen.

Der Missionär hatte nämlicb den unklugen Einfall gehabt: die Ceremonien, dureh welche die Yiachen, die gleichzeitig Priester, Ärzte und Zauberer sind, den bösen Geist Jolociamo besehwören, auf eine possierliche Art nachahmen zu lassen. Er 


\section{$-61$}

glaubte seine Neubekehrten dadurch auf eine treffliche Art ïberzeugen zu können, dafs der Teufel nun weiter keine Gewalt über sie habe. Etliche den Zusagen des Missionärs vertrauende Indianer waren bereit, die Rolle des Teufels zu übernehmen; sie hatten zu dem Ende schon Jaguarfelle mit langen Schleppschwänzen angezogen, und sich mit schwarzen und gelben Federn geschmückt. Der Platz vor der Kirche ward mit den Soldaten der Mission umstellt, damit das Vorhaben der Ordensmänner desto leichter Eingang finden möchte. Dic Indianer, welclie dem Erfolg dieses Tanzes und der Ohnmacht des bösen Geistes nicht recht trauten, wurden dem Feste beizuwohnen genöthigt. Nun aber gewann die Partei des alten Aberglaubens die Oberhand, Schrecken bemächtigte sich ihrer und Jedermann wollte al monte fliehen, so dafs der Missionär sein Vorhaben, den Dämon des Landes zu verspotten, auf gelegenere Zeit zu verschieben für gut fand. Das Unternehmen des Missionärs ist um so seltsamer, als sich alle Missionäre bemühen, die Todtentänze, die Tänze der heiligen Trompete, den Schlangentanz, den Gueti auszurotten, in denen die listigen Thiere dargestellt werden, welche vom Walde lierkommen, und mit dem Menschen trinken, um sie $z u$ betrügen und ihnen ihre Weiber zu rauben.

Nach einer zweistündigen Falurt waren sie in der Mission Daripe eingekehrt, wo sie der Missionär mit Madera bewirtlete. Ein Stücl Weizenbrot wäre ihnen jedoch viel lieber gewesen. Der Nordländer 
vermifst in diesen Gegenden das Brot aus Getreide mehr, als die geistigen Getränke. Der Madera Wein wird durch die Portugiesen den Rio Negro herauf gebracht. Die Missionäre, welche nicht sehr in der Geographic bewandert sind, wufsten nicht, ob sie sich des Madera bei der Miesse bedienen dürften, denn da Madera im spanischen auch $\mathrm{Hol}_{z}$ bedeutet, so glaubten sie der Madera: Wein dürte der Hol\%. saft irgend eines Baumes, wie der Palmwein, scyn. Sie verlangten daher vom Pater Guardian Aufschlufs, ob der Vine de Madera Traubenwein oder Baumsaft sey? Gleich im Anfange der Eroberung ward die Frage aufgeworfen, ob man sich eines gegohrnen Baumsaftes zur Communion bedienen dürfe? Sie ward, wie natürlich, mit Nein beantwortet.

In Davipe wurden Speisevorräthe geliauft, vor. züglich Hühner und ein Schwein, welches letztére die Indianer, welche schon seit mehreren Tagen lsein Fleisch gegessen hatten, kaum erwarten konn. ten, dafš es gebraten würde. Sie trieben daher so sebr zur Abreise, dafs Herr von Humboldt kaum im Pfarrhofe die Vorräthe von Mani-Harz und dem Tauwerke untersuchen konnte, welches aus dem Palmbaume, Chiquichiqui, verfertigt wird. Dieses Tauwerk verdiente auch in Europa bekannt zu seyn, denn es ist leichter und dauerhafter, als das hän. fene. Es war ein Weilser, ein Officier, Don Antonio Santos, der auf seiner Reise zur Erforschung des Parime-Sees, im Lande berühmt geworden ist, welcher die Blattstiele des Chiquichiqui zu Striclien 


\section{$-63$}

zu benutzen gelehrt bat. Dieser Officier ist auch der einzige Weifse, welcher von Angostura zum Grofspara auf dem Landwege von Rio Caroni zu demjenigen des Rio Branco gelangt ist. Er hatte die Verfertigung des Tauwerkes in den portugiesischen Colonien erlernt, und in Guiana eingeführt. Etwas davon wird nach den Antillen ausgeführt, und in Angostura um 5o, 6o vom Hundert wohlfeiler, als das hänferne verkauft. Weil jedoch nur junge Palmbäume dafür benutzt werden können, so müfsten dieselben angepflanzt und cultivirt werden.

Gleich oberhaib Davipe nimmt der Rio Negro einen Arm des Cassiquiare auf. Das Daseyn dieses Arms ist sehr merliwürdig. Dieser Arm des Cassiquiare geht nordwärts von Vasira aus unter dem Namen Itinivini, und nachdem er eine flache, völlig unbewohnte Landschaft in einer Länge von 28 Meilen durchzogen hat, ergiefst er sich in den Rio Negro, unter dem Namen Rio Conorichite. Der Rio Negro ist hier 120 Toisen breit, und es wird seine Masse durch die weifsen Gewässer vermehrt. Obgleich die Strömung des Conorichite sehr schnell ist, so wird doch die Schiffalirt von Davipe nach Esmeralda, um drei Tagereisen abgekürzt. Diese doppelte Einmün. dung des Cassiquiare kann um so weniger befremden, wenn man bedenkt, dafs die meisten amerika. nischen Strömungen bei ihrer Einmündung Delta's bilden. Auf solche Art gehen der Rio Branco und der Rio Jupura durch zahlreiche Arme in den Rio Negro und in den Amazonenstrom über. Beim Über- 


\section{- $64-$}

gange des Jupura in den Rio Negro zeigt sich jedoch eine noch viel merkwürdigere Erscheinung. Ehe nämlich der Rio Negro in den Amazonenstrom abfliefst, gibt er, welcher doch der Hauptsammler ist, drei verschiedene Arme, die den Namen Uaranapu, Manhama und Avateparana fülıren, dem Ju. pura $a b$, welcher doch wieder nur ein Zuflufs des Rio Negro ist. Welch eine seltsame Durchkreuzung dieser Flufsnetze und natürlichen Canäle! Man überläfst sich mit einer Art Wohlbehagen den Träumen, welche die Zukunft uns enthüllen, und uns hier das Bild einer zahlreichen geschäftigten Bevölkerung darstellen, welche die Produkte ihres so ïbcraus reichen Landes auf diesen Canälen verführen wird. Man sieht in Geiste die Mosquitos vertrieben, die Luft gereinigt, den Boden sorgfältig angebaut, die Achseln der Ströme mit zahlreichen Handels. städten besetzt und ein glückliches Volk Friede und Überfufs geniefsen.

Leider bieten diese Gegenden nur traurige Erinnerungen dar. Hier war es, wo die Portugiesen den Sclavenhandel mit den Eingebornen trieben, und diese als Vieh jagten und als Waare verbandelten. Der Grenzzug des Solano hat diesem Handel 1756 ein Ende gemacht. Es hatten zwar schon Carl V. und Philipp II. Gesetze erlassen, wo unter Androhung des Verlustes aller Ämter und 2000 Piaster Geldbufse die Glaubensbekehrung der Landeseingebornen durch gewaltsame Mittel und der Gebrauch der Soldaten gegen sie untersagt wurde. 
Allein so gewifs ist es, dafs die wohlthätigsten Gesetze und die menschenfreundlichsten Verordnungen der Machthaber nichts vermügen, wo dic angedrolsten Folgen ohne Erfüllung bleiben. Jedem Gesetze mufs die Genugthuung gewifs seyn, und jeder mufs überzeugt seyn, im Übertretungsfalle der angedrohten Strafe auf keine Weise entgehen zu können. Da die Hand der Regierung von Madrid hier gar nicht gefühlt werden konnte, so verloren auch die Worte alle Bedeutung. Die Cariben, ein liriegerisches und handeltreibendes Volk, erhielten von den Portugicsen und Holländern Messer, Angeln, Spiegel und allerlei Glaswaaren. Sie reizten dic armen Indianer zu gegenseitigen Befehdungen an, kauften ihnen die Gefangenen $a b$, und führten mit diesen zugleich noch andere hinweg, deren sie sich durch List oder Gewalt bemächtigt hatten. Sie hatten dann nur die Sorge, die Armen an die Portugiesen zu überliefern, welche sie dann über die brasilischen Grenzen brachten.

Bei Sonnenuntergang kam die Piroguc mit unsern Reisenden auf der Insel Dapa an, welche mitten im Flusse eine sehr malerische Lage hat. $\mathrm{Zu}$ ihrem gröfsten Erstaunen fanden sie hier bebautes Land, und auf einem kleinen Hügel eine indische Hütte. Vier Eingeborne safsen um ein Feuer, und afsen eine Art weifsen, schwarzgefleckten Teig, der die Neugierde der Reisenden nicht wenig in Anspruch nahm. Was meinen nun meine Leser, was dieses für eine Speise gewesen seyn mag? Nichts anders, 
als - Ameisenkuchen! Es werden dazu eine grofse Art Ameisen, Vacbacos genannt, deren Hintertheil einem Fettklumpen gleiclit, gesammelt; sie werden gedörrt und geräuchert, und unter den Teig gemengt. Es hingen mehrere Säcke dieser Kostbarlieit um das Feuer. Die guten Lcute achteten nur wenig auf die Fremden. In der Hütte fanden sich noch vierzehn Personen, die in vüllig üher einander geschichteten Hängematten lagerten. Als der Pater Zea eintrat, liatten die Indianer grofse Freude; sie sind überhaupt mehr den Mönchen, als Soldaten zugethan. Zwei junge Weiber stunden sogleich auf, um Cassave-Torten zu bereiten. Auf die Frage: ob der Boden der Insel fruclitbar scy, antworteten sie, der Manioc gedeilie zwar nicht sonderlich, aber es wäre gutes Ameisenland, und sie hätte an Lebensmitteln keinen Mangel. Diese Ameisen liefern wirklich ein kräftiges Nahrungsmittel für die Einwohner am Rio Negro. Als die Cassave - Torten bereit wa. ren, liefs der Pater Zea sich einen Sack mit geräucherien Vachacos geben, mischte die zerquetschten Insekten dem Manioc-Melile hei, und lud nun die Europäer ein, diese Mischung zu kosten. Sie schmeckten wie Brotkrumen mit ranziger Butter; demnach konnten sie in das Lob dessen, was die Missionäre einen vortrefflichen Ameisenteig nannten, nicht einstimmen.

Da der Regen gervaltig fiel, so flüchtete sich alles in die Hütte, welche nun genugsam bewohnt war. Die Indianer schliefen von $8 \mathrm{Uhr}$ Abends bis $2 \mathrm{Uhr}$ 
Morgens, von dieser Zeit an plauderten sie und schürten ibr Feuer an.

Den folgenden Tag kamen sie nach zwölf Stunden angestrengter Fahrt in San Carlos del Rio Negro an. Diese Festung liegt unter $1^{\circ}, 54^{\prime} 1^{\prime \prime N}$ N. Br. Hier wurden sie nach langer Zeit wieder bei einer weltlichen Person einquartirt, nachdem sie bisher immer bei den Mlissionären wohnten. Es war hier ein Commandant, Miiizlieutenant, der das Fort z.u bewaehen harte. Von der Gallerie des Hauses genofs man einer schönen Aussicht über drei sehr lange und mit dichter Vegetation bewachsene Inseln. Der Strom läuft hier so schnurgerade von Norden nach Süden, dafs man glaubte, er sey durch Menschenhände gegraben worden; aber wegen des allc. zcit bewölliten Limmels erhält dic Landschaft ein ernstes und dïsteres Ausseben. Im Dorfe fanden sich mehrere Stämme der Juvia, dieses majestätischen Gewächses, von dem die dreieckigen Mandeln lierkommen. Dieses Gewächs ist unter dem Namen Bertoletia excelsa hekannt gemacht worden; cs hat schon im achten Jahre cine Höhe von 3o Fufs. Die Besatzung besteht aus siebenzehn Mann, wovon zehn zum Scbutze der benachbarten Nlission detachirt waren. Die Luft ist hier so feucht, dafs kaum vier Flinten zum Feucrn tauglich waren. Die Portugiesen haben an eben dieser Grenze eine Festung: San Jose de Maravitanos, und in ihr 25 bis 30 besser bekleidete und besser bewaffinete Soldaten zur Besatzung. Das Fort San Carlos liegt dem Castello de San Fe. 


\section{$-08$}

lipe gegenüber, welches ein vierecliges, aus Back. steinen erbautes Gebäude ist, in dem sich sechs Feldstücke befanden, Der Commandant trug Bedenken, diese gewaltigen Festungswerke Herrn Bonpland zu zeigen, weil sie zwar die Erlaubnifs hätten, Berge zu messen und Höhen zubestimmen, und überall trigonometrische $\Lambda$ rbeiten vorzunebmen, aber nicht feste Plätze zu besehen. Aber Don Nicolas Solo war als spanischer Officier glücklicher, und erhielt die Erlaubnifs, über den Flufs zu setzen, wo er denn auf einer abgelsolzten Ebene den Anfang zu einer Erdfestung fand, welche, wenn sie vollendet gewesen wäre, eine Besatzung von 500 Mann bedurft hätte. Es ist jedoch weiter nichts, als ein Viereck mit einer fünf Fufs hohen Brustwehr und einem kaum sichtbaren Graben. Zwei Bastionen auf der Flufsseite können vier bis fünf Stücke auf. nehmen. Das ganze Werk enthält vierzehn gröfstentheils demontirte Kanonen, die von zwei Mann bewacht wurden. Um das Fort stehen einige indianische Hütten, welche die Dorfschaft San Felipe genannt werden. Nach dem $A$ bendläuten ward Bericht erstattet, und dem Commandanten im ganz ernsthaften Tone gemeldet, dafs alles um dic Festung her ganz ruhig zu seyn scheine. Es erinnert dieses an die afrikanischen Faktoreien, welche in ihren zum Schutze erbauten Fortins ebenfalls vier bis fünf Mann Besatzung haben. Die Soldaten befinden sich hier eben so übel, wie in den afrikanischen Fakto. reien; sie werden schlecht gekleidet und genährt 
und erhalten keinen Sold in Geld, sondern alle Bedürfnisse liefern die Officiere für grofse Preise. In Angostura ist die Besorgnifs, in die Grenzörter versetzt oder vielmelrr dahin verbannt zu werden, so grofs, dafs man die gröfste Mühe hat, die nöthigen Rekruten zu erhalten. Die Lebensmittel sind hier sehr theuer, weil an den Ufern des Rio Negro nur wenig Manioc und Pisang gepflanzt wird, und der Strom, wie alle schwarzen und lilaren Wässer, fisch. arm ist. Die meisten Vorräthe kommen aus den portugiesischen Besitzungen am Rio Negro, wo unter den Indianern Arbeitsfleifs und Wohlstand herrschen.

Wenn einst die Ausrottung der Wälder die Feuchtigkeit der Luft und die schädlichen Insekten vermindern wird, dann wird auch Fruchtbarkeit in diesen Ländern einheimisch werden. Gegenıärtig gedeiht der Mais beinabe gar nicht, der Tabak, welcher sehr geschätzt ist, wird nur an Stellen gepflanzt, wo altes Hauerwerk und verlassene Hütten sich finden. Der frisch abgeholzte Boden ist zu wässerig und scheint oline Kíraft zu seyn. In der Nähe der Dorfschaften Maroa, Davipe und Tomo wäclıst der Indigo wild; einst wird jedoch unter einer zweckmäfsigeren Verwaltung der Indigo, Caffee, Cacao, der Mais und der Reis in Menge gedeihen. Man hätte von hier aus an die Küste Brasilien's auf dem Amazonenstrome eben so schnell gelangen können, als zurück an die Küsten von Caracas. In San Carlos vernahmen die Reisenden jedoch, dafs 
der politischen Verhältnisse wegen, es in diesem Augenblicke sehr schwierig seyn würde, aus den spanischen in die portugiesischen Besitzungen zu gelangen. Erst nach ihrer Rückkehr nach Europa erfuhren unsere Freunde jedoch den ganzen Umfang der Gefahr, welcher sie eine solche Reise ausgesetzt haben würde. In Brasilien wufste man viel. leicht aus Zeitungen, deren wohlmeinende Geschäftigkeit ihnen öfter nachtheilig wurde: dafs sie den Rio Negro beschiffen und den natürlichen Canal besichtigen wollten, der zwei Flufssysteme verbindet. Bisher hatte man nur in den Händen der Grenz-Com. missäre Instrumente gesehen, und die Unterbeamten der portugiesischen Regierung begriffen nicht, wie ein vernünftiger Mensch sich langen Reisen aussetzen lönnte, um Ländereien zu messen, die nicht scin Eigenthum sind. Man hatte also Befelile ertheilt, sich der Person der Reisenden, ilrer Instrumente, und der besonders für die Sicherheit des Staates so gefährlichen Verzeichnisse astronomischer Bcobach. tungen zu bemächtigen. Man wollte sie auf dem Amazoncnstrome nach Grand-Para und von da nach Lissabon senden. Das Ministerium zu Lissabon hatte freilich, sobald es von dem unberufenen Diensteifer seiner Unterbeamten in Kenntnifs gesetzt wurde, die gemessensten Befeble ertheilt: die Arbeiten der Reisenden nirgends zu stören, sondern sie vielmehr auf alle Weise zu begünstigen, wofern sie, wo immer, durch die portugiesischen Provinzen ihren Weg nehmen würden. Dieses war nun recht schön, 
nur würde diese Sorgfalt eines aufgeklärten Ministeriums vermuthlich zu spät gekommen seyn.

Sie verweilten in San Carlos drei Tage und setz. ten ain 10. Mlai ihre Reise fort, um sie bis zur Ein. mündung des Cassiquiare fortzusetzen, und alsdann über diesen Flufs, der den Orinoko mit dem Ama. zonenstrome vereinbart, Untersuchungen anzustellen. Obwohl der Himmel heiter war, so verdunlelte er sich doch gleich wieder, als die Sonne anstieg. Dieser beständig trübe Himmel betrübte die Reisenden sehr. Dem Herrn Bonpland gingen seine sämmtlichen Pflanzen zu Grunde, urid Herr von Humboldt fürchtete durch die beständigen Nebel den Zweck seiner Reise, nämlich die astronomische Bestimmung der Vereinigungspunkte des Cassiquiare mit dem Rio Negro und Amazonenstrome zu verlieren. Blieb der Himmel bedeckt, und ward kein

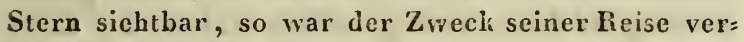
fehlt, und alle Beschwerden vergeblich erduldet. Die Reisegefährten hatten gewünscht, auf dem kürzesten Wege durch die kleinen Flüsse zurück zu kehren. Herr von Humboldt und Bonpland zogen es aber vor, dem Reiseplane getreu zu bleiben. Von San Fernando de Atabapo bis San Carlos hatten sie bereits 180 Meilen zurückgelegt gehabt, in. dem sie durch den Cassiquiare in den Orinoko zurückkehrten, sollten sic abermal 320 Meilen zu Wasser machen. Auf diesem Wege mufsten sie zehn Tage gegen die Strömung kämpfen, dann ging es den Orinoko abwärts. Der Pilote verhiefs ihnen 


\section{- 72}

auch Sonne und die grofsen Sterne, welche die Sonne fressen, sobald sie die schwarzen Gewässer verlassen hätten. Es ward also der Plan beharrlich ausgefülırt, und glücklich brachten die weifsen Gewässer heitern Himmel, Sterne, - Mosquitos und Ḱrokodille.

Jetzt fuliren sie zwischen den Inseln Zaruna und Mini durch, die mit dichtem Pflanzenwuchse bedeckt sind, und nachdem sie die Rapides der Piedra de Vicunar angestiegen waren, gelangten sie, acht Meilen von San Carlos, an den Cassiquiare.

Auf dem Felsen Uinumane, der Insel Chamanare gegenüber, am Rande der Wasserfälle, fanden sie einige Flechten, und weil der Cassiquiare sich nahe bei seiner Mündung plötzlich von Ost gegen Südwest dreht, so sahen sie hier zum ersten Male diesen majestätischen Arm des Orinoko in seiner ganzen Breite. Er hat, der allgemeinen Ansicht der Land-

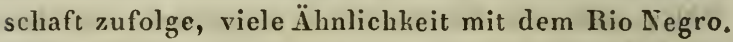
Wie im Flufsbette dieses letzteren, dehnen die Bäume sich auch dort bis an's Gestade aus, und bilden da einen dichten Wald; aber der Cassiquiare hat weifse Gewässer und wechselt öfter seine Richtung. In der Näle der Rapides von Uinumane erscheint er beinalse breiter, als der Rio Negro, und bis oberhalb von Vasiva ward er überall 250 bis 280 Toisen breit gefunden. Ele sie bei der Insel Garigave vorbei kamen, bemerkten sie nordöstlich fast am Horizonte einen Hügel mit halbkugelförmigem Gipfel. Diese Form ist unter allen Zonen den Granitbergen 


\section{$-73$}

cigenthümlicb. Erst weiter östlich aber findet sich ein zusammenhängendes Gebirge. Südwärts der Raudales von Caravine nähert sich der Cassiquiare abermals in der Krümmung seines Laufes dem Fort San Carlos. Von San Carlos bis zur Mission Franzisco Solano beträgt der Weg nur dritthalb Meilen zu Lande, zu Wasser aber sieben bis acht. In der vergeblichen Hoffnung, einen Stern zu sehen, brachte Herr von Humboldt einen Theil der Nacht im Freien zu.

Die am linken Ufer des Cassiquiare gelegene Mission von San Franzisco Solano erhielt ihren Namen zu Ehren des schon öfter erwähnten ziveiten Befehlshabers des berühmten Grenzzuges, der die Grenzen berichtigen, und zum Schutze derselben Missionen und Forts anlegen sollte. Solano ist übrigens nicht über San Fernando de Atabapo hinausgekommen, und hat diese Gegenden, in denen sie jet\%t veriveilten, nie gesehen. Zur Zeit dieses Grenzzuges wurden Dörfer angelegt, nach Mafsgabe, wie ein Corporal mit seinen Leuten vorrückte. Ein Theil der Landeseingebornen zog sich, um unabhängig zu bleiben, zurück; andere, deren mächtigste Iläuptlinge gewonnen waren, schlossen sich den Missionen an. Wo keine Kirche war, begnügte man sich, ein grosses Kreuz von rothem Holze aufzurichten, und neben dem Kreuze eine Casa fuerte $z u$ bauen, das will sagen, ein Haus, dessen Wände aus grofsen, wagerecht über einander liegenden Balken bestundeı. Dieses Haus hat zwei Stockwerke; im obern waren Bibl. naturh. Reiseu. IV. 
¿wei Sturmböller oder Kíanonen von kleinem fíaliber aufgestellt; in Erdgeschosse wohnten zwei von einer indischen Familie bediente Soldaten. Diejenigen unter den Eingebornen, mit denen man in Frieden lebte, legten ihre Wohrungen unweit der Casa fuerte an. Von den Soldaten wurden sie durch den Schall eines Horns oder einer botudo aus gebrannter Erde zusammengerufen, wenn eia fcindlicher Angriff zu fürchten war. Auf diese Art wurden die angeblichen neunzehn Dörfer oder christlichen Niederlassungen, durch den Antonio Santos auf dem Wege von Esmeralda nach Erevato gestiftet.

Zu San Franzisco trafen sie zwei Indier an, dic zwei Völkern angehörten, den Pacimonales und den Cherurichahenas. Obwohl die letztern vom Rio Jegro berkamen, so konnte man doch von ihnen. keine Auskunft über die Quellen des Rio Negro erhalten, weil sie den Sinn der Frage nicht begriffen. Man kaufte hier zwei schöne grofse Vögel, den Toucan und Ana, cine Art Aras, von 17 Zoll Länge, über den ganzen Kürper purpurroth, wie der $\mathbf{P}$. Macao. Sie hatten nun ein wahres Paradies in der Pirogue. Sieben Papageien, zwei Mlanakins, einen Motmot, zwei Guans oder Pavas de Monte, zwei Manaviris (Vivera caudivolula) und acht Affen, Summa vier und zwanzig. Es beschwerte sich aber auch, wiewohl leise, der Pater Zea, über den täg. lichen Wachsthum dieser Reisegefährten. Der Toucan ist in seiner Lebensweise und an Verstand dem Raben gleich, ein kühnes und leicht zähmbares Thier. 


\section{$-73$}

Sein langer und starker Schnabel dient ihm als Waffe. Er will Herr im Hause seyn, stiehit, was ihm erreichbar ist, badet sich oft und fischt gerne am Flufsufer. Dieser Toucan war noch sehr jung, und batte auf der ganzen heise ein eignes Vergnügen, die finstern und zornigen Cusicusis oder Nachtaffen zu necken. Es fand Herr von Humboldt nicht bestätigt, was einige naturhistorische Werke behaupten, dafs der Toucan, um seine Speise zu verschlingen, dieselbe erst in die Höle werfen müsse. Man mufs überhaupt gegen die Geschichtchen und T'bier-Anelidoten, womit die gewöhnlicinen Naturgeschichten ausgeschmückt sind, eben so auf derHuth seyn, wie gegen die Wundermährchen alter Reisebeschreibungen. Sie sind gewölnnich fremle Zuthat, und verschwinden bei genauer Untersuchung. So ist es auch, was vom Toucan erzählt wird, er müsse allezeit die Speise mit dem Schnabel fassen, über sich in die Höhe werfen, den Schnabel weit öfnen and so seinen Frafs sich in den Schlund fallen lassen. Das Wahre ist, er fafst nur mit Mühe von der Erde die Speise mit seinem selir grofsen Schnabel auf, hat er sie aber einmal gefafst, dann hält er nur den Schnabel in die Höhe, und bält ihn senłrecht, so lange das Niederschlueken dauert. Beim Trinken macht er nicht weniger seltsame Geberden. Die Mönche sagen: er schlage über dem Wasser das Zeichen des Ḱreuzes, und dieser Volksglaube hat ihm bei den Creolen den wunderlichen Namen di ostedé (Gott vergelt dir's) gegeben. 
Die meisten der Thiere waren in kleine Korkkäfige eingeschlossen, andere liefen in der ganzen Pirogue frei umher. Wenn es nun zu regnen drohte, so erhoben die Aras ein abscheuliches Geschrei; der Toucan strebte zum Fischfange an's Ufer hin, die kleinen Titis. Affen suchten den Pater Zea auf, um sich in den weiten Ärmeln seines Ordenskleides zu bergen. Die burlesken Auftritte wiederholten sich öfter, und belustigten so, dafs sie die Plagen der Mosquitos darüber vergafsen. Des Nachts, wenn man im Freien bleiben mufste, kam in die Mitte der lederne Proviantkasten zu stehen, neben ihm. die Instrumente und die Käfige mit den Thieren, ringsum die Hängematten der Herren und aufsen die der Indianer. Den Aufsenkreis bildeten alsdann. die Fcuer, welche als Schutz gegen die Jaguare angezündet wurden. So brachten sie die Nächte am. Cassiquiare zu.,

\section{conosonsonsons \\ $Z$ we ites $K$ ap it el.}

Die Menschenfresser. - Fahrt bis Mandaraca.

Am 11. Mai verliefsen sie ziemlich spät die Mission San Franzisco Solano, um eine nur kleine Tagreise zu machen, weil man immer auf heiteres Wetter hofite. Wirklich fingen auch die Wolken an aus der allgemeinen Dunstschichte in bestimmte Gestalten überzugehen, und ein schwacher Ostwind in den obern Luftregionen liefs ihnen Hoffnung scliöpfen, 
kommende Nacht einen Stern durch den Meridian gehen zu sehen. Sie fuhren wicder bei mehreren Flufsmündungen vorbei, südwärts bei dem Canno Daquiapo, nordwärts bei dem Guachaparu und ei. nige Meilen weiter die Rapides von Cananivacari. Sie landeten hier, und wenige Schritte vom Ufer fand Herr Bonpland einen prächtigen Stanm der Bertholetia excelsa. Dieses löstliche Gewächs, welches jene süfsen und überaus fetten dreieckigen Mandeln liefert, hatten die Reisenden am Cassiquiare nicht vermuthet. Wahrscheinlich ist er nur der Vorläufer einer ganzen Waldung dieser Bäume, die sich hier im Lande befindet.

Einige Meilen weiter entdeckt man Felsen von höchst seltsamer Gestaltung. Zuerst eine Mauer bei achtzig Fufs hoch, und senkrecht abgeschnitten, hernach am südlichen Ende dieser Mauer zwei Thürmchen, deren $z$ weite Grundschichten fast wagerecht liegen. Man glaubt Trümmer eines alten Gebäudes zu sehen. Es scheinen diese Klippen in dem alten Binnenmeere, welches diese Ebenen einst dargestellt haben, Eilande gewesen zu seyn, oder sind diese Granitthürme durch elastische Ḱräfte im Innern des Planeten emporgehoben worden? (Sind es nicht alle Urgebirge auch?) Es mag erlaubt seyn, über dic Entstehung der Berge auch ein wenig zu träumen, wenn man die Vertheilung der mexikanischen Vulkane und Trachyt-Gipfel auf einem ausgedehnten Erdrisse gesehen hat; wenn man in den südameri. kanischen Anden, in der gleichen Kette, Urgebirg 
und vulkanisches Gebirg an cinander gereiht sah, und wenn man sich jener Insel von drei Meilen Umfang und aufserordentlieher Höbe erinnert, die in unsern Tagen nahe bei Unalaschka aus dem Meeres. grunde emporgestiegen ist.

Die Ufer des Cassiquiare sind geschmückt mit herrlichem Basmwuchs, der seine Zierde durch die häufigen Chiriva-Palmen erlöht sieht, welche gefiederte und amUntertheile silherfarbneBlätter haben. Die Nacht verhiefs Sterne, und man bivouakirte nahe bei einem abenteuerlichen Granitfelsen, der Piedra de Culimucare genannt wird. Diese Bemerkung ist nothwendig für die astronomischen Beobachtungen. Denn da der Mensch hier ohne Spuren hinier sich zu lassen, vorübergeht, so müssen die Naturbeob. achtungen bei solchen Naturdenkmälern gemacht werden, die der Flüehtigkeit menschlicber Werke sicht ausgesetzt sind. Es gelang diese Naclit eine gute Breitenbeobachtung im Alpha des Südkreuzes zu erhalten, die Länge konnte nicht eben so gut mittelst der zwei schönen Sterne zu den Füfsen des Centaurs beobachtet werden. Der Felsen von Culimucari liegt sehr genau unter $2^{\circ}, o^{\prime} 42^{\prime \prime} \mathrm{N}$. Br. und wainrscheinlich $69^{\circ}, 33^{\prime} 50^{\prime \prime}$ W. L. von Paris. Diese 3eobachtungen sind für die Grenzbestimmungen zwischen Columbien und Brasilien wichtig. Die GrenzCommissarien nelımen gewöhnlich den Aequator zur Grenze an, und die meisten Cliarten zeigen das portugiesische Fort südlich vom Aequator. Die Beobachtungen des Herrn von Humboldt zeigen aber, dals 
CS 25 Meilen nördlich rom Aequator liegt, San Carlos aber nicht $0^{\circ}, 53^{\prime}$, sundern vielmehr $1^{\circ}, 53^{\prime} 42^{\prime \prime}$ N. Br.zu suchen ist.

Bei der Fortsetyung ihrer Fahrt, am 12. Mai, empfanden sie die Mosquitosplage um so heftiger, je weiter sie sich rom Rio Negro entfernten. Im Thale des Cassiquiare fanden sich zwar ḱcine Zacundos, aber desto mehr Simulien und alle andern giftigen Insekten der Schnakenfamilie; zudem war die Strömung des Flusses heftig, und erlaubte, bei der gröfsten Anstrengung, nur kleine Tagreisen zu machen, so dafs sie oft vierzehn Stunden brauchen, um drei Meilen zurüclizulegen. Bei Sonnenaufgang lamen sie bei der Mündung de Pacimoni vorhei. der in einem Berglande entspringt und schwarzes Wasser führt; nocb scbwärzer ist das des Vasiva. Sees, der sich auch in den Cassiquiare ergiefst; zwischen beiden schwarsen Wässern ergiefst sich auch der Rio Idapa mit weifsem Wasser.

Sic kamen nun in der Mission Mandavaca an. sie zühlt secbzig Landeseingeborne. Der Zustand dieser christlichen Ansiedlung ist so elend, daf's auf der ganzen Länge des Cassiquiare von 5o Meilen keine 200 Einwohner angetroffen werden. Diese nähren sich den gröfsten Theil des Jahres hindurch von jenen grofsen Ameisen, deren oben gedacht wurde, also eigentliche Myrmecophagen. In Mandavaca trafen sie den alten guten Missionär, der nun schon zwanzig Mosquitos. Jahre in den Wäldern des Cassiquiare zugebracht hatte, und dessen Schenkel der- 
mafsen von Insektenstichen getigert worden, dafs die eigentliche Hautfarbe unkenntlich geworden war. Er sprach von seiner traurigen Lage und Verlassen. heit und der Nothwendigkeit, in den beiden Missionen von Mandavaca und Vasiva die gräulichsten Verbrechen ungestraft lassen zu müssen. So batte in Vasiva ein Alcalde seine Frau gefressen, nachdem er sie zuvor in seiner Hütte gut genährt und gefüttert hatte. Die Sucht in Guiana, einander zu fressen, erwacht oft, nachdem sie lange in den Missionen geschwiegen und geschlummert hat. Nachstehender Vorfall hatte sich zu Esmeralda wenige Monate vor der Ankunft unserer Freunde ereignet. Ein Indianer aus der Waldgegend, hinter dem Duida gebürtig, unternahm eine Reise mit einem andern Indianer, welcher früher an den Gestaden des Ventuari von den Spaniern war gefangen genommen worden, seither aber im Dorfe, oder wie man hier sagt, unter dem Glockenschalle ruhig gelebt liätte. Der letztere litt am Fieber und mochte darum nur langsam fortkornmen. Der Reisegefährte, über die Zögerung ärgerlich, schlug ihn todt, und verbarg den Leich. nam in der Nähe von Esmeralda. Dieses Verbrechen wäre nun wohl unentdeckt geblieben, hätte der Mörder nicht folgenden Tag ein Gastmal zu geben unternommen. Er wollte seine Kinder, die in der Mission erzogen und Cbristen geworden waren, bereden, mit ihm einige Stücke des Leichnams zu holen. Die Kinder wollten nicht, es entstand Streit, und dieser brachte die That zur Kenntnifs 
des Soldaten, der in der Mission postirt war. Die abscheuliche Sitte, einander zu fressen, und die damit verbundene Gewohnheit, Menschenopfer zu bringen, wird leider in allen Weltgegenden angetroffen, und zwar unter Menschen verschiedener Abstammung und Cultur. Es rechnen sich's viele, eben nicht ganz rohe Völker, zur Ehre, ihre Gefangenen aufzuspeisen. Dieser Gedanke erregt in dem gesitteten Menschen Abscheu und Schauder vor sich selbst. Es ist diese Sucht nach Menschenfleisch nicht Folge natürlicher Wildheit, denn die Erfahrung liat gelehrt, dafs die Anthropophagen-Völker die ersten Stufen der Cultur schon erreicht hatten, und ganz Wilde keine Menschenfresser sind. Dieses wahrhafte Laster (denn das ist der rechte Name für diese abscheuliche Sitte) ist Folge menschlicher Verkchrtheit und Ausartung. Eben der Halbgebildete ist's, der mit ausschweifender Phantasie an allen Genüssen künstelt, und die Unruhe seines Innern durch solche Extravaganzen zu beruhigen sucht. Man betrachte nur die Wollüste der Trunkenheit und sinnlicher Ausschweifungen der ungebildeten unter den gebildeten Nationen, und man wird den Cannibalismus darin nicht verkennen.

Die Verkehrtheit des Sinnes zeigt sich d̉em Psychologen auch in dem folgenden Ereignisse. In der Pirogue des Herrn von Humboldt befand sich ein flüchtiger Indianer vom Rio Guaisia, der sich innerhalb weniger Wochen so weit ausgebildet hatte, dafs er den Reisenden bei der Aufstellung ihrer In- 


\section{$-82$}

strumente Hülfe leisten konnte. Er schien so sanft und verständig, und Herr von Humboldt schien geneigt, ihn in seinen Diensten zu behalten. Mit grossem Ledauern aber erfuhren sie von ihm in einem durch den Dolmetscher stattgefundenen Gespräche : das Fleisch der Marimondes. Affen, wenn es gleich schwärzlich aussehe, schmeclie ihm wie Menschenneisch. Er versiclierte: seine Verwandten balten am Mensclien, wie an dem Affen, das Innere der Hände für den gröfsten Leckerbissen. Während dieser Erählnng drückten seine Geberden eine wilde Fröblichleit aus. Sie fragten den Indianer, der sonst selur sanft und bescheiden war, ob er wohl auch jetzt noch Lust hätte, von Cheruvichahena-Indianern ein Stücli zu speisen. Er antwortete ganz ruhig: weil er in der Mission sicb aufhalte, werde er nichts anders essen, als was er die Parlres essen sehe. Macht man den Indianern Vorwürfe über ihre Sucht nach Menschenfleisch, so macht das auf sic denselben Eindruck, als wenn man einem Europäer gegen scine Sucht nach $\nabla$ öllerei und Ausschweifungen Vorstellungen macht. Der Indianer von Guaisia bält den von Cheruvichahena für ein von ihm ganz verschiedenes Wesen, das or mit voller Be. fugnif's tüdten und speisen kann, wie den Jaguar des Waldes. Nur aus Rücksicht des Anstandes wollte er, so lange er in der Mission war, sich des Men. schenfleisches enthalten. Wenn aber die Eingebornen etwa wieder in ibre Meimath zurückkehren, oder vom Hunger geplagt werden solleen, so nehmen sic 
alsliald ihre Anthropophagen - Sitte wieder an. Wie sellten wir uns aber auch über diesen Umstand bei den Völkern am Orinoko wundern; wenn furchthare und nur allzugervisse Beispicle uns an Ereignisse erinnern, die in grofsen Hungersnüthen unter gesittigten Völisern stattgefunden haben? Im dreizehnten Jahrhusderte hatte sich in Egpyten die Gewohnbcit, Menschenfleisch zu essen, unter allen Classen der Einwolner verbreitet. Insonderheit wurden den Ärten Fallstricke gelegt. Hungernde gaben sich für Jirank aus, licfsen den Arzt rufen, und frafsen ihn. Ein völlig glaubwürdiger Geschichtschreiber crzählt folgendermafsen darüber. "A!s arme dürftige Nienscben dis Menschenfleisch zu essen anfingen, war der Abscbeu und das Erstaunen über eine so fürchterliche Erscheinung so grofs, dafs dieses Verbrechen zum Gegenstande aller Gespräcbe wurde, und Niemand von etwas andern reden wollte. In der Folge jedoch gewöhnte man sich dermafsen daran. und fand an der entsetzlichen Nahrung auch so viel Geschmacli, dafs selbst begüterte Leute und Personen vom Stande sich ihrer zur gewöhnlichen Speise bedienten, ihr Licblingsgericht daraus machten, und sogar Vorräthe davon veransialteten. Es wurde dieses Fleisch verschiedentlich zubereitet, und der nun einsnal cingefülirte Genufs desselben, ging nun auch in dic Provinzen über, so dafs kein Theil Egyptens übrig blieb, wo er nicht Nachahmung fand. Die Sache crregte nun weiter kein Erstaunen mehr, der zuvor gefühlte Abscheu verschivand nun gänzlich. 


\section{$-\quad 81 t$}

Man sprach davon und hörte davon sprechen, wie von einer ganz gleicligültigen Sache; diese Wuth, sich einander zu fressen, ward in der dürftigen Classe so gemein, dafs sehr viele Personen auf diese Weise umkamen. Dic Bösewichter bedienten sich mannigfaltiger List, um die Menschen zu überraschen und unter täuschendem Vorgeben in ihre Falle zu locken. Dieses widerfuhr drei Ärzten aus meiner Bekanntschaft, und ein Buchhändler, welcher nur Bücher verkaufte, ein bejahrter und sehr fetter Mann, mochte sich nur mit grofser Mühe aus der ihm gelegten Schlinge retten. Alle Thatsachen, deren wir als Zeugen gedenken, sind uns nur zufällig vor. gekommen, denn wir vermeiden so viel als möglich, Zeugen solcher abscheulichen Auftritte zu seyn.« Dieser Mann, den wir als Zcuge hier angefüìrt liaben, hiefs Abd-Allutif, und war ein Arzt aus Bagdad.

Die Indianer vom Cassiquiare legen leicht ihre barbarischen Gewohnheiten ab, nelimen sie aber auch eben so leicht wieder an. Sic lernen leicht spanisch, was besonders dadurch befördert wird, dafs man Indianer von drei bis vier Stämmen, deren jeder eine andere Sprache hat, in den Missionen vereinigt. Da nun keiner den andern versteht, so lernen sie alle spanisch, um sich mit einander zu besprechen. Herr von Humboldt hörte einen Poignave mit einem Guahibos sich unterhalten, obgleich beide erst seit drei Monaten in der Mission waren. Sie drückten sich jedoch allezeit in Gerundien aus, 
z. B.: als ich gehend Padre; oder: Padre mir sagend. Die Jesuiten hatten eine sehr vernünftige Idee, da sie eine gebildete amerikanische, zu einer allgemeinen Sprache machen wollten, weil eine solche, sowohl den amerikanischen Organen, als der gewolnten Art sich auszudrücken, angemessener wäre, als die lateinische, welche man in einem Pro. vinzialkapitel in vollem Ernste vorschlug. Die Indianer vom Cassiquiare werden als verständiger und fleifsiger, denen vom Orinoko in Angostura vorgezogen. Dic Mandavacas sind durch die Verfertigung des Curare-Giftes berühmt, welches dem Curare von Esmeralda an Stärke nichts nachgibt. Der Boden des Cassiquiare ist sehr fruchtbar, und würde angebaut, einen Überflufs der köstlichsten Produkte liefern. Nur müiste die Ausrottung der Wälder im Grofsen vorgenommen werden, weil kleine Pflanzungen nicht sehr gedeihen, wegen der aufserordentlichen Feuchtigkeit der Luft - und der Insekteniwolken, welche diese Landschaft beinahe unbewohnbar machen. Selbst bei vollkommen heiterm Himmel zeigte der Hygrometer nie unter $52^{\circ}$. Die Ameisen fallen in langen Zügen die saftigen Pflanzen verwüstend an. Wenn ein Missionär Salat oder etwas curopäisches Gemüse pflanzen will, mufs er seinen Garten gleiclssan in die Luft hïngen. Er füllt nämlich einen alten Kalın mit guter Erde, und wenn er sie besäet hat, längt er ihn bei vier Fufs über der Erde mit Sricken an Palmen auf. Nur wenn die Kü̈stengegenden übervölkert und die Men. 


\section{$-80-$}

schen in Masse gegen das Innere des Landes rorgedrungen seyn werden, wird es auch gelingen, diese Wälder in gesegnete und dem Mensehen unterthänige Fluren umzuschaffen, und so sehr jetzt diese Berichte denen gleich sehen, welchen einst rümische Feldherren von Germanien machten, so werden alsdann die Indianer, Tiger und Mosquitos zur Aus. schmürkung der Mährchen dienen, und bei den amerikanischen Schöngeistern unsere Drachen, Bären und Tlülfe ersetzen.

Mandavaca liegt unter $2^{\circ}, 4^{\prime} 7^{\prime \prime} \mathrm{N}$. Br. und $69^{\circ}, 27^{\circ}$ W. Länge.

\section{Drittes Kapilel.}

Fahrt bis zur Gabeltheilung. - Nacht-Besuch rom Jaguar.

Den 14. Mai früh um halb drei Uhr verliefsen sie die Mission Mlandavaca. Noch hatten sie eine Fahrt von acht Tagen gegen den reifsenden Cassiquiaré vor sich, und das Land, durch welches sie vieder nach San Fernando de Atabapo gelangen sollten, war dermafsen öde, dafs sie erst nach einer Tahrt von dreizelun Tagen zu der Mission von San Barbara zu gelangen hoffen konnten. Sie kamen nach sechs Stunden vor der Mündung des Itapa, der weifses Wasser führt, vorbei.

Sie schlugen ihr Nachtlager nahe bei dem Raudal von Cururi auf, dessen.Getöse die Nacht merklich verstärkte, was die Indianer für gewisse Vor- 


\section{- 87}

boten des Regens bielten. Auch die Benohner der Sclweizer-Alpen machen diese Bemerkung, und wirklich regnete es ganz tropisch, noch vor Sonnenaufgang. Ubrigens hatten die $\Lambda$ fen durch ihr $G e$ heul ebenfalls den nahen Regen verkündigt.

Die Mosquitos und mehr noch die Ameisen vertrieben sie schon un cin Uhr von ihrem Lager. Sey es, dafs sie auf den Stricken in die Hängematten Jrochen, oder sich vor den Bäumen in sie stürzten, genug sie erhiclten diesen lästigen Besuch so zahlreich, dafs sie Mübe hatten, diesen Inseliten los zu werden. Der Flufs wurde nun zusehends schmäler, und die Ufer so sumpfig, dafs Herr Bonpland nur mit Mühe sich einer Carolinca princeps nähern konnte, welche mit Purpurblumen übersäet war. Dieser Baum ist dic scrönste Zierde dieser Wälder, und deren vom Rio Negro. Man untersuchte den Tag über die Temperatur des Wassers, und fand sie zu zwei Grad nedriger, als die der Luft, nämlich $24^{\circ}$, wenn die Luft $25^{\circ}, 6$ zeigte. Dieses ist dieselbe Temperatur des Rio Negro, hingegen $4^{\circ}$ bis $5^{\circ}$ geringer, als die des Orinolio. Nachdem sie die Flufsmündung des Caterico, der schwarzes Wasser führt, vorbeigeliommen waren, veriliefsen sie das Flufsbett, um an der Insel zu landen, auf welcher die Nission Vasiva errirhtet ist. Der See, welelier sie umgibt, ist eine Meilc breit und bängt durcl Abfüsse mit dem Cassiquiare zusanmen. Die selır sumpfige Umgebung ist ein wahres Ficherland. Der See vertroçket zur 2.cit grofser Hitze, und dann 
mügen den aus seinem Schlamme sich erhebenden Miasmen dic Indianer selbst nicht widerstehen. Ein Theil des Dorfes ist nach einer trocknen Stelle versetzt worden, was einen Streit zwischen dem Missionär und dem Statthalter veranlafst hat; der behaup. tete, ohne Zuziehung der Civilbehörde könne so etwas niclit geschehen. Mit der geographischen Lage völlig unbekannt, hatte er sich mit seiner Beschwerde an den 150 Mleilen weit entfernten Missionär von Carichana gewandt. Solche Mifsgriffe geschehen hier häufig, wo die Statthalter von dem Lande, das sie statthaltern sollen, auch nicht den geringsten Begriff haben. So hatte man im Jahre $1785 \mathrm{dem}$ Pater Valor die Mission Padami übertragen, mit dem Befehle, sich sogleich zu den Indianern zu verfügen, die keinen Missionär hätten. Es stand der Ausführung dieses Befchls weiter nichts entgegen, als dafs dic Mission seit fünfzehn Jahren von der Erde verschwunden, und die Indianer al monte gegangen waren.

Vom 14. bis 21. Mai mulsten sic die Nacht immer unter freicm Himmel zubringen, und zwar ohne nur die Orte angeben zu können, wo sie übernachteten. Der Himmel gab auch nicht eine Sternbeobachtung. Wo Xer Cassiquiare den oben erwälnten Arm Itinivine aussendet, fanden sie die sumpfige Flufsachsel mit Bambus bewachsen. Dieses bildet eine neue Gattung mit sehr breiten Blättern; es wird 20 Fufs hoch und ist am Gipfel gekrümmt. Als ein Bild der Beschwerlichkcit der heise auf dem Cassiquiare setze 
ich folgende Erzählung des Herrn von Humboldt wörtlich her. "Unser erster Bivak, oberhalb Va. siva, war bald zu Stande gebracht. Wir fanden einen kleinen, trocknen, von Gesträuch freien Erdfleck, südwärts von Canno Curamuni, an einer Stelle, wo Kapuziner-Affen, durch den schwarzen Bart und ihr trauriges und scheues Aussehen kenntlich, langsam auf den wagerechten Ästen eines Genipa dahin schritten. Die fünf folgenden Nächte waren um so beschwerlicher, als wir der Gabeltheilung des Orinoko uns näherten. Die Üppigkeit des Pflanzen wucl. ses vermehrt sich auf eine Weise, von der man sich kaum eine Vorstellung machen kann, selbst wenn man auch mit dem Anblicke der Waldungen zwischen den Wendekreisen bekannt ist. Man hat einen bei 200 Toisen breiten Canal vor Augen, welcher mit zwei gewaltigen, durch Schlingengewächse und Laubwerk bekleideten Mauern eingefafst ist. Wir versuchten öfters zu landen, ohne einen Fufs aufser das Fahrzeug setzen zu künnen. Bisweilen suchten wir gegen Sonnenuntergang wohl eine Stunde lang am Gestade; nicht eine Lichtung im Walde (deren gibt es gar keine), sondern eine minder dichte Stelle zu finden, vo wir mit Mühe und mit Hülfe der $\mathbf{A x t}$ unserer Indianer sattsamen Raum für einen Bivak, der $\mathbf{z}$ wölf bis dreizeln Personen fassen konnte, gewinnen möchten. Die Mosquitos, welche uns den Tag über quälten, häuften sich des Nachts unter den Toldo, dem Dach der Pirogue, aus Palmblättern, das uns vor Regen und Sonne schützen sollte. Nie 


\section{- $00-$}

hatlen wir so angeschwollene Hände und Gesichter gehabt. Der Pater Zea, welcher sich bisher rühmen nochte, in seinen Missionen der Catarakten die grörsten und tapfersten (las mas feroces) Mosquitos zu besitzen, legte nun allmählich das Geständnifs ab, die Insektenstiche am Cassiquiare seyen schmerzhafter, als alle, die er je zuvor empfunden habe. Mitten in dieser dichten Waldung war es cine gar schwierige Aufgabe, Holz für dic Feuer zu crhalten. Denn in diesen Aequatorial. Gegenden, wo beständiger Regen fällt, sind dic Baumäste so saftreich, dafs sic beinahe gar nicht brennen. Wo es keinc dürren Gestade gibt, kann man sich jenes alte $\mathrm{Holz}$, von dem die Indianer.sagen, es sey an der Sonne gebraten, beinahe gar nicht verschaffen. Inzwischen bedurften wir des Feuers nur noch als Schutzmittels gegen wilde Thiere; von Lehensmitteln war cin so grofser Mangel bei uns cingetreten, dafs wir für ihre Zubereitung seiner ganz entbehren konnten.《

„Am 18. Mai gegen Abend entdecliten wir einc Uferstelle, die mitwilden Cacaobäumen besetzt war. Ihre Bohne ist klein und bitter. Dic Indianer des Waldes saugen die Fleischhülle aus, und werfen die Bohne weg, welehe von den Indianern der Mis. sionen aufgehoben wird. Man verkauft sie an solche, die nicht allzu lecker in der Bereitung ihrer Chocolade sind. "»Hier ist der Puerta del Cacao « , sagte der Pilote, ע» hier übernachten los Padres, wenn sie nach Esmeralda reisen, um Sarbacanen und Juvias (die 
schmacklıaften Mandeln der Berthollelia) einzukaufen.«« Indessen gehen das Jahr durch keine fünfFahrzeuge durch den Cassiquiare und von Maypures aus, also. seit einem Mlonate hatten wir auf den Flüssen, welche wir aufgefahren sind, aufser in der unmittelharcn Nähe der Hission keise lebendige Secle angetroffen. Südıärts vom Duractumuni - See brachten wir die Nacht in einem Palmivalde zu. Der Fiegen fiel in Strömen, aber die Polhos, die Arum und die Schlingpflanzen bildeten ein so dichtes $\mathrm{Geflechte,}$ dafs sie uns, wie unter einer gewölbten Laubdecke schützten. Dic zunächst an's Ufer gelagerten Indianer hatten aus in einander geflochtenen Helico. nien und andern Musaceen eine Art Dachung über ihre Hängematten errichtet. Unsere Feuer beleuch. teten auf 50 bis 60 Fufs Höhe die Palmbaum-Stämme, die mit Blumen beladenen Schlinggewäclıse und die weifslichen senkrecht aufsteigenden Rauchsäulen. Es war ein prachtvoller Anblick, dessen ruhigen Genufs aber eine von Inseliten freic Atmosphäre erheischt hätte.«

"Unter allen Körperleiden sind die erschöpfendsten jene, welche einförmig andauernd und nur durch lange Geduld bekämpft werden können. Wahrscheinlich hat Herr Bonpland in den Waldungen des Cassiquiare sich den Keim der furchtbaren lírankheit geholt, die ihn bald nach unserer Ankunft in Angostura dem Tode nahe brachte, Zu seinem und meinem Glücke hatten wir keinerlei Ahnung der ihm drohenden Gefahr. Wir fanden den Anblick des 
Stromes und das Gesumme der Mosquitos etwas einförmig, aber ein Überrest natürlicher Fröblichkeit half uns die Langewcile tragen. Wir machten die Entdeckung, dafs wenn wir kleinere Partien von geriebenem Cacao ohne Zucker afsen, und Flufs. wasser darauf tranken, damit die Efslust auf meh. rere Stunden gestillt ward. Die Ameisen und Mosquitos beschäftigten uns mehr, als die Feuchtigkeit und der Mangel an Lebensmitteln. Der Entbehrungen ungeachtet, die wir wabrend unserer Wanderungen durch die Cordilleren erlitten haben, ist uns jedoch die Schiffahrt von Mandavaca und Esme. ralda als der beschwerlichste Zeitraum unsers Aufenthaltes in Amerika vorgekommen. Ich rathe den. Reisenden, die Fahrt des Cassiquiare derjenigen des A tabapo nicht vorzuziehen, wofern sie kein besonderes Verlangen fühlen, die Gabeltheilung des Orinoko zu beschauen."

„Oberhalb des Canno Duractumuni zeigt sich dic Richtung des Cassiquiare gleichförmig von Nordost nach Südwest. Hier ist es, wo man am rechten Ufer das neue Dorf Vasiva zu gründen angefangen hatte. Die Missionen von Pacimona, von Capivari und von Buena-Guardia, so wie das angebliche Fortin beim See von Vasiva sind blofs Erdichtungen unserer Charten. Überraschend war uns zu sehen, wie durch die plötzlich eintretenden Wasserhöhen die beiderseitigen Ufer unterhöhlt wurden. Entwurzelte Bäume bilden gleichsam natürliche Flöfse: halb im Schlamme versenlst, sind sie für die Piroguen 
sehr gefährlich. Wer das Unglück hätte, in diesen unbewohnten Gegenden Schiffbruch zu leiden, der würde wahrscheinlich verschwinden, ohne dafs eine Spur von der Zeit und Art seines Untergangs übrig bliebe. Man würde einzig nur und schr spät an den Secküsten hören, es sey ein von Vasiva abgegangenes Boot, hundert Meilen weiter in den Missionen von Santa Barbara und San Fernando de Atabapo, nicht wieder gesehen worden.»

"Die Nacht vom 2o. Mai, die ietzte unserer Schifffahrt auf dem Cassiquiare, brachten wir unweit von der Stelle der Gabeltheilung des Orinoko zu. Wir hatten Hoffnung, eine astronomische Beobachtung machen zu können, indem Sternschuppen von seltener Gröfse durch den Nebel, der den Himmel deckte, sichtbar wurden. Wir schlossen hieraus, es könne diese Nebelschichte nur sehr dünne seyn, weil solche Meteore fast niemals unter einer Wolke sind gesehen worden. Die, welche uns zu Gesichte kamen, nahmen ihre Richtung nordwärts und folgten sich einander beinahe in gleichen Zeiträumen. Dic Indianer, welche die Bilder ihrer ausschweifenden Phantasie durch die Sprache nicht leicht veredeln, nennen die Sternschuppen: den Harn oder den Speichel der Sterne. Die Wolken verdichteten sich neuerdings, so dafs wir nun weder Meteore, noch die seit mehreren Tagen so ungeduldig erwarteten wahren Gestirne zu sehen bekamen.»

"Man hatte uns angekündigt, wir würden die Insekten in Esmeralda noch grausamer und. gefrälsiger 


\section{- 9r}

finden, als auf dem Arme des Orinoko, welchen wir aufsuchten; defsungeachtet überliefsen wir uns freudig der. Hoffnung, endlich wieder an einem bewohnten Orte schlafen, und durch Herborisiren uns einige Bewegung geben zu können. Diese vergnügte Aussicht erlitt im letzten Bivak auf dem Cassiquiare eine Störung. Ich crlaube mir die Erzählung dieses Vorfalls hier einzurücken, indem er die Schiffahrt durch ein wildes Land charakterisirt. Unser Nachtlager beiand sich am Eingange des Waldes. Mitten in der Nacht meldeten die Indianer, das Geschrei des Jaguars habe sich sehr genähert, und ertöne von den nahestehenden Bäumen herab. Es sind dic Wälder dieser Landschaften so dicht, dafs kaum andere Thiere darin vorkommen, als die auf die Bäume klettern, wie die Quadrumanen, die Cercolepten, die Viverren und die verschiedenen Íatzen arten. Weil unsere Feuer gut brannten, und man in Folge längerer Gewöhnung sich endlich auch über nicht blos eingebildete Gefabren beruhigt, so blieben wir ziemlich gleichgültig über dieses Jaguar-Geschrei. Der Geruch und die Stimme unsers Hunces hatie die Thiere angelockt. Dieser Hund (er gehörte zur grofsen Doggenrasse) bellte anfänglicb, als der Tiger näher kan, fing er an zu heulen, und barg sich unter unsere Hängematten, er suchte Schutz bei Menschen. Seit unserem Bivak am Rio Apure waren wir an diesen Wechsel von Muth und Schüch. ternheit eines noch jungen, sanften und gern lieb. kosenden Thicies gewöhnt. Wir wurden demnach 


\section{$-\quad 05$}

sehr unangenchm überrascht, als uns am Morgen, im Augenblicke der Einschiffung, die Indianer an. zeigten, der Hund sey verschwunden! Es lag aufser Zweifel, dafs die Jaguare ihn geraubt hatten. Vielleicht hatte er, als ihr Geschrei aufhörte, sich vom Feuer gegen das Ufer hin entfornt, oder wir hatten, in ticfen Schlaf versenkt, das Klaggesehrei des Hundes nicht mehr gehört. Die Anwohner des Orinoko und Rio Magdalena hatien uns öfter versichert, die ältesten Jaguare seyen listig genug, um Thiere aus der Mitte eines Bivaks zu entführen, indem sio durch Halswürgen ihr Schreien hindern. Wir ver. weilten einen Theil des Vormittags, in der Hoffnung, das Thier könnte sich verlaufen haben. Drei Tage später kamen wir auf die nämliche Stelle zurück. Das Geschrei des Jaguars liefs sich nochmals hören, dean diese Thiere zeigen Vorliebe für gewisse Orte; aber alles unser Suchen war umsonst. Die Dogge, welche uns von Caraeas aus begleitet hatte, und die so oft der Verfolgung der Frokodille durch Schwim. men entgangen war, ist im Walde ze:rissen worden."

Aus dieser Probe mögen meine jungen Leser abnehmen, dafs die Reisen in entfernte und wilde. Gegenden mit Aufopferungen verbunden sind, die zu bringen etwas melir erfordert wird, als blofse Reiselust. Nur die ungemessene Hochachtung vor der Wissenschaft und die innigste Liebe zur Natur können den Muth stäblen und dem Gemüthe eine Spannung verleihen, welche nie entmuthig: wird. Was uns anbelangt, so können wir nur den grofsen 
Mann bewundern, der selbst in diesen beschriebenen Situationen seinen Geist aufrecht erbielt, und das In. teresse der Wissenschaft wahrzunehmen wufste.

Am 21. Mai, drei Meilen unterhalb der Mission Esmeralda, hatten sie endlich den Punkt vor sich, um defswillen sie seit einem Monate alle die Bcschwerden erduldet hatten. Die Gabeltheilung des Orinoko lag vor ihnen. Noch hatten sie eine Was. serfahrt von 750 Seeneilen vor sich, aber diese Fahrt ging stromabwärts. Man fuhr mitten im Flusse, und entging dadurch den Qualen der Mosquitos und der schnakenartigen Insekten, welche sich am Ufer, an welches man sich bei der Auffahrt halten mufs, vervielfältigen.

\section{nomonomonomos \\ Vi e r t e s K a p it e l.}

Dis Gabeltheilung des Orinok.

Die Gabeltheilung des Orinoko ist einer derjenigen Punkte der Erdoberfläche, welcher für die Geographic von der gröfsten Wichtigkeit ist. Ein Strom erster Gröfse, dem unzählige Flüsse zinsbar sind, von dem viele so grofs sind, als unsere gröfsten europäischen Ströme, sendet hier plötzlich einen Arm aus, um sich mit dem Amazonenstrome, dem gröfsten der Erde, zu verbinden. Es ist, als ob zwei mächtige Nachbaren freundschaftlich sich verbänden und vermählten. Unermefslichen Ländern hat die Natur dadurch Strafsen bereitet, welche nur derer 


\section{$-07$}

zu harren sclieinen, die sich dieselben zu Nutzen machen wollen.

Die Stelle dieser Gabeltheilung ist durch die Schönheit und Pracht der Natur ausgezeichnet. An westlichen Ufer erheben sich hohe Gebirge, und man erkennt ron weitem die zwei Gipfel des Maraguaca und den Duida. Am linken Ufer des Orinoko, westwärts und ostwärts der Gabeltheilung bis zur Einmündung des Tamabama, gibt es keine Berge. Hier ist der Felsen Guaraco, von dem man behauptet, dafs er zur Zeit der Regenzeit Flammen speie. Wo der Orinoko südwärts nicht mehr von Bergen umgeben ist, findet sich eine gegen den Rio Negro geneigte Niederung; hier theilt er sich in zwei Arme. Da nun die Niederung keine Berge enthält, wo der getrennte Arm, wie es bei so vielen andern Flüssen der Fall ist, wieder die Richtung gegen den Hauptstrom erhielte, so nimmt er unter dem Namen Cassiquiare seine Richtung südostwärts, um durch den Rio Negro in den Amazonenstrom sich zu ergiefsen. Eben daselbst, wo eine südliche Neigung den $\Lambda$ bflufs des Cassiquiare begünstigt, zieht sich das Terrain auch nordwärts, und verhindert den zweiten Arm des Orinoko gegen den Amazonenstrom abzufliefsen, er setzt daher seinen Lauf unter dem Namen des Rio Paragua in westnordwestlicher Ricls. tung fort, und strömt als Orinoko, nachdem er sich nach Norden und dann gegen Osten wendet, an derselben Küste bei Angostura in's atlantische Meer, 
an dessen Küsten er etwas weiter südwärts seinen Ursprung genommen hat.

Wie schon gesagt, sind es nicht Berge, die den Lauf der Flüsse ändern, sondern leichte Neigungen des Bodens und Gegenhänge. Man ist gewohnt, sich den Lauf eines Flusses allezeit in ein Thal oder eine Niederung zwischen zwei Gabellinien eingeschränkt z.u denken. Darum haben auch die Erdbeschreiber Südamerika's sich ohne Bergketten bei Verfertigung der Charten nicht zu behelfen gewufst, und mitten in die Ebenen Amerika's Berge hingemalt, deren keiner da war. Es läfst sich auch bei der Gabeltheilung des Orinoko nur ein kleiner Gegenhang in der Mitte des Stromes denken, welcher die Theilung verursacht. Die Cordillerenkette Neu - Granada's ist so weit von dieser Gabeltheilung entfernt, dafs sie in dieser vollkommenen Ebene keinen Einflufs auf die Theilung des Flusses haben kann.

Fährt man flufsabwärts gegen Angostura, so scheint es freilich, dafs die hohe Bergkette von Parime, welche man immer zur Linken hat, die-Schwelle zwischen den zwei grofsen Flufsgebieten vom Orinoko und Marannon bilden. Allein es findet gerade das Gegentheil Statt. Dic Bergkette von Parime zeigt gerade an ibrem südlichen Abhange die Quellen des Orinoko. Dieser Strom zieht sich um die Bergkette herum, welche von beiden entgegengesetzten Abbängen ihm ihre Gewässer zusenden. Aus den Alpenthälern von Maraguaca entspringend, nimmt er seinen Lauf westlich und nordwestlich, als sollte 


\section{$-\quad 09$}

er in das Südmeer auslaufen. Nicht weit von dem aus Westen kommenden Guaviare, der aber auch durch Ebenen fliefst, wendet er sich nach Norden bis zur Mündung des aus den Steppen kommenden Apure, wo er wieder einen Rücklehrpunkt hat, und sich nun wieder nach Osten wendet, um sich nach einem Laufe von 1350 Meilen, kaum 300 Meilen von jeinem Ursprunge in das Meer zu ergief'sen. Wähiend seines Laufes nimmt er, aufser allen von der Bergkette von Parime kommenden Flüssen, auch loch andere Gewässer auf, welche aus den ihm umgebenen Ebenen von Norden, Westen und Südwesten herkommen. Um sich also einen richtigen Begriff zu bilden, mufs man sich folgender Weise den Boden Südamerilia's denken. Die Anden mit ihren Verzweigungen umgeben den nordwestlichen Theil des Continents halbmondförmig. Die Gebirge verflächen sich in der Richtung gegen Süden und Südost, und bilden daselbst die unermefslichen Ebenen, die bis auf einige Verengungen an's Feucrland sich erstrecken. Aber auch diese Ebenen sind südöstlich und ungefähr auf ciner Parallele zivischen dem $1^{\circ}$ und $2^{\circ} \mathrm{N}$. Br. gegen Süden geneigt. Die Neigungen gegen Südwesten und Süden verursachen einen Gegenhang, welcher die Wasserscheide bildet, und gerade mitten im Orinoko in einen spitzen Winkel ausläuft, welcher sich dann gezwungen sicht zur berühmten Gabeltheilung. Ohne die inselfürmige Gruppe der Parime-Kette würde wohl kein Orinoko vorhanden seyn, statt dessen aber eine Menge an- 
derer kleiner Ströme, die ihren Lauf unmittelbar in's atlantische Meer nähmen. Die Bergkette also, welche auf den meisten Charten gefunden wird, am linken Ufer des Orinoko, ist in der Natur nicht vorhanden.

Aus der gegebenen Darstellung ergibt sich die Erklärung dreier merkwürdiger Erscheinungen am Orinoko-Strome.

1. Die beharrliche Anhänglichkeit dieses Stromes an die Bergkette von Parime.

2. Die Lage seiner Quellen auf einer Erdstrecke, von der man glauben sollte, sie gehöre zum Gebiete des Rio. Negro.

3. Die Gabeltheilung, wodurch er einen andern. Strome einen Arm zusendet.

Wenn man sich blofs von Schlüssen leiten läfst, so sollte man denken, dafs Flüsse, wenn sie in Gebirgen entspringen, sobald sie heraustreten, sich alsbald auch von den Gebirgen entfernen müfsten. Die Erfahrung lehrt jedoch das Gegentheil. Es ist in allen Strömen Indien's und China bemerkt, dafs es ihnen eigen ist, sich den Gebirgen anzuschmicgen, und einen mit der Bergkette parallelen Lauf anzunehmen. Die Bemerkung ist alt, dafs an den steilsten Abhängen gewöhnlich Niederungen sind, so wie, dafs Ströme, Seen und Meeresküsten da die höchsten und steilsten Abhänge bilden, wo die Gewässer am tiefsten sind, und also hohe, steile Ufer mit grofsen Ticfen der Gewässer zusammentreffen. Dem Bearbciter dieses scbeint sich aus der gegen- 
seitigen Lage der Gebirge, noch eine andere Ur. sache dieser Erseheinung zu ergeben. Die gewaltige Cordilleren-Masse verflächt sich gegen das atlantische Meer, während sie gegen das Südmeer steil abstürzt. Hier sieht man nur Küstenflüsse und keiner sehmiegt sich der Cordillerenkette an. Gegen Osten aber verfäeht sich dic Andeskette, und bildet einen ungeheuren Abhang, dessen Fortsetzungen die Ebenen von Calabozo, Brasilien und Buenos-Ayres sind. Die Parimekette ist gegen die Antillenkette zu unbedeutend, als dafs sie zu dem Abhange derselben eine Gegentafel bilden könnte. Natürlich ist es also, dafs der Cordilleren-Abhang, der den Parime gleicl: sam bcherrseht, und die Niederung, welche zwei ğlcichmächlige Gebirgsketten in die Mitte der Ebene versetzen würden, an den $\mathrm{Fuf}$ 's der schwächern $\mathbf{P a}$ rime zurückdrängt. Dieses dürfte zu einer geolo. gischen Regel führen, dafs die Flufsbetten allezcit zwischen zwei Bergketten sich der geringern anschmiegen. Man bemerkt dasselbe bei den indischen und elinesischen Flüssen, welche ebenfalls bei ihrem Austritte aus dem Gebirge sich der Bergkette anschmiegen.

Eine andere Eigenthümlichkeit des Orinoko ist die, daf's das Wasserbecken dieses Stromes sich mit dem Amazonenstrome zu verbinden scheint. Wirft man einen Blick auf die Charte, so sieht man, dafs der Orinoko in derselben Ebene seinen Lauf von Osten nach Westen nimmt, in welcher der Amazonenstrom, aber in entgegengesetzter Richtung, sei- 
nen Lauf nimmt. Aber eben der Lauf der Gewäs ser zeigt uns, dafs auch grofse Ebenen ihre Thälev und Niederungen, so wie ihre Erhöhungen und $\mathbf{A b}$, hänge bilden. Diese Thäler sind durch Erhöhungen getrennt, welche man Gicbellinien nennen kann. Diese bilden nun gang eigentlich und mehr als die Gebirge die Wasserscheide (divortia aquarum). Der ganze wcite Raum zwischen $31^{\circ} 2^{\circ} \mathrm{N}$. Br. und $14^{\circ}$ S. Br., zwischen der Bergkette von Parime und derjenigen von Chiquitos und Brasilien auf einer Streclie von 204,000 Quadrat-Meilen, ist mit Waldung erfüllt, und gibt seine Gewässer an den Amazonenstrom ab. Weiter nördlich hingegen wird, vermöge einer besondern Lage der Ebcnen, alles Gewässer dem Orinoko zugefiilirt. Die Central-Ebene vou Siidamerilia bilden daher zwei grofse Flufssysteme, deren jedes dic Gervässer befafst, die sich in der Gesammtoberfläche der Umgebung befinden, dessen Neigungslinien in das Flufsthal auslaufen; das will sagen: in die Längensenkung, welche das Bett des Hauptstromes bildet. In dem kurzen Raume, zwi. schen dem $68^{\circ}$ und $70^{\circ}$ Länge, empfängt der Orinoko die von dem südlichen Abhange der Parime kom. menden Gewässer. Die Zuflüsse hingegen, welche von dem nämlichen Abhange östlich den $68^{\circ}$ abflics. sen, fallen in den Amazonenstrom. Ungarn zeigt uns ein ähnliches und sehr merkwürdiges Beispiel von Flüssen, die, während sie auf der Südseite ciner Bergkette entspringen, dem Wassersysteme des nördlichen Abliangs angehören. Die Wasserscheide zwi- 
schen dem baltischen und sehwarzen Meere ist nicht, wie man glauhen sollte, der Gipfel der Kar. pathen (wie überhaupt Berggipfel nie Theilungsgräten sind), sondern sie ist südwvärts von der Tatra, zwvischen Tepliz und Ganócz, auf einem Plateau von nicht 3oo Toisen Hölıe. Dic Waag und die Her. nód fliefsen südwärts zur Donau $a b$, wäbrend der Poprad die Gruppe des Tatra westlich umläuft und sich ncbst dem Dunajetz nordwärts in die Weichscl ergiefst. Der Poprad, welcher seiner Lage nach dem System der Zuflüsse des schwarzen Meeres angehört, sondert sich $a b$, um seine Gewässer dem baltischen Meere zuzuführen.

Die dritte Eigenthümlichkeit im Laufe des Orinoko ist dic Gabeltheilung, deren Daseyn oft und nament* lich vor der Abreise des Herrn von Humboldt aus Europa in Zweifel gezogen worden ist. Die Gabel. theilung ist nun durch Herrn von Humboldt erwahrt, und befindet sich unter $3^{\circ}, 10^{\circ} \mathrm{N} . \mathrm{Br}$. und $68^{\circ}, 37^{\circ}$ W. L. von Paris. Man findet Delta's oder Theilungen der Flüsse in mehrere Arme bei ihren Ausmün. lungen. Wo das Land eben ist, kommen dieselben Erscheinungen vor. Die Ursachen der Delta's kön. nen folgende seyn: die ganz kleinen wellenförmigen Erhebungen einer Ebene, welche gleichzeitig zwei Stromsysteme befafst, die Entfernung von einem Hauptsammler, und die Lage des Flufsbettes am Rande der zwei Flufsbette scheidenden Grenze. Letz: teres ist beim Orinoko der Fall, Sehr breite Flufs. betten haben ilhre Tiefe nicht in der Mitte und kön= 


\section{- 104}

nen mehrerc Furchen neben einander besitzen. Die kleinste entgegenstehende Gräte kann daun dic Erscheinung hervorbringen, von der hicr die Rede ist. Wo die Gabcltheilung Statt findet, durchstreift die Theilungsgräte der Länge nach das Strombett, und der Flufs theilt sich da, wo sich dieselbe zu verlieren scheint.

Man liat die Frage aufgeworfen: ob nicht mit der Zeit das Flufsbett des Cassiquiare durch Anschwemmungen verstopft werden möchte? Herr von Humboldt antwortet : der Cassiquiare ist keineswegs, wie die Dichter Latiums sich ausdrücken, ein bequem schleichendes Flülschen; er gleicht nicht dem Cocytus, der träge dahin sich wälzt, indem or auf dem gröfsten Theile seines Laufes die ausnelımende Schnelligkeit von 6 bis 8 Fufs auf die Sekunde besitzt, und so ist auch nicht zu fürchten, dafs er ein mehrere hundert Toisen breites Bette gänzlich ausfüllen und verschütten sollte.

Dic Gabcltheilung des Orinoko und diese äufserst wichtige Verbindung zwischen dem Orinoko und dem Amazonenstrome war - oft belauptet, oft verläugnet. Portugiesische Sclavenhändler befahren den Cassiquiare, ohne im Rio Paragua den Orinoko zu erkennen. Pater Roman, ein Jesuit, war der erste, der den Cassiquiare vom Orinoko aus besuchte. Er war allein, ohne Kírieger, am 4. Fcbr, 1744 von Carichana abgereist. Als er an den Ort kam, wo jetzt San Fernando de Atabapo steht, beim Zusammenflusse des Orinoko mit dem Guaviare und Atabapo, 


\section{$-105$}

salı er den Orinoko eine Pirogue herabkommen. Er machte zum Zeichen des Friedens das Crucifix am Vordertheile des Schiffes fest. Die Weifsen, es waren portugiesische Sclavenhändler vom Rio Negro, erkannten unter Freudenäufserungen die Ḱleidung vom St. Ignatius - Orden. Nicht ohne Erstaunen vernalımen sie, dafs sie aut dem Orinoko seyen. Sie führten nun den Pater Roman durch den Cassiquiare nach dem Rio Negro zurück, von wo er auf dem nämlichen Wege, nach siebenmonatlicher $\mathrm{Abreise}$ durch den Cassiquiare nach Carichana zurückliehrte. Er ist der erste weifse Mensch, von dem man mit Gewifsheit weifs, dafs er aus dem Rio Negro, oline Landschaft blos zu Wasser in den Orinoko zurückgekehrt ist. Seitdem hatte man die Verbindung bald auf den Charten verzeichnet, bald bestritten. Noch auf einer 1798 bekannt gemachten Charte von Guiana heifst es: die von lang her geglaubte Verbindung zwischen dem Orinoko und dem Amazonenstrome ist eine geographische Ungereimtheit, um die dies. fallsigen Vorstellungen zu berichtigen, sey erforderlich, die Richtung der grofsen Kette, welche die Gewässer scheidet, zu erforschen.

Herr von Humboldt war so glüchlich, an Ort und Stelle diese Bergkette untersuclien zu können. In der Nacht rom 2/4. Mai ist er mit seiner Pirogue durch diese geographische Ungereimtheit gefalıren. Fände sich hier eine Gabellinie, so hätte Herr von Humboldt von Esmeralda aus den Strom hinauffahren müssen, statt dafs er ihn wirklich bei sehr schnel- 


\section{$-100$}

lem Fail herabfuhr, und seinen Lauf ununterbrochen bis St. Barbara und St. Fernando de Atabajo fortsetzte.

Hätten die Völker Guianás an der Gesittung Theil genommen, welche die Hochebene Peru's und Mexiko's verschönerten, so wrürde diese ungeheure Landschaft zwischen dem Orinoko und dem Amazonenstrome die Entwicklung ihres Gewerbfleifses begünstigt, ihren Handel belebt und die Fortscbritte ilırer Staatseinriclitungen befördert haben. In der alten Welt erblicken wir überall den mächtigen Einflufs der Beschaffenheit des Bodens auf die Entwick. lung der Cultur. Hier bleihen jedoch die Begünstigungen, welche die Natur anbot, bei den schwachen Horden ohne Erfolg. In Egypten, in Indien und Griechenland haben offenbar die Beschaffenheit des Bodens und der Lauf der Gewässer die Entivicklung der Menschheit mächtig gefördert. Wo jedoch die Natur etwas wirken soll, müssen ilıre Begünstigungen von einer empfänglichen Menschheit dankbar aufgenommen werden. Dieses war in Guiana nicht der Fall. Diese Menschenfresser hatten sich noch zu keiner gesellschaftlichen Ordnung verbunden.

„Seit ich die Gestade des Orinoko verlassen habe,* schliefst Herr von Humboldt, " hat eine neue Zeitrechnung für die Völker des Westens begonnen. Den Sturmgewittern bürgerlicher Zwiste werden die Seg. nungen des Friedens und eine freiere Entwicklung gewerbfleifsiger Künste folgen. Diese Gabeltbeilung des Orinoko, diese Landenge des Tuamini, welche 


\section{- 107}

ein künstlicher Canal so leicht durchschneiden kann, werden die Blicke des europäisclien Handels auf sich ziehen. Der Cassiquiare, an Breite dem Pheine gleich und 180 Meilen lang, wird niclit ferner unbenïtzt bleiben, sondern eine beschiffte Strafse zivischen zweien Strombetten bilden, die eine Oberfläche von 190,000 Quadratmeilen umfassen. Das Getreide von Neu-Granada mag dem Rio Negro zugeführt werden; an den Quellen des Napo und Ucagala, aus den Anden von Quito und dem Oberlande von Peru wird man zu Wasser nach den Mündungen des Orinoko reisen, in einer Entfernung, welche derjenigen von Tumbuctu nacb Marseille gleicht. Ein Land, neun bis zehn Mal gröfser denn Spanien und durch dic mannigfaltigsten Natur-Erzeugnisse bereichert, ist mittelst des natürlichen Canals vom Cassiquiare und den Gabeltheilungen seiner Flüsse in allen Rich. tungen schiffbar. Eine Erscheinung, welcbe cinst für die Staatenverhältnisse der Völker höchst wich. tig seyn wird, verdiente unstreitig auch höchst sorgfältig geprüft zu werden.«

Was laann der Menschenfreund noch Sehnlicheres wünschen, als dafs in Ländern, die von der Natur so reichlich ausgestattet und gleichsam mit dem Füllhorne ihrer besten Güter üherschüttet sind, statt Mlosquitos, Tiegern und Krokodillen eine zablreiche und glückliche Menschheit wohne, und den Reich. thum ihres Geistes mit dem der Natur zum schön. sten Gemälde irdischer Glückseliglieit vereinigge. 


\section{Fünftes Kapitel.}

Der Ober - Orinoko. - Esmeralda. - Das Curare. - Das Juvia. fest. - Juvia. - Schilf und Bast.

Der Grabeltheilung des Orinoko gegenüber befindet sich, im Halbkreise geordnet, eine Gruppe Granitfelsen; aus ihr ragt imposant der Duida hervor, welchen die Missionäre einen Vulkan nennen, und der beinahe 8000 Fufs Höhe hat. Auf der Südund Westseite senkrecht abgestutzt, hat er ein riesenhaftes Ansehen. Sein Gipfel ist nackt und fel. sig, allein überall, wo der weniger steile Abhang Erde trägt, ist er auch mit dichter Waldung bewachsen, worin die Natur das Riesenmodell der längenden Gärten Babyloniens vorgebildet zu haben sclıeint. Am Fufse dieses Prachtkegels liegt die Mission Esmeralda, vielleicht der Keim cinstiger Grüfse, jetzt nur eine Art Weiler mit achtzig Bewolneru. Line reizende Ebene mit Bächen von schwarzem, aber hellem Wasser durchschnitten, ungibt den Weiler. Sie ist ein schöner Wiesengrund, auf der sich Gebüsche der überaus nützlirhen Mauritia.Palıne erheben. Näher am Duida wird die Sumpfwiese zur Savane, die sich am Fufse des Duida hinaufschmiegt. In dieser Savane wachsen Ananas von ausgezeichne. ter Gröfse und vortrefflichem Wohlgeruche. Diese Ciattung Bromelie wächst allezeit abgesondert \%wischen den Gräsern, wogegen die Karatas, eine andere Art derselben Gattung, wie unsere Heidelbeeren, gesellig wachsen. Die Ananas von Esmeralda 
ist in ganz Amerika berühmt, sie scheint hier den hüclisten Grad ihrer Vollkommenheit zu erreichen. Die vortrefflichen Ananas von Esmeralda sind der Schmuck der Felder in der Havannah, wo sie in lieihen gepflanzt werden; in Esmeralda schmücken sie die Savane am Fufse der Duida. Diese löstliche Pflanze hat sich im sechzehnten Jahrhunderte im Innern von China verbreitet, und ist in neuerer Zeit mit andern unzweifelhaft amerikanischen Pflanzen im Innern Afrika's am Rio Congo gefunden worden. Die Ananas gehört zu den edelsten Gaben der Tropennatur, welche sich auch durch Menschen der weitesten Verbreitung zu erfreuen hat.

In Esmeralda wohnt kein Missionär. Der Ordens. mann, der hier Messe lesen mufs, wolnt in St. Barbara, über 5o Meilen entfernt, und braucht vier Tage zur heise hieher, wohin er auch nur drei bis vier Mal des Jahres kommt. Statt seiner wohnt hier ein alter Kriegsmann, der die Reisenden berzlich willkommen hiels. Er glaubte, sie seyen catalonische Irrämer, und machte sich über die I'apierballen und Bücher lustig, womit er das Boot angefüllt sah. whhr hommt hier in ein Land", sagte er lächelnd, zwo diese Waare keinen Absatz findet. Hier wird nicht geschrieben; dürre Palmen - und Heliconienblätter reichen hin, um unsere Nadeln und Angeln aufzubewahren«. Dieser Soldat verübte bürgerliche und geistliche Gewalt. Er unterrichtete die Kinder im Hosenkranze, zum Zeitvertreibe besorgte or das Glockengeläute, und von christlicheın Amtseifer ge- 
trieben, gebrauchte er seinen Cantor-Stab auf eine den Eingebornen eben nicht angenehme Weise.

Auffallend war es, hier viele Zambos und Mu. latten zu finden, wie auch andere farbige Leule. Sie nennen sich Espannoles, weil sie nicht roth, wie die Indianer, sind. Sie sind Leute, die als Ver. brecher hieher verwiesen werden, um die Mission schneller zu bevölkern.

In den Granitfelsen von Duida fanden sich sehr schöne Bergkrystalle in den offenen Gängen. Sic sind zum Theil vollkommen hell und durchsichtig, mitunter mit Chlorit gefärbt. Man hatte sic irriger Weise fiir Diamanten und Smaragde gehalten. So nahe bei den räthselhaften Quellen des Orinoko träumte man von nichts, als der Nachbarschaft der grofsen Goldstadt, Dorado, und den Ruinen der grossen Stadt Manoa am Parime-See. Zur Zeit der Gründung von Esmeralda ward der Name und das Vorrecht einer Stadt, Villa, für sie verlangt. Man träumte nur von den Reichthümern des Duida, der jedoch nur aus Glimmer, Bergkrystall und Rutill besteht. Die Weifsen und Farbigen, die hingeschickt wurden, bielten den Ackerbau für unwürdig, von vernüntigen Lcuten, gente de razon, betrieben zu werden, und so sank Esmeralda zu einem elenden Weiler herab, der jetzt nur durch seine Mosqnitos berüchtigt ist. Man sicht es als eine Verbannung an, dahin gesandt $z u$ werden, und man bedroht ungehorsame Laienbrider damit, zu den Mosquitos von Esmeralda gesandt, um von den Mosquitos und 
Zacundos gefressen zu werden, welche Gott den Menschen zur Strafe erschaffen liat.

So seltsame Strafen sind aber nicht immer nur den Laienbrïdern zu Theil geworden; - man hat Beispiele, dafs bei den kleinen Kloster-Revolutionen, die hier Statt fanden, auch Patres hicher geschickt wurden, um von den Mosquitos gerichtet zu werden. Übrigens mufs die Ursache, warum dic Stadt Esmeralda von 60 Einwohnern ein abscheulicher Aufenthaltsort ist, nicht allein in den Mosquitos, sondern in dem Mangel an Cultur gesucht werden. Die Lage der Mission ist sehr malerisch und gehört zu den schönsten der Erde; die Umgegend ist an. muthig und fruchtbar. Nirgend siebt man so hohe Pisangstämme; Indigo, Zucker und Cacao würden vortrefflich gedeiben. An dem Duida sind herrliche Weiden, aber nur die Heerden fehlen. Jetzt speist man wenigen Pisang und Manioc, Affenschinken, und leidet mitten im fruchtbarsten Lande Hunger. Übrigens wird Esmeralda in diesem Gemälde ge. wifs sich einst nicht wieder erkennen. San Fernando, Javita, San Carlos und Esmeralda sind von der Natur zu wichtigen Punkten der Civilisation bestimmt, und vielleicht kommt bald die Zeit, wo diese Waldungen gelichtet, von Ungeziefern jeder Art gereinigt, so durch Menschen belebte Fluren voll Segen und Gedeihen darbieten werden. Eine spätere Nachwelt wird die Paradiese besingen, wo unsere Klaglieder eine Hölle von Peinigungen finden.

Esmeralda ist der Ort, wo am Orinoko das be- 
rüchtigte und berühmte $\mathrm{Cu}$ rare, dieses wirksame Gift in Krieg und Jagd bereitet wird. Unter allen bekannten Giften sind das Ticunas.Gift vom Amazonenstrome, der Upas. Tieute von Java und das $\mathrm{Cu}$ rare von Guiana die tödtlichsten unter allen Sub. stanzen.

Bei ilirer Ankunft in Esmeralda fanden unsere Freunde die Indianer von einem Zuge heimgekehrt, der wegen der Einsammlung der Mandeln der Juvia (Bertholetia) und der Schlingpflanzen, die das $\mathrm{Cu}$. rare liefern, unternommen worden war. Die WVeiber hatten Getränke bereitet, um die Rückkehr der Indianer durch ein Fest zu feiern, und zwei Tage lang sah man nichts als betrunkene Indianer. Man war jedoch so glücklich, einen alten Indianer zu treffen, der weniger betrunken, als die andern, eben dieses furchtbare Gift bereitete. Er war der Chemiker des Orts, und sals bei einem grofsen fíessel aus Thon, um die Pflanzensäfte zu kochen. Er hatte um sich flache Gefälse, un das Ausdünsten der Säfte zu befürdern, und Tüten aus Pisangblättern, um sic zu seihen. Es herrschte in diesem Laboratorium die gröfste Ordnung und Reinlichkeit. Dieser Mann war in der Mission unter dem Namen des Giftherrn bekannt, und besafs ganz den steifen und pedantischen Ton eines Apothelers. "Ich weifs, sagte er, dafs die weifsen Menschen das Geheimnifs besit\%en die Seife zu bereiten, und jenes schwarze Pulver, welches den Nachtheil hat, Lärm zu machen und dieThiere zu verscheuchen, wenn man sie fehlt. 


\section{- 113}

Das Curare, welches wir vom Vater auf Soln zu bereiten verstehen, ist ungleich vorzüglicher, als alles, was ihr da unten (jenseits der Meere) verfertigt. Es ist der Saft einer Pflanze, der ganz in der Stille tödtet, ohne dafs man weifs, woher der Schlag gekommen ist."

Das Verfahren des Giftherrn war sehr einfach. Man bedient sich dazu einer Schlingpflanze, die ostwärts an dem linken Ufer des Orinoko wächst, und unter dem Namen Bejuco de Mavacure bekannt ist. Es ist eine Pflanze aus der Strychneen - Familic, deren wir schon oben im Walde von Pimichin er. wähnten. Es wird sowohl trocken, als im frischen Zustande angewendet. Das Gift ist in der linde und dem Splinte der Pflanze enthalten. Diese wird nun abgeschält, zwischen zwci Steinen zermalmet, wodurch die ganze Masse eine gelbliche Farbe an. nimmt. Nun wirft màn sie in einen neun Zoll hohen und vier Zoll weiten Trichter, und macht einen kalten Aufgufs darüber, welcher als cine gelbliche Substanz tropfenweise abfliefst. Dieses ist nun der giftige Saft, welcher durch Kochen zu einem Syrup verdünnt wird, und jetzt erst seine ganze Stärke erhält. Der Giftherr forderte die Fremden von Zeit zu Zeit auf, die Masse zu kosten; nach ihrem mehr oder minder bittern Geschmacke urtheilt man, ob der Saft hinlänglich eingesotten sey. Mit diesem Verfahren ist durchaus keine Gefahr verbunden, denn das Gift wird nicht durch den Genufs, sondern nur durch die Vermischung mit dem Blute tödtlich. 
Auch ist das Einathmen des Dunstes keineswegs gefährlich. Der so eingesottene Saft ist jedoch nicht das berühmte Curare-Gift, welches im Handel vorkommt! Das Curare in die Wunde gebracht, tödtet beinahe plötzlich, eingenommen ist es cin magen. stärkendes Mittel von grofser Vortrefflichkeit.

Auch der Giftsaft der Ticunas am A mazonenstrome wird aus einer Schlingpflanze gezogen, welche jedoch von dem Bejuco ganz verschieden ist. Da diese Gifte den jagdtreibenden Völkern unentbehrlich sind, so widersetzen sich die Missionäre der Bereitung keineswegs. Die erwähnten Gifte sind jedoch ganz verschieden von denjenigen aus la Peca, so wie vom Gifte von Lamas und Moyobamba. Sie rühren von ganz verschiedenen Pflanzen her. Die Bereitung des Curare ist ganz einfach; die Verfer. tigung des Giftes von la Peca sehr verwickelt. Dem Safte des Bejuco de Ambiuhasca wird jamaischer Pfeffer, Sanango (Tabernae montana) und der Milchsaft ciniger Apocineen beigemischt. Der frische Saft der Ambiuhasca wird tödtlich, sobald er in Berührung mit dem Blute kömmt, wogegen der Saft des Mavacure erst eingesotten werden mufs. Als Herr von Humbold bei sehr schwäler Witterung die Pflanze, welche das fürchtbare Gift von la Peca liefert, zwischen den Fingern eine Zeitlang ricb, fühlte er die Hände ganz erstarrt, und eine Person, dic neben ihm arbeitete, empfand diesclbe Wirkung der Einsaugung durch die unverletzte Haut. In den Missionen ist die allgemeiue Art, die Thicre zu töd. 
ten, sie mit giftigen Pfeilen in den Schenkeln zu verwunden. Es wird beinahe kein IIuhn verspeist, olıne auf diese Art getödtet worden zu scyn. Grofse Vögel sterben in zwei bis drei Minuten, ein Schwein oder Pelari zwischen 9 bis 12 Minuten. Man darf sich nicht das geringste Bedenken machen, ein Thier zu verspeisen, das auf diese Art getödtet worden ist. Es wird dieses Gift durchaus unschädlich, wenn es nicht die Blutmasse berührt, allein mit dem Blute in Berïhrung gebracht, ist es furchtbar wirksam. In Maypures verferligte ein Zambo für Herrn Bonpland solche vergiftete $P$ feile, mit denen durch Blasrohre auf kleine Affen und Vögel Jagd gemacht wird. Er war ein Zimmermann von ungewöhnlicher Stärke. Weil er nun die Unvorsichtigkeit begangen hatte, das Curare zwischen den Fingern zu reiben, nachdem er sich zuvor leicht verwundet hatte, so fiel er, vom Sehwindel ergriffen, zu Boden, und blieb beinahe eine halbe Stunde in diesem Zustande. Er würde auch unfehlbar gestorben seyn, wäre es nicht zum Glücke geschwächtes Curare gewesen, welches man bei Thieren anwendet, die man wic. der zum Leben bringen will, indem man salzsaure Soda in die Wunde bringt. Herr von IIumboldt selbst wäre beinahe das Opfer geworden seiner Versuche. Aus einem nicht gut geschlossenen Gefälse hatte sich das Curare in ihre Wäsche ergossen. Beim Auswasehen batte man vergessen, einen Strumpf umzuwenden, in den sich das Curare ergossen hatte, und erst, indem er ihn anzieben wollte, wurde er 


\section{$-110$}

gewahr, dafs er mit klebriger Materie beschmutzt war. Die Gefahr war um so furchtbarer, als die Fufszelien durch mifslungenes Auszielien der Sandflöhe blutige Wunden hatten. Der Reisende, welclier dieses Gift mit sich führt, mufs es daher mit grüfster Vorsicht bewahren. Gegen die Wirkung des Curare kennt man kein sicheres Gegenmittel, wenn dasselbe frisch und in geköriger Stärke in die Wunde loonmt. Man wendet Soda, Zucker und älniliche Gegenmittel an, allein es ist allezeit melir die geringe Verletzung und die Schwäche des Giftes. Man Jann einen verwundeten Menschen relten, wenn die Wunde grofs genug ist, der Pfeil schnell herausgezogen wird und das Blut sanft herausfliefst. Die Intianer beschreiben die Symptome der Vergiftung ganz dem Bisse gifliger Schlangen ähnlich. Die verwundete Person füllt einen vermehrten Blutantrieb z.um Kopfe und der Schwindel nöthigt zum Niclersitzen. Es folgt Ekel, wiederholtes Erbrechen, brennender Durst, Betäubung und Erschlaffen der Theile um die Wunde her.

Der Giftherr freute sich sehr dèr Theilnahme, die ilım bezeiget wurde, or bezweifelte gar nicht, dafs die Herren von Humboldt und Bonpland gute Seifensicder scyen, denn nach dem Curare schien ihm die Seife die herrlichste Erfindung des mensch. lichen Geistes zu seyn. Aus Dankbarkeit führte er sie zum Indianerfeste, der Juvias-Ernte. Es ward durch Tänze gefeiert, wobei man sich der rohesten Völlerei überliefs. Die Hülte, in der die Indianer 
versammelt waren, gewährte einen der seltsamslen Anblicke. Weder Tisch noch Bank war in der Hütte, aber in symmetrischer Reihe standen grofse, geschwärzte und gebratene Affen an der Mauer um. her, es waren Marimonden oder die bärtigen Kapu. ziner- $\boldsymbol{\Lambda}$ fen. Der Anblick ist dem civilisirten Men. schen widrig und ekelhaft. Es wird nämlich der Affe auf einem hölzernen Rost in der Stellung eines sitzenden Kindes gebraten, und sieht man die Wilden-diese Affen hernehmen und verspeisen, so wird der geringe Abscheu, den diese Menschen vor dem Menschenfleische haben, sehr erklärlich. Ist ein Mal die Phantasie an den Anblick des Essens menschenähnlicher Thiere gewöhnt, so dürfte er sich den Menschen selbst um so mehr schmecken lassen, als das Flcisch des letztern unendlich schmackhafter, als das zähe und dürre Affenfleisch ist.

Der Tanz der Indianer ist selır einförmig. Dic Weiber sind ausgeschlossen. Die Männer, alt und jung, geben sich die Hände, und drehen sich stundenlang still und ernst, langsam von der Rechten zur Linken. Die Jäger sind zugleich auch Musikanten, welche dumpfe Töne aus einer Reihe von Schilfrohr ungleicherLänge hervorbringen; den Takt bezeichnet ein Anführer durch das Zusammenbiegen der Kniee. Diese Scenen erinnern an die Bachusumzäge auf den Gefäfsen Grofs - Griechenlands. Mit Verwunderung sieht man junge Indianer in das Schilf * eilen, sich Flöten schneiden, dieselben stimmen, und sogleich gebrauchen. Überall hat das Schilf 
eine grofse Rolle in der Culturgeschichte der Völ. ker gespielt, und mit Recht sagten davon die Griechen, es habe das Schilfrohr die Völker unterjocht, indem es Pfeile lieferte; es habe aber auch die Sit. ten gemildert, durch den Reiz der Musik; hinwieder habe es dem Verstande sich entwickeln geholfen, indem es Schreibwerkzeuge gevährte. Diese verschiedene Benützung des Schilfrohrs bezeichnet gleichsam drei Perioden in Völkerleben. Die Völker am Orinoko stehen auf der untersten Stufe. Das Schilfrohr dient ihnen als Kriegs- und Jagdwaffe; die Flöte des Hirtengottes hingegen bat ihnen noch keine Töne geliefert, welche sanfte und humane Gefüble hervorrufen.

In der Hütte, in welcher das Fest gefciert wurde, trafen sie eine grofse Menge vegetabilischer Erzeugnisse an. Drei darunter waren besonders merkwürdig. Das erste ist die Frucht der Juvia, die wir schon öfter erwähnt haben. Der Almendron oder Juvia, Bertholetia excelsa, ist einer der prachtvollsten Waldbäume der neuen Welt, und verdankt seine Bekanntmachung vorzüglich Herrn von Humbolat. Er wird in den Wäldern an den linken Ufern des Orinoko angetroffen, und die Indianer versicherten, dafs oberhalb Gehette und Chiguire die Juvia und wilden Cacao-Bäume ganz gemein wären, so dafs man beim Einsammeln von den Wilden gar nicht gestört werde, weil der Überflufs so grofs ist, dafs man ihnen keinen Eintrag thut. Die Juvia trägt sehr grofse harte Früchte, Drupa genannt. 
Sic haben die Grölse eines Menschenkopfs, und in dieser aufserordentlich harten Hülle sind dreieckige Mandeln enthalten. Die Sammler laufen grofse Gefahr, wenn diese Früchte reif sind, und dann von einer Höhe von 50 bis 60 Fufs herabfallen. Die Mandeln geben vortreffliches öhl, und sind schon lange in Europa unter dem seltsamen Namen der Kastanie aus Brasilien bekannt. Der Baum, welcher diese Mandeln liefert, hat insgemein nur zwei bis drei Fufs Durchmesser, aber er erreicht eine IIöhe von 100 bis 120 Fufs. Er breitet seine selır langen Äste gegen die Gewohnheit anderer Tropenbäume, die gerade auf stehen, weit aus. Sie sind unten fast nackt, gegen die Spitze lin aber mit dich. ten Blattbüscheln besetzt. Da die Blätter nur zwei Fufs lang und halb lederartig, mithin schwer sind, so beugen sich die $\ddot{\Lambda}$ ste gegen die Erde binab. Die Blätter sind auf der Unterseite etwas silberfarb. Herr von Humboldt sah ibn nicht blühen. Er blüht erst in einem Alter von fünfzehn Jabren, und seine Blumen öffnen sich Ende März oder Anfang $\Lambda$ pril. Die Früchte reifen gegen Ende Mai, und einige Bäume behalten derer bis Ende August. Da diese Früchte oft 12 Zoll im Durchmesser halten, und sehr hart sind, so verursacht ihr Fall, zur Zeit der Reife, ein entsetzliches Getöse. Nichts kann die Kraft der Vegetation in diesen Ländern besser begreifen machen, als der See - Cocosbaum unter den Monocotyledonen und die Bertholetia unter den Dicotyledonen. Nur unsere Kürbisse können etwas 


\section{- 120}

dergleichen aufiveisen, wie Gewächse in wenig Monaten Früchte von so aufserordentlicher Grölse hervorbringen können; aber in Hinsicht auf Gehalt künnen unsere wässerigen Kürbisse freilich nicht verglichen werden, mit jenen Früchten voll Kraft und Gelalt. Unter dem Tropenhimmel bildet sich innerhalb 5o bis 60 Tagen eine Fruchthülle, deren holziger Theil einen halben Zoll Dicke hat, und mit den besten Werkzeugen kaum durchsägt werden kann, und der kein Baumholz gleichkommt. Die Fruchthülle stellt die Grundzüge von vier Abtheilungen dar, zuweilen auch fünf. Die Samen haben zwei völlig getrennte Hüllen, welcher Umstand die Bildung der Frucht zusammengesetzter macht, als bei andern Nüssen. Die erste Decke ist beinig, holzig, dreieckig und auf der äufsern Fläche höckerig und zimmtfarb. Vier oder fünf, zuwcilen acht diescr $N$ üsse sind an einer Centralscheidewand befestigt, und da sie sich später bei voller Reife ablösen, so bewegen sie sich frei in dem grofsen kugelförmigen Fruchtbehälter. Die Kapuziner-Affen, die besondere Licbhaber sind von diesen Mandeln, werden schon durch das blofse Geräusch angelockt. In jeder Frucht werden gewöbnlich 15 bis 22 Mandeln angetroffen. So lange sie frisch sind, ist ihr Genufs äufserst angenehm, und man kann sie ohne Nachtheil in beträchtlicher Menge speisen. Die zweite Hülle der Frucht ist braungelb. Sic enthal. ten sehr viel Öhl, was denn die Ursache ist, dafs sie sehr schnell ranzig werden. Der Behälter ist 
an der Spitze durchbohrt, und springt nie von selbst auf. Viele verlieren daher die Ḱeimfähigkeit durch Ausflufs des Öhls aus dem Samenlappen, bevor die äufsere Hülle des Fruchtbehälters in der Regenzeit sich durch Fäulnifs öffnet. Man erzählt wohl ein Mährchen, dafs die Kapuziner-Affen die Frucht mittelst Umherrollens zu öffnen verstünden : allein das ist unmöglich, und nur mittelst der Zähne kann es beharrlichen Nagern gelingen, sich der Früchte zu bemächtigen. Sobald die Nüsse fallen, sammeln sich die Thiere des Waldes, die Affen, die Monavìs, Eichhörnchen, Cavia, Papageien und die Aras, die alle das Vermögen besitzen, die Früchte zu öffnen. Sie eilen mit den Mandeln auf die Bäume, und auch sie, sagen die Indianer, feiern ihr Fest, und aus den Kílagen dieser kann man schliefsen, dafs jene sich für die legitimen Herren der Ernte balten. Da die Mandeln schnell keimunfähig werden, so müfste man junge Pfänzchen in Kisten, mit der Erde gefüllt, darein sie gekeimt sind, zu Tausenden setzen, und sie so auf Piroguen nach dem Orte ihrer Bestimmung führen.

Eine zweite merkwürdige Pflanze, welche Here von Humboldt in der Hïtte der Indianer fand, ist das Schilf, woraus sie Blasrohre verfertigten. Dic Länge desselben betrug 15 bis 20 Fufs, ohne dafs daran der mindeste $\Lambda$ stknoten zu bemerken gewesen wäre. Die Schilfrobre kommen vom Fufse der Ge. birge von Yumariquin und Guanaja her, und sind jenseits des Orinoko unter dem Namen des Schilf-

Bibl, naturh. Reisen, 1V. 
rohrs von Esmeralda sehr gesucht. Ein Jäger behält lebenslänglich sein Schilfrohr, und weifs von demselben so viel zu erzählen, als unsere Jäger von ihren Flinten. Herr von Humboldt lionnte das Ge. schlecht nicht bestimmen, zu velchem dieses bewundernswerthe Schilf gehört, und eben so wenig die Pflanze, aus welcher die Marima-Hemden verfertigt werden. Am Abhange des Duida sahen sie Stämme des Hemdenbaumes (die Mosquitos ausgenommen, ist es doch ein wahres Schlaraffenland die. ses Guiana, und mit der Zeit werden die Leute da Dorado finden) von fünfzig Fufs Höhe. Die India. ner schneiden röhrenförmige Stücke davon $a b$, wel. che zwei Fufs im Durchmesser halten, von denen sie die rothe, faserige Rinde trennen, und sich dabei vor Längeneinschnitten in Acht nehmen; nun machen sie zwei Seitenöfnungen für die Arme, und schliefen hinein, und haben ein Hemd, das einem Saclic ohne Nath aus grober Leinwand gleichsieht. Sic tragen dasselbe zur Regenzeit, wo es ihnen treffliche Dienste leistet. Die Missionäre sagen daher mit Recht, dafs den Wilden die Hemden auf den Bäumen wachsen; dazu kommen noch die Scheiden-oder Spitzhauben, bestehend in der grofsen Blumenscheide einiger Palmenarten, die cinem spitzigen Gewebe gleichen.

Von dem erwähnten Feste waren die Weiber aus. geschlossen. Ihr Geschäft war: die Männer mit Affenbraten, Palmenwein und Palmkobl zu bedic. 
nen, wenn diese sich genug getanzt hatten. Das heifse ich doch eine verkehrte Welt! -

\section{Sechstes Kapitel.}

Der Lauf des Orinoko oberhalb Esmeralda. - Abreise von Esmeralda. - Tiger.

Die meisten dieser Völker leben in ihrem wilden Zustande in Vielweiberei. Das Christenthum du'det dieses nicht, und darum behält der Indianer, welcher sich taufen läfst, nur ein Weib, deren Wahl er meist dem Missionär überläfst. Die Weiber sind Sclavinnen der Männer und werden von diesen wohl gar aufgefressen. Nur das Christenthum kann die Völker civilisiren, und es ist kein geringer Vorzug desselben, dafs es die Ehe ordnet, und so das gröfste Hindernifs der Cultur, die Vielweibcrei abschafft und die Hausfrau zu der ihr gebührenden Würde erlıebt.

Über den Lauf des Orinoko, ostwärts der Mission Esmeralda, weifs man bis jetzt nicht viel, und auch Herr von Humboldt liefert nur das, was er aus den Angaben der Indianer abnehmen konnte. Der Duida gehört ciner Gruppe von Granitbergen an, welche vom Rio T'amatama west-und ostwärts vom Rio Quapo begrenzt wird. Zwischen diesen beiden $\mathrm{Zv}$. flüssen des Orinoko fliefst mitten durch die Wälder der Mauritia-Palmen der Rio Sodomoni, an dessen Ufer vertreffliche Ananas wachsen. Da der Baro- 
meter in den Wäldern des Orinoko zerbrochen war, so mufste der Berg Duida trigonometrisch gemessen werden. Diese Messung gab 1118 Toisen über der Ebene von Esmeralda, und also wahrscheinlich 1300 Toisen über der Meeresfäche. Der Barometer brach durch die Feuchtiglieit, welche das hölzerne Gefäfs anschwellte, und dessen Spannung die Glas. röhre nicht widerstehen konnte. Vorrichtungen aus Zinn oder Silber dürften für diese Instrumente überhaupt zweckmäfsiger, als Holz seyn. Der Duida weicht an Hö̆le nur wenig der Silla von Caracas, und wird auch hier im ganzen Lande für einen Rie. senberg gehalten, ein Umstand, aus dem man schliessen kann, dafs die ganze östliche Berggruppe des Parime keinen Gipfel enthält, der den höchsten Spitzen der Pyrenäen gleich käme. Der Gipfel des Duida ist dernafsen senkrecht abgestutzt, dafs die Indianer ihn bisher vergebens zu besteigen versucht haben; bekanntlich sind auch die niedern Berge nicht selten die unersteiglichsten. Im Anfange und zu Ende der Regenzeit nimmt man, nach dem ein. stimmigen Zeugnisse der Missionäre und Indianer, auf dem Gipfel des Duida Flammen wahr, welche nicht immer an gleieber Stelle zu verbleiben scheinen. Dieser Umstand liat dem Berge den Namen eines Vulkans verschafft. Man könnte zwar glauben, dafs der Blitz von Zeit zu Zeit das Gebüsch entzïnde, dieses ist jedoch hier in diesem nassen Klima, bei den saftstrotzenden Pflanzen nicht so leicht, und die Flammen zeigen sich oft da, wo der Boden kaum 
mit cinigem Rasen bewachsen ist, und dann werden diese Erscheinungen an völlig gewitterlosen Tagen und auch auf dem Gipfel des Guaraco, eines am entgegengesetzten Ufer des Orinoko liegenden Berges, wahrgenommen, welcher Hügel bis $600 \mathrm{Fufs}$ über die Ebene erhöht ist. Es ist daher wahrscheinlich, dafs irgend eine unterirdische Ursache diese Flammen erzeugt. Der Duida ist mit Gängen angefüllt, dic zum Theil offen, zum Theil mit Quarzund Schrvefellies ausgefüllt sind. Gasartige Ausdünstungen künnen daher durch diese Verklüftungen leicht aus dem Innern der Erde zu Tage kommen. Wir hahen ähnliche Erscheinungen schon im ersten und zweiten Theile beschricben: z. B. den Cuchivero bei Cumanacoa. Der Grund aller dieser Erscheinungen ist im Urgebirge tief unter dem Ubergangund Flötzgebirge zu suchen. Die wärmsten Quellen finden sich im Granit - und das Steinöhl haben wir aus Glimmerschiefer quellen sehen. Furchtbare f́nalle sind in Encamerada mitten im granitischen Boden gehört worden. Hier, wie auf dem ganzen Erdballe, liegt der Herd der Vulkane im ältesten Gebirge, und zwischen den grofsen Erscheinungen, welche die Rinde unsers Planeten emporbeben und flïssig machen, und jenen feurigen Erscheinungen, die man auf der Oberfäche der Erde wahrnimmt, und die man, ihrer Kleinheit wegen, atmosphärischen Einflüssen ganz allein zuzuschreiben geneigt ist, scheint ein inniger Zusammenhang zu bestehen. Obgleich der Duida die Höhe, welche der Volks- 


\section{$-\quad 120$}

glaube ihm zuscbreibt, niclut besitzt, so ist er doch der liöchste Punkt der ganzen Berggruppe, welche das Becken des Orinoko von dem des Ainazonen. stromes treunt. Diese Berge senken sich noch schnel. ler nordıärts, als ostwärts. Die höchsten Gipfel nach dem Duida sind nordirärts der Cuneva, an den Quellen des Rio Paru, der Sipapo, der Calitamini, welcher mit dem Cunavani und den Pik von Uniana eine gemeinsame Gruppe bildet. Ostwärts zeichnen sich aus der Maravaca, zwischen dem Rio Causimomi und Padamo; am linken Ufer des Orinoko: die Berge von Guanaja von Yumariquin.

Von Esmeralda fälırt man noch aufivärts bis zu den Wasserfülien, die von den Guaicas-Indianern besetzt sind, und für's erste alles weiterc Vordringen der Spanier hindern. Bis dahin hat man zwei Tagfahrten zum Rio Padame, wo der Orinoko auch eine Breite von 3 bis 400 Toisen behält. Er liat vom rechten Ufer zahlreiche Zuflüsse, weil da die Ufer durch hobe Berge begrenzt sind. Der Pflanzenwuchs ist hier sehr kräftig, so dafs sich überall eine uncrmefsliche Menge Bauholz findet. Die Ceiba wird daselbst in Stämınen von $16 \mathrm{Fufs}$ Durchmesser angetroffen. Vom Padamo gelangen die Indianer in anderthalb Tagen zum Rio. Mlavaca, der in den hohen Bergen von Unturan entspringt. Zwischen den Einmündungen des Podamo und Ma. vaca empfängt der Orinoko den Ocamo, in welchen sich der Rio Mataconna ergiefst. An den Quellen dieses Flusses wohnen die Guainares.Indianer, wel- 
che nieht so kupferroth, sondern sehwarzbrauner sind, als die andern Eingebornen dieser Gegenden. Beim Einflusse des Mavaca nimmt der Orinoko plötzlich an Breite ab, und oberhalb bei den Wasserfällen der Guahibos ist er schon so schmal, dafs die Guahibos - Indianer cine Brücke aus geflochtenen Lianen - Gewäclssen über denselben gespannt hat,en, welehe sie an die aus dem Wasser ragenden Felsen befestigen. Die Gualibos-Indianer, nebst noeh cinigen Stämmen, sind von kleinerer Statur und hellerer Farbe, als die übrigen Indianer. Das ganze Land oberhalb der Wasserfälle der Guahibos ist sn gut, wie unbekannt, und daher das Land der Vermuthungen, der Mährehen, und ofters sehon der Schauplatz grausamer Gemetzel. Hlier sueht man die Goldstadt und den See Parime voll Sehätze; hicher werden, wie sehon oben erwähnt, die Ungeheuer der frühern Reisebesehreiber versetzt. So viel seheint gewifs, dafs der Orinoko nieht aus einem See Parime, der nirgend vorhanden zu seyn scheint, sondern aus mehreren Quellen des Berglandes und der Vereinigung mehrerer Flüsse zu entspringen seheint. Das Land bietet feuehte Wildnisse, und wilde Stämme von Indianern, die bisher ihre Unab. hängigkeit zu erhalten gewufst haben, und jetzt darauf um so eifersüchtiger zu seyn seheinen, als ihnen das Loos der besiegten Stämme keineswegs beneidenswerth erschien. Ein Commandant von San Carlos hatte einen Zug in diese Gegenden unternommen, ward von den Indianern mit vergifteten Pfei- 


\section{- 128}

Ien angegriffen, und richtete unter ihnen ein fürch. terliches Gemetzel an. Diese rächten sich später da. für, indem sie 1776 die zwischen Esmeralda und dem Rio Erevato errichteten Militärposten in einer Nacht angriffen, und dieses Unternehmen mit solcher Külnheit ausführten, dafs man es bis jetzt nicht mehr gewagt hat, in jenc Gegenden einzudringen. Die Quellen des Orinoko sind also bis jetzt noch unerforscht, und selbst Herr von Humboldt fand es unthunlich, bis zu ihnen vorzudringen.

Am 23. Mai verliefsen sie die Mission Esmeralda. Die Pirogue war bereits von den Arneisen in Besitz genommen, und mulste ihnen förmlich wieder abgenommen werden, und das war keine leichte Arbeit. Noch hatten sie beinahe einen Monat in ilır zuzubringen, bis sie Angostura erreichten, und schon jetzt zeigte sich eine Schwäche in ihrem Körrper, welche eine Folge ausgestandener Mühseligkeiten und der schlechien Nahrung war. Im Augen. blicke der Einschiffung drängten sich die andern erwähnten farbigen Leute, welche nach Esmeralda verbannt waren, zur Pirogue, und baten, sich beim Statthalter für sie zu verwenden, danit sie Esme. ralda verlassen dürften. So schwer auch, meinten sie, ihre Vergehungen seyen, so hätten sie doch seit zwanzig Jahren unter den Qualen der Mosquitos dafür gebüfst. Herr von Humboldt hat es auch gethan; allein vergehens. Übrigens kam Herrn von Itumboldt die Mosquitos. Plage in Esmeralda nicht gar so heftig vor, als auf dem Cassiquiare. Die 
Ursache mag jedoch darin liegen, dafs er hier sich Bewegung machen konnte; auf dem Cassiquiare aber mufsten sie in der Pirogue, gleichsain angesclımiedet, sich den Mosquitos Preis geben. Sie gebrauchten hier auch küblende Waschwasser. Der Citronensaft und mehr noch jener der Ananas minderte die Schmerzen, und schien die Geschwulst zu heben. Übrigens erzählen die Einwoliner von Esmeralda einen besondern Vorfall, der in der Mosquitos-Geschichte Epoche machte. 1795, eine Stunde vor Sonnenuntergang, wo die Mosquitos eine dichte Wolke zu bilden pflegen, wurde die Luft plötzlich von Mosquitos frei. Kein einziges Insekt konnte wahrgenommen werden, und doch war der Himmel unbewölkt und kein Wind verkündigte Regen. Man mufs in diesen Gegenden gelebt haben, um sich einen Begriff von dem Erstaunen zu machen, wel. ches das plötzliche Verschwinden dieser Insekten hervorbrachte. Man beglückwünschte sich gegen. seitig, und befragte sich, ob dieses Glück und diese Erleichterung wohl Dauer haben möchte. Bald jedoch überliefs man sich ängstlichen Besorgnissen, man glaubte die Ordnung der Natur habe sich umgekehrt. Alte Indianer, diese Gelehrten des Landes, behaupteten: das Verschwinden der Mosquitos müsse der Vorläufer eines heftigen Erdbebens seyn. Man stritt sich mit Hitze, lauschte jeder Bewegung der Luft, und als sich diese wieder mit Insekten füllte, freute man sich ganz eigentlich über ihre Wieder. kehr. So ist der Mensch der Gewohnheit unterwor- 


\section{- 130}

fen, dafs er bei jeder Veränderung ängstlich wird, tind beim Gefühle seines Looses auf Erden mifstrauisch, sogar sich die einmal gewohnten Plagen zurückwünscht.

Nach einer vierstündigen Fahrt stromabwärts schlugen sie ihr Bivouak nun wieder an der Stelle auf, bei dem Punkte der Gabeltheilung, wo vor wenigen Tagen die Jaguare den getreuen Hund entführt hatten. Alle Versuche der Indianer, nur cine Spur des Thieres zu entdecken, war ohne Er. folg geblieben. Die ganze Nacht hindurch umgaben Jaguare mit ihrem Geheule das Lager. Sie sind hier ungemein zablreich, und hier ist auch der schwarze Tiger $\%$ finden, dessen Felle man den Fremden in Esmeralda gezeigt hatte. Dieses Thier ist durch seine grofse Wildheit berüchtigt, und scheint durch seine Gröfse noch den gemeinen Jaguar zu übertreffen. Die Indianer behaupten, der schwarze 'Tiger sey sehr selten, er vermische sich nie mit dem gemeinen Jaguare und bilde eine eigene Rasse. Diese Bemerkungen sind durch neue Forschungen bestätigt worden. In Paraguay sind weifse Tiger gesehen worden, denn diese Thiere, die man die schönen Panther von Amerika nennen könnte, haben zuweilen so blasse Flecken, dafs sie auf dem völlig weis. sen Grunde kaum bemerkt werden können. Bei den schwarzen Jaguaren ist es die dunkle Farbe, welche die Flecken verschwinden macht. Man müfste sich lange in Esmeralda aufhalten, und die Indianer auf ihren oft gefährlichen Tigerjagden begleiten, wenn 
man diese Thierarten genau kennen lernen wollte. Übrigens ist die Menge dieser Thiere sehr bemerkenswerth in einem Lande, welches von Vieh ent. blöfst ist. Der Tiger am Orinoko führt ein elendes Leben im Vergleiche mit jenem der Pampas von Bue. nos-Ayres, der Llannos von Caracas und anderer mit Hornvich besetzten Ebenen. In den spanischen Colonien werden jährlich bej 4000 Jaguare getödtet, worunter mehrere die Gröfse der asiatischen Königs. tiger erreichen.

Am 24. Mai, mit Aufgang der Sonne, fuhr man weiter. In einer Felsenbucht, welche einst den Durimundi-Indianern zur Wohnung gedient hatte, war der aromatische Wohlgeruch der Pflanzen so stark, dafs er den Reisenden lästig fiel. Sie konnten jedoch nicht erfahren, von welchen Blumen dieser Wohlgeruch herliam, weil es unmöglich war, in den Wald einzudringen. Herr Bonpland glaubte es seyen Blumenbüsche von Pancratium und andern Liliengewächsen, welche die Luft mit ihren Ausdünstungen sättigten. Den Orinoko abvärts fahrend, kamen sie verschiedenen Flüfsmündungen vorbei. Die Ufer sind hier völlig öde, nordwärts erheben sich hohe Berge, welche von einigen wilden Stämmen bewohnt werden; südwärts debnen sich unabsehbare Ebenen aus, bis über die Quellen des Atabapo hin, aber in ihnen wird auch nicht eine einzige Spur menschlicher Wesen angetroffen. Dieser öde grofse Strom, auf dem nicht einmal eine Fischerbarke schwebt, hat etwas Trauriges und ge. 
wälart beut zu Tage ein Bild der öde und Verlas. senheit. Immer war es nicht so. Einst bewegten sich hier Völker, die eine höhere Stufe der Cultur erreicht hatten, als die wilden Völker, die jetzt in zerstreuten Familien schüchtern umherirren. Die Ebenen der Guaina-Savánen sind mit Felsen bedeckt, die aus dem härtesten Granite bestehen. Diese Felsen sind mit rohen Sculpturen bedeckt, welche Bil. der von Sonne, Mond und Sterne, von Land - und Wasserthieren darstellen, und auf ein Volk hindeu. ten, wovon die wilden Banden nur nocl traurige Uberreste sind. Diese Sculpturen gleichen, in einem Umfange von melireren tausend Quadrat-Meilen vollkommen denen, welche wir schon oben an der Mündung des Apure erwähnt lıaben. Weiter ösilich trifft man in der Ebene des Cassiquiare und Conorichite, in einer Entfernung von 150 Meilen, ebenfalls diese Hicroglyphen in den Felsen an. Es sind keine Buchstaben, sondern unförmliche rohe Figuren, welche Himmelskörper, Tiger, Ḱrokodille, Boas-Schlangen und zur Bereitung des Manioc.Mehls dienliche Werkzeuge darstellen. Die Bedeutung die. ser Bildwerke, die Art ihrer Entstehung und wer die Urheber waren, wird wohl immer in Dunkel gehüllt bleiben; für den Forscher der Menschen - Ge. schichte haben sie jedoch Wichtigkeit. Diese Denk: mäler scheinen dem Bergthale von Esmeralda eigen. thümlich. Sie finden sich im Hafen von Sedenno biṣ an die Gestade des Caura, wo der Granit nackt zu Tage liegt. Die Tamanaken.Völker, als die alten 
Bervohner des Landes, erhalten auch hier eine alte Sage, die sich auf diese Gegenden bezieht, und mit allen Überlieferungen, die auf die Erneuung des Menschengeschlechtes Bezug haben, in Ubereinstimmung ist. Amalivaca, der Vater der Tamanaken (das will sagen: der Schöpfer des Menschenge. schlechts; denn jedes Volk hält sich für den Urstamm der Menschheit), traf zur Zeit der grofsen Über. schwemmungen in einer Barke ein. Diese Zeit heifst dic Wasserzeit, als dic Fluthen des Oceans sich im Binnenlande an den Bergen von Esmeralda zerschlu. gen. Damals ertranken alle Menschen, mit Ausnahme eines Mannes und eines Weibes, die sich auf einen unweit von den Gestaden des Asiveru oder Cuchiveru befindlichen Berg flüchteten. Dicser Berg ist also auch hier wieder ein Ararat. Amalivaca hat auf sciner Fahrt in der Barke die Bilder in die $\mathrm{g} \mathrm{e} \mathrm{m}$ a $\mathrm{l}$. nen Felsen cingeliauen. Die über einander gethürmten Granitblöcke heifsen noch heut zu Tage Haus oder Wohnung des Ahnherrn der Tamanaken (Amalivaca Chambural). Unfern von dieser Hütte wird in der Ebene von Maita ein grofser Stein ge. zeigt, welcher Amalivaca's Trommel gewesen ist. Diese Person hatte in der Heldenzeit einen Bruder, Vochi genannt, welcher dem Amalivaca Hülfe leistete, um der Erde ihre gegenwärtige Gestalt $z u$ geben. Diese zwei Brüder wollten dem Flusse Orinoko die Einrichtung geben, dafs die eine Seite des Stromes aufwärts, die andere abwärts flöfse, was ihnen jedoch bei aller ihrer Gewalt unmöglich war. 


\section{$-\quad 154$}

Amalivaca hatte mehrere Töchter, die grofse Neigung für Reisen hatten, und denen er daher die Beine zerschlug, um sie an ein beständiges Leben zu gewöhnen, und zu zwingen, das Land der Tamanaken zu bevölkern. Nachdem Amalivaca hier diesseits des grofsen Wassers in Amerika alles vollbracht hatte, schiffte cr sich wieder ein, und kehrte an das andere Ufer, von welchem er hergekommen war, vieder zurück. Seit die Eingebornen von Missionären besucht worden, bilden sie sich ein, Europa sey das andere Land, und sie fragten sogar den Pater Gili, ob er den Amalivaca, den Vater der Tamanaken, von dem diese Bilder auf dem Fel. sen herrühren, gesehen habe. Ähnliche Sagen findet man im ganzen Amerilia, und sie schlicfsen sich an die der alten Welt zu sehr an, um nicht in ilırer Verstümmelung eine und dieselbe Offenbarung zu erkennen. Die Grundzüge bleiben immer dieselben. Und was die heilige Urkunde der Bibel so rein und wahrhaft aufbewalırt hat, finden wir, wenn gleich mannigfaltig entstellt, doch in seinen Grundzägen sehr deutlich, bei allen Völkern der Erile wieder.

Diese Angaben von einer grofsen Wasserfluth und einem geretteten Menschenpaare, welches dic Früchte der Mauritia rücklings warf, um die Erde auf's neue zu bevölkern; diese National - Gottheir, Amalivaca, die über Wasser aus einem fremden Lande herkommt, der Natur Gesetze vorschreibt, und die Völker auf ihre Wanderungen zu verzichten $z$ wingt; diese verschiedenen Züge einer alten 
Glaubenslehre verdienen Aufmerksamkeit. Was dic Tamanaken crzählen, dürfte von andern Völkern, die vor ihnen dies Land bewohnten, auf sie übergegangen seyn. Amalivaca ist jedoeh nicht der grofse Geist oder der Alte vom Himmel, sondern eine Person der Heldenzeit. Bei allen Völliern ver. menschlichen sich die Götter, und alle bekennen eine Offenbarung der Gottheit. Diese geschieht auf zweierlei Art. Bald steigen die Gottheiten auf die Erde nicder, und werden Gesetzgeber und Einriehter der Staaten, wie im Morgenlande; bald sind es, wie bei den Griechen und abendländischen Völkern, Priesterkönige, denen man die Menschliehkeit abstreift, um sie zu National.Gottheiten zu erlieben. Amalivaca war ein Ausländer, wie Manko-Kapak, Bohica und Quetzalcohuatl. Diese aufserordentliehen Menschen, die im alpinisehen oder civilisirten Theile von Amerika, auf dem Plateau von Peru, Neu-Granada und Anahuak die Einrichtungen der bürgerliehen Gesellsehaft getroffen, die Opferungen angeordnet, die Religions-Orden gestiftet haben. Der Mexikaner, Quetzalcohuatl, dessen Abkömmlinge Montezuma in den Gefährten des Cortez zu crkennen geglaubt hatte, stellte noch eine Ähnliehkeit mehr mit Amalivaca dar. Im hohen Alter verliefs der Oberpriester von Thula die Landsehaft $\Lambda$ nahuak, die er mit seinen Wundern erfüllt hatte, um in ein unbekanntes Land, Tlapelan genannt, zurüekzukehren. Als der Mönch Bernhard in Mexiko eintraf, wurde er daselbst eben so gefragt: ob er Quetzalcohuatl 
gesehen habe, wie man zweihundert Jahre später den Pater Gili in Hinsicht auf Amalivaca befragte.

Vom 24. bis 27. Nai hatten sie nur zwei Mal am Lande übernachtet. Da der Flufs klippenfrei ist, so hatten sie sich ganz demselben überlassen. Einmal landeten sie in der Mission Santa Barbara, einem kleinen Dorfe von 120 Einwohnern, wo einiger Ge. werbfleifs angetroffen wird, der jedoch nicht den Eingebornen, sondern, wie überall in den Missionen, dem Missionär zu Gute kommt. Es gibt hier auch einiges IIornvieh, welches man jedoch nicht zum Treten der llühlen verwendet, als wo Indianer gebraucht werden. Die Weiden der Ebenen von St. Barbara sind nicht so fett, als in Esmeralda, aber doch besser, als in San Fernando. Am 26. verliessen sie St. Barbara, wo die Indianer beschäftiget waren, dem Missionär ein Haus zu bauen. Sie fuh. ren nun abwärts, und die Fahrt ging schnell von Statten. Den ganzen Tag hatten sie die reizenden Berge von Sipapo, die nordwestlich sich auf $18 \mathrm{Mej}$. len erstrecken, vor Augen. In dieser Gegend ist der Pflanzenwuchs üppig und durch Mannigfaltigkeit schön und reizend. Die Nacht über bivakiren sie auf der Insel Minisi und trafen am 27. Mai wieder in San Fernando de Atabapo ein. Einen Monat vorher hatten sie dasselbe Haus des llissionärs bewohnt, jetzt bewohnten sie es wieder, nachdem sie eine grofse, gefahrvolle Reise vollbracht hatten. Der Aufenthalt in diesem reizenden Dorfe, unter dem Schatten der Pfirsich Palme, dauerte nur einen Tag. 
Es wurde verschiedentlich von der Mission und ihren bessern Einrichtung gesprochen, und dic Hütten der Indianer besucht. Um diese IIütten, die übrigens schr rein zu seyn pflegen, flogen zahme Pauxis berum, und Affen gehörten zu den Hausthieren. Unter diesen letztern trafen sie auch eine neuc Art an, die sich durch ihren schönen Ṕelz und gelehrige Sanftheit auszeichnet.

Am 27. Mai setzten sie ihre Reise fort. Sie reiseten nun schon wie durch ein bekanntes Land, und gelangten so nach Maypures, wo sic zwei Tage verweilten, um die Pirogue durch dic Cataraliten führen zu lassen. Der Pater Zea war hier zu Hause, und wollte nun noch unsere Freunde bis Atures begleiten mit sieben Indianern. Der Indianer Zerepe aber, der auf der Tortuga -Insel die Schläge bekommen hatte, war schr traurig. Er hatte seine Geliebte durch die Reise eingebüfst, welche er heirathen wollte, und die jetzt für ihn verloren ging. Er war in Maypures geboren, und bei seinen Verwandten vom Stamme der Macos in der Wildnifs erzogen worden. Er hatte ein zwölfjähriges Mädchen mit in dic Mission gebracht, und wollte es nach seiner Rüclkehr von den Reisen mit unsern Freunden heirathen. Der jungen Indianerinn kam das Leben in der Mission sehr langweilig vor. Es ward ihr gesagt, die Weifsen zögen in das Land der Portugiesen, und nähmen Zerepe mit sich. Hie. durch in ihren Hoffnungen getiuscht, bemächtigt sie sich eines Kahns, setzt in Begleitung einer ihrer 
Geführtinnen über das Raudal, und flüchtet al Monte, um vieder zu den Ihrigen zu kommen. Die Erzäh. lung dieser muthvollen That war die grofse Nenig. lieit des Ortes. Indefs dauerte Zerepe's Niedergeschlagenheit nicht lange. Er dünkte sich vornehmer zu seyn, als ein gewöhnlicher Wilder, weil ev christlich geboren war und castilianisch sprach, und mochte daher ein Mädchen der Wildnifs leicht ver. gessen.

\section{Siebentes Kapitel.}

Die Höhle von Ataruipe. - Reise nach Carichana.

Da die folgende Beschreibung zu den sclönsten Theilen der Reiseberichte des Herrn von IIumboldt geliört, so wage ich es nicht, einen Auszug daron z.u geben, sondern will sie lieber wörtlich einschalten, aus Furcht, das schöne Gemälde möchte zu viel yon seinem Reize einbüfsen. Der Bericht über eine sehr wichtige Sache ist folgender.

"Am 31. Mai kamen wir bei den Rapides der Guahibos und von Garcita vorbei. Die mitten aus dem Sirome sich erhebenden Inseln glänzten im schönsten Grün. Die Winterregen hatten die Blumenscheiden der Vadgiai-Palmen entwickelt, deren Bilder senkrecht emporstehen. Man mag der Ansiclsten nicht satt werden, wo Bäume und Felsen der Landschaft einen grofsen und ernsten Charak. ter ertheilen, welchen man im Hintergrunde der 
Gemälde von Titian und Poussin bewundert. Kurz vor Sonnenuntergang landeten wir am östlichen Ufer des Orinolso bei Puerta de la Expedition. Es geschah dies in der Absicht, die Höhle von Ataruipe zu untersuchen, von der früher schon die Rede war, und die das Begräbnifs eines ganzen untergegangenen Volkes zu seyn scheint. Ich will versuchen, diese unter den Landeseingebornen berühmte Höhle zu beschreiben.

"Mühsam und nicht ohne einige Gefahr ersteigt man einen steilen und völlig nackten Granitfels. Fast unmöglich liefse sich auf der glatten und stark geneigten Oberfäche der Fufs festhalten, wenn nicht grofse Feldspathlirystalle, die der Zersetzung wielerstehen, aus dem Felsen hervorragten, und dem Fufse Stützpunkte darböten. Sobald wir den Gipfel erstiegen hatten, überraschte uns die aufserordentliche $\Lambda$ nsicht der umliegenden Landschaft. Das schäumende Wasserbett ist mit einem von Palm. bäumen bewachsenen Insel - Archipelagus angefüllt. Westwärts am linken Ufer des Orinoko dehnen sich die Savanen von Meta und Casanare aus. Das Ganze glich einem Meere vom schönsten Grün, dessen neblichter Horizont von den Strahlen der untergelıenden Sonne erleuchtet war. Dieses, wie eine Feuerkugel, über der Ebene schwebende Gestirn, dieser abge. sondert stehende Pil von Uniana, der um so höher erschien, da seine Umrisse in Dünste eingehüllt, wie verwischt waren: alles trug dazu bei, die Scene erhaben zu machen. Unsere Blicke tauchten gleich- 
sam unter in dem nahen, tiefen und allseitig geschlos. senenThale, Raubvögel und Nachtschwalben schwärm. ten einzeln durch den unzugänglichen Kíreisraum. Mit Vergnügen folgten unsere Blicke ihren beweglichen Schatten, welche langsam über die Felsen. abhänge hinglciteten.

„Über einen schmalen Kamm gelangten wir auf einen benachbarten Weg, dessen abgerundeter Gipfel ungeheure Granitblöcke trug. Ihre Mlassen haben über 40 bis 50 Furs Durchmesser, und ihre Form ist so kugelrund, dafs sie den Boden nur mit wenigen Punkten ihrer Oberfläche zu berühren scheinen, und man glauben sollte, schon der geringste Stofs eines Erdbebens müfste hinreichen, um sie in einen Abgrund zu wälzen. Ich erinnere mich nicht, eine ähnliche Erscheinung, mitten unter den Zersetzungen, welche die granitischen Gebirgsarten darbieten, irgendwo gesehen zu haben. Würden diese Steinkugeln auf ciner verschiedenartigen Gebirgsart aufliegen, wie bei den Jurablöcken der Fall ist, so liefse sich annehmen, sie wären entweder durch die Wirkung des Gewässers abgerundet oder durch die Kraft einer elastischen Flüssigkeit geschleudert, aber ihr Vorkommen auf dem Gipfel eines gleichfalls granitischen Hügels macht wahrscheinlicher; dafs sie ihren Ursprung einer fortschreitenden Zersetzung des Gebirges verdanken.

"Der hinterste Theil des Thales ist mit dichter Waldung besetzt. In dieser schattigen und einsamen Gegend, am steilen Abhange eines Berges, öfnet 


\section{- 141}

sich die Höhle von Ataruipe. Es ist aber nicht so sehr eine IIöble, als ein vorstehender Fels, in welchen die Wasser eine Vertiefung eingegraben haben, zur Zeit, wo sie bei frühern Umwälzungen unsers Planeten diese Höhe erreichten. In dieser Grabstätte einer verschwundenen $\nabla$ rölkerschaft zählten wir in kurzer Zeit über 5oo wolılerhaltene und regelmäfsig geordnete Gerippe, dafs man sich in Hinsicht ilırer Zahl nicht leicht irren mochte. Jedes Gerippe liegt in einer Art Kö̈rbe, welche aus Blatt. stielen von Palmbäumen geflochten sind. Die Einwohner nennen diese Körbe Mapires und sie haben die Gestalt eines viereckigen Sackes. Ihre Grölse ist verschieden, nach dem Alter der Leichen; es finden sich auch solche, die für todtgeborne Kinder be. stimmt waren; wir haben von on Zoll bis auf $3 \mathrm{Fufs}$ 4 Zoll lange gesehen. Alle diese in sich selbst gekrünınten Skelette sind derınafsen vollständig, dafs ihnen keine Rippe und kein Glied fehlt. Die Knochen sind auf drei verschiedene Arten zubereitet, entweder an Luft und Sonne gebleicht, oder mit Onoto, einem aus der Bixà orellana gezogenen Fär. bestoff, roth gefärbt, oder gleich wirklichen Mumien mit wohlriechenden IIarzen überzogen, und in Heliconien- und Pisang - Blätter gewickelt. Die Indianer erzäblten uns : die Leichen werdcn erst in den feuchten Boden gelegt, damit die fleischigen Theile sich allmählig zersetzen. Nach einigen Monaten gräbt man sie wieder aus, um die noch an den Knochen befindlichen weichen Theile mit ge- 
wetzten Steinen vollends abzuschaben. Verschiedene Iorden in Guyana befolgen diese Sitte jetzt noch. In der Nähe der Mapires oder Iü̈rbe finden sich halbgebrannte Thongefäfse, welche die Knochen einer ganzen Familie zu enthalten scheinen. Die grölsten dieser Gefäfse oder Todten-Urnen sind drei Fufs hoch und 4 Fufs 3 Zoll lang. Ihre Farbe ist graulich grün und ihre Gestalt ein gefälliges Eirund. Die Henkel haben dic Form von Krokodillen oder Schlangen; der Rand ist mit Mäandern, Labyrinthen und eigentlichen Grekken aus verschiedentlich zusammengesetzten geraden Linien verziert. Solche Zeiclnungen finden sich unter allen Zonen, bei Völkern, die von einander am weitesten entfernt sind, sowohl hinsichtlich auf ihren Wohnsitz, als in Bczug auf den Grarl von Cultur, welche sie erreicht haben. Noch heut zu Tage tragen die Bewohner der lleinen Mlission von Maypures diese Zeichnungen auf ilure gemeinste Töpferwaare; sie dienen dem Schilde der Otaheiter, den Fischergeräthen der Eslimos, den Mauern des mexikanischen Pallastes von Witla und den Gefäfsen von Grofs. Griechenland gleichmäfsig zum Schmucke. Eine rythmische Wicderholung der nämlichen Form erfreut das Auge überall, wie dic taktmäfsige Wiederholung der Töne dem Olıre gefällig ist. Analogien, welche ihren $G$ rund in den Gefüblen der Menschenbrust und in den natürlichen Anlagen unsers Verstandes haben, können sich nicht eignen über Herkunft und frühere Verhälınisse der Völker Aufschlüsse zu geben. 


\section{- 143}

"Wir mochten zu keiner bestimmten Meinung über den Zeitpunkt des Ursprungs der Mapires und der bemalten Töpfe gelangen, die sich in derBeingrotte von Ataruipe vorfinden. Die meisten scheinen nicht über ein Jahrhundert alt; es ist jedoch wahrseheinlich, dafs unter dem Einflusse ciner gleichförmigen Temperatur und in Ermanglung aller Feuchtigkeit, die Erhaltung dieser Dinge auch in viel längerer Zeit gleich vollkommen seyn müfste. Einer unter den Guabibos Indianern vorhandenen Überlieferung zufolge, sollen die kricgerischen Atures dureh die Cariben verfolgt, sich auf die in der Mitte der grossen Catarakten befindlichen Felsen geflüchtet bahen. Hier ist dicse vorhin so zahlreiche Nation und mit ihr zugleich ihre Sprache allmählich erlosehen. Die letzten Familien der Atures haben noch im Jahre ${ }_{17}{ }^{6} 7$ gelebt, zur Zeit des Missionärs Gili. Iı Zeitpunkte unserer Reise (der Umstand scheint bemerkenswertlı) wurde in Maypures ein alter Papagei gezeigt, von dem die Einwohner bezeugten, man verstehe nicht, was er sage, wcil er die Atures. Sprache rede.«

Dic Reisenden öfneten nun mchrere Körbe, um die Schädel zu untersuchen. Die Indianer sahen das ungern, es beleidigte mit Recht ihr Zartgefühl, dic Gebeine ihrer Vorältern beunruhigt zu sehen.

»Wir wählten «, fährt Herr von Humboldt fort, 》) in der Grotte von Ataruipe mehrere Schädel, ein Kinder-Skelett von 6 bis 7 Jahren, und zwei Skelette von Erwachsenen, aus der Atures.Familic. Diese 
Knochen, alle zum Theil roth gefürbt, zum Theil mit wohlriechenden Harzen überzogen, waren in eben den Körben enthalten, die wir so eben beschrieben haben. Sie machten fast eine ganze Maulthierladung aus, und da uns der Eingeburnen abergläubischer Abscheu vor Leichen, nachdem diese einmal beerdigt sind, bekannt war, so unterliefsen wir nicht, die Canastos in frisch geflochtene Matten einzuwickeln. Diese Vorsicht war jedoch zu unserm Leidwesen durch den Scharfsinn und den ausnehmend feinen Geruch der Indianer unnütz. Allentlalben wo wir Halt machten, in der Mission der Cariben, mitten in den Llannos, zwischen Angostura und Neu-Barcellona, sammelten sich die Eingebornen um unsere Maulthiere, durch die Affen angelockt, welche wir am Orinoko gekauft hatten. Kaum aber hatten diese guten Leute unsere Ladung berülırt, so verkündeten sie die nahe Einbufse des Saumviches, das die Todten trüge. Umsonst versicherten wir sie, ihre Muthmalsung sey irrig, in. dem die Körbe Gebeine von Krokodillen und SecIühen enthielteı; sie blieben bei ihrer Behauptung »es seyen von ihren Voreltern und sie riechen das Harz der Skelette."

"Es kostete alles Ansehen der Ordensleute, un Maulthiere zu erlangen, und bei allen dem ging die ganze Sammlung in dem sclion in ersten Theile erwähnten Schiffhruche verloren, der auch jenem jun. gen Ordensmann, Juan Gonsalez, das Leben kostete. "Stillen Betrachtungen dahin gegeben, verliefsen 
sie die Grotte. Es war eine der ruhigen und heitern Tropen - Nächte; mild funkelten dieSterne und die Nebelgestirne des südlichen Himmels kamen der Phantasie zu Hülfe. In der Luft verbreiteten eine zahllose Menge leuchtender Insekten ein röthliches Licht, und man glaubte sich plötzlich in eine höhere Welt, oben und unten von Sternen umringt, versetzt. Sie blieben daher am Ausgange der Grotte wie bezaubert stehen, um diesen aufserordentlichen Anblick zu geniefsen. Den Eingang der Grotte zierten Palmen, von wohlriechenden Vanillien und Bigonien umsponnen.

Ziemlich spät trafen sie in der Mission ein. Ihre Phantasie war lebhaft angeregt, und schweifte durch die ganze Welt und alle Vergangenheiten, mit denen sie der gehabte Anblick in Berührung brachte. So ist der Mensch ein Spiel seiner Phantasie! Weh. müthige Sehnsucht erhebt seine Brust, er trauert über Gräbern und Mumiensärgen der Vorwelt, der er doch selbst im nächsten Augnbelicke angehört!

Solche Grotten mögen sich am Orinoko wohl noch mehrere befinden, ohne dafs jedoch ihre Entdeckung und Erforscliung zu wiclitigen Ergebnissen führen künnten. Übrigens haben die amerikanischen Völker eine sehr grofse Anhänglichkeit an diese Grabstätten ihrer Vorfahren, und sind darin gleich allen Völkern, bei denen Verfeinerung die Gefühle der Natur noch nicht erstickt hat.

In Atures verweilten die Reisenden nur so lange, als nöthig war, die Pirogue, deren Boden schorn Bibl. naturh. Reisen. IV. 
sehr dünn geworden war, durch die Catarakten zu bringen. Der Missionär Zea, der durch zwei Monate ihr Begleiter gewesen war, nahm hier Abschied. Er hatte sein Wechselfieber nicht verloren, aber es war ihm zur Gewohnheit geworden. In Atures aber waren seit jhrer ersten Durchreise Fieber schlimmerer Art eingerissen. Die Einwohner konnten ihre Hängematten niclıt verlassen, und um etwas CassaveBrot zu erhaiten, mufste man einen benachbarten Stamm kommen lassen. Die edien Fremdlinge waren bis jetzt in diesem fieberreiclén Lande noch immer von dieser Krankheit verschont geblieben.

Sie besuchten nun nochmals die Catarakten. Brau. send stürzt das Wasser über die Dämme hinab, und inwendig stürzt es mit dumpfem Getöse rückwärts. Sie fanden einen ansehnlichen Theil des Orinoko ausgetrocknet, weil sich das Wasser unterirdische Canäle geöffnet hatte. Hier nistet der goldgefiederte Mlanakin, einer der schönsten Tropenvögel. Sie stiegen in eine der Höhlen hinab, und jetzt rollte der Flufs seine Gewässer über ihre Köpfe. Er sah einem gegen die Felswand brausenden Meere gleich. Am Eingange derGrotte konnte man trocken stehen unter dem niederstürzenden Wasserbogen. Sie genossen hier nochmals den Anblick dieses Cascadenmeeres, dieser meilenlang andauernden Catarakten, und zwar länger, als es ihnen lieb war. Das Boot hatte nämlich einen langen Umweg zu machen, um sie wieder einzuholen, und die Fahrt fortzusetzen. Schon hatten sie anderthalb Stunden gervartet, und 


\section{- 147}

noch war es nicht da; sie glaubten daher, das Boot sey zerscliellt, und die Indianer, nach ihrer sorglosen Art, in die Mission zurückgekehrt. Zudem kain ein heftiges Gewitter, der Regen scbofs in Strö. men herab und die Nacht brach ein. Herr Bonpland wollte durch die Catarakten schwimmen, um in der Mission IIülfe zu suchen, und konnte nur mit Mühe zurückgehalten werden. Zwischen den heftigen Wirbeln konnte er verunglücken, und zugleich zcigte es sich, dafs die Krokodille die Wasserfälle nicht so scheuen, als es bei der Auffahrt den Anschein hatte. Als nämlich das Gewitter ausbrach, fingen die auf der Insel ausgeschifften Affen zu heulen an, und sogleich stellten sich zwei grofse Krokodille ein, die durch ihre Bleifarbe ihr grofses Alter beurkundeten. Die Reisenden sahen nun, dafs es selir unvorsichtig war, bei ihrer Auffahrt in dem Orinoko zu baden. Endlich kam bei einbrechender Nacht die Pirogue glücklich an, sie schiffen sich ein, und erreichten das Nachtlager auf der Insel Panumana, wo sie bei der Auffahrt Limonade gemacht hatten.

Den andern Tag schifften sie die Mission San Borja vorbei, und gelangten nach Carichana, wo sie der Missionär als alte Bekannte empfing. Hier gelang es Herrn Bonpland, eine neun Fufs lange Seekuh zu zergliedern. Es war ein weibliches Thier, dessen Fleisch dem Ochsenfleische glich. Die Piraoas. Indianer, wovon einige Familien in Carichana wohnten, verabscheuen dieses Thier so sehr, dafs sic 


\section{$-148$}

die Höhle verliefsen, um nichts davon berülıren zu müssen. Sie behaupten, dafs wer von ihrem Stamme davon essen würde, müfste unfehlbar sterben. Die. ses Vorurtheil ist um so auffallender, als ihre Nachbarn dasselbe Thier als einen Leckerbissen betrachten.

\section{nomomonomonos \\ Achtes Kapitel.}

Mission von Carichana. - Hission Uruana. - Die Otomalten oder Erdfresser.

Nach so grofsen Mühseligkeiten war unsern wifsbegierigen Forschern gewifs eine kleine Ruhe herzlich zu gönnen, allein Herr Bonpland, der den Iieim einer schweren Krankheit in sich trug, vermoclite nicht dem Tricbe zu widerstehen, in den schönen und reichen Wäldern und an den Flufsmündungen zu herborisiren, wo er dann des Tags mehr. mal bis auf die IIaut durchnâfst vvurde. Im Hause des Missionärs waren sie gut beherbergt. Sie fanden hier Maismehl und sogar Milclr. Die Kühe geben Überflufs in den niedern Gegenden der heifsen Zone, wo hinlängliche und gute Weide vorhanden ist. Man ist aber übrigens hier, wo ursprünglich kein Hornvich war, so gleichgültig gegen Milchspeisen, wie in China und Asien, das unter gleicher Breite liegt. Woher mag diese Gleichgültigkeit kommen? In Amerika liefse es sich erklären, aus der frühern $A b$ wesenteit des Hornviehs; aber nicht so leicht läfst 
es sich bei den Chinesen erklären, dic ursprünglich ein Hirtenvolk gewesen sind.

In zwei Tagen gelangten sie von Carichana nach der Mission Uruana. Diese Mission hat eine sehr malerische Lage, indem sic an einen Granitberg angelehnt ist. Aus dem Walde und über dem höch. sten Gipfel der Berge stelıen dic Granitsäulen, wie Pfeiler empor. Nirgend gewährt der Orinoko cin majestätischeres Ansehen. Seine Breite beträgt hier über 2600 Toisen, indem er seine Richtung gerade nach Osten nimmt, was ihm, da er hier nur einen Wasserspiegel bildet, das Ansehen eines Canals gibt, der von Giganten erbaut ist. Die Mission Uruana wird von Otomaken bewohnt, einem Völkerstamme, der sich vor andern durch Rohle eit auszeichnet, und eine der merkwürdigsten Erscheinungen darbietet.

Die Otomaken sind Erdfresser, d. h. sie verschlucken melirere Monate lang täglich sehr ansehnliche Portionen davon, um ibren Hunger zu stillen, und oline den geringsten Nachtheil für ihre Gesundheit daraus zu verspüren. Dieses ist eine unbestreitbare Thatsache. Herr von Humboldt sah in Uruana in den Hütten der Indianer dic Art der Bereitung die ser Erde, die gesammelten V'orräthe und die Portionen, welche innerhalb 24 Stunden verschluckt werden. Die Otomaken sind übrigens nicht das einzige Volk, welches am Orinoko Erde verspeist, auch bei den Guamas finden sich Spuren dieser ungewöhnnlichen Efslust, und zwischen dem Meta und A pure spricht man von der Geophagie oder Erd. 
esscrei, als einer von Alters her bekannten Thatsache.

Die Otomaken sind ein Volk der Savanen, welche für die Sittigung weniger, als die Völker der Wälder empfänglich sind, für Ackerbau wenig Sinn zeigen, und blos von der Jagd und dem Fischfange leben. Es sind häfsliche Menschen, aber von festem Kíörperbaue, wild, rachsüchtig und leidenschaftliche Liebhaber gegohrner Getränke. Sie sind im eigentlichsten Sinne: Allesfresser. Sie werden von den übrigen Indianern sogar als Wilde betrachtet, und es gebt die Sage, dafs es nichts Ekelhaftes gebe, das ein Otomake nicht esse. So lange die Gewässer des Orinoko niedrig stehen, mähren sie sich von Fischen und Schildkröten. Sie wissen die Fisclie schr geschickt mit Pfeilen zu durchbohren, sobald sie sich auf der Oberfläche des Wassers sehen lassen. Sobald jedoch das Steigen der Ströme, das man übrigens dem Schmelzen des Schnees zuschreibt, be. ginnt, so höret der Fischfang auf. Es hält dann eben so schwer, sich Fische zu verschaffen, als auf offener See, und den armen Missionären mangeln sie alsdann oftmals sogar für die Fastlage. Während dieser Überschwemmung nun, die zwei bis drei Monate dauert, verschlucken die Otomaken cine ungeheure Portion Erde. In ihren Hütten liegen Vorräthe aufgehäuft, die drei bis vier Fufs hohe Pyramiden bilden, in Kugeln von 5 bis 6 Zoll Durchmesser. Sie essen jedoch nicht jede Erde, sondern die, welche von ihnen gespeiset wird, besteht in 


\section{$-151$}

einem graugelben, sehr feinen, schmierigen Thon. Die Klööse werden etwas im Feuer gebraten und haben daher ein röthliches Aussehen. Sie wählen den Thon sorgfältig aus, und nehmen nur diejenigen Lager, welche den feinsten und schmierigsten Thon enthalten. Sie essen diese Erde nicht nur wäh. rend der nassen Jahreszeit, sondern mischen allen ihren Speisen etwas von dieser Thonerde bei. Dieses Erdeessen ist aber ihrer Gesundheit gar nicht nachtheilig, sie sind dabei im Gegentheile kräftig, und bekommen auch keinen aufgetriebenen harten Bauch davon. Man hat geglaubt, dafs sie dem Thone Schildkröten - und Krokodillenfett beimischen; es hat sich jedoch dieses keineswegs bestätigt.

Es sind aber nicht die Otomaken allein, wclche Erde essen, man trifft diese Neigung und Lust, einen fetten Thon zu essen, ziemlich allgemein in der heifsen Zone an. Man ist öfter den Kinderı die Hände fest zu binden oder sic einzusperren gez.wungen, um sie am Erdeessen zu hindern. Am Magdalenenstrome, im Dorfe Banco, hat Herr von Humboldt Weiber gesehen, die, wälirend sie Thongefäfse verfertigten, grofse Stücke dieses Materials verschlangen, mit der Behauptung: die Erde sey eine Speise, die gar keinen Nachtheil bringe. Auch in Afrika, an den Küsten von Guinea, speisen die Neger eine gelbe Erde, der sie den Namen Caouac geben. Die Sclaven, die nach Amerika gebracht werden, suchen sich denselben Genufs zu verschaffen; aber hier ist ihnen derselbe nachtheilig, ob. 
gleich sic sich selbst durch Peitschenhiebe nicht abhalten lassen. Sie sagen: $\triangleright$ die Erde auf den Antillen lasse sich nicht so gut verdauen, als die ihres eigenen Landes."

Aucb auf den asiatischen Inseln und besonders in Java ist das Erdeessen bekannt. Man verkauft daselbst lileine, viereckige, geröstete Thon-Brödchen, welche von den Landeseingebornen gerne gekauft und gegessen werden. Doch essen diese Speise hier meist die Weiber, welche dadurch mager werden. Es gibt noch eine Menge Beispiele aus andern Gegenden der heifsen Zone, dafs die Sucht, Erde zu essen, hei diesen Völkern allgemeine Neigung sey, und dafs sic damit den Hunger stillen, ohne daraus Nachtheile für ihre Gesundbeit zu verspüren. Es sind auch nicht einerlei Erden, welche genossen werden. Man nimmt dazu Kalk., Bitter- und ThonErden. In Deutschland selbst pflegen die Arbeiter in den Sandsteingruben des Kiffliäuser-Berges einen feinen Thon, welchen sie Steinbutter nennen, auf das Brot zu streichen, welchen sie für sehr nahrl.aft und leicht verdaulich halten. Endlich findet man selbst bei Thieren, „.B. bei den Ḱrokodillen und mehreren Vögeln, und selbst unsere zahmen Hausgeflügel, daf's sie mineralische Substanzen, und die Krokodille Granitstücke verschlingen.

Bis jetzt ist es jedoch der Chemie noch nicht gelungen, in allen diesen Erdarten eine Substanz zu entdecken, welche als nährend für den menschlichen Körper angenommen werden könnte. Es ist 
daher sehr schwer zu erklären, wie der Otomakc Monate lang Erde geniefst, ohne an Kraft oder Kürperumfang abzunchmen. Er scheint sich also wirklich von Erde zu nähren, und dieses ist eine Erfahrung, welche die Wissenschaft zu crklären bis jetzt durchaus unfähig ist.

Die Verwaltung der kleinen Mission Uruana gibt dem Missionär übrigens bei weiten mehr zu schaffen, als die übrigen Missionen. Die Otomaken sind ein unruhiges, lärmendes, von wilden Leidenschaften beherrschtes Volk. Sie sind dem übermäfsigen Genusse starker Getränke so sehr ergeben, dafs sie, um sich in cine Art Wuth zu versetzen, aus den Samenhülsen der Acacia Niopo ein Pulver bereiten, das eine Wahnsinn ähnliche Betäubung hervorbringt. Um das Narrenpulver $z u$ bereiten, zerhacken sic die erwähnten Hülsen und lassen sie angefeuchtet gähren. Wenn dic Masse schwarz wird, so kneten sie selbe zu einem Teige, und vermengen ihn mit Maniocmehl und einem aus Muscheln gebrannten Kalk, und lassen ihn bei ziemlicher Hitze auf einem Roste aus hartem Holze rösten. Wollen sie vor diesem Kuchen Gebrauch machen, d. h. närrisch werden, so pulverisiren sie denselben, streuen den Staub davon auf einen Teller, und ziehen ihn mittelst eines gabelförmigen Vogelknochens in die Nase. Es raubt ihnen nun für einige Stunden den Verstand, und die Ausschweifungen sind dann denjenigen eines europäischen Trunkenbolds sehr ähnlich. Wenn man die cben erwähnte Art sich zu be- 


\section{- 154}

rauschen bedenkt, wenn man sieht, wie viele Mühe sich der Otomake gibt, dieser wilde Erdfresser, der den Boden, welchen zu bebauen er zu dumm und zu faul ist, lieber auffrifst als bearbeitet; wenn, sage ich, man die raffinirte und fein gekünstelte Art betrachtet, wie er seines Verstandes, wenn auch nur auf einige Stunden, sich zu entledigen sucht: so liann man wirklich des Unwillens gegen sein eigen Geschlecht sich kaum erwehren. Hat denn der Mensch gar so vielen Überflufs der küstlichen Gabe Gottes, der Vernunft, dafs er nicht genug eilen kanń, um dieselbe los zu werden? Mit dem Aufwande von Nachdenken und Industric, welchen der Otomake darauf verwendet, sich unter das Vieh lıerab zu entwürdigen, würde derselbe auslangen, um durch Bebauung seines Bodens und Benützung der Geschenke der Vorsehung, sich nach und nach zum Überflusse cines gemächliclıen Lebens, zur Civilisation und eben dadurch zum Ebenbilde Gottes emporzuschwingen. So gewifs ist es, dafs mit der Hälfte Mühe und Vernunftaufwand, den wir machen, um uns in's Verderben zu stürzen, wir auslangen würden, um die glücklichsten Menschen zu werden. Wir bemitleiden den rolsen Otomaken seiner Entartung wegen; allein man blicke auf unser glänzendes Elend, wie wir das ganze Leben hindurch so geschäftig sind, uns eben dieses Leben sauer zu machen!

Übrigens sind es nicht die Otomaken allein, welche sich durch Schnupfpulver verunreinigen; am 
Amazonenstrome sind die Omaguas, gebildeter zwar, aber mit den Otomaken gleichen Ursprungs und gleicher Sitten. Beide gebrauchen das Niopo oder den Tabak, beide essen Erde, beide bedienen sich auch zu verschiedenen Zwecken des Caoutchouc oder der zerronnenen Milch der Euphorbien und Urticeen.

Was jedoch den Gebrauch des eigentlichen Ta. baks anlangt, so fand man ihn bei allen Völkern Amerika's überall, schon zur Zeit der Eroberung. Laster und Unarten vermehren sich, wie alles Unlraut; nur die Tugenden müssen, wie Weizen und Reben, gepflegt werden. Nach Europa kam übrigens die erste Tabakstaude, diese stinkende Giftpflanze, im Jahre 1559 , nicht aus Virginien oder Südamerika, sondern aus der mexikanischen Provinz Yucatan. Sir Walter Raleigh aber war es, der diese häfsliche Sitte des Tabakrauchens in England einführte. Auch dieses also eine Woblthat Englands! Camden sagt daher in seinen Annalen der Königinn Elisabeth 1585, Seite 145: $\rtimes$ Seit jener Zeit fing der Gebrauch des Tabaks an überhand zu nehmen in England und sehr in Werth zu kommen, da dic meisten den stinkenden (graveolentem) Rauch desselben mittelst eines beinernen Röhrchens einsaugen, und sogleich wieder durch die Nase von sich geben, so sebr, dafs die Körper der Engländer zum Naturel der Barbaren ausgeartet scheinen, da sie sich gleich den Barbaren ergötzen.»

Von den giftschnupfenden Trunkenbolden, den 
Oiomaken, erzählte der Missionär noch Folgendes: Wenn sie durch den Gebrauch des Niopo und der gegohrnen Getränke in einen melirere Tage andauernden Zustand von Trunkenheit versetzt sind, so bringen sie einander ohne Waffen um's Leben. Die bösartigsten unter ilınen vergiften sich den Nagel des Daumens mit Curare, und der blofse Eindruck des vergifteten Nagels kann tödtlich seyn, wenn das Gift recht kräftig ist, und der Blutmasse beigemisclit wird. Wenn die Indianer bei einem Streite nächtlicher Weile einen Mord begehen, so werfen sie die Leiche in einen Strom, damit keine Spuren der verübten Gewalt daran entdeckt werden mögen. So oft ich, sagte der Pater Bueno, die Weiber an einer ungewohnten Stelle des Ufers Wasser schöpfen sehe, so vermuthe ich, es sey ein Mord in meiner Mission vorgefallen.

In den Hütten der Indianer von so eben beschriebener Liebenswürdigkeit fanden die Reisenden auch den sogenannten Ameisenzunder. Er ist ein blutstillendes Mittel, und wird von so unfriedlichen Trunkenbolden natürlich sehr gesucht. Er ist das Nest der Formica spinicollis, einer neuen Art Ameise von smaragdgrüner Farbe. Sie sammelt sich in ihre Wohnung den zarten und fein anzufühlenden Flaum einer Melastome. Dieses Ameisennest ist viel zarter, als das Ameisennest von Cayenne, welche in unsern europäischen Spitälern gebraucht werden und sehr schwer $z u$ bekommen sind.

Sie nahmen jetzt Abschied von dem Pater Bueno. 
Es schien, als habe man hier absichtlich entgegengesetzte Extreme zusammengefügt. Der Pater Bueno war unter zehn Missionären, die sie angetroffen hatten, der Gebildetste und Vernünftigste. Er wufste das Verhältnifs der wilden Völker am gründlicbsten zu beurtheilen, und war einer der ordentlichsten und besten Mienschen, die man sich denken kann. Gerade ihm waren die Otomaken zu Theil geworden! Das ist nun einmal das Schicksal!

\section{Neuntes Kapitel.}

\section{Reise nach Angostura.}

Nachdem sie Uruana verlassen hatten, übernach. teten sie auf der Insel Cucuruparu, welche ebenfalls eíne Schildkröten-Insel ist. An der Ostseite befindet sich die Einmündung des Canno de la Tortuga, welcher von den Bergen von Cerbatana, die stets in Wolken gehült sind, herabkommt. Unfern von hier befindet sich die kleine, beinahe ganz zer. störte Mission San Miguel de la Tortuga. In der Nähe dieses kleinen Dörfleins befinden sich eine Menge Fischottern mit sehr feinem Haare, die von den Spaniern Wasserhunde genannt werden, und was noch merkwürdiger ist, zweifüfsige Eidechsen, vielleicht eine Siren lacertina. Aufser den ArauSchildkröten gibt es zwischen Uruana und Encara. mada am Orinoko auch noch eine Menge Landschildkröten, welche Morocoi heifsen. Die Thiere halten 
ich zur Zeit der Dürre und Hitze, ohne şNahrung einzunelumen, unter Steinen oder in selbstgegrabenen Löchern verborgen. Die Terekay thun dasselbe. Es ist dicses der Sommerschlaf der Thiere der heissen Zone. Die Eingebornen kennen die Löcher, vrorin mitten im ausgedorrten Lande dic Schildkrö. ten schlafen, und sie holen aus solchen, indem sic 15 bis 18 Zoll weit graben, oft eine grofse Anzahl nebst den Eiern hervor. Dieses ist jedoch nicht imner ohne Gefahr, denn nicht selten machen Schlan. gen mit den Schildkröten Gemeinschaft, indem sie sich mit einander vergraben.

Von dieser Insel sind 95 Meilen bis Angostura, zu denen man neun Scliffahrttage brauclit. Am 8. wa. ren sie wieder am Rio Apure, durch den sie zum ersien Male in den Orinoko eingefalıren waren. Dies. mal fuhren sie den Apure vorbei. Sie landeten, der Mündung des Apure gegenüber, bei dem Meierhofe San Rafael de Capuchina, der sehr malerisch gelegen ist. Wie kleine Inseln erheben sich Granitfelsen aus den weitläufigen Wiesengründen. Vom Gipfel dieser Granitklippen entdeckte das Auge die fernen Ebenen von Calabozo. Diese Steppe war nach einem so langen Aufenthalte in den Wäldern wieder neu und reizte die Phantasie mächtig auf. Die Steppe nahm bei Sonnenuntergang eine graulich grüne Farbe an; da aus ihr die Sterne, wie aus dem Weltmeere, aufsteigen, so war es, als ob sie an einem Vorgebirge in die weite See hinaussälien. Diese Täuschung war ganz vollkommen, Der Be. 
sitzer des Meierbofs war ein Franzose, hatte seine Sprache ganz vergessen, freuté sich aber dennoch, Menschen zu sehen, die aus seiner Heimath kamen. Seit 40 Jahren war er aus Frankreich entfernt und die Revolution war ihm ganz unbekannt geblieben. Wenige Meilen von diesem Meierhofe befinden sich die kleinen Städte Caycara und Cabruto. Die Überschwemmung macht den Meierlof zu einer Insel und schneidet alsdann denselben von der Gemeinschaft mit der Welt ab, das Rindvieh zieht sich sodann auf die kleinen Erhöhungen zurïck.

Endlich fing auch der Orinoko ein wenig belebt zu werden an; am 9. Juni sahen sie die ersten Piro. guen von Angostura heraufkominen, um, mit Kaufmannswaaren bcladen, in den Apure einzulaufen. Diese Wasserstrafse ist, was man in diesen Gegenden lebhaft nennen kann, denn es kommen vielc Fahrzeuge von Angostura und gehen in die Provinz Varinas nach Torunos. Hier trennte sich denn auch Herr Nicolaus Soto, der sie begleitet liatte, um in den Schoofs seiner Familie zurückzukehren.

Unterhalb San Rafael steht eine kleine Anzahl Häuser beisammen, welche den vornehmen Namen Villa führen. Alle zwischen der Mündung des A pure und Angostura gelegene Städte sind jetzt auch der. lei elende Nester. Sie heifsen : Alta Gratia, la Cividad de la Piedra, Real Corona, Borbon. Man pflegte in Madrid schon um den Titel einer Stadt nachzusuchen, wenn oft laum der Grund zu einer Kirche gelegt war. Man wollte damit das Ministe- 


\section{$-100$}

rium von den schnellen Fortschritten und dem Wohl. stande dieser Colonien überzeugen.

Nahe bei Caycara ist der Fels del Tyranno, so genannt von dem Eroberer Senndo. In diesen Fels sind die Bilder von Sonne und Mond eingehauen, von denen oben die Rede war. Es ist cine Arbeit der Alten, sagen die Eingebornen. Man behauptet, es finden sich auf einem vom Gesiade entfernten Felsen Decoma diese Bilder bis zu hundert Fufs Höbe. Vormals kannten die Indianer einen Land. reg, welcher von Caycara nach Demerare und Es. sequebo führte. Sollten vielleiclit auf diesem Wege die Völkerschaften, welche diese Bilder in den Felsen gruben, an den Amucu-See gelangt seyn? Und sind diese Zeichen am Ende dennoch das rohe Werk wilder Völker, welche damit iliren Jagdbezirk und die Richtung ihrer Wege und Wanderungen bezeich. weten? Religiösen $Z$ weck scheinen sie durchaus nicht zu haben, denn es gibt hier keinen Sterndienst; auch Cultur scheinen sie nicht zu verrathen, denn diese rohen Figuren brauchten nur Geduld und lange Weile, und diese haben die Waldmenschen im Überflusse.

Von Caycara gelangten sie der Einmündung des Cuchivero vorbei, wo die Amazonen gewohnt haben sollen, nach Alta Gratia, und weiter unten an den Ort, wo sich der Orinoko ostwärts dreht. Hier sind auf der rechten Seite ununterbrochene Wälder und die nackten Steppen von Venezuela zur Linken. Je mehr man sich der IIauptstadt nähert, desto mebr 
nimmt auch die Bevölkerung zu. Man trifft wenige Indianer, aber desto mehr Weifse, Neger und Menschen von gemischter Herkunft an. Die Zahl der Neger ist nur klein, und die Dürftigkeit ihrer Herrn bereitet ihnen ein trauriges und hartes Loos. Ein Bewohner von Caycara war erst vor kurzem zu vierjälrigem Gefängnisse und 100 Piaster Geldbufse verurtheilt worden, warum? - weil er vor kurzem im Zorne eine Negerinn mit den Jüfsen an den Schweif seines Pferdes gebunden, und im sclinellen Galopp durch die Savane zu Tode geschleift hatte: - Die Audiencia ward jedoch allgemein dafür getadelt, eine so gräuliche Frevelthat nicht schärfer bestraft zu haben. Es gab aber auch Personen, welche sich klüger dünkten, und die Bestrafung eines Menschenmörders als unlulug tadelten, weil sich die Neger in San Domingo damals im vollen Aufstande befanden.

Wo alte Vorurtheile und Casteneinrichtungen be. droht sind, fehlt es nie an solclien Leuten, welche rathen, auch in den unvernünftigsten Dingen nicht naclizugeben. Seitdem sind jedoch in diesen Ge. genden keine Sclaven melir. In Folge bürgerlicher Unruhen sind die Schwarzen bewaffnet worden, und viele traurige Erfahrungen lehrten die Sclavenherren es bereuen, den, vernünftigen Vorschlägen edler Mïnner nicht gehorcht zu haben, welche anriethen, keine Sclaven mehr einzubringen und den vorhandenen ein besseres Loos zu bereiten.

Am 10. Junius hatten sie mitten im Flusse über- 
nachtet, und kamen dann vor der Mündung des Ris Caura vorbei, der einer der bedeutendsten Zuflüsse des Orinoko ist. Nahe an der Einmündung des Flusses befanden sich mehrere christliche Niederlassungen, von denen jedoch die volkreichste auch nicht über 250 Seelen zählt. Auch ist hier San Luis, eine Colonie, theils freigelassener, theils flüchtiger Neger von Essequebo. Die Ufer des Rio Caura sind ausnehmend fruchtbar, auch finden sich daselbst Weiden für 15,00o Ochsen, aber die Bewohner haben Mangel an Hornvieh und $6 / 7$ des Bodens sind öde, und nur mit einigen wilden Stämmen besetzt. Auch der Rio Caura hat zwei Catarakten, die von Mura und Para. Letztere kann nicht befaliren werden, und es befindet sich anneben ein Landweg, worüber die Piroguen gewälzt werden. Man hat auch mehrere Missionen angelegt, die jedoch alle wieder eingegangen sind. Nalic an der Einmündung des Caura, zwischen den Dörfern San Pedro de Alcantara und San Francesko de Aripao, hat sich im Jahre 1790 in Folge eines Erdbebens durch einen Erdsturz ein See gebildet, der 400 Toisen Durchmesser hat. Es war ein Stück Wald, welches 80 bis 100 Fufs unter das Erdreich versank. Die Bäume blieben mehrere Monate grün, und man glaubte sogar, einige haben unter dem Wasser frische Blätter getricben. Es ist diese Thatsache um so merkwür. diger, als es vermuthlich granitischer Boden ist. Einst mag jedoch das schöne Thal von Caura sich 


\section{- 103}

durch seine Lage und seine Erzeugnisse in eine wichtige und reiche Gegend verwandeln.

Tiefer unten, zwischen den Städten la Piedra und Muniaco oder Real Corona, finden sich Wirbel und Strudel: der Torno und der Höllenschlund. Früher fürchtete man die Rapides, welche man jetzt ohne Anstand vorüberfährt. Mitten im Höllenschlunde landeten unsere Reisenden auf einer Insel die unter $67^{\circ}, 10^{\prime} 3 \mathrm{\imath}^{\prime \prime} \mathrm{W}$. L. sich befindet. Real Corona liegt unter $7^{\circ}, 59^{\prime} 20^{\prime \prime} \mathrm{N}$. Br. Sie übernachteten zu Mutiaco zum letzten Male im Freien; die Fahrt daucrte jedoch noch zwei Tage bis Angostura. Die Fabrt auf diesem Wege ist überaus sanft. Der Strom bewegt seine ungeheure Wassermasse still und majestätisch dem Meere entgegen. Man hat bei dieser Fahrt durchaus nichts zu befürchten, aufser die natürlichen Flöfse, von denen oben die Rede war.

Endlich sahen sie, rach vielenBeschwerden von meh. reren Monaten, Angostura vor sich. Mit einem un. beschreiblichen Gefühle naheten sie sich der Stadt, es war gleichsam aus einem wilden Elemente ein rettender Eintritt in die civilisirte Welt. Die Beschwerden hatten sich schon mehrere Tage zuvor vermindert. Man fand bessere Lebensmittel, und dic Mosquitos hatten nach und nach sich verloren. In 75 Tagen hatten sie fünt grofse Flüsse, den Apure, den Orinoko, den Atabapo, den Rio Negro und den Cassiquiare in einer Länge von 500 Meilen beschiffr. Nur selten hatten sie bewohnte Örter angetroffen. Ihr Anzug war nach solchen Beschwerden 


\section{$-\quad 104$}

wohl nicht zum Besten bestellt, sie säumten jedoch nicht, dem Statthalter Felipe de Ynciarte ilire Aufwartung zu machen. Er nahm sie mit vieler Zu. vorkommenheit auf, und wies ihnen bei dem Sekre. tär der Intendanz Wohnungen an.

"Nach einem Aufenthalte in fast völligen Einöden war uns «, sagt Herr von Humboldt, 》 die Regsamkeit einer kleinen, 6ooo Einwohner zählenden Stadt auffallend. Wir bewunderten die Menge Bequemlichkeiten, welche Industrie und Handel dem civilisir. ten Menschen gewähren. Einfache Wohnhäuser dünk. ten uns jetrt präcbtig, und alle Menschen, mit denen wir sprachen, kamen uns geistreicb vor. Lange Entbelıungen geben auch den kleinsten Geniissen Werth, und ich weifs das Vergnügen nicht auszudriicken, womit wir zum ersten Male Weizenbrot an der Tafel des Statthalters erscheinen salıen. Man schätzt sich glücklich, wieder unter civilisirten Menschen zu leben; doch mag diese Empfindung nur auf kurze Zeit diejenige der Wunderdinge, wodurch die Natur den heifsen Erdstrich ausgeschmückt hat, verdrängen. Das Andenken erlittener Bescliwerden verschwindet bald, und kaum auf den von Europäern bewolnten Küsten eingetroffen, geht man mit neuen Planen zur Rückkehr in das Binnen. land um. «

Ein sehr betrübter Zufall zwang sie jedoch einen ganzen Monat in Angostura \%u verweilen. Die ersten Tage sogleich fühlten sie Ermattung, und der Körper, welcher dem Schwunge des Geistes nach- 


\section{$-105$}

gegeben hatte, behauptete nun sein Recht. Fast am nämlichen Tage wurden beide durch das Fieber ihren Arbeiten entrissen, durch eine Krankheit, welche bei Herrn Bonpland sogleich den Charakter der Bösartigkeit annahm. Die Luft war jedoch damals in Angostura sebr gesund, und sie hatten daher den Keim der Krankheit in den nassen Gegenden des Cassiquiare gesammelt. Herr Bonpland, der sich rïcksichtloser und mit dem ganzen Feuer, welches seiner Nation eigen ist, dem Wetter und der Durcl.nässung ausgesetzt, und sich weniger geschont hatte, mufste nun auch das Meiste leiden, und schwebte schnell am Rande des Grabes. Der Mulatten-Bediente, der der Nässe am meisten ausgesetzt gewesen war, ward am neunten Tage für todt angesagt. Es war jedoch nur eine starke Obnmacht, auf welche Genesung folgte. Herrn von Humboldt wurde beim ersten Anfalle Honig mit dem Extracte der China von Carony (cortex Angosturae) gereicht, das Fieber ward auf dieses Mittel heftiger, aber am zweiten Tage war es gänzlich verschwunden. Herr Bonpland war jedoch mehrere Wochen in einem sehr bedenklichen Zustande, aber zum Glücke so sehr bei Bewufstseyn, dafs er sich selbst behandeln konnte. Er wurde, was in den Tropenländern fast allezeit der Fall ist, von der Rubr befallen, wodurch die Krankheit gefährlicher wurde. Herr Bonpland zeigte auch hier seinen gewöhnlichen Muth und eine Charakter.Milde, die ihn nie verlassen hat. Herr von IIumboldt machte jedoch betrübte Betrachtungen. 


\section{$-100$}

Unweit Angostura war Linne's Zögling, Löfling, gestorben, als Opfer seines Eifers für die Wissen. schaften. Herrn Bonpland konnte es eben so gehen, und fast reuete es Herrn von Humboldt, die nassen Wälder durchıühlt zu haben, und nicht lieber nach Neu. Granada gewandert zu seyn. Endlich milderte sich das Fieber, nachdem die Schmerzen der Ein. geweide nachgelassen hatten, und langsam schritt er der Genesung entgegen, wie dieses bei dem nicht acclimatisirten Europäer allezeit der Fall ist.

Sie mufsten daher, um die Wiedergenesung ab. zuwarten, bis 10.Juli in Angostura verweilen, weil es nicht rathsam war, früher in die Llannos sich zu wagen, zumal da die Regenzeit nahte und man in den Steppen oft nur auf gedörrtes Fleisch rech. nen durfte. Sie brachten demnach einen Theil der Zeit in einer Pflanzung zu, wo die Brotfrucht und der Mangohaum gezogen wurden. Die BrotfruchtBäume hatten hier in zehn Jahren schon 40 Fufs Höhe erreicht, und es gab Blätter von $3 \mathrm{Fufs}$ Länge und 18 Zoll Breite.

Angostura wurde seit Ende des sechzehnten Jahr. hunderts drei Mal gegründet. Die erste Stadt lag der Insel Faxardo gegenüber, beim Zusammenflusse des Carony und des Orinoko, und ward von den Holländern unter Anführung des Adrian Jahnson zerstört 1579. Die zweite war 12 Meilen östlicher gestiftet. Sie leistete kräftigen Widerstand, wurde aber von den Engländern unter Sir Walter Raleigh zerstört. Die dritte Stadt ist das gegenwärtige An- 


\section{$-107$}

gostura oder St. Thomas von Guiana. Die Gründung begann 1764 . Sie wird auch zum Unterschiede von der zweiten Stadt, welche auch die Festung oder Alt - Guiana heifst, in den Urkunden: Santo Thomé de nueva Guiana genannt. Weil jedoch dieser Name gar lang für eine Stadt ist, so wird sie auch nur Angostura, der Engpafs genannt.

Angostura lehnt sich an einen Hügel von Hornblende-Schiefer, der von aller Vegetation entblöfst ist. Mehrere Häuser sind auf Felsengrund erbaut. Man bält jedoch die schwarzen von der Sonne crhitzten Steinschichten sehr nachtheilig für die Gesundheit, obwohl es die hinter der Stadt befindlichen Pfützen mehr seyn möchten, die man fürchten sollte. Die Häuser sind hier hoch, schön und meist aus Steinen erbaut, welches beweist, dafs man Erdbeben nicht zu fürchten scheint. Diese Sicherheit ist aber leider nicht so fest begründet. Es erleiden zwar die Küsten von Venezuela sehr starke Erschütterungen, wie wir im ersten und zweiten Theile sattsam sahen, obne davon in Angostura etwas wahr. zunchmen. Die traurige Erschütterung Cumana's am 4. Februar 1797 ward hier nicht verspürt, aber das grofse Erdbeben von 1766, welches Cumana ebenfalls zerstört hatte, ward an beiden Ufern des Orinoko bis über die Catarakten von Maypures verspürt. Aus diesen und noch melhreren Thatsachen geht hervor, dafs man in. Angostura keineswegs gesichert ist vor einem Schicksale, welches die Städte des südlichen Amerika schon so oft beweint haben. 


\section{- 108}

Die Erschütterungen hahen ihren Herd tief im Innern der Erde, und pflanzen sieh fort durch Zerklüftungen, welchc ganz aufserhalb menschlieher Bereehnung liegen.

\section{nomansomonoss \\ Zehntes Kapitel.}

Umgebungen von Angostura, - Die Krokodille. - Die Mündung des Orinoko. - Das Steigen und Fallen der Ströme.

Die Umgebungen von Angostura sind ziemlich einförmig, aber der Anblick des Stromes ist erhaben. Er bildet einen grofsen Canal von Südwest nach Nordost. Die Regierung wollte die Breite des Stroms, der Vertheidigung wegen, hier genau kennen. Die Messungen, welche Herr von Humboldt anstellte, ergaben auf dem engsten Punkte 380 Toisen, was 4 bis $5 \mathrm{Mal}$ die Breite der Seine bei dem Pflanzengarten übertrifft. Dennoch ist dieses der Platz, welcher der Engpafs genannt wird, und wo der Wasserspiegel nur durch einen Felsen in der Mitte des Stromes unterbrochen wird, der bei hohem Wasserstande völlig verschwindet.

Wenn die Gewässer hoch sind, so überschwemmen sie die Quais, und man ist um diese Zeit in der Stadt selbst zur grölsten Vorsicht genöthigt, wenn man nicht von den Krokodillen in seinem eigenen Hause gefressen werden will, Eben, als unsere Freunde in Angostura verweilten, ward ein Guayquerier-Indianer von der Margarethen-Insel, 


\section{$-109$}

der in Begrife stand, seine Pirogue in einer Bucht zu befestigen, cin Opfer der Grausamkit dieser Reptilien. Ein sehr grofses Krrokodill, das sieh gewöhnlich in dieser Gegend aufhielt, paekte ihn beim Beine, entfernte sieh vom Ufer, und sehwamm ganz gemächlieh auf der Oberfäehe des Wassers mit ihm davon. Der arme Indianer schrie gewaltig, und eine Menge Menschen kam herbei gelaufen, unter ibrien auch Herr von Humboldt. Der unglückliche Menseh war entsehlossen, sein Leben zu vertheidigen, suchte in der Tasehe des Beinkleides naeh einem Messer, als er es nieht fand, ergriff er das Krokodill beim Kopfe, und drückte ihm die Finger in die Augen. Jedermann weifs in Amerika dieses Mittel, sich zu retten. Aber das Krokodill war ein alter Praeticus, und öffnete seinen Rachen nicht, um die Beute fahren zu lassen, sondern tauehte im Strome unter, ertränlite den Indianer, und kam sodann mit dem Leichname auf einer dem Hafen gegenüber liegenden Insel zum Vorscheine, wo es denselben rubig verzehrte.

Da das Lrrokodill, vermöge des Baues der Organe seines hachens, im Wasser seine Beute wohl haschen, aber nicht verschlingen kann, so geschieht es allezeit, dafs es einige Stunden nachber mit derselben in einiger Entfernung wieder zum Vorseheine lommt, um seine Mahlzeit zu halten. Diese Ereignisse sind bei weitem nieht so selten, als man denkt, und besonders in Europa glaubt. Unvorsiclitigkeit und die häufigen Überschwemmungen, welche diese 
bösen Gäste bis in die Dörfer führen, lassen jähr. lich viele Menschen die Opfer der Grausamkeit dieser Reptilien werden. Dieselben Krokodille balten sich gewöhnlich mehrere Jahre an demselben Orte auf, und sie werden von Jahr zu Jahr kühner, besonders wenn sie ein Mal Menschenfleisch gekostet haben. Sie sind auch so listig, dafs es schwer fällt, sie zu tödten. Der Schufs prallt an ihrem l'anzer $a b$, und tödtet nur, wenn Mund, Auge oder Ach-. selhöhle getroffen wird. Die Indianer greifen das Hrokodill mit Lanzen an, sobald es sich an einem eisernen Haken, woran Fleisch als Köder war, gefangen hat. Man nähert sich jedoch dem Thiere erst dann, wenn es von den Anstrengungen, sich los zu machen, ermüdet ist. Auch bei vorgerückter Civilisirung und Bevölkerung ist es eben so wenig, als in Egypten zu erwarten, dafs diese Unthicre ganz vertilgt werden. Das Flufslabyrinth liefert täglich neue Legionen dieser Eidechsen. Alles, was zu erwarten ist, dürfte darin bestehen, dafs sie mehr Respekt und Furcht vor dem Herrn der Erde bekommen, wenn dieser ilınen zu imponiren in Stande seyn wird.

Man erzählt rührende Geschicbten von afrikanischen Sclaven, die ihr Leben gewagt haben, um dasjenige ihrer Herren zu retten, welche in den Rachen der Krokodille gerathen waren. So geschah es vor wenigen Jahren zwischen Uritucu und der Provinz Abaxo, dafs ein Neger plötzlich vom Geschreie seines Herrn erschreckt wurde, der in den 
Rachen eines Krokodills gerathen war. Der Neger stürzte sich sogleich, mit seinem Machette bewaffnet, in den Strom, durch Eindrücken der Augen "wang er das Thier, seinen Raub fahren zu lassen, und sich unter das Wasser zu verbergen. Der Sclave brachte nun scinen Herrn schwimmend an's Ufer; es war jedoch vergebens, denn schon war ex im Wasser erstickt. Die Kinder des Verstorbenen schenkten, ob sie gleich arm waren, dem Sclaven seine Freiheit. Es sind überhaupt die Neger nicht so selten, als man glaubt, welche sich durch die treue Anhänglichkeit an ihre Gebieter auszeichnen.

Es läfst sich denken, dafs im einem Lande, wo der Mensch mit der Natur noch in immerwährendem Kampfe sich befindet, er auch stets gerüstet ist, diesen Gefahren nach Kräften zu begegnen. Es wird von ihnen stets gesprochen, und man theilt sich gegenseitig die Mafsregeln mit, welche Erfahrung bestätigt oder fremder Rath überliefert hat. Jedermann weifs daher von Jugend auf, wie er sich zu beneh. men hat, und da schwerlich in diesen Ländern eines Menschen Leben vorübergeht, ohne Gelegenheit diese Mittel anzuwenden, so findet man eine Uner. schrockenheit und den überlegtesten Muth, welcher in dem vor Gefahren gesicherten Europa nur Wenigen $\% u$ Theil wird. Nicht nur Mädchen aus der untersten Volksklasse, wie wir oben ein Beispiel gesehen haben, sondern Frauen aus dem ersten Stande der Gesellschaft sind mit diesen Gefahren und ihren Gegenmitteln vertraut. Es war am 4. Februar 1797, 
als 35,000 Indianer innerhalb wenigen Minuten durch Erdbeben ihr Leben einbürsten. Eine junge Dame hatte sich und ihre Kinder gerettet, indem sie diesen zurief: sie sollten die Arme ausstrecken, in dem Augenblicke, wo der aufgerissene Boden im Begriffe stand, sie zu verschlingen. Als man die Geistesgegenwart die. ser Frau bewunderte, sagte sie: "Schon als Kind ist mir gesagt worden, wenn das Erdbeben dich im Innern eines llauses überrascht, so stelle dicb un. ter eine Thüre, die aus einem Zimmer in das andere führt. Bist du im Freien und füllst du den Boden unter dir sich öffnen, so strecke deine beiden Arme aus, und suche dich an den Rändern der Spalten fest zu balten.« So steht der Mensch hier gegen die Wuth der Krokodille und das Toben der Elemente stets gerüstet.

Angostura liegt 2.5 Lieues vom Meere entfernt, oberhalb des Delta, welches die Mündung des Orinoko bildet. Die Fieber pflegen auch hier zu herrschen, und man spricht sehr oft, dafs es besser wäre, die Stadt wieder dem Meere näher zu legen. Diese Lage würde dem Handel bequemere Vortheile darbieten, denn dic Schiffe können nur sehır schwer bis an die jetzige Stadt hinauffalıren. Auch gewährt ibre jetzige Lage weder Schutz gegen die Feinde und Fieber, noch Bequemlichkeiten für den Handel.

Es ist schon gesagt, dafs die jetzige Hauptstadt von Guiana durch das Delta, welches der Orinoko bildet, getrennt wird. Grofse Flüsse baben nämlich die Gewobnheit, sich kurz vor ihren Einmür. 
dungen in das Meer in mehrere Arme zu theiler, zwischen den zwei äufsersten Armen aber Sand und Schlamm anzuhäufen, und zwischen diesem flachen Lande sich wieder zu verästeln und so eine grofse dreieckige Insel, die wieder in mehrere, oft unzählige kleine getheilt ist, zu bilden. Dieses ist es nun, was man Delta nennt; von dem Delta des Nil in Egypten, das durch seinen vormaligen Reichthume und seine grofse Fruchtbarkeit so berühmt ist. Dev Name liommt von der Gestalt $\Delta$, welches das grolse griechische D ist, und Delta heifst. Das Delta des Orinoko beginnt gleich unterhalb Angostura, und die zwei äufsersten Arme desselben laufen aus einander, so dafs ihre Entfernung beim Einflusse in's Meer 47 Seemeilen beträgt. Die Zahl der Ausmündungen zwischen diesen beiden ist noch unbelannt, und nach alter Gewohnheit gibt die Völkersage, so wie dem Nil und der Donau, also auch dem Orinoko sieben Mündungen. Es ist jedoch gewifs, dafs "wenigstens eilf bedeutende Ausfüsse gezählt werden müssen, ohne der Mlenge kleiner Verästelungen. Diese verschiedenen Ausmündungen haben verschie. dene Namen; Ausmündung heifst Bocca, und da findet sich denn die Bocca de Dragos oder die berüchtigten Drachenmúundungen, die in das Antillenmeer ausgehen. Die Bocca de Navios, die schiffbar ist, dann die ebenfalls für die Schiffahrt nützliche Bocea von Mariusas, von Macarco, von Pedernales und von Macamao grande.

Dieses Delta des Orinoko bildet jedoch keine 
wüsten Schotterinseln, es ist vielmehr ein frucht. bares und bebautes Sumpfland, überall mit Grïn bedeckt. Ganze Wälder der Mauritia-Palme bedecken die Inseln des Delta, und verschönern sie. Diese Mauritia oder der Lebensbaum der Missionäre ist der wohlthätige Baum, dessen wir schon öfter erwähnt haben; er ist der Sagobaum des Landes. Er liefert viel gutes und nahrhaftes Mehl, aus welchem das Yuruma-Brot bereitet wird. Zur Zeit des hohen Wasserstandes sehen diese Palmen nur mit dem Obertheile hervor, und scheinen in Was. ser gewachsene Wälder zu seyn. Auf diesen Palınen leben die Guaraonier, ein Völkerstamm, welcher auf Bäumen, gleich den Vögeln nistend, sich wic diese der Sclaverei der Spanier zu entziehen gewufst hat. Ihre Wohnungen hängen an den Bäumen, und man wird beim Durchfahren durch die Canäle des Delta sehr überraseht, wenn man die Gipfel der Bäume durch grofse Feuer beleuchtet sieht. Dicse Völker hängen nämlich grofse Matten an die Bäume, füllen sie mit Erde, und zünden hier ihre nöthigen Feuer an. Dieser Lebensweise verdanken diese Menschen seit Jahrhunderten ihre Freiheit und Unabhängigkeit. Sie allein sind auch im Stande, auf dem schlammigen Boden zur Zeit der Trockenheit ohne einzusinken fortzuwandeln. Diese Palmen, dieser weiche unsichere Grund, worauf sie gedeihen, ist ihr Erbtheil. Der Lebensbaum gewährt ihnen nicht nur Wohnung und Schutz, sondern Nahrung: in seinen schuppigen Früchten, in 
seinem mehligen Mark, und in seinem an Zuckerstoff so reichen Safte. Er gewälrt ihnen auch in den Fibern seiner Blattstiele Fascrn, um Matten und Seilc daraus zu verfertigen. So beruht das Daseyn einer ganzen Vülkerschaft auf einem einzigen Baume; gleichwie es Insekten gibt, die sich nur von einer Blume oder den einzclnen Thcilen eines Gewächses nälıren.

Der Orinoko hat endlicl mit allen Strömen der heifsen Zone auch das noch gemein, dafs seine Gcwässer in gewissen Perioden steigen und fallen. Das Stcigen und Fallen dieser Ströme kehrt jährlicb zur selben Zeit wicder. In Egypten ist dic ganze Cultur des Bodens, und man kann wohl sagen, die ganze Civilisation auf diesc Erscheinung gegründet gewesen. Sic mufste um so mehr auffallen, als der Nil in alten Zeiten der cinzige belannte Strom war, welchem dieser periodische Wasserwechsel cigen schien. In unscrn Tagen wissén wir, dafs alle Ströme der heifsen Zone diese Veränderung erlciden. Schon obcn erwähnten wir, wie die Erklärung dieser Erschcinung dadurch, dafs man das Schmelzen des Gebirgsehwees als Ursache des Steigens angibt, ganz unstatthaft sey. Denn erstens kommen diese Ströme nicht allezcit aus Schneealpen, und dann ist auch die Wassermasse zu grofs, als dals die jährliche Quántität des Schnees für sie hinreichend wäre. In der heifsen Zone läfst man sich solche Erklärungen gar nicht beikommen, die so frostig sind, als das Land, wo sie herkommen, und wo das beständige 


\section{$-\quad 170$}

Eis freilich oft eisige Gedanken erzeugt. Dort ist Jedermann die Ursache dieser Erscheinungen bekannt, und es verstehen selbst gemeine Leute den ganzen Verlauf dieser Erseheinungen auf das Genaueste zu berechnen.

Nach der Frülılings. Nachtgleiche kündigt näm. lich das Aufhören der Scewinde (Brise) die Regenz.eit an, und das Verhältnifs des Steigens der Flüsse steht mit der Masse des Regenwassers in genauer Verbindung. Die Überschwemmungen sind also durchaus blos Folgen des Aequinoctial-Regens. Herr von IHumboldt hat berechnet, dafs in den Wäldern vom Ober-Orinoko und Rio Negro der Ertrag der Aequinoctial-Regen 90 bis 100 Zoll betrage, eine Wassermasse, die mehr als hinreichend ist, ihre Abzugkanäle zu überfüllen. Der gewöhnliche Gang des Anwachsens des Orinoko ist folgender: Alsbald nach dem Frühlings-Aequinoctium (das Volk sagt am 25. März) wird das Steigen des Flusses wahrgenommen. Anfänglich beträgt das Stcigen in 24 Stunden nur einen Zoll. Er erreicht seine gröfste Höhe im Julius und bleibt vom Ende Juli bis 25. August in gleicher Höhe, wo er allgemach wieder zu sinken anfängt, jedoch langsamer, als er gewaclı. sen war. Seinen tiefsten Wasserstand erreicht er im Januar und Hornung.

Dieses ist ungefälır der Verlauf des Wasserstandes bei allen Strömen der heifsen Zone in beiden Hemisphären; der Ganges, der Niger und der Gam. bia erreichen mit dem Orinoko im August den höch- 


\section{$-177$}

sten Standpunkt; nur der Nil bleibt um zwei Monate zurück, es sey einiger örtlicher Umstände wegen, die in Abysinien zu suchen seyn würden, oder wegen der Länge seines Laufes. Die nordischen Erdbeschreiber behaupten jedoch, es steige der Nil in Hahesch und Senaar bereits im Monate April, ungefähr wie der Orinoko; in Cairo wird man es jedoch erst im Sommersolstitium gewahr. Die gröfste Höhe erreicht der Nil im September, und den niedrigsten Wasserstand im April und Mai.

In der südlichen Halbkugel haben die Ströme in den entgegengesetzten Jahreszeiten denselben Verlanf; der Amazonenstrom steigt, wenn der Orinoko fällt, und fällt, wenn dieser steigt. Die Höhe, zu wetcher der Orinoko ansteigt, wird von Herrn von Ilumboldt in Angostura zu zít und 25 Fufs angege. ben. Die Piloten nehmen für das gewöhnliche Steigen des Unter-Orinoko go Fufs an, andere geben es auf 13 Klafter an. Das Steigen des Nils beträgt in Ober-Egypten 30 bis $35 \mathrm{Fufs}$, in Cairo 23 und im nördlichen Theile des Delta 4 Fuís. In An. gostura könnte auf einem mitten im Strome gele. genen Felsen cben so ein Orinoko-Messer er. richtet werden, wie der Nilmesser auf der Insel Roudah ist. 


\section{$-\quad 178$ \\ Eilftes Kapitel.}

Das rechte Ufer des Orinoko. - Die Mission von Carony. El-Dorado. - Der Parime-See.

Unterhalb Angostura erweitert der Orinoko sein Bette abermals und erhält eine sehr grofse Breite. Dic beiden Ufer bieten jedoch sehr grofse Verschicdenheiten der Cultur den Reisenden dar. Auf dem linken oder nördlichen Ufer sieht man den ödesten Theil der Provinz Cumana vor sich, jene unbewohnten Steppen, welche sich gegen die Mesa oder Ebenc von Gtianipa ausdehnten. Das rechte oder südliche Ufer ist jedoch mit blühenden Missionen besetzt. Es sind dieses die Missionen von Carony, eines grossen, aus Süden kommenden Stromes, der sich in deı Orinoko ergiefst. Am Ufer des letzteren Flusses bestelien die drei volkreichen Missionen: San Miguel de Uriala, San Felix und San Joaquin. Las letztere Dorf, welches nicht weit von den Wasserfällen des Carony Flusses liegt, hält man für die Niederlage und den Hauptort der catalonischen Missionen. Auf der weitern Schiffahrt nach Osten, zwischen Angostura und den Mündungen des Carony, hat der Pilote viele Vorsicht nöthig, um die Felsen von Guarampo, die Untiefen von Mamo und die Ílippen von Rosario zu vermeiden. Die Landschaft zwischen dem Carony, dem Meere und dem Orincko ist übrigens der Theil Guianas, welcher die euro. päischen Ansicdler am meisten ansprechen wird. 
Die ganze Gegend war dazumal, als Herr von Humboldt da verweilte, mit Ausnahme zweier spanischer Dörfer, derVerwaltung der Missionär-Mönche unterworfen. Es waren beinahe 24,000 Eingeborne diesen Geistlicben unterworfen. Die Franziskaner hatten 7300 und die catalonischen Kapuziner 1700 unter sicl. Diese Missionen sind viel blühender, als die traurigen Missionen am Ober-Orinoko. Die ganze Provinz enthält 16,80o Geviertmeilen, und zwei Drittel ihrer Bewohner sind zwischen dem Rio Imataca und Angostura angesiedelt, auf einem Landstriche von 55 Meilen Länge und 3o Meilen Breite. Weifse Menschen dürfen in den Missionen nicht ansiedeln, und man sieht sie nicht ein Mal gern dahin kommen. Diese Gegenden liaben jedoch seit jener Zeit durch Bürgerliriege und Seuchen sehr viel gelitten. Damals, 1804, besafsen die catalonischen Kapuziner daselbst wenigstens 60,000 Stück Hornvieh, die in den Savanen weideten. Diese Savanen grenzen südostwärts an die englischen Besitzungen in Guiana oder die Colonie am Essequibo; längs den Gestaden von Pararagua und von Paraguamusi linauf berübren sie endlich die Besitzungen der Portugiesen am Rio Branco. Dieses ist eine schöne und offene Landschaft, voll schöner Savanen und ganz verschieden von derjenigen am Ober-Orinoko. Es stehen hier herrliche Wiesengründe, unterbrochen durch waldige Hügel, welche die prächtigsten Gegenden darbieten, und durch schöne Landschaften 
und licbliche Gegenden zum Anbaue einladen. Das Klima ist gesund. Der Cacao, der Reifs, die Baumwolle, der Indigo und der Zucker waclisen in Menge überall, wo der jungfräuliche Boden der Cultur unterworfen wird. Die ersten christlichen Niederlassungen gehen nicht über das Jahr 1721 hinauf. Die Bestandtheile der gegenwärtigen Bevölkerung sind die drei Indianerstämme der Guayanos, Cariben und Guaycas. Die Guaycas sind ein Gebirgsvolk, und ihr Wucbs ist nicht so klein, wie derjenige in Esmeralda. Sie sind schwer an bleibende Wohnsitze zu gewöhnen, und mehrere mit ihnen bevölkerte Mlissionen sind wicder zerstört worden, weil sie das freie Leben in den Bergen dem unter der Glocke vorzichen.

Die Guayanos sind leichter zu civilisiren, sanfter und geschmeidiger, als die Cariben. Die Jesuiten haben auch am Amaznnenstrome einen Guayanos-Stamm gefunden. Es ist jedoch schwer auszu. mitteln, ob diese beiden Stämme, die in so weiter Entfernung von einander angetroften werden, wirklich einem Volke angehören.

Die meisten und bevölkertsten Mlissionen sind auf einen Umfang von 460 Geviertmeilen beschränkt; oslwärts und südwärts sind die Savanen beinahe gar nicht bewohnt, und dennoch wäre zu wünschen, dafs die von den Flüssen entferntern Gegenden besser bewohnt würden, weil sie etwas höher liegen und darum auch gesünder sind. Der Flufs Carony 


\section{- 181}

liat cin sehr klares Wasser, nur wenig Fische und von der Stadt Barcellona an, gar keine Klippen. Oberhalb dieser Stadt jedoch schlängelt er sich zwischen zahllosen Kilippen und Felsen hin, und bildet Wirbel und Wasserfälle, zwischen denen sich nur die Cariben mit ihren kleinen Booten hindurch wa. gen. Der grofse Fall oder Salto befindet sich aber bei dem sehr schön gelegenen Dorfe Carony, dessen Bevölkerung darnals aus 700 Indianern bestand. Der Fall wird auf 15 bis $20 \mathrm{Fufs}$ geschätzt, er läfst jedoch einen Canal für die Piroguen frei, da hier der Flufs 300 Fufs Breite hat.

Die ganze südliche Landschaft wird von unab. lı̈̈ngigen Cariben durchschweift. Das sind die schwachen Überreste jeres schönen Ḱriegervolkes, das einst den Missionären so furchtbar geworden war, bis zum Jahre 133 und 35, wo der Bischof Gervais von Labrid, der Pater Lopez und mehrere andere Ordensınänner durch die Hand der Cariben um's Leben gekommen sind. Die Gefahren sind nun verschwunden, und die Regierung ist auf die Reste der Cariben, die noch unablıängig herumschweifen, nur des Schleichhandels wegen eifersüchtig, welchen sie so sehr mit den englischen und bolländischen Colonien der Nachbarschaft befördern. Sie entführen auch den Missionären das Vieh, und verlocken die neubekehrten Indianer in dic Wälder zurückzukel. ren. Früher nahmen die Cariben Antheil an dem Sclarenhandel, und dieser abscheuliche Handel ward 
durch die Weifsen befördert, welche die Stämme gegen einander reizten, und sie sogar bewaffneten, um durch sie ihre Brüder als Sclaven zu erhalten. Die Menschenjagd ward damals eben so betrieben an diesen Gestaden, wic man sie leider jetzt noch am Gambia betreibt, und in beiden Weltheilen haben sich die Europäer gleicher Arglist und gleicher Schandthaten schuldig gemacht.

Wir müssen hier noch unsern jungen Lesern von einer Pflanze erzählen, welche durch den Gewerbfleifs der thätigen Kapuziner berülımt geworden ist. Dies ist der Cuspare-Baum, dessen schon im zweiten Bändchen Erwähnung geschehen ist. Dieser bc. rühmte Baum ist es, der die Cortex Angosturae lie. fert. Er ist keine Cinchona oder Chinabaum, sondern eine eigene Gattung, die unter dem Namen Bonplandia in die Botanik aufgenommen ist und zur Familie der Meliaceen gehört. Die, von der wir hier reden, heifst die dreiblättrige oder Bonplandia trifoliata. Die sehr schönen Äste dieses heilsamen Baumes haben 8 Zoll lange Blätter, von überaus angenehmen Geruch. Dieser Baum trägt den ein. heimischen Namen Cascarilla, er wächst fünf bis sechs Meilen vom östlichen Ufer des Carony am Fufse der Hügel, welche die Missionen von Capapui, von Upata und Alta Gratia einfassen. Die CaribenIndianer gebrauchen den Aufgufs dieser Rinde als eine stärkende Arznei. Herr Bonpland hat ilın auch westivärts von Cumana im Mleerbusen von Santa Fe. 
cntdeckt, und wahrscheinlich kommt er auch in den Wäldern von Guiana vor.

Die catalonischen Kapuziner verfertigen von der Rinde einen Extrakt, welcher bekannter zu werden verdiente, und gegen Fieber und Ruhr überaus wirksam sich bezeigt. $\mathrm{Zu}$ bedauern ist, dafs der gewissenlose Ḱrämergeist auch dieses herrliche Arzneimittel verfälscht, und so gegen die Rinde von Angostura mit Recht mifstrauisch gemacht hat. Man hat statt ihrer öfters die falsche Angostura oder Angostura pseudo-ferruginea eingebracht. Sie wirkt stark auf die Nerven, verursacht heftige Anfälle von Starrkrampf, und entlält eine Substanz, welche dem Morphin und Strychnin, zwei heftigen Giften, sehr nahe verwandt ist. Diese Verfälschung hat mehrere Regierungen veranlafst, die Anwendung der Cortex Angosturae in der Medicin gänzlich zu untersagen. Solche nicderträchtige Verfälschungen, welche billig als die gröfsten Verbrechen geahnlet werden, kommen leider öfter vor, und erst vor kurzem fand man in Frankreich die Senesblätter mit andern giftigen Blättern vermischt, welche mehreren Personen den Tod brachten.

Der Baum, welcher die echte Cuspare oder Cas. carille licfert, kommt selten vor, und er verdiente daher von den fleifsigen Kapuziner. Mönchen in eigenen Pflanzungen gezogen zu werden. Die Kapuziner sind thätiger, als andere Mönche. Sie haben. in ilłren Dörfern Gärbereien und Baumwollspinne- 
reien, und wenn sie künftighin auch den Indianern die Früchte ihrer Arbeit zu Theil werden lassen, so dürften sie einen sehr wohtlhätigen Einflufs bekalten. Sic waren oft mit dem Statthalter und selbst mit dem Bischofe im Streite, welche ibre Macht einschränken wollten, und erwehrten sich stets des Einflusses der weltlichen Macht. 1768 liefs ihnen der Statthalter 20,00o Stück Vieh wegnehmen, und dieselben an die dürftigsten Einwohner vertheilen. Diese Gewaltthätigkeit hatte für den Statthalter üble Folgen, denn auf eingelegte Klage in Madrid ward er abgesetzt, ob er gleich viele Verdienste hatte, und seit jener Zeit hatte sich die weltliche Gewalt in die Regierung der Missionen jeder Ein. mischung enthalten. Die bürgerlichen Kriege haben jedoch auch hier grofse Veränderungen herrorgebracht, und alles mag jetzt eine andere Gestalt haben.

Die ganze Gegend ist aber eine der glücklichsten auf Erden, und wenn man früher hier goldene Städte und ein irdisches Paradies träumte, so dürfte wohl eine Zeit kommen, wo man sie auf diesem Platze nicht vergebens suchte. Diese Gegenden vereinigen die Vortheile der Thäler von Aragua mit denen der Steppen von Calabozo. Der Reichthum des Landes berubt auf Viehzucht und dem Anbaue der ColonialErzeugnisse. Es ist zu wünschen, dafs dię Bevölkerung wachse, sich dem Feldbaue getreu widme, und nicht zu frühe den Bergbau versuche. Es ver. 
trïgt sich wohl Berg- mit Landbau, wenn die Bevölkerung zahlreich ist, und der Landbau bereits in der Blüthe steht; im entgegengesetzten Falle kann der Bergbau leicht der Cultur des Landes Gefahr bringen. Der Rio Carony war es, an dessen Quellen man den Dorado-See, die Goldstadt und den vergoldeten Künig suchte, und leicht könnten diese Mythen den auri sacram famem (den heiligen Golddurst) der Bewohner erregen. Man hatte schon früher viel Geld an den Bergbau verschivendet, bis es sich zeigte, dafs die Schwefelkiese keine Spur des Goldes enthielten; allein noch immer heifst jedes glänzende Gestein in Guiana una madre del oro, dic Goldmutter. Die besten Goldminen sind ein gut angebautes Land, eine fleifsige Bevölkerung, Handel und Gewerbe begünstigt von einer guten und gerechten Regierung!

Nach diesen Erzählungen läfst Herr von Humboldt eine Abhandlung folgen, die sich sowohl mit dem Mährchen vom Goldlande und Goldkönige beschäftigt, als mit den Quellen des Orinoko und andern geographischen Einleitungen. Das Resultat ist, dafs zu den Goldminen wahrscheinlich die oben erwähnte Art sich zu schmücken Veranlassung gegeben hat, indem nämlich sich die Wilden mit Harz oder Schildkrötenfett bestreichen, und mit glänzenden Glimmerblättchen bedecken lassen, erhalten sie das Anseben von galonirten Kleidern und Goldtressen, und mögen von den goldgieri. 


\section{$-180$}

gen Europäern leicht für goldene Männer angesehen worden seyn.

Sowohl die Eroberer als ihre Naclfolger haben zur Entdeckung des El-Dorado die abenteuerlichsten Züge unternommen. Ihre von Begierde nach Gold erkrankte Phantasie liefs sie bald hier, bald dort den Goldsee, die Goldstadt und den Goldkönig sehen. Viele Ausrüstungen wurden unter den abenteuerliehsten Umständen unternommen, und endigten gewöhnlich mit dem Untergange der Theilnehmer. Das letzte dieser Abenteuer wurde noch $\mathbf{1 7 7 5}$ mit eben demselben Erfolge, wie die frühern, ausgeführt. Jetzt scheint man von dem Nicbtvorhandenseyn desselben überzeugt. Es war den raubsüchtigen Europäern nicht genug, die blühenden civilisirten Staaten auf den Hochebenen der Anden zerstört und verniehtet $z u$ haben. Sie waren mit dem Fluche der unterdrückten Völker nicht zufrieden; es war ihnen leid, nieht noeh mehr zerstören und die Blut. schuld vergiöfsern zu können.

Was die Quellen des Orinoko betrifft, so geht aus den Untersuchungen des Herrn von Humboldt hervor, dafs alle Angaben über dieselben, welche von den ältern Geographen gegeben wurden, theils Irrthümer, theils wirkliche Erdiehtungen sind. Eben so sind auch die Angaben der Orinoko-Quellen auf allen Charten unriehtig. Der sogenannte ParimeSee, der sogar auf den neuesten Charten zum Theil noch figurirt, ist $\mathrm{n}$ ir $\mathrm{g}$ end vorhanden, und gewifs 


\section{$-187$}

ist nur so viel, dafs die Quellen des Orinoko noch eines Entdeckers warten.

Um nieht durch Gegenstände, welche eine grössere Masse von Kenntnissen zu ihrer Würdigung fordern, als ich bei meinen Lesern voraus setzen darf, zu ermüden, setze ich nur die Schlufsworte des Herrn von Humboldt am Ende des achten Bu* ches her.

"Icli habe die drei Zonen durchwandert, die von Norden nach Süden, von dem Mittelmeere der Antillen bis an die Wälder am Ober.Orinoko und Amazonenstrome einander folgen. Dem fruchtbaren Küistenlande, welches der Mittelpunkt des landwirtl. sehaftlichen Reichthums ist, reihen sich die von Hirtenvölkern bewohnten Steppen an. Diese Step. pen hinwieder finden sich durch die Region der Wälder begrenzt, deren Bewohner im Genusse, ich will nicht sagen, der Freiheit (weil diese allezeit Folge der Civilisation ist), aber einer wilden Unabhängigkeit leben. Dic Grenze zwischen den beiden Jetztern Zonen war der Scliauplatz des Krieges, der über das Schicksal Amerika's entschied. Jieine Ver. änderung kann aber den Charakter des Landes ver. ändern, wenn auch die Sitten eine andere Gestal. tung erhalten. Diese Betrachtungen können das In. teresse für diese im Anfange dieses Jahrhunderts gemachte Reise nur steigern. Man findet in ihr die civilisirten Völker des Küstenlandes gemeinschaftlich und vercinigt dargestellt; mit jenen schwachen Über. 
resten der Landeseingebornen am Orinoko, die keinen andern Cultus kennen, als den der Naturkräfte, und die gleich sind den alten Germanen, von denen Tacitus sagt: Unter dem Namen der Götter verstehen sie dasjenige, was sie blos durch das Gefühl der Ehrfurcht sehen.ณ 

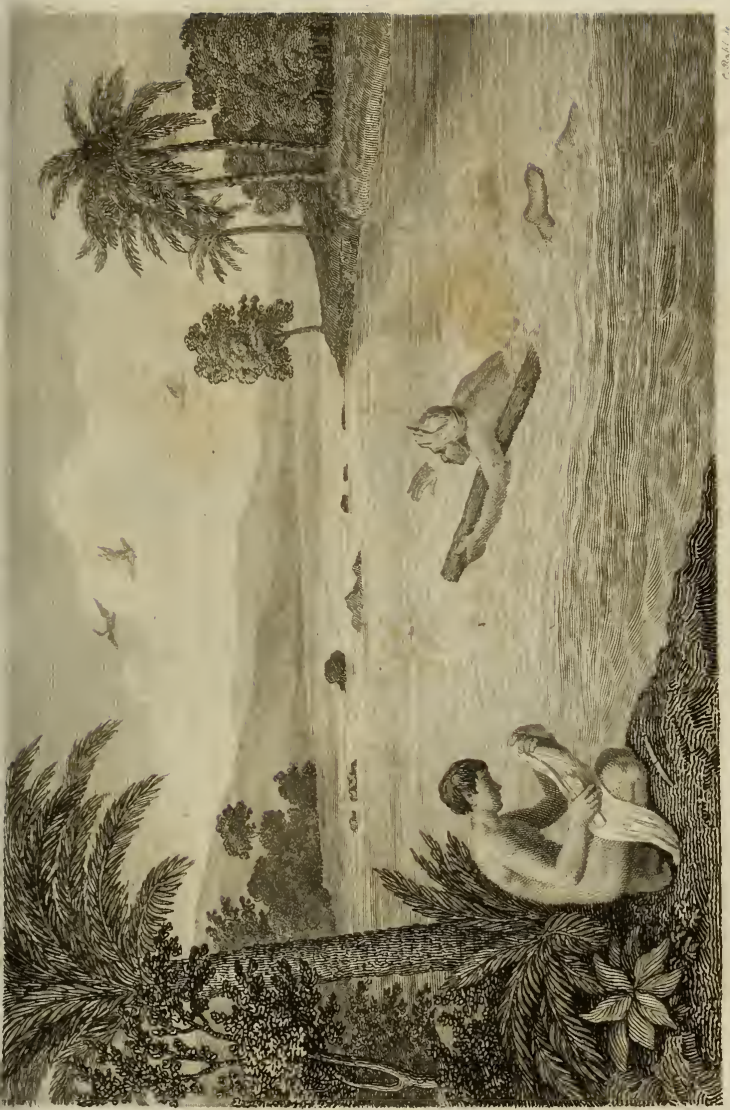

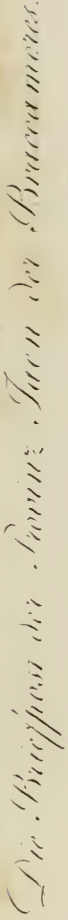





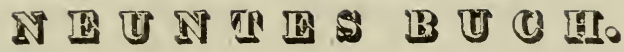

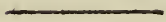





\section{Erstes Kapitel.}

Abreise von Angostura. - Die Mission der Cariben. - Historische Bemerkungen über die Völker Amerika's.

$\mathrm{E}_{\mathrm{s}}$

s waren nun beinahe sechs Wochen seit der Landung in Angostura verflossen, als endlich Herr Bonpland sich nun stark genug fühlte, die Reise fortsetzen zu können. Sie setzten daher über den Orinoko, um in der Nähe der Festung San Rafael zu übernachten, und mit Tagesanbruch die Wanderungen durch die Steppen von Venezuela anzutreten. Sie sehnten sich nun, die Küsten von $\mathrm{Cu}$ snana zu erreichen, um da ein Fahrzeug nach Cuba und von da nach Mexilso zu erlangen. Nach einer Monate lang dauernden Flufsfahrt in einem engen Boote, von Mosquitos umschwärmt, kam ihnen eine Seereise reizend vor. Indem sie nun vom Orinoko Abschied nahmen, gedachten sie nicht mehr nach Südamerika zurückzukehren, sondern ein Jahr in Neu-Spanien zu verweilen, und dann mit der Ga. lione von Acapulco nach den Philippinen zu gehen, die noch so wénig bekannt sind, und so die Rück. kehr nach Europa über Bassora und Alepo zu vol. lenden. Diese Plane verkürzten ihnen die Zeit während der Wanderung in den dürren Stepper. Am linken Ufer des Orinoko erwarteten sie schon 


\section{- 102}

die Maulthiere. Das Gepäcke hatte sich durch die Pflanzensammlungen und Mineralien ansehnlich ver. mehrt, und da es nicht rathsam ist, auf Reisen sich von seinem Gepäcke zu trennen, so mufste man ciner langsamen Reise durch die Steppen entgegensehen. Die Hitze war ausnehmend grofs, durch das Zurückprallen der Sonnenstrahlen von dein dürren Boden der Steppe. Der Thermometer stieg bei Tage nicht über $33^{\circ}$ bis $34^{\circ}$ und des Nachts nicht über $27^{\circ}$ bis $28^{\circ}$. Es ist also nicht die grofse llitze, als vielmehr ihre Dauer, welche beschwerlich fällt. Sie brauchten 13 Tage, um durch die Steppen zu wandern. Dieser östliche Theil der Llannos hat dasselbe wüste Aussehen, wie der westliclıe, der oben schon, bei Gelegenheit der Wanderung aus den Thälern Araguas nach San Fernando de Apure, beschrieben worden ist. In der trocknen Jahreszeit, die hier Sommer heifst, obwohl es eigentlich Win. ter ist, weil die Sonne in der südlichen Halbkugel weilt, weht hier die Brise (Seewind) heftiger, als in den westlichen Steppen. Diese Steppen bilden nämlich cin Becken, welches ostwärts gegen das Meer zu offen, aber westlich, nördlich und südlich von Bergketten umschlossen ist. Jetzt war jedoch die Regenzeit vorhanden, und die Brise welite nicht; ob gleich es in den Llannos nicht regnete, so liatte doch die veränderte Sonnenwende die Po. larströmungen gestillt. Hier geschieht alles mit der gröfsten Regelmäfsigkeit, so dafs man die Zeit der Veränderungen in der Atmosphäre mit der Sicher. 


\section{- 193}

lieit einer Uhr angeben kann. Die Ordnung ist einförmig, das Aufhören der Brise, der Eintritt der Regenzeit und die häufigen elektrischen Entladungen. Sie kehrten hier bei einem Franzosen ein, der aus Lyon gebürtig war, und ihnen mit der Liebensvürdigkeit, die seiner Nation eigen ist, Aufnahme und Nachtherberge zusagte. Er war eben beschäftigt, grolse Stücke Holz zusammen zu leimen. Er bediente sich dazu eines Pflanzenleimes, hier Guayca genannt, der dem besten Thierleim gleicht. Es ist dieser Lcim der Saft einer Liane. Er tropft, völlig zubereitet, in grofser Menge aus der Pflanze hervor, der man einige Seitenäste abschneidet. Dic Pflanze heifst hier Veyuco de Guayca. So findet sich in den Tropenländern völlig zubereitet und brauchbar, was man in unsern Ländern erst durch Kunst berciten mufs.

Am dritten Tage nach der Abreise von Angostura trafen sie in der Cariben-Mission von Cari ein. Hier war der Boden weniger zerspalten, als in den Llannos von Calabozo. Etliche Regengüsse waren gefallen und hatten die Gegend neu belebt. Sic fanden liier verschiedene Kräuter und grüne Rasen, so wie auch einzelne Stämme der Fächerpalme, Rho. pala und Malpighia mit glänzenden lederartigen Blättern. Wo feuchte Stellen sind, sicht man auch die Gruppen der schon oft gerühmten Mauritia - Pal. men, die eben jetzt mit ihren rothen schuppigen Früchten überladen waren. Die Affen in den Käfigen waren sehr lüstern darnach und machten die Bibl. naturh. Reison. IV. 


\section{- 194}

possierlichsten Sprünge. Die Ebene schien, ver. möge der Luftspiegelung, sich wie ein Meer in Wellen zu bewegen. Die Palmen schienen in der Ferne wie Masten der Schiffe, und vollenden die Täuschung, welche den Wanderer an die See versetzt.

Die Mission Cari gehört den Franziskanern des Collegiums von Piritu. Unsere Freunde wolnten, wic gewöhnlich, im Kloster, d. h. beim Pfarrer. Man kann ganz S̈̈damerika durchreisen, wenn man, wie diese Männer, mit Empfeblungsschreihen an die geistlichen Behörden ausgestattet ist. Der Pfarrer konnte nicht begreifen: "wie Leute aus dem europäischen Norden, von den brasilianischen Kü̈sten durch den Rio Negro und Orinoko und niclit vielmelır auf dem Küstenwege von Cumana bei ilım eintreffen künnten." $\mathrm{Er}$ war jedoch gastfrei, nur mufsten die gesammelten Mineralien Gold enthalten, und die gesammelten Pflanzen mufsten Arzneipflanzen seyn. Man weifs hier die $W$ issenschaften nur in so fern zu schätzen, als sie der Gesellschaft un. mittelbaren und in die Augen fallenden Nutzen gewähren. Dem einen ist sie eine himmlische Göttin, dem anderen eine tüchtige Kulh, die ibn mit Butter versorgt.

Im Dorfe Cari trafen sie über 500 Indianer vom Stamme der Cariben an. Dieses Volk, das erst vor Kurzem sich vom herumstreifenden Leben in feste Wohnsitze gefügt hat, unterscheidet sich durch körperliche und geistige Kraft von allen Indianera. 
Nirgend lann man einen Stamm schönerer und colossalischer gebildeter Männer sehen; sie sind alle 5 Fufs 6 Zoll und 5 Fuls 10 Zoll hoch. Die Männer sind, wie dies in Amerika allgemein der Fall ist, mehr bekleidet, als die Weiber. Diese tragen nämlich nur das Guajuco, einen schmalen, oft kaum 3 Zoll breiten Leibgürtel, die Männer sind hingegen bis an die Hüfte mit einem schwarzblauen, grofsen Stücke Tuch bekleidet, womit sie an kühlen Abenden auch ibre Achseln bedecken. Ihren Körper bemalen sie mit dem im dritten Theile beschriebenen Onoto, und so sehen ibre grofsen Gestalten, dic malerisch drapirt und roth bemalen sind, bronzenen Statuen gleich. Der Haarschnitt der Männer ist für dieses Volk bezeichnend, er ist dem der Mönche und Chorlnaben auf das genaueste ähnlicl. Die Stirne wird rasirt, wodurch sie roth erscheint. Ein grofser Haarbüschel ist kreisförmig ausgeschnitten auf dem Scheitel. Diese Art, die Haare zu be. schneiden, ist nicht etwa eine Nachahmung der Mönche, um ihnen gleich zu seben, sondern es war diese Art, die Haare zu verschneiden, ihnen schon eigentlü̈mlich, bevor noch Europäer die neue Welt betraten. Sie unterschieden sich schon dazumal durch diese Art die Haare zu verschneiden. Die Männer des Cariben-Volkes unterscheiden sich auf das Vortheilhafteste von allen Eingebornen, sowohl durch schönen Wuchs, als die Regelmäfsigkeit ilurer Züge. Sie haben keine so breite und platte Nase, keine so hervorstehenden Backenknoclien und über- 


\section{$-190-$}

liaupt kein mongolisches A ussehen. Ihre Augen sind. schwärzer und ausdrucksvoller, als bei den übri. gen Stämmen von Guiana. Das Färben der Augen. hraunen, so wie die. Sucht, sich schwarze Flecken. in das Gesicht zu malen, gibt ihnen ein wildes und lkriegerisches Aussehen. Die Weiber sind weniger schön, und sind mehr dic Lastthiere der Männer, indem sie alle Haus. und Feldarbeit allein besorgen müssen. Sie baten sehr dringend um Stecknadeln, und befestigten dieselben an den Unterlippen, und durchstechen damit die Haut so, dafs der Kopf der Nadel in der Mundhöhle bleibt. Sie liaben diese Gewolınlieit noch aus dem wilden Zustande beibehalten. Die jungen Mädchen sind mit Onoto be. malt, und den Guajuco ausgenommen, völlig nackt. Es zeigt sich auch bei dem Begriffe der Nacktlyeit. dieselbe Beweglichkeit der. Begriffe, welche den Menschen überall charalterisirt. In einigen Gegenden Asien's würde der Wohlstand auf das Schreck. lichste verletzt werden, wenn auch nur die Fingerspitzen einer Frau aus den Gewändern lervorbliclsten, während die Caribin sich keineswegs für nackt hält, wenn sie nur ein zwei Zoll breites Guajuco um. gibr,und die Haut mit Onoto bemalt ist. Ersteres ist jedoch nicht so nothwendig, um in guter Caribischer Gesellschaft zu erscheinen, als letzteres; denn die Hütte verlassen, ohne mit Onoto bemalt zu seyn, würde gegen allen Caribischen Wohlstand verstofsen. Es kamen die Vorsteher der Gemeinde, die Go. vernador und Alcaldes, um den Fremden ihre Auf- 
merlisamkeit $z u$ bezeugen. Sie haben allein das Recht, lange Rohre zu tragen. Es fanden sich unter ilhnen Jünglinge von achtzehn bis zwanzig Jahren, da ihre Wahl blos von dem Willen des Missionärs abhängt. Dieses mit Onoto bemalte diplomatische Caribencorps benahm sich mit demselben Ernste und abgemessener Feicrlichkeit, wie nur immer in Europa. Diese Indianer waren vor der Ankunft der Europäer das mächtigste Volk im östlichen Theile Amerika's. Sie waren kriegerisch, handeltreibend und erobernd. Sie hatten eine ansehnliche Flotte und spielten überall die Herren, wo sie hinkamen. Selbst die Europäer empfanden ihre furchtbare Macht bis in die neucre Zeit. Der Schrecken vor dem Namen Caribe ist selbst bis jetzt noch nicht ganz aus den Gliedern der Weifsen verschwunden. Es ist. wohl keinem $\mathrm{Z}_{\text {weifel }}$ unterworfen, dafs ohne die Dazwischenkunft der weifsen Cariben, die rothei in ihrer Cultur fortgeschritten, und für die Amerikaner dasselbe geworden wären, was die Römer in der alten Welt waren.

Úberall am Orinoko erinnert man sich noch der Einfälle der Cariben. Diese Einfälle erstreckten sich von den Quellen des Carony und Erevato bis an die Gestade des Ventuari, Atacari und des Rio Negro. Auch ibre Sprache war eine von denen, die in die. sem Welttheile sich am meisten verbreitet hatte. Unter den unzähligen Völkerschaften (Herr von Humboldt führt 200 davon namentlich auf), die im östlichen Amerika zerstreut sind, haben die Cariben 
vorzugsweise eine einflufsreiche Rolle gespielt. Thre Geschichte ist jedoch nicht vorhanden. Grofse Reiche und wahrhafte Staaten haben sich bis zur Eroberung nur auf den westlichen Hochgebirgen eingerichtet. Mexiko war eine grofse Monarchie von Freistaaten umgeben. In Cundinamarca und in Peru fanden sich eigentliche Theokratien, Priesterstaaten, mit befestigten Städten, Strafsen und grofsen steinernen Denkmälern, das Feudal-System und die Casteneinrichtung, Männer - und Frauenklöster, strenge Ordensbrüderschaften. Mit allem diesen war auch die Zeiteintheilung verbunden, welche den Kalendern, Thierkreisen und der Astrologie der Asiaten nicht unähnlich war. Alle diese Einrichtungeen wurden in Amerika jedoch nur auf einer Strecke vom $30^{\circ}$ N. B. bis $25^{\circ} \mathrm{S}$. B. längs einer $\mathrm{Alpenregion} \mathrm{gefunden.}$ So wie in der alten Welt in der Richtung von Osten nach Westen mehrere Völker auf einander bald biidend, bald verwiistend folgten, so geschah es auch in Amerika in der Richtung von Norden nach Süden. Auch hier waren die Gebirge die Leiter; aber sie haben auf die Civilisation einen bei weitem gröfsern Einflufs geübt, als das Hochgebirg Europa's auf das Schicksal der Völker gehabt hat.

Mitten in den Ebenen des nördlichen Amerika hat ein mächtiges Volk, das nicht mehr vorhanden ist, kreisförmige, vier - und achteckige Festungsverke angelegt; Mauern erbaut, die 6000 Toisen lang sind; Grabhügel errichtet, die 700 bis 800 Fufs Durchmesser und 140 Fufs Höhe haben. Sie 
sind theils rund, haben melirere Stockwerke und enthalten Tausende von Beingerippen, die ciner weniger schlanken und mehr untersetzten Völkerschaft angehören, als die ist, welche jetzt noch diese Gegenden bewohnen. Andere Gerippe, welche in Tüeher gelıüllt sind, die denen der SüdseeInsulaner gleiehen, findet man in natürlichen Grotten, im Staate Kentuky. Man weifs nieht mehr, was aus den Völkern geworden ist, die ehemals Luisiana bewohnt haben; dic jetzigen Indianer daselbst behaupten eine asiatische Abkunft, und ihr ganzes W'esen verräth den Mongolen. Auch in Süc. amerika trifft man aufgeworfene Hügel an, nirgends sind sie aber denen am Obio ähnlich; aber man findet dafür mit Symbolen bedeckte Granitfelsen, denen am Orinoko gleich. Auf den westwärts gelegenen Cordilleren scheint zwischen Mexiko und Cundinamarca keine Verbindung Statt gefunden zu haben, aber die Cariben tragen die $Z$ üge fremden Ursprunges an sich.

\section{monomonomoses \\ Z w e it e s $K$ a p it e l.}

Bemerkungen über die Cariben.

Bei den Cariben sind Uberlicferungen und Sagen vorhanden, welche auf eine vormalige Verbindung der Völker beider Amerika's hindeuten, und darum verdient dieses Volk besondere Aufmerksamkeit. Wie grofs auch die Verwilderung aller Völker, die 


\section{- 200}

nicht auf den Anden wohnten, gewesen seyn mag, so scheinen doch alle ibren Sagen und Überlicferungen, Trümmer eines grofsen Schiffbruchs zu seyn, den Völker erlitten haben, die bereits die ersten Stufen der Civilisation erstiegen hatten.

Gegenwärtig bewohnt die schöne Nation der Cariben nur einen kleinen Theil der zur Zeit der Eroberung Amerika's von ihr bewohnten Landschaften. Die durch Europäer verübten Grausamkeiten haben dieses Volk von den Antillen und von den Íüsten von Darien gänzlich vertrieben. Es hat sich der Herrschaft der Missionäre unterworfen, und bildet nun zahlreiche Dörfer in den Provinzen von Neu - Barcellona und Guiana. Die Anzahl derer, welche in den Llannos von Piritu an den Gestaden des Carony und Cuyuni Yeben, kann füglich auf 35,00o berechnet werden. $\mathrm{Zu}$ diesen kommen noch die westwärts der cayennischen Gebirge lebenden unabhängigen Cariben, mit welchen man annehmen kann, dafs hier noch ein Stamm von 40,00o Cariben von reiner, unvermischter Art lebe. Dieses ist um so wichtiger, weil man von den Cariben, als einem erloschenen Stamme gesprochen hat. Man glaubte nänlich, die klcinen Antillen scyen die einzigen Wolnsitze der Cariben gewesen, und es seyen von diesen nur noch versteinerte Knochen auf den kleinen Antillen vorhanden, die Nation selbst aber, wie die Guanchen der Canarien, verschwunden.

Alle Caribenstämme, die einem Volke angehören, bezeichnen sich auch nit demselben Namen. Der 
Name Caribe kommt aus der Verstümmlung des Wortes Calina und Caripuna. Es ist selır merkwürdig, dafs dieser Name, den Columbus aus dem Munde der Völker auf der Insel S. Domingo hörte, siclı auch auf den Festlande zur Bezeichnung derselben Völkerschaft wieder findet. A us Carina oder Calina ist Galibi oder Caribi geworden, ein Name, den man in Guiana einer Völkerschaft am Cari gibt, die kleiner als die Cariben, doch dieselbe Sprache reden. Die Inselbewohner dieser Völkerschaft werden in der Sprache der Männer Calinago, in der der Weiber aber Callipinan genannt. Bei den Stämmen der Cariben findet man die Eigenheit der Sprá. che auf das deutlichste vorherrschen, dafs die beiden Geschlechter eine verschiedene Sprache haben, die zivar beide verstelien, deren sich jedoch nur der Theil bedient, dem sie von Geschlechts wegen zukommit. Diese Sonderbarkeit findet sich bei mehreren Völkern, auch der alten Welt, wo dic Weiber eine vor den Männern gleichsam abgesonderte Lehensweise führen. Die Weiber hängen daun fester an gewissen Redensarten. Nirgend ist dieser Umstand jedoch so überraschend, wie bei den Cariben. Der Grund mag in der mehreren kriegerischen Völkern gemeinsamen Gewolnbeit liegen, bei feindlichen Einfällen die Männer alle zu tödten, die Weiber aber fortzuführen. Schon Cicero bemerkt, dafs die Weiber an gewissen Redensarten fester hängen. Die Cariben machten nämlich öfters Einfälle auf den Antillen, tödteten die Männer, und verbanden sich 


\section{- 202}

mit den Weibern, wodurch denn natürlich fremde Worte und Redensarten in die Weibersprache kamen. Allein, welche Sprache muls das seyn, deren Reste man in der Weibersprache findet? Es läfst sich nichts mit Gewifsheit bestimmen.

Aufser dem Namen Cariben wurde ihnen auch der Name Cannibalen beigelegt, und Cariben und Cannibalen ist bei den frühern Schriftstellern ganz gleich bedeutend. Diese Namen bedeuten überhaupt : Íraft, Geistesstärke, Weisheit, und nicht, wie man gewöhnlich glaubt, Menschenfresser. Man weifs, dafs zur Zeit der Eroberung die Zauberer der Brasilianer auch Cariben genannt wurden, und Herr von Humboldt meint, ob dieses reiselustige Volk nicht dieselbe Rolle gespielt habe, wie die Caldäer in der alten Welt ?

Es fragt sich nun, wo die Cannibalen urspriing. lich einheimisch waren, ob auf dem festen Lande oder auf den Inseln. Sie selbst erzählen Folgendes: Die kleinen Antillen seyen vormals von Aruacas bewohnt gewesen, einer kriegerischen Nation, deren Reste heut zu Tage noch das ungesunde Land von Surinam bewohnen. Diese Aruacas sollen nun auf den Antillen, mit Ausnahme der Weiber, von den Mündungen des Orinoko kommenden Cariben vertilgt worden seyn. Sie führen für diese Meinung dic Sprachähnlichkeit der Cariben und der Aruacas an. Allein die Aruacas gehören zu dem. selben Volke, wie die Cariben, ob sie gleich Feinde sind, und ibre Sprachen sind mit einander so ver. 


\section{- 203}

wandt, wie die Griechische und Persische, dic Deutsche und das Sanskrit. Nach einer andern Sage sind die Cariben von den Aruacas vertrieben worden. Eine dritte, und zwar die wahrscheinlichste Sage läfst die Cariben aus Nordamerika, und zwar aus Florida kommen. Der Reisende Bristok behauptet, alles gesammelt zu haben, was auf ihren Ursprung Bezug hat, und erzählt: ein Stamm der Confachiten habe lange Zeit mit den Apalachiben Kírieg gefübrt, diese hätten sodann demselben einen Distrikt von Cumana zum Wohnplatze abgetreten, und ihre neuen Bundesgenossen, Caraiben, d. i. tapfere Fremdlinge, genannt. In Folge sey jedocb zwischen illnen, der Religion wegen, Streit entstanden, und so wären die Caraiben wieder aus Florida vertrieben worden. Flüchtig kamen sie sodann nach den bermudischen Inseln, und sodann nach den kleinen Antillen, endlich seyen sie wieder nach dem Festlande übergeschifft. Man glaubt, dafs diese Wanderung zwischen dem eilften und zwölften Jahrhun. derte unserer Zeitrechnung Statt gefunden babe. Während diesen Wanderungen haben die Caraiben niemals die grofsen Antillen berührt, deren Bewol. ner übrigens ihren Ursprung aus Florida herleiten. Nach dem Zeugnisse der Eroberer waren die Be. wohner der grofsen Antillen von den Caraiben ganz verschieden. (Washington Jrving, im Leben des Columbus, erwähnt sehr oft des Cariben-Häuptlings Caonabo, der als Eroberer auf der Insel San Domingo wohnte, und mitten unter den Seinigerr 


\section{- 201}

gefangen, auf dem Schiffe des Columbus sein Leben endete.)

Da die Cariben zu herrschen seit langer Zeit gewohnt waren, so ist es ganz natürlich, dafs das Gefühl ihrer frühern Gröfse ihnen einen Nationalstolz, eine Überlegenheit eingeflöfst hat, der in ihren Manieren und Reden sich gemeinschaftlich kund gibt. y Wir allein nur, wir bilden ein Volk, die andern Menschen sind nur da, um uns zu bedienen.« Gegen ihre alten Feinde, die Cabren, hegen sic entschiedene Feindschaft. Herr von Humboldt sah ein Kind, als es Cabre genannt wurde, in die gröfste Wuth über diesen Schimpf gerathen. Dennoch hatte dieses Kind noch nie einen Menschen dieser Nation gesehen, von der die Stadt Cabruta ihren Namen hat, und die von den Cariben fast ganz vertilgt worden ist. Es ist übrigens eine allgemeine Eigenheit der Menschen, National-Namen besiegter Völker als Schimpfnamen zu betrachten.

Der Missionär führte die Reisenden nun in mehrere Hütten, in welchen die gröfste Ordnung und Reinlichkeit herrschte. Sie sahen hier mit Wehmutb die unvernünftigen Qualen, welchen Mütter ihre Kinder von dem zartesten Alter an unterwarfen, und mit welchen sie die Fleischmassen an den Beinen, von den Knöcheln bis zum Oberschenkel zu vergröfsern bemüht sind. Bandstreifen von Leder oder Baumwollenzeug werden in einer Entfernung von zwei zu zwei Zoll fester und fester um die Beine gewunden, und dadurch die Muskeln in 


\section{$-205$}

den Zwischenräumen fester angetrieben und zum Schwellen gebracht. Obwohl auch unsere Kinder in ihren Wickeln und Binden sehr viel leiden, so ist doch das nichts gegen die der Cariben, welche doch dem Naturzustande noch so nahe sind. Die Missionäre können gegen diese thörichte Angewohnheit nichts ausrichten, denn so sehr man von der Einfachheit der Naturmenschen fabelt, gibt es nicht leicht ein Geschöpf, welehes hartnäckiger an seinen auf Schmuck und Schönheit und Woblanstand sich beziehenden Gebräuchen hinge, als eben diese so. genannten Natur-Menschen. Übrigens scheint die Muskelkraft unter dieser unsinnigen Behandlung gar nicht zu leiden, denn es gibt kein Volk, welches kräftiger und zum schnellen Laufe mehr geeignet wäre, als die Cariben.

Ein übler Gebrauch, der früher allgemein war, ist bei den Cariben - Müttern dennoch abgekommen. Wenn schon die Beine wellenfürmig gezogen wer. den, so pflegen doch die Mission-Cariben- Weiber der Llannos ihren Kindern die Köpfe zwischen Bretern und Kissen nicht mehr platt zu drüeken, wie solches früher der Fali war. Die Cariben haben daher sehön gebildete Köpfe mit hohen Stirnen. In mehreren europäiscben Werken findet man ganz platt gedrückte Schädel abgebildet, diese sind künstliche Schädel alter Cariben. Was man für Caribische Sehädel von St. Vincent ausgibt, und welehe fast gar keine Stirne haben, sind nichts anders, als zwisehen Hölzern plattgedrüekte Schädel der Zam. 


\section{$-200$}

bos, welche von Negern und Cariben abstamnicn. Man findet die Gewohnheit, die Schädel zusammen zu drücken, bei vielen Völkern ganz verschiedener Abstammung. Sogar in nördlichen Amerika hat man sie angetroffen. Gleiche Sitten und Fehler deuten jedoch nicht auf gleiche Abkunft hin, aufser man steigt zum Grofsvater Adam hinauf.

Wir kommen nun noch auf ein Gerïcht, welches die Cariben anlangt. Die Haut schaudert dem Europäer bei dem Namen Cannibalen. Denkt man sich ein Volk derselben, so zucken die europäischen Nerven, indem sie schon den $Z$ ahn derselben $z u$ fühlen glauben. Kommt man nun mit Herrn von Humboldt in dieses Land der Cariben oder Cannibalen, und sicht man hier nun ein schönes, reinliches, arbeitsames Volk, das so ruhig unter dem Glockenschalle lebt, so kann man es wohl kaum glauben, dafs dieses dieselben Menschenfresser seyn sollten, von denen uns unsere Ammen und selbst unsere Lehrer so grausenhafte Geschichten zu er. zählen wufsten. Anghiera sagt in seiner dem Papste Leo X. gewidmeten Reise : " die das Fleisch der Menschen essen, sind neue Menschenfresser, die wir Cariben nennen, welche Cannibalen genannt wer. den." Es läfst sich gar nicht zweifeln, dafs die Ca. riben, als sie auf den Inseln Sieger waren, sich mehr Grausamkeit gegen die Besiegten zu Schulden kommen liefsen, wie alle Sieger. Allein gewifs ist, dafs die Europäer diese Grausamkeiten auch übertrieben haben, indem sie dadurch einen Vorwand 


\section{$-207$}

zu erhalten meinten, ihre cignen zu rechtfertigen. Was nun das Menschenfleisch essen betrifft, so versichern alle Missionäre am Carony, wie am Nieder. Orinoko, cinstimmig, dafs unter allen Nationen von Guiana, die Cariben. Nation diejenige sey, welche am wenigsten geneigt ist, Menschenfleisch zu essen. Dieses ist nach ihrer Versicherung sogar mit den unabhängigen Nationen der Fall.

Zu dem Rufe ihrer Wildheit mag wohl folgender Umstand beigetragen haben. Als Menschenfresser angegeben, erging wider sie 1504 ein Dekret vom Köonige von Spanien, welches sie zu Sclaven erklärte. Sie vertheidigten sich nun als Helden, mit einer Erbitterung, wie nur ein Volk äufsert, das alles zu verlieren hat. Schon Christoph Columbus, der keineswegs so sanft und menschlich war, wie man ihn aus Hals gegen scine Feinde schildert, gab den ersten Gedanken an, gegen diesen Volksstamm zu wüthen, der ihm der gefährlichste schien, weil er der tapferste war. Später, 1520, ward der Licentiat Figuero beauftragt, ein Verzeichnifs der Völker Südamerika's zu machen, die man $z u$ den caraibischen oder cannibalischen zählen könne, oder, welche zu den friedlichen Bundesgenossen oder Guatios gehörten! Dieses Dekret ist eines der merkwürdigsten Aktenstücke zurn Belege der Grausamkeit der ersten Eroberer. Hier bezcichnete man alle, von denen man vorgab, dafs sie nach der Schlacht Menschenfleisch genossen hätten, als Ca. raiben oder Cannibalen. Sie alle waren nun der 


\section{$-208$}

Sclaverei preisgegeben, man konnte gegen sie den Vertilgungskrieg führen. In diesen blutigen Kriegen wiederholte sich nun, was früher unsere tapfern Vorältern gegen die Römer in Anwendung brach. ten. Man sahe nach dem Tode der Männer die Weiber sich mit so verzweiflungsvoller Wuth vertheidigen, dafs man sie für ein Amazonenvolk halten mufste.

Es gab Dominikaner - Mönche, welche die Drangsale durch ihre Deklamationen gegen diese armen Völker verlängerten, wie es Thomas Hortiz that; aber bei weitem mehrere erhoben ihre Stimme zu Gunsten der Menschheit. Besonders waren es Mönche und Religiosen, die, wie es sich für Clristen. priester ziemte, sich gegen weltlichen Eigennutz der seufzenden Völker annahmen, und sich in Opposition gegen das grausame Verfahren setzten. Gomarra sagt: 》Es ist ein heiliges Gesetz, durch welches der Kaiser verbietet, die Indianer zu Sclaven zu machen. Es ist gerecht, dafs alle Menschen, welche frei zur Welt kommen, es auch bleiben, und dafs keiner des andern Sclave sey."

Von der Fähigkeit der Indianer, an ihre Lands. leute Reden zu halten, sehen wir besonders die Cariben Beispiele geben. Herr von Humboldt sah 18 bis 2ojährige Jünglinge, welche die Stelle eines Fiskals in der Mission verwalteten, wie sie lange Re. den voll Kraft und Ausdruck hielten, und der Missionär versicherte, dafs diese Reden klar, deutlich und ohne allen Schwulst seyen. Der Missionär pre. 


\section{- 209}

digte sogar caraibisch. Alles zeigt, dafs es ein Volk sey, das für Cultur sehr empfänglich ist. An Festtagen versammelt sich die ganze Gemeinde vor der Kirche. Junge Mädchen legen alsdann Büschel voin Brennholz, Mais, Pisangzweige und andere Lehensmittel, deren der Haushalt bedarf, dem Missionär zu Füfsen. Gleichzeitig verrichten der Gouvernador, Fiskal und Municipal-Beamte ihr Amt. Sie sind alle Cariben, ermahnen die Indianer zum Fleifse und Arbeit, ordnen die Geschäfte für die Woche, geben den Trägen Verweise und züchtigen die Ungehorsamen, oftmals mit viel Grausamkeit. Stockschläge werden mit gleicher Unempfindlichkeit ausgetheilt und empfangen. Wenn der Reisende von Angostura kommt, so sieht er die Schläge schr häufig und in starken Portionen austbeilen, und zwar an Männer und Weiber ohne Unterschied. Es scheint einigermafsen den Wohlstand zu verletzen, dafs die Missionäre solche Züchtigungen, sogleich wenn sie aus der Hirche hommen und noch im vollen Ornate sind, vornehmen lassen; oder ist es vielleicht das beste Mittel, den Predigten Nachdruck zu geben? Es ist übrigens begreiflich, dafs unter Cariben, die zu civilisiren sind, solche handgreifliche Beweise mitunter zur Erhaltung der Ordnung und des Gehorsams nothwendig seyn mögen, so sehr sich im Menschen gegen das Schlagen der Menschen ein gewisses Gefühl empört.

Die wilden Cariben leben zwischen den Quellen des Orinoko, in einer Art Bundesgesellschaft. Sie 
sondern sich stolz von allen andern Stämmen ab, und fordern aucl in den Missionen, dafs man sie nicht vermische. Die wilden Cariben stehen unter Häuptlingen, deren Ansehen sich von dem Vater auf den Sohn forterbt. Der junge Caribe, welcher sich verehelichen will, wird allerlei Vorbereitungen unterworfen. Er mufs fasten. Man gibt ihm die Frucht einiger Euphorbien zum Abfülıren, er wird in den Schwitzkasten eingeschlossen, und mufs Arzneien verschlucken, welche die Marirris oder Piachis bereiten. Die Marirris sind die be. rühmtesten unter allen: Priester, Gaukler und Heilkünstler zugleich. Sie überliefern einander ihre Lehren, Íünste und Arzneien. Die Arzneien werden allezeit mit Händeauflegungen, gelıeimnifsvollen Geberden und Ceremonien begleitet, welches dem Magnetisiren gleichkommt. Herr von Humboldt konnte nicht ausmitteln, ob diese Cariben-Priester eine eigene Caste ausmachten. In Nordamerika nimmt man wahr, dafs die Priester (Shavanoes) allezeit aus einem Stamme genommen werden. Auch die Inkas der Peruaner waren Priesterkönige, und nannten sich Söhne der Sonne. So waren auch bei den Natchez Sonnenlönige, wie die ältesten Heliaden bei den Rhodiern.

Es ist der Mübe werth, die Cariben genau zu kennen; die Missionäre behaupten von ilınen, dafs je näher man sie kennen lernt, je mehr auch die Vorurtheile schwinden, welche man in Europa gegen sie gefafst hat. 


\section{$-211$}

\section{Drittes Kapitel.}

Abreise von Cari, - Villa del Pao. - Reise nach Neu-Barcellona. -. Betrachtungen über die Steppen.

Als sie von Cari abreisen wollten, weigerten sich die indianischen Maulthiertreiber, Maulthiere für das Gepäcke unserer Freunde herzugeben. Die Ux: sache haben wir schon im vorigen Buche erwähnt. Sie hatten nämlich, trotz aller Sorgfalt, die Gr. beine der Höhle von Ataruipe gerochen; denn nichts entgeht dem Scharfsinne des Cariben. Trotz aller Versicherung des Gegentheils, behaupteten sie fest, es wären die Gebeine ihrer Vorfahren, und das Maulthier, welches damit beladen würde, müfste unfelslbar damit zu Grunde gehen. Es bedurfte der ganzen Gewalt des Missionärs, um dic Indianer dahin zu bringen, Thiere herzugeben, und die Reisenden wciter zu schaffen.

Der Rio Cari wurde in einem Boote übersetzt, und ein anderer Flufs durchschwommen. Der bewegliche Sand des Grundes machte den Übergang beschwerlich, besonders da der Flufs sehr reifsend ist, was in einer so grofsen Ebene, wo dic Flüsse so wenig Fall haben, befremden mufs. Ls hat jedoch schon Plinius beim Clitumnus die Bemerkung gemacht, dafs der schnelle Fall nicht von der Nei. gung des Flusses, sondern vielmehr von der Menge und gleichsam von dem eigenen Gewichte des Was. sers abhängig sey.

Bevor sie das Städtcben Pao erreichten, hatten 
sie zwei eben so schlechte Nachtlager, wie im Neicrhofe zum Caiman auf der Reise nach Calabozo; nämlich in Matagorda und Riecitos. Sie trafen überall gleichförmige Hütten aus Rohr und Thierfellen, berittene, mit Lanzen bewaffnete Männer, die ihre Heerden hüten; halbıvilde, einfärbige Rindviehheerden, welche die Weide mit Pferden und Maulthieren theilten. Weder Schafe noch Ziegen werden auf diesen unermefslichen Steppen gefunden. In den Tropenländern Amerika's gedeihen die Schafe nur auf einer Höhe von tausend Toisen, wo keine Jaguare diesen kleinen $W$ iederkäuern gefährlich werden können. Denn da sie gar keine Waffen haben, so werden selbst zahlreiche Heerden durch Katzen vertilgt.

Am 15. Juli trafen sie nun in der Villa Pao ein, welche 1744 gegründet wurde, und zum Verkehre $z$ wischen Neu.Barcellona und Angostura recht glücklich gelegen ist. Sie liegt unter $8^{\circ}, 37^{\prime} 57^{\prime \prime}$ N. Br. und $67^{\circ}, 8^{\prime} 12^{\prime \prime} \mathrm{W}$. L. In den Umgebungen von Pao werden, was hier eine Seltenheit ist, einige Obstbäume angetroffen, und sogar Cocospalmen, die trotz ihrer weiten Entfernung vom Meere, dennoch ein recht gesundes und kräftiges Aussehen hatten. Hiernach ist es auch begreiflich, wie selbst zu Tombuktu, mitten in Afrika, Cocosbäume anzutreffen seyen.' Herr von Humboldt sah noch öfter, hundert Meilen von den Küsten, mitten in den Pflanzungen am Magdalenenstrome, schöne Co. cospalmen. 
In fünf langweiligen Tagreisen gelangten sie von Villa del Pao nach Neu-Barcellona. Je mehr sie sich dieser Stadt nälıerten, desto heiterer wurde der Himmel, der Boden staubiger, die Hitze brennender. Sie durclizogen auch das Dorf Santa Cruz de Cachipo, welches eine kleine Cariben-Mis. sion mit ungefähr 500 Seclen ist. Dieses Dörfchen liegt auf einem kleinen Plateau, das unter dem Namen Messa de Amana bekannt ist. Sie bildet die Wasserscheide zwischen dem Orinoko, dem Quaropiclse und dem Küstenlande von Neu-Andalusien. Die Erhühung dieses.Plateau ist jedoch unbedeutend. Dic Cariben wohnten frülıer meistens zwischen dic. ser Messa und dem nördlichen Küstenlande, wurden jedoch ilırer feindlichen Einfälle wegen, durch den Statthalter von Cumana 1720 nach den Gestaden des Unter - Orinoko vertrieben.

Die ganze Ebene, ein Raum von $\mathbf{7 2 0 0}$ Gèviertmeilen, besteht aus Secondarformation; der rothe Sandstein mit Überresten von fossilem Holze liegt allentlialben zu Tage, bis er weiter östlich von Kalk und Gypsformationen bedeckt ist. "Diese unermefs. lichen Ebenen würden sich auch vortrefflich eignen, um Meridiangrade zu messen, und zwar viel besser, als alle die Gegenden auf dem.Plateau der Cordil. leren, in Norwegen und überall, wo man bisher noch solche Messungen vorgenommen hat. Solcbe Messungen der Meridiangrade gewähren für Wissenschaft und Leben die gröfsten Vortheile. Für dic Wissenschaft dienen sic zur Erforschung der un- 


\section{- 214}

gleichen Abplattungen des Erdkürpers und anderer Eigenschaften unsers Planeten; für das Leben zur Verfertigung der Charten, die für die Regierung eines jeden Landes von so grofser Wichtigkeit sind.

Das Dorf Santa Cruz, wo sie den 16. Juli übernachteten, ist, wie schon gesagt, eine Cariben-Mission. Sie wohnten beim Missionär, und die Einsicht in die Kirchenregister überzeugte sie auch hier von dem schnellen Wachsthume des Wohlstandes, der durch dic Einsicht und den Eifer des Missionärs sehr befördert wurde. Die Hitze hatte in den Steppen einen so hohen Grad erreicht, und die Nächte waren so schön, dafs die Reisenden gerne die Nächte zu ihren Reisen benutzt hätten. Dieses war jedoch der vielen Räuberbanden wegen unmöglich, besonders da sie unbewaffnet waren. Die Ebenen waren mit Räuberschwärmen erfüllt, und sie mordeten besonders alle Weifsen, die ihnen in die Hände fielen, mit unerhörter Grausamkeit. Die Rechtspflege war unerhört schlecht. Allenthalben waren die Gcfängnisse mit Missethätern angefüllt, über die erst nach sechs bis acht Jahren ein Urtheil gefällt wird. Vielen darunter gelingt es sich durch Flucht zu befreien, und die menschenleeren Llannos gewälren ibnen Sicherheit und Nahrung. Sie treiben ihr Räubergewerbe, wie die Beduinen, beritten. Die Gefängnisse sind sehr ungesund, und diese Ungesundheit würde alle wegraffen, wenn sie sich nicht durch die Flucht retteten. Schon oben haben wir gehört, dafs selbst das nach langem Zügern von der Audiencia 


\section{- 215}

zu Caracas gefällte Todesurtheil aus Mangel eines Scharfrichters nicht vollzogen werden konnte, wo dem dann Gnade ertheilt wird, der die Hinrichtung der übrigen Verurtheilten übernimmt.

Die Führer erzählten Herrn von Humboldt, dafs lurze Zeit vor ihrer Ankunft in Amerika ein Zambo, welcher durch besondere Riohheit und Entartung ausgezeichnet war, den Entschlufs gefafst labe, sich durch Übernahne des Henkergeschäfts der Strafe zu entziehen. Als er jedoch die Zurüstungen zu den Hinrichtungen sah, wurde sein Entschlufs erschüttert; er entsetzte sich über sich selbst, und zog den Tod dem Übermafse der Schande vor, die dureh cine solche Lebensrettung ihn treffen mufste. Er bat, dafs man ihm die bereits abgenommenen Ketten wieder anlegen möge. Seine Haft dauerte jedoch nicht mehr lange, wcil die Niederträchtigkcit eines Mitschuldigen die Vollzielung seiner Strafe bewirkte. Ein solches Erwachen der Seele eines Mörders ist eine Sache, die das Nachdenken des Psy. ehologen verdient. Derselbe Mensch, welcher als Raubmörder der Reisenden in der Steppe oftmals Blut vergossen hatte, schauderte vor dem Gedanken zurück, sich zum Werkzeuge der Gerechtigkeit zu machen, und eine Sirafe an Andern zu vollziehen; die er selbst verdient zu haben fühlt. Er, der un elenden Raub willen mordete, will lieber sein Le. ben verlieren, als das Blut seiner Mitverbrecher vergiefsen. Ist dieses nicht die instinlitmäfsige Ge. ralt des Gewissens? 


\section{$-210$}

Wenn jedoch die Llannos schon in friedlichen Zeiten, in welchen Herr von Humboldt und Bonpland dieselben besuchten, die Zufluchtsstätten der Missethäter gewesen waren, dic irgend ein Verbrechen in den Missionen am Orinoko begangen oder aus den Gefängnissen sich geflüchtet hatten, wic ınag es da wohl in diesen Steppen jetat beschaffen seyn, wo sie der Schauplatz der Bürgerliriege geworden sind? Die ungeheure Ausdelinung des Raumes gewährt dem Flüchtigen Straflosigkeit. Man verbirgt sich leichter in den Savanen, als in unsern Wäldern, und alle die Kunstgriffe einer curopäischen Polizei scheitern da, wo es zwar Reisende gibt, aber leine Strafsen; Heerden, aber keine Hirten, und die Meiereien so vereinzelt sind, dafs man, trotz der Luftspiegelung, ganze Tage reisen kann, oline auch nur eine einzige im Horizonte zu erblicken.

Herr von Humboldt wirft nun die so äufserst in. teressante Frage auf: ob es der Cultur wohl jemals gelingen wïrde, diese ungeheuren Steppen und Ebenen der menschlichen Cultur zu unterwerfen, oder ob sie immer zu nichts andern, als Viehweiden verwendet werden könnten? Jetzt sind sie wahre Hindernisse des Fortschreitens des Ackerbaues und mit diesem auch der Civilisation. Sie hindern den Ackerbau, sich von Venezuela nach Guiana und von Potosi aus sich Buenos-Ayres zu nähern. Die Steppenbewohner sind immer und überall roher, als dicjenigen, welche urbares Land bewohnen. Aus 


\section{$-\quad 217$}

demselben Grunde geschieht es aber auch, dafs der Irrieg sich gern in die Ebene zieht. Auch bei den Unabhängigkeits. Kriegen waren die Llannos und dic Pampas der Schauplatz der sich bekriegenden Parteien, und die Einwohner von Calabozo haben beinahe vor ihren Mauern das Schicksal Columbien's entscheiden gesehen. Die Steppen sind daher für das Land selbst von dèr gröfsten Wichtigkeit. Von Hriegsheeren werden dieselben mit der gröfsten Leichtigkeit durchzogen, indem diese allenthalben einen grofsen Überflufs an Pferden und Hornvieh, mithin an Transport und Lebensmitteln antreffen.

Nirgends findet man aber auch verschiedenartige Eigenschaften des Bodens und Kilima so nahe beisammen. Die Gebirge sind kalt bis zum ewigen Schnee, die Ebenen heifs. Daher der Unterschied der Tieras calientes und der Tieras fria, deren Bewohner verschieden sind an Sitten, Cultur und Neigung. Diese Gegensätze werden jedoch nur sehr langsam verschwinden, und Jahrhunderte werden vorübergehen, bis die Wälder Guianas gelichtet werden. Die Natur setzt lier mächtige Hindernisse entgegen, und selbst die schwer zu lüftenden Wälder werden leichter menschlicher Gewalt weichen, als die Steppen sich dem Ackerbaue unterwerfen. Was in den vereinigten Staaten so schnell vor sich gegangen ist, wird hier nicht so leicht gelingen. Die gut bewässerten Savanen Nord-Amerika's werden von den Steppen Süd - Aınerika's an Ausdehnung, Trockenheit und Dürre bei weitem übertroffen. Bibl. naturh. Reisen. IV. 
Schon die Wälder Guianas sind schwer anzubaueu, weil die Baumstämme, von 8 bis 10 Fufs Durchmesser, unter der Axt nur schwer fallen, ein ausneh. mend hartes Holz von dem ewigen Regen besitzen, und selbst mit dem Beile gefällt, sich an andere Baumstämme anhängen, und durch die Schlingpflanzen gleiclisam schwebend erhalten werden. Ncch schwerer dürfte jedoch der allgemeine Anbau der Llannos werden. Übrigens zweifeln die Colonisten nicht, dals es gelingen werde, auch die Ebenen dem Ackerbaue zu unternerfen. Die Hindernisse sind freilich grofs, allein die wenigen Flüsse können zur künstlichen Bewässerung benutzt werden, ihre grofse Ausdehnung kann dureh eine grofse Volksmenge; ihre Unfruchtbarkeit durch den. Fleifs derselben überwunden werden. Jetzt ist freilich noch nicht. an ihre Urbarmachung zu denken; indessen haben Versuche um Calabozo und Pao berviesen, dafs der Boden keineswegs ungeneigt sey, Bäume hervorzu. bringen. Überall, wo Gebüsche von Mauritia-Palmen stehen, ist auch fruchtbares Erdreich, und wenn es gewifs ist, dafs dieses Buschwerk den feuch. ten Stellen sein Daseyn verdankt, so ist nichts desto weniger eben so gewifs, dafs die Bäume die fruchtbaren Oasen vergröfsern. helfen, in einem Lande, das seine Pflanzendecke durch eine uns unbekannte Catastrophe verloren. hat. Jetzt ist es freilich der. Fall, dafs diejenigen Colonisten, welche sich aus den angebauten Küstenländern in die Llannos bcgeben, in der Civilisation. einen Rückschritt thun, 
indem die Steppenbewolner auch hier, wie überall in der Welt, an Bildung den Bergbewohnern nachstehen. Allein defswegen darf man gar nicht zweifeln, dafs es nicht einer zahlreichen Bevölkerung im Laufe der Jahrhunderte gelingen werde, auch diese Ebenen zu bevölkern und dem Ackerbaue zu unterwerfen. Eine gute Regierung und ein fleifsiges, zahlreiches Volk (z. B. 20 Millionen Deutsche) würden sogar Sahara, die grofse Sandwüste Afrika's, in ein Paradies verwandeln.

Wie wichtig die Llannos von Caracas in militärischer Hinsicht sind, ist schon erwähnt worden, und ein Feind, der an den Quellen des Orinoko landete und durch die Llannos einbräche, würde dem blühendsten Theile Columbiens äufserst furchtbar werden. Von den Llannos aus könnte er das blühende Küstenland von Cumana, Caracas und Neu-Granada heftig beunruhigen; im Falle eines Rückzuges immer in den Ebenen Zuflucht, Lebens - und Transport-Mittel finden, und so in ihren Besitze Herr des Landes bleiben. Die spanische Regierung hat sehr viel auf die Befestigung der Nordküste Vene«uela's, von Cumana bis Barcellona, verwendet; der militärisch wichtige Punkt sind jedoch die Westküsten und die Mündungen des Orinoko. Die Nothwendigkeit, diese Küsten zu bevölkern und durch feste Städte zu vertheidigen, wie auch sich gegen eine Hirtenbevölkerung, deren Geneigtheit zum Kriege und zu Unruhen bekannt ist, sicher zu stellen, müssen eine aufgeklärte Regierung bewegen, 
der Cultivirung der Steppen allen mögliclien Vorschub zu leisten. Mit der landwirthschaftlichen Betriebsamkeit werden alsdann auch mildere Sitten sich einfinden, und wenn auch nicht überall, so werden sich doeh an den Ufern der Flüsse feste und bequeme Wohnsitze einer humanen Bevölkerung erheben.

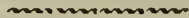 \\ Viertes Kapitel.}

Erscheinungen in den Llannos. - Neu-Bareellona. - Aufenthalt daselbst. - Ausfüge.

Nach dreitägiger Reise bekamen sie endlich wieder die Bergkette von Cumana zu Gesicht, welche die Llannos, oder wie man hier sagt: das grofse Meer von grünem Grase von den Küsten des Antillenmeeres trennt. Wenn der Brigantin über 800 Toisen Höhe hat, so müfste derselbe auf einer Entfernung von 27 Seerneilen zu sehen seyn. Allein die Beschaffenlieit der Atmosphäre entzog den Anblick dieses Berges noch lange. Endlich zeigte sich eine Nebelschichte in der Entfernung; allmählich schien sich die Dunstwolke zu vergröfsern, zu ver. dichten, und alle Erscheinungen, die sich dem Seefahrer bei Annäherung der Küsten darbieten, sind hier ebenfalls zu bemerken, wenn man aus der Steppe kommt. Endlieh schien das Himmelsgewölbe nicht mehr auf den Ebenen zu ruhen, sondern ge. gen Norden begrenzt zu werden. 


\section{- 221}

Der Llannero ist nur dann glüchlich, venn er rings um sieh freie Aussiclıt hat. Was wir ein flach. lıügeliges Land nennen, mit Wald und Thälern besetzt, das ist in seinen Augen ein scheufsliches Land, voll Berge. Daher sind die Begriffe von Berg und Ebene, in Bezug auf ein Land, sehr relativ. Nach cinem Aufenthalte mebrerer Monate am Orinoko in seinen dichten Wäldern, wo man sich gevöhnie, sobald man vom Strome entfernt ist, die Gestirne nur noch mehr am Zenith, wie aus einer Grubenöfnung, zu betrachten, hat eine Wanderung durch die Steppen etwas Freundliches, Angenehmes, und man geniefst mit den Llanneros das Glück, frei um sich schauen zu können. Dieser Genufs ist jedoch von kurzer Dauer. Unstreitig liegt ctwas Ernstes und Imponirendes in dem Anblicke eines Horizonts, der sich, so weit das Auge reichen mag, ausdehnt. Wir bewundern dieses Sehauspiel, sey es auf dem Gipfel der Anden, sey es mitten auf dem Meere oder in der Steppe. Es ergreift uns das Gefühl von des Raumes Unendlichkeit, und erhebt die Seele derer, die an Begriffen einer höhern Ordnung und der Ruhe eines einsamen Nachdenkens Vergnügen finden. An jedem Orte gewälirt dieser unermefsliche Anblick einen eigenen Genufs. Vorn Gipfel eines hohen Berges erfreut uns die Mannigfaltigkeit des menschlichen Treibens, auf das wir blicken; auf der See ist die belebte und bewegliche Wasserfäche mit ihrem dunkeln Blau und ihrer Menge lebender Geschöpfe, welche eine lange Seereise kürzt. 
Die einen grofsen Theil des Jahres hindurch staubige und zerrissene Steppe macht hingegen einen traurigen ur.l ermüdenden Eindruck, und ist man nach acht- bis zelintägiger Wanderung einmal an die Luftspiegelung und das glänzende Grün der einzelnen Mauritia-Büsche gewöhnt, so fühlt man das Bcdürfnifs mannigfaltiger Eindrücke, und freut sich herzlich, wieder in Gegenden zu gelangen, wo die grofsen Bäume der Tropenländer, die stürzenden Ströme und dic fleifsig bearbeiteten Kï̈sten den Ekel des Einerlei in uns verwischen.

Dic Ebene Sïdamerika's umfafst 98,00o QuadratMeilen, die Wüste Sahara 194,000 Quadrat-Meilen. Beide Ebenen liegen in der heifsen Zone. Würden sie.noch ausgedehnter seyn, so nähmen sie den Landstrich ein, durch welchen ein grofser Theil der schönsten Erzeugnisse der Tropenländer verloren ginge. Die Heiden des Nordens und die Steppen an der Wolga können nicht ärmer an Pflanzen und Thierarten seyn, als diese Ebene unter dem schönsten Himmclsstriche der Erde, in dem Klima der Brotfruchtbäume und der Pisang. Bei der Armuth an Pflanzenreichthum erinnern nur des Nachts die schönen Sternbilder des Südens den Reisenden, dafs er sich in den Tropenländern befindet.

In den Ebenen der neuen Welt findet man auch keineswegs die Granitblöcke zerstreut, womit die nordischen Ebenen bedeckt sind, nämlich diejenigen der baltischen Ebenen. Man glaubt nun mit Gewifsheit, dafs diese Granitblöcke Trümmer eines 


\section{$-\quad 223$}

zerstürlen Urgebirges sind, das auf der scandinavischen Halbinsel zerstört wurde, und durch eine unbelannte Revolution seine Trümmer in die Ebenen Deutschlands geworfen hat. Hier in Amerika ist nichts dergleichen zu finden, obwobl sie von Urgebirgen umgrenzt sind, die in ihren ausgezackten Gipfeln die Spuren gewaltsamer Zerstörung nicht verläugnen. Man findet auch nicht ein Steinchen, und es scheint diese Erscheinung in ganz Südamerika sich zu wiederholen, und wahrscheinlich auch in Afrika's Ebene. Die Granitblöcke des Nordens scheinen dalser durch eine ganz eigene, gewaltige Wasserfluth in die Ebenen geworfen zu seyn. (Wie wenn die ganze Ebene einc Ausfüllung eines Meerbusens durch ein vom Erdbeben zerstörtes Urgebirg wäre? Die Erdbeben der Vorwelt können nicht nach denen bemessen werden, die wir erleben.)

Am 23. Juli langten unsere durchnäfsten, verbrannten uud allen Beschwerden glücklich entkommenen Freunde in Neu-Barcellona an. Die seit lange gewohnte Hitze hatte sie nie so sehr belästigt, als die Sandwinde, deren anhaltende Wirkung schmerzhafte Risse und Spalten in der Haut verursacht hatten. Sieben Monate zuvor hatten sie hier gelandet, und bei Herrn Lavie gefällige Aufnahme gefunden. Der Hausvater war damals gefangen, weil er beschuldigt wurde, dem unglücklichen $E s$. panna, der als Staatsverbrecher geächtet und später in Caracas hingerichtet worden war, Aufenthalt gewährt zu haben. Jetzt war er frei, und unsere 
Reisenden liatten die Freude, denjenigen in seiner Familie sehen zú können, dem sic früher im Grfängnisse Besuche abgestattet hatten. Übrigens hatte die erlittene Behandlung seine Gesundheit dermafsen untergraben, dafs er dic neuesten Ereignisse, die scinem Vaterlande Selbstständigkeit gaben, nicht mehr erlebte.

Neu-Barcellona ist ein wichtiger Handelspla:z. Die Stadt wurde 1637 von dem catalonischen Eroberer Juan Urpin gegründet; 1790 hatte sie 10,000, und im Jahre 1800 16,000 Einwohner. Man hatte an der Mlïndung des Rio Neveri 1588 eine indianische Stadt gebaut, die den Namen St. Christoval de las Cumanagotos fülırte. Die Bervohner waren lauter Eingeborne, aus den Salinen von Apaicuare dahin gekommen. 1637 erbaute Juan Urpin zwei Meilen landeinwärts die spanische Stadt Neu-BarcelIona. Beide Städte lebten neben einander 3/4 Jahre lang im Streite, bis 1671 der Gouverneur Angulo sie beredete, sich in einer dritten Stadt dem nunmehrigen Neu-Barcellona zu vereinigen. Diese Stadt liegt nun unter $10^{\circ}, 6^{\prime} 52^{\prime \prime} \mathrm{N}$. Br.

Die alte Stadt Cumanagoto ist berühmt durch ein wunderthätiges Bild der heiligen Jungfrau, das, nach Angabe der Indianer, in dem hohlen Stamme eines Tutumo oder Crescentia Cujete gefunden ward. Das Mutter-Gottesbild ward in Procession nach Neu. Barcellona gebracht; jedes Mal jedoch, wenn der Clerus init den Bewohnern der neuen Stadt unzufrieden zu seyn Ursache hatte, entfloh das Bild nächt- 
licher Weile aus der Stadt, und kehrte in den Baum. slamm zurück an die Ausmündung des Flusses. Dic. ses beunruhigende Wunder hörte nicht eher auf, bis ein grofses Klloster für die Franziskaner und das Bild erbaut ward.

Das Rlima von Neu - Barcellona ist niclıt so lieifs, wie das ron Cumana, hingegen feucht, und in der Regenzeit elwas ungesund. Herr Bonpland hatte die beschwerliche Rieise durcb die Llannos recbt gut ausgehalten, und mit seinen Kräften seinc $T$ lıätigkeit wieder erlangt. Herr von Humboldt fühlte sich jedoch in Neu-Barcellona übler, als in Angostura. Einer jener Tropenregen, wo bei Sonnenuntergang. Tropfen von aufserordentlicber Gröfse,

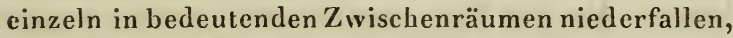
hatte ihm ein Ubelseyn verursacbt, das einen Anfall von Typhus, der damals auf der Küste herrschte, befürchten lief's. Sie verweilten daher einen Monat in Neu. Barcellona, und genossen daselbst aller Liebe und Sorgfalt, welche die zuvorkommendste Freundschaft zu leisten vermag. Hier fanden sie auch jenen Ordensmann aus Cumana wieder, Franz Juan Gonzalez, der früher schon auf die oben erwähnte Art den Orinoko bereist hatte. Er be. dauerte die Kürze der Zeit, welche die Reisenden auf die Untersuchung jenes unbekannten Landes hat. ten verwenden können. Er betrachtete mit der in. nigsten Theilnahıne die Pflanzen und Thiere, wel. clie sie mitgebracht hatten. Er hatte beschlossen, nach Europa zurückzukchren, und die Reisenden 
nach der Insel Cuba zu begleiten. Sie waren sieben Monate nun beisammen mit diesem muntern, geistreichen und dienstfertigen Ordensmanne, und Niemand ahnte wohl das Unglück, welches seiner wartete. Er hatte einen Theil der Sammlungen mit. genommen; ein Hnabe ward ihm anvertraut, der in Spanien erzogen werden sollte; die Sammlungen, das Kind, der junge Ordensmann, alles ward eine Beute der Wellen, von denen sie verschlungen wurden.

Südostwärts von Neu-Barcellona, in der Ent. fernung von zwei Meilen, erhebt sich eine sehr hohe Bergkette, die an den Brigantin gelehnt ist. Der Ort ist unter dem Namen der heifsen Wasser bekannt. Als sich Herr von Humboldt wieder besser befand, machten sie einen Ausflug dahin, an einem lühlen, neblichten Morgen. Die schwefelhaltigen warmen Wasser kommen aus quarzigem Sandsteine, der auf Kalkstein autliegt. Die Temperatur des Wassers beträgt nur $43^{\circ}, 2$ Centesimal - Theile, während die Atmosphäre $27^{\circ}$ beträgt. Anfänglich rinnt es in einer Länge von 40 Toisen über die felsige Bodenfläche, alsdann stürzt es sich in eine natürliche Grotte, aus der es durch den Fálkstein am Fufse des Berges, am linken Ufer des kleinen Flus. ses Nariqual hervorquillt.

Die mit der Atmosphäre in Berührung stehenden Quellen liefern einen beträchtlichen Schwefelniederschlag. Die Schwefelwasser von San Juan, die, gleich jenen von Brigantin, aus dem Kalkgebirg her. 
vorliommen, zeigen auch nur eine schivache Tem. peratur, nämlich $31^{\circ}, 3$, während diejenigen in der nämlichen Region von Mariara und von Trinchera, die eine $58^{\circ}, 9$, die andere $90^{\circ}, 4$ Temperatur be. sitzen. Man könnte glauben, die Wärme, welche die Quellen im Innern der Erde erhalten haben, nehmen in dem Verhältnisse ab, wie sie vom Urgebirge in die auf diesem aufliegenden Secondärformationen übergehen.

Der Ausflug hatte etwas sehr Unangenehmes in seiner Begleitung. Der gefällige Wirth hatte für die geliebten Gäste seine schönsten Reitpferde hergegeben. Sie wurden zu gleicher Zeit gewarnt, den kleinen Flufs Nariqual ja nicht zu durchreiten. Sie machten daher ihren Übergang auf einer kleinen Brücke aus neben einander liegenden Baumstämmen, und liefsen die Pferde am Zaume schwimmen. Das= jenige, welches Herr von Humboldt geritten hatte, verschwand plötzlich; sie sahen, dafs es unter dem Wasser eine Weile umberschlug, aber es war verloren, ohne die Ursache dieses Ereignisses zu erfahren. Die Führer meinten, das Thier sey durch die häufigen hier befindlichen Caymans bei den Füssen gepackt worden. Herr von Humboldt befand sich nun in der grölsten Verlegenheit. Bei der Gefälligkeit, dem Reichthume und Zartgefühle ilıresWir. thes war nicht daran zu denken, Ersatz zu leisten. Herr Lavie suchte sie aus der Verlegenheit zu zie. hen, indem er die Leichtigkeit, mit der er schöne Pferde aus der Savane erhalte, übertrieb. 


\section{$-228$}

Die Krokodille vom Rio Neveri sind grofs und zahlreich, besonders in der Nähe der Ausmündung des Flusses. Sie nelimen sogar mit Pferden vorlieb. lhr Naturell ist jedoch milder, als derjenigen vom Orinoko. (Ob sich übrigens meine jungen Freunde, die dieses lesen, der Milde eines solchen I'ferdebändigers anvertrauen mögen, stelle ich ihnen anheim.) Die Wildheit dieser Thiere bietet in Amerika-dieselben Widersprüche dar, wie in Egypten und Nubien, und wie solche aus aufmerksamer Vergleichung der Erzählungen des unglücklichen Burkhardt sowohl, als des Herrn Belzoni hervorgehen. Der Culturzustand der verschiedenen Länder, und die Verhältnisse der Bevölkerung in der Näle der Flüsse bringen auch wesentliche Veränderungen in der Lebensart dieser Eidechsen hervor, die auf trocknem Lande furchtsam sind, und selbst im Wasser, wofern sie sattsame Nahrung haben, und der Angriff mit einiger Gefalır verbunden ist, den Menschen fliehen. (Sind denn aber wirklich die zahınen Irrokodille dieselben, welche die wilden sind? oder sind es nicht vielmehr verschiedene Arten? Neuere Naturforscher wollen im Nile wirklich mehrere Arten bemerkt haben, von denen einige reifsend, an. dere ganz unschädlich sind.)

In Neu-Barcellona wenden die Indianer ein eigenes Verfahren an, um ihr Holz zu Markte zu bringen. Die grofsen Scheiter und Klötze werden in den Flufs geworfen, dessen Strömung sie fortführt. Die Eigenthümer des Holzes begleiten sie, 
und schwimmen, wo es nöthig ist, um dic zahlreichen Stücke, die in Buclıten hängen bleiben, wie. der los zu machen. In andern amerikanischen Flïзsen, wo Krokodille sind, dürfte man ein solches Verfahren nicht wagen. Die Stadt Neu-Barcellona besitzt nicht, wie Cumana, eine indianische Vorstadt, und die wenigen Eingebornen, die man zu sehen bekommt, sind aus den benachbarten Missionen oder aus den in der Nähe zerstreuten Hütten. Es sind keine Cariben, sondern Cumanagoten, Palenken und Piritu's, kleine untersetzte Menschen, meist Müfsig. gänger und Trunkenbolde. Der gegohrne Manioc ist ihr Lieblingsgetränk, denn der Palmenwein findet sich an den Küsten beinahe gar nicht. Sonderbar! dafs die Sucht, sich zu berauschen, unter allen Him. melsstrichen den Menschen entehrt. Nicht nur alle Pflanzen, sondern sogar giftige Blätterschwämme (Amarita muscaria) werden zu solchen abscheulichen Zivecken benutzt. Und die Koriäken trinken diesen Saft, und wic tief kann Trunksucht den Menschen entehren! sie lassen ihn öfter durcȟ den Leib ge. lien, nur um öfter sich berauschen zu können. Dicser Blätterschivamm verursacht ein fünf Tage lang anhaltendes Zittern des Körpers. Wahrlich so lange die Menschen nicht auf Mittel gerathen, sich der Trunksucht zu entschlagen, so lange die entehrende Gewohnheit, sich zu berauschen, die Gesellschaft befleckt, ist weder an Civilisation noch Humanität, ain allerwenigsten aber an Treue und Glauben, an den Fortbestand der bürgerlichen Gesellschaft zu 
denken. Der nüchterne Mensch ist ruhig, fleifsig, fromm, vernünftig und treu. Der Trunkenbold hat auf alle Tugenden Verzicht geleistet. Indem er sich der Elıre, Mensch \%u seyn, beraubt hat, so dafs sich seiner Genossenschaft auch das Thier schämen würde, hat er auch zugleich jeder Tugend entsagt, welche den Menschen ziert. Nicht nur selbst un. fähig zum Guten, ist er feil jedem Laster, das mit Befriedigung seiner abscheulichen Sucht bezahlt wird.

\section{nomonosmosomsons \\ Fünftes Kapitel.}

Reiso nach Cumana. - Aufenthalt daselbst. - Abreise nach der Havannah.

Da seit drei Monaten dic Packetboote ausge blieben waren, so muthmafste man, sie seyen von den Engländern genommen worden. Indem es jedoch für die Reisenden wichtig war, Cumana zu erreichen, um mit erster Gelegenheit nach Veracruz abzugehen, so mietheten sic am 6. August 1800 ein offenes Boot oder Lancha, wie man sie hier nennt. Da die See hier meist ruhig ist, so bedient man sich häufig solcher Lanchen. Diese Lancha war mit Cacao beladen, um ibn nach der Insel Trinidad ein. zuschmuggeln, wefshalb der Patron des Fahrzeugs auch nichts von den englischen Schiffen besorgte, welche damals alle spanischen Häfen blokirten.

Sie schiften nun ihre Sammlungen und Instru- 
mente ein, und fuhren den Rio Neveri hinab, um nach Cumana zu gelangen. Kaum waren sie jedoch in den sclimalen Canal gelangt, der das Festland von den Felsen.Inseln la Boracha und Chimanas trennt, so begegneten sic auch, zu ihrem nicht geringen Erstaunen, einem bewaffneten Falurzeuge, welches mit Flintenschüssen ihnen still zu stehen befahl. Es waren dies Matrosen, die einem Corsaren von Halifax gehörten. Unter den Matrosen befand sich auch ein aus Memel gebürtiger Preufse, den Herr von Humboldt an seiner Physiognomie und Stimme erkannte. Obwohl die deutschen Töne in so fernen Landen und nach so langer Zeit lieblich in die Ohren des Herrn von Humboldt tönten, so hätte er doch seinen Landsmann lieber bei einer andern Gelegenheit begrüfst. Trotz aller Protestatio. nen mufste man auf den Corsaren wandern, der die Yässe, welche der Gouverneur von Trinidad den Schmugglern ausstellte, nicht kennen wollte, und alles sammt und sonder für gute Prise erklärte.

Herr von Humboldt trat nun mit dem Capitän in Unterhandlung, um nicht nach Neu-Schottland gebracht zu werden, und bat, auf der benachbarten Küste ausgesetzt zu werden. Allein während Herr von Humboldt die Rechte des Bootes vertheidigte, brach auf dem Verdecke plötzlich Lärm aus; dem Capitän ward leise Bericht erstattet, und dieser schien davon eben nicht sehr erbaut zu seyn, in welcher Stimmung er Herrn von Humboldt sogleich verliefs. 
Die Scene änderte sich nun. Eine englische Corvette hatte in dicsen Wässern gekreuzt, den Seeräuher ersehen, ihm Halt zugerufen, und da er, wie alle Räuber, nicht halten wollte, eine runde Bot. schaft aus einer Kanonenröhre abgesandt, die ihn sogleich zum Stehen brachte. Die englische Corvelte hatie nun einen Seecadetten an Bord gesandt, der ein höflicher junger Mlann war, und sogleich Hoffnung machle, dafs das Boot frei gelassen werden würde, damit sie am folgenden Tage ihre Fahrt fortsetzen könnten. Er schlug auch Herrn von Humboldt vor, ihn auf die Corvette zu begleiten, wo der Capitän ihn ein angenehmeres Nachtlager, als der llalifax, anbieten würden.

Herr von Humboldt nahm den Antrag an, und der Capitän erwies ihm Höflichkeiten aller Art. Er hatte mit Vancouver die Reise nach der Nordwest. küste Amerika's gemacht, und äufserte lebbafte Theil. nahme für alles, was Herr von Humboldt über die Catarakten des Orinolio und den Amazonenstrom erzählte. Es waren auch mehrere Officiere am Bord, die mit Lord Marcurtney in China gewesen waren; die Gesellschaft bestand also aus vielen kenntnifsreichen Personen, und war sehr angenehm. Da man durch die englischen Zeitungen von des Herrn von Irumboldts Reise unterrichtet war, so behandelte man ihn sehr vertraulich, und wies ihm ein Nacht. lager im Zimmer des Commandanten an. Beim Abschiede schenkte man ihm auch einen Jahrgang astronomischer Ephemeriden, die für IIerrn von Hum- 


\section{$-233$}

boldt von sehr grofser Wichtigkeit waren. Nach langem Leben mit Wilden in den Wäldern des Cas. siquiare muls das Zusammentreffen mit kenninifsreichen Männern von dem grölsten Interesse seyn. Die Unannehmlichkeit mit dem Corsaren hatte daher einen sehr angenehmen Genufs und einen sehr fröhlichen Abend zur Folge.

A $m$ folgenden Morgen wurde in dem nun wieder freien Falırzeuge die Fahrt in dem Canale forigesetzt. Die Falirwasser sind hier tief, und die Felsenwände so steil, dafs sie die Corvette ganz nalıe an den Felsenmauern hinstreifen sahen. Die Menge der Alcatra's, die gröfser, als unsere Schwäne sind, die der Flamingo's, welche in Buchten Fiselie fingen ciler die Pelikane verfolgten, verkündigten die Nähe des ewvig heitern Cumana. Es war schön, die Vöge! zu beobachten, die beim Sonnenaufgange plötzlich hervorkommen, und die Landschaft beleben; es erinnert dies an die Regsamlieit, welche unsere Städte des Morgens entwickeln.

Gegen neun Uhr Morgens befanden sie sich wieder am Eingange des Golfes von Cariaco; jetzt sahen sie sich das Schlofs St. Anton hervorlieben. Mit. Rülırung erkannten sie das Ufer, wo sie den Boden Amerika's zuerst betreten hatten, wo sie die erste P'flanze gepflückt, die ersten Guayquerier gesehen, und Herr Bonpland die Gefalır mit dem Zambo bestanden hatte. Jetzt wurden auch die zwischen den Cactus-Leuchtern liegenden indianischen Hütten sichtbar, der Wald von Cactus, die 


\section{- 234}

zerstreuten Hütten, der grofse Ceiba-Baum, unter dem sie so gerne gebadet hatten, alles war ihnen bekannt.

Nun kamen ihnen auch ihre Freunde aus Cumana entgegen; alle Bekannte biefsen sie herzlich willkommen. Diese Freude war um so herzlicher, als sich wenige Monate zuvor die Nachricht verbreitet hatte, dafs sie am Orinoko umgekommen seyen. Sie beeilten sich nun, den Gouverneur zu besuchen, dessen Empfehlungen ihnen während der Reise so nützlicb geworden waren. Er verschaffte ihnen sogleich ein sehr bequemes Haus mitten in der Stadt, das für Sternbeobachtungen äufserst bequem lag. Es hatte Terrassen, von denen man die prachtvollste Aussicht auf das Meer, die Halbinsel Araya und die Inseln des Meerbusens geniefst.

Der Hafen von Cumana ward durch englische Schiffe täglich enger blokirt, und dieser Umstand zwang sie, noch dritthalb Monate länger in Cumana zu verwcilen. Sie waren oft ungeduldig, und wollten nach den dänischen Inseln übersetzen, we!clıe neutral, d. h. mit keiner Partei im Kriege waren; allein sie fürchteten, dafs wenn sie einmal die spanischen Colonien verlassen hätten, es ihnen nicht so leicht seyn dürfte, in dieselben wieder zurückzukehren. Es wurde also die Zeit mit botanischen, geognostischen und mineralogischen Arbeiten ausgefüllt.

Die lebenden Thiere, welche sie vom Orinoko mitgebracht hatten, waren ein Gegenstand grofser Neugierde der Einwohner von Cumana. Der Kapuziner- 
Affe von Esmeralda, welcher durch seine Physio. gnomie dem Menschen so ähnlich ist, und der Schläfer-Affe (simia trivirgata) waren lier noch nie gesehen worden. Diese Affen waren für den Pflanzengarten zu Paris bestimmt, allein sie starben alle auf Guadeloupe; und nur die Haut der simia chiropodes kam nach Paris.

Vom 3. bis 5. November besuchten sie nochmals die Halhinsel Araya. Sie besuchten alle Orte und Gegenstände wieder, die schon im ersten Bändchen beschrieben sind. $\mathrm{Zu}$ diesem kam noch, dafs dic Indianer Arum aus den Bergen brachten, und IIoffnung gaben, dafs in den Bergen von Maniquarez eine Alaunmine zu finden scyn dürfte. Ob sie auch den philosophischen Schulmeister, der die Perlen verachtet hatte, besuchten, ist nicht gesagt. Um die erwälınte Alaun-Mine aufzusuchen, gingen sie am 4. November um 1 Uhr nach Mitternacht unter Segel. Widriger Wind verzögerte die Fahrt, sie wurden aber durch den Anblick des phosphores. cirenden Mecres dafür entschädigt. Illeine Delphine umkreisten die Pirogue und machten den Anblick noch schöner. Noch ein Mal fuhren sie an der Stelle vorbei, wo das Erdöhl aus dem Glimmerschiefer hervorquillt, und den Geruch davon weit umher verbreitet. Wenn man sich erinnert, dafs melir östlich, nahe bei Cariaco, heifse, im Grunde des Meeres sich öfnende Quellen ansehnlich genug sind, um die Temperatur des Meerwassers zu verändern, so liegt wohl aufser Zweifel, dafs das Erdöhl durch 


\section{$-250$}

eine Art Destillation aus ungeheurer Tiefe und aus jenem Urgebirge hervorkömmt, unter welchem der Heerd aller vulkanischen Erschütterungen zu su. chen ist.

Die Laguna Chica ist eine von senkrecht abgestutzten Bergen eingeschlossene Bucht, die mit dem Golfe von Cariaco durch einen schmalen, 25 Iflafter tiefen Canal zusammenhängt. Hier verengert sich die Halbinsel Araya so sehr, dafs sie von einem Meere zum andern nur etwas über 4000 Toisen breit ist. Diesen kurzen Weg mufsten sie zurücklegen, um den Alaun zu erreichen, und an das Cap zu gelangen, das den Namen Punta de Chuparuparu führt. Der Weg wird jedoch dadurch schwierig, dafs es keinen gebalınten Fufspfad gibt, und man über eine nackte zerrissene Felsengräte den Weg sich erst bahnen mufs. Der höchste Punkt hat nicht über 200 Toisen Hühe, aber die Berge zeigen hüchst seltsame Gestalten. Man sieht bier wahre Spitzberge und Zacken, die man, aus der Ferne geselien, für isolirt halten möchte. Pflanzenerde findet sich nur bis 3o Toisen Erhöhung; wenn aber auf die blühenden Melonen nur etwas Regen fällt, so liefern sie, der anscheinenden Trockenheit der Luft ungeachtet, Früchte von 60 bis 70 Pfund Gewicht. Die Trockenheit der Luft ist hier nur scheinbar, und der Hygrometer zeigt, dafs sie fast von Dünsten gesättigt ist. Ob nun wohl hier oft in 12 und 15 Monaten kein Regen fällt, gedeihen in dieser warmen und feuchten Luft die Wassergewächse doch 


\section{$-237$}

vortrefflicb, und die Kürbisse, Agaven und die Cactus, besonders die halb im Sande vergrabenen Melonen-Cactus, erhalten seltene Vollkommenheit. Als die Reisenden im Jahre vorher hier waren, herrschte, wegen der grofsen Dürre so grofser Wassermangel, dafs mehrere hundert Ziegen umkamen. Seit der Zeit hatte sich die Jahreszeit umgekehrt, und es waren sehr häufige Regenniederschläge erfolgt. In Europa kann ein Steinregen die Phantasie nicht mebr beschäftigen, als die ordinären Regen hier, wo diese so selten sind.

Nach neunstündigem vergeblichen Suchen fanden sie endlich das Mineral in einer sehr schwer zugänglichen Schlucht, welches ihnen als Alaun in Cumana vorgewiesen worden war. Der Glimmerschiefer ging plötzlich in gekohlten Thonscliefe: über. Es war sogenannter Zeichenschiefer. Die Gewässer der dort befindlichen kleinen Quellen hatten einen zusammenziehenden Geschmack, und die Wände der benachbarten Felsen waren mit haar. förmigen Ḱrystallen, und Blumen von Alaun überzogen. Es dehnten sich wirklich zwei Zoll dicke Schichten von natürlichem Alaun, so weit das $\stackrel{A}{\text { uge }}$ reichte, über den Thonschiefer aus. Das Mineral ist weifsgrau, aufsen etwas matt, inwendig aber von einem glasartigen Glanze; sein Bruch ist nicht faserig, sondern unvollkommen schneckenlinig. In dünnern Bruclsstücken ist er halb durchsichtig. Der Geschmack ist etwas suifslich und zusammenziehend, oline Beimischung von B:tterkeit. Übrigens scheint 
die ganze Umgebung auf Urgebirg hinzudeuten, und so ist das Vorkommen des Alauns im Urgebirge sehr bemerkenswerth.

Im Jahre 1785 ist in Folge eines Erdbebens eine grofse Felsenmasse in den Aroyo del Rebalo niedergestürzt, da sammelten die Indianer Alaunstücke, die 5 bis 6 ' Zoll im Durchmesser hielten, und völlig durchsichtig und rein waren. Dieser Alaun ward in Cumana, das Pfund um zwei Realen, an Schuster und Färber verkauft, während der aus Spanien kommende Alaun sechs Mal so viel kostete. Dieser Preisunterschied beruhte mehr auf Vorurtheil, als auf geringerer Qualität des Alauns; denn gereinigt würde der einheimische eben so gut seyn.

Jetzt empfängt Südamerika seinen Alaun aus Europa, wie Europa denselben bis ins 15. Jahrhundert von den Asiaten erhalten hatte. Indessen wird auch Südamerilı mit der Zeit seine Reichthümer nützen lernen, und finden, dafs es in keinem Stücke von der Natur vernachläfsigt ist. Nach diesen Untersuchungen fuhren sie mit der Familie des Herrn Navarete nach Maniquarez, wo sie erst in der Nacht eintrafen.

Der Aufentlialt in Cumana wurde nocb um zwei Wochen verlängert, in der Hoffnung, das spanische Courierschiff zu erwarten, um mittelst desselben nàch Cuba zu gelangen. Da jedoch keine Hoffnung vorhanden war, diese Gelegenheit ankommen zu sehen, so benutzten sie ein amerikanisches Fahrzeug, welches in Neu-Barcellona Pökelfleisch einnahm, um 


\section{- 239}

solehes nach der Insel Cuba zu bringen. Sechzehn Monate waren nun verflossen an diesen Küsten und im Innern von Venezuela, und die Sehnsucht nach den Cordilleren immer lebhafter geworden. Sie hatten um 50,00o Franken Wechsel auf die besten Häuser in Havannah bei sich, dennoch wären sie ohne die Vorschüsse des Gouverneurs beinahe in Verlegenheit gerathen. Es war nämlich zwischen den Colonien desselben Mutterstaates nicht immer der vertrauliche Zusammenhang, den man vermuthen sollte.

Am 16. November trennten sich unsere Reisenden, um die Fahrt zum dritten Male im Golfe von Cariaco nach Neu-Barcellona zu versuchen. Die Nacht war kühl und sehr angenehm. Nicht ohne Rübrung, sagt Herr von Humboldt, sahen wir zum letzten Male die Gipfcl der an den Ufern des Man. zanares sich erhebenden Cocospalmen, von der Mondscheibe beleuchtet. Geraume Zeit blieb unser Blick an die w.eifsliche Küste gefesselt, auf der wir ein einziges Mal nur über Menschen zu klagen Ursache hatten. Der Wind wehte so günstig, dafs wir in weniger als sechs Stunden beim Morro de Nueva Barcellona ankerten. Das Schiff, das uns nach der Havannah bringen sollte, war zum $\mathbf{A b}$. segeln bereit. 


\section{0 \\ Sechstes Kapitel.}

Allgemeine statistische Bemerkungen über Venezuela.

Nachdem Herr von Humboldt die Geschichte seiner Reisen bis zur Abreise nach Cuba vollendet hat, macht er in der Erzählung einen Stillstand, um in einem sehr langen Kapitel alles zusammenzustellen, was er in Hinsicht auf Landesreichthum, Bevölkerung, Ausdehnung, Erzeugnisse und ähnliche zur Statistik Amerika's gehörige Gegenstände gesammelt hat. Alle diese Gegenstände sind nun äufserst lehrreich, aber für junge Gemüther, wie ich mir meine Leser und Leserinnen denke, etwas trocken. Es gibt hier viele Zahlen, und die liebe Jugend rechnet nicht gerne, obwohl es ihr sehr zu empfehlen ist, weil das Rechnen denn doch die schönste Erfindung des menschlichen Geistes ist. Ganz hann ich jedoch meine Leser nicht davon befreien, ich werde daher in diesem Kapitel alles dasjenige darlegen, was ich glaube, dafs es für die jungen Leser Interesse hat. Es wird demnach eine vergleichende Schilderung des Territorial - Reichthums, der Bevölkerung, des Handels u.s.w. folgen. Bemerken mufs ich jedoch meinen jungen Lesern auch, dafs dasjenige, was auf Bevölkerung und Ackerbau Be. zug hat, nur für damals gilt, als Herr von Hum. boldt in Amerika war. Leidige Natur - und BürgerRevolutionen haben seit der Zeit so manches verändert. Das Territorium ist aber noch dasselbe, 


\section{- 241}

und auch der alte Ceiba stebt noch an der Küste von Cumana.

Die amerikanische Welt findet sich gegenwärtig unter drei Nationen europäischer Herkunft getheilt. Das mächtigste Volk ist deutschen Ursprungs, das ausgebreitetste ist lateinischer Abkunft. Viertausend Meilen Küstenland sind allein von den Spaniern und Portugiesen besetzt. Die zwei Völker, welche in Europa auf der Pyrenäen - Halbinsel Nachbaren sind, sind es auf einer ungleich colossalern Halb. insel auch über dem Meere geworden, und seltsam ! beinahe in derselben Proportion. Man kann sagen, von Calefornien bis zur Mündung des la Plata, auf dem Rücken der Cordilleren, wie in den Wäl. dern des Amazonenstroms, sind ihre verbreiteten Sprachen Denkmäler des Nationalruhmes, welche alle politische Veränderungen überleben wcrden.

Dic Bewohner vom spanischen und portugiesischen Amerika bilden heut zu Tage cine beinahe zwei Mal gröfsere Bevölkerung, als jene die von brittischer Abstammung sind. Die französischen, dänischen und holländischen Besitzungen sind von geringerem Belange. Man mufs jedoch auch noch der Colonien slavischer Herkunft erwähnen, welche sich von der Halbinsel Alatschka in Calefornien anzusiedeln bemühen; dann mufs man auch die grofse Negercolonie auf Haiti bedenken, welche Belzoni's Weissagung von 1545 erfüllt haben. Die Insel Haiti ist dritthalb Mal so grofs, als Sicilien, und von grofsem politischem Gewichte. Was aus diesem Volke 
wird, das mufs man erwarten. Alles genau genom. men bleibt Amerika doch hauptsächlich zwischen drei Nationen, den Britten, Spaniern und Portugiesen getheilt. Die Britten bedccken die Mecre mit ihren Schiffen, und der Handel der Anglo-Amerilianer hat eine bisher in der Geschichte beispiellose Ausdelinung erhalten. Sie haben vom Mutterlande Aufbiärung, Literatur, Fleifs und Einrichtungen geerbt. Die Cultur der Colonial - Produkte hat den schändlichsten Sclavenhandel besonders in die spanischen und portugiesischen Besitzungen eingeführt, und die Einführung der Neger ist für beide Halb. lugeln verderblich geworden. Glücklicher Weise ist die Sclavenbevölkerung auf dem Festlande des spanischen Amerika, im Verhältnisse zu Brasilien, nur gering. Die spanischen Colonien haben bei einer Gröfse, die Europa um ein Fünftel übersteigt, nicht so viel Negersclaven, als der einzige Staat Virginien davon besitzt. (Jetzt aufser Cuba und Portorico keine mehr.)

Jetzt erreicht die Gesammtbevölkerung Amerika's die von Frankreich oder Deutschland nicht, allein es läfst sich mit Gewifsheit vorhersagen, dafs keine anderthalb Jahrbunderte vergehen werden, bis sie die von ganz.Europa übersteigt, und es ist nicht zu viel angenommen, wenn man sich einst eine Bevölkerung Amerika's denkt, welche die jetzige des ganzen Erdballs begreift. Defswegen wird aber Europa nicht zu Grunde gehen, vielmehr wird sich alles ausgleichen, und IIutter und Tochter blühen 


\section{$-243$}

und gedeilien. Es liegt gerrifs nicht aufser dem Plane der Vorselung, dafs der ganze Erdball der Aufklärung und des Christenthums, oder was dasselbe ist, einer dauerhaften Sittigung theillaftig werde.

Übrigens wird sich Südamerika nicht so schnell bevölkern, wie Nordamerika, weil die AequinoetialLänder der hohen Gebirge, der Wälder, die dem Beile und Feuer trotzen, der mit Inseliten erfüllten Luft wegen dem Anbaue mehrere Hindernisse entgegensetzen, als die vereinigten Staaten. Wir kommen nun zum Umfange des Landes und seiner ge. genwärtigen Bevölkerung!

Vier und dreifsig Millionen Menschen bewohnen jetzt dieses ungeheure Festland, wovon $16 \frac{1}{2}$ Millionen in den Besitzungen spanischer Amerikaner, 10 Millionen im brittischen Amerika, und 4 Millionen im portugiesischen Antheile sich befinden. Die vereinigten Staaten sind beinahe um eín Vierttheil grös. ser, als Rufsland westwärts vom Ural, und das spanische Amerika gröfser als ganz Europa. Die vereinigten Staaten haben $5 / 8$ der Bevölkerung des spanischen Amerika, obgleich ihre Landes-Oberfläche nicht halb so grofs ist. Brasilien enthält noels dermafsen öde Landschaften, dafs auf ihrer Oberfläehe, die nur ein Drittheil kleiner, als spanisch Amerika ist, die Bevölkerung sich wie 1 zu 4 gegen das spanisehe Amerika verhält. Folgende T'abelle ist das Resultat der Berechnungen des Herrn von Hum. boldt. 


\begin{tabular}{|c|c|c|}
\hline $\begin{array}{c}\text { Grofse politische } \\
\text { Eintheil ungen. }\end{array}$ & $\begin{array}{l}\text { Ober- } \\
\text { fläche in } \\
\text { Meilen, } \\
\text { wovon zo } \\
\text { auf einen } \\
\text { Grad. }\end{array}$ & $\begin{array}{c}\text { Bevölkerung } \\
\text { im Jahre } \\
1813 .\end{array}$ \\
\hline 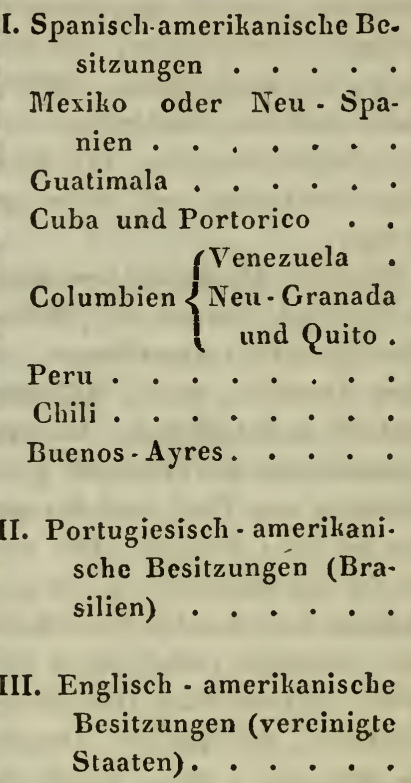 & $\begin{array}{r}75,830 \\
16,740 \\
4,430 \\
33,700 \\
58,250 \\
41,420 \\
14,240 \\
126,770\end{array}$ & $\begin{array}{r}16,785,000 \\
6,300,000 \\
1,600,000 \\
800,000 \\
785,000 \\
2,000,000 \\
1,400,000 \\
1,100,000 \\
2,300,000\end{array}$ \\
\hline
\end{tabular}

Dieser Tabelle fügen wir noch eine andere nach den neuesten Berechnungen bei. 


\section{$-245$}

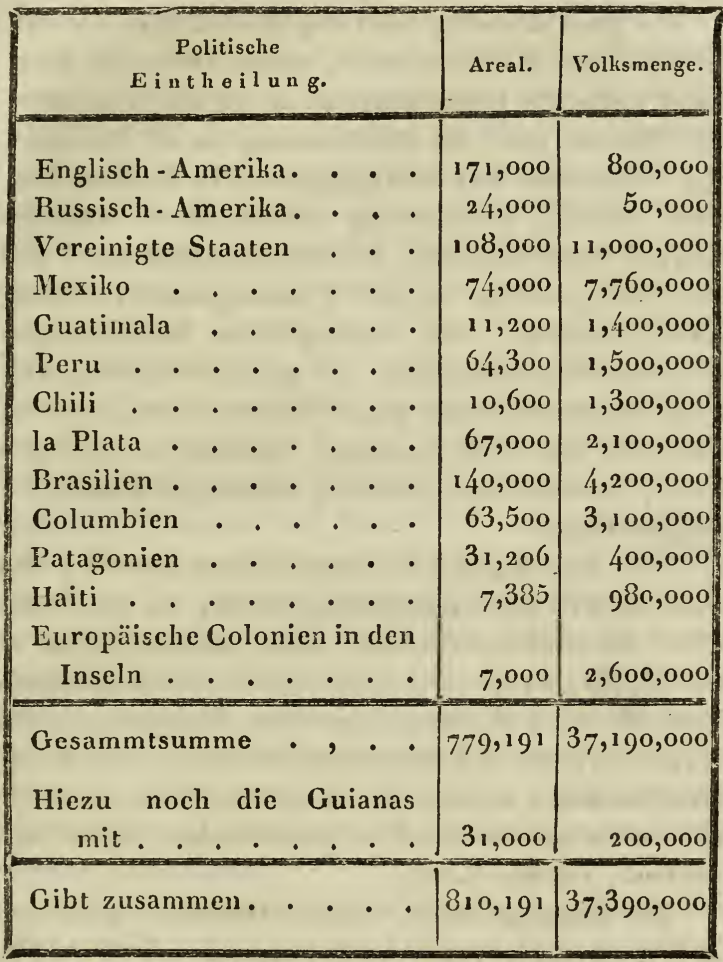

Die erste dieser Tabellen gibt die Übersicht nach Herrn von Humboldt von 1813; die zweite gibt den Flächen - Inhalt und dic Bevölkerung des gesammten Amerika von 1823 . 


\section{$-\quad 240$}

Für ganz Amerika, vom Cap Horn bis zum Parallelkreise der Melville. Insel, nimmt Herr von Hum. boldt $1,186,930$ Quadratmeilen zu 20 auf einen Grad ar. Nimmt man die Bevölkerung zu 38 Millionen an, so kommen auf eine Quadratmeile 32 Menschen. Nach Hassel's Berechnung enthält Nord-Amerika 539,453 Quadratmeilen, die Inseln (Antillen) 18,018 und Süd-Amerika 524,555 Quadratmeilen, zusammen 1,072,026. Dafs mannigfaltige Berechnungen von einander abweichen, ist ganz natürlich, weil noch nicht alle Theile genau bekannt sind, und man nur nach und nach zu einiger Genauigkeit gelangen kann, indessen aber sich mit beiläufigen Zahlen begnügen mufs.

Was nun Columbien insbesondere betrifft, von dem es sich hier eigentlich bandelt, so ist dieses einer der gröfsten Slaaten, denn man bereclinet es auf 93,952 Quadratmeilen mit 2,500,000 Einwohnern. Darunter sind Weifse, Gemischte, Eingeborne oder Ifupferfarbene und Schivarze oder Neger. Die bunte Bevölkerung, welcher es zu wünschen ist, dafs sie sich mit einander friedlich verschmelze, betaut ein grofses, reiches Land.

Ein flüchtiger Blick auf die Charte zeigt schon, daf's Columbien reich an Erzeugnissen der warmen Länder seyn müsse, indem es beinahe ausschliefslich manche der edelsten Erzeugnisse in seiner Gewalt hat. Unter diese gehört:

1. Der Cacao. Venezuela allein erzeugt 193,000 Fanegas von 110 spanischen Pfunden. Davon werden 


\section{- 2.:5}

ausgefülurt bei 145,00o Fanegas, im Wertice von fünf Millionen harten Piastern. Im Jahre 1814 zälılte man 16 Millionen Cacao-Bäume. Der Cacao hat das Land berühmt gemacht, er wird jedoch durch die Cultur des Zuckerrohrs und der Baumwolle ver. drängt. Der Cacao ist nicht allein als Handelswaare, sondern auch als Nahrung für die Rewohner sclbst sehr wichtig. Je mehr also die Bevölkerung zunimmt, desto gröfser wird auch der innere Verbrauch werden müssen, und mithin ist Cacao ein Landesreichthum, der im Innern wie nach aufsen gleich wichtig und vortheilhaft ist. Der Cacao von Uritucu, Capiriqual und San Bonifacio, in den Provinzen Caracas, Cumana und Barcellona, ist ungleich? besser, als der von Guayaquil, da der von Gualan gar nicht in den europäischen Handel kömmt.

z. Der Caffee. Für den Anbau des Caffee's sind besonders alle Plateaus von 250 bis 400 Toisen Erhöhung geeignet, die in diesen Provinzen häufig vorkommen, und dem Anbauc dieses köstlichen Strauches sehr zusagen. Obwohl erst seit 1784 eingeführt, sticg doch schon im Jahre 1812 der Ertrag auf $6 \mathrm{c}, 000 \mathrm{Zentner}$.

3. Die Baumwolle der Thäler von Aragua, von Naracaibo und aus dem Golfe von Cariaco ist vorzüglich schön und gut; es betrug jedoch die Ausfuhr im Jahre 1809 nur noch 25,000 Zentner.

4. Zucker. Davon wurden schöne Pflanzungen im Anfange dieses Jahrhunderts in den Thälern von Aragua und Tuy angelegt, in der Nähe von Guatire 
und Caurimare. Die Ausfuhr war höchst unbedeutend. Es iäfst sich jedoch mit Grund annehmen, dafs der Anbau des Zuckers auf dem Festlande einst von gröfster Ausdehnung seyn wrrde.

5. Indigo. Die Cultur dieses wichtigen Produkts lsat sich sehr vermindert, und ist nur noch in der Provinz Varinas im Flore und an den Ufern das Ta. chira. Der Werth des Indigo von Caracas stieg in der günstigsten Zeit auf 1,200,000 Piaster.

6. Der Tabak von Venezuela ist besser, als der Virginisclie, und wird an Güte nur von dem der Insel Cuba ïbertroffen.

7. Cercalien, d.h. Getreidearten. Diese werden in Venezuela angebaut, an allen Orteu, welche einer gemäfsigten Temperatur sich zu erfreuen haber, und man kann nicht olıne Vergnügen von Colum. bien sagen, es sey das Land der Bananen und Getreidearten. Wir lıaben in den Thälern von Aragua, mitten unter dem Caffee und Zuckerrohr, Weizen. felder gesehen. Hat sich einst dieses reiche Land in die Reihe civilisirter Länder emporgeschwungen, so wird man auch allenthalben Getreidearten auf den Feldern sehen, wo das f́lima und dic Lage reiche Ernten verspricht. $\mathrm{Da}$, wo die gemäfsigten Regionen in die heilsen übergehen, zwischen 300 und 50o Toisen Höhe, ist der Anbau des Zuckerrohrs, des Caffec's und der Cerealien gleich möglich; dic Erfahrung zeigt jedoch, dafs dic zwei erstern eint räglicher sind.

8. Quinquina. Der Cuspare oder Cortex Ango 


\section{- 240}

sturae ist ein herrliches Erzeugnifs, dem die catalo. nischen Kapuziner Ruhm verschafft haben. Es gibt eine Cuspare auch bei Cunana, die herrliche fiebervertreibende Kräfte besitzt. Neu-Granada besitzt auch dic echte Cinchona oder den Chinarindenbaum, und so ist Columbien beinahe ausschliefslich im Besitz der wohlthätigen Rinde, deren Anwendung immer allgemeiner werden mufs, und welche als cine Kostbarkeit des Landes angesehen werden kann, die es mit Ostindien in eine Classe stellt.

Bei Grelegenheit der Aufzählung der Reichthümer aus dem Pflanzenreiehe mufs man noeh erwähnen: dic Quassia. Simaruba im Caura-Thale, die Unona febrifuga von Maypures, die Sassaparille vom Rio Negro, das Öhl des Cocosbaumes, die Juvia-Mandeln, die köstlichen Harze am Ober - Orinoko, das Federharz oder Dapiche (Caoutehouc), die Arome von Guiana, wie die Tonga. Bohne, der Pucheri (Lamens Pucherim), das Varinaeu oder den uneeh. ten Zimmt, die Vanille, die schönen Färbestoffe, woraus das Chica bereitet wird, das Blutharz, das Drachenblut, Saftpflanzen, welche die Coehenille ernähren, köstliche Holzarten zu Ebenisten-Arbeiten, treffliehes Bauholz, Bast, zu trefflichen Seilerwaaren, u. s. w. Kann wohl die Natur ein Land herrlicher ausstatten? Und nun rufen wir unsern jungen Lesern in's Gedäehtnifs zurüek, was wir im zweiten Bande gesagt haben, dafs sich das Land von selbst in drei Zonen spaltet. Ackerbau, Vicbzueht, Jagd folgen einander, wie man von der Nordküste 
gegen den Amazonenstrom wandert. Die Küstengegend kann man als dem Ackerbaue, die Ebenen der Viehzucht, die Wälder der Jagd anheingegeben betrachten. Dic oben angegebenen Produlite gehören der ersten und letzten dieser Regionen an. In der Mitte liegt die der Viehzucht. Zur Zeit der Reise des Herrn von Humboldt wurden ausgeführt 30,000 Maulthiere, 174,80o Ochsenhäute und 35,00o Zentner Tasajo, d. h. gedörrtes, leicht gesalzenes Fleisch, die Ilauptnahrung der Sclaven auf den Antillen. Es hat Columbien auch noch Gold, Platina, Quecksilber, Salz, Kohlen und andere noch nicht hinreichend bebaute mineralische Reichthümer. Leider haben bürgerliche Unruhen und die Befreiungskriege den Woblstand gemindert, die Industrie gehemmt, und überbaupt, wie alle Ḱriege, dem Lande viel Nachtheil gebracht. Wird aber die Rulse wiederkehren und sich befestigen, so wird gewifs das Steigen des Wohlstandes nicht minder schnell vor sich gehen, als in den vereinigten Staaten. Woblstand und Hu. manität sind Kinder des Friedens und der Sicherheit, und wenn wir nach jenen Gegenden blicken, dic sich gleichsam jetzt erst aus dem Chaos der bürgerlichen Kriege loswinden, so könrien wir wohl nicht anders, als ihnen den Geist des Friedens, der Eintracht, der Ruhe und Verträglichlieit wünschen; das Übrige hat die Natur alles besorgt!

Sollte zu diesem auch das so wünschenswerthe Work eines Canals ausgeführt werden, und ein Canal an der Grenze Columbien's auf der Landenge 


\section{$-\quad 251$}

von Panama die beiden Meere vereinigen, so würden dem Handel neue Wege geöffnet, wobei der Wohlstand Columbien's nur wachsen und zunebmen könnte. Dafs ein solcher Canal möglich sey, ist linlänglich dargethan, und Herr von Humboldt hat vieles darüber mitgetheilt; zur Ausführung eines solchen Werkes gehört aber eine friedliche Zeit.

\section{Siebentes Kapitel.}

Gestaltung des Landes. - Unebenheiten des Bodens, - Berga knoten, - Ebenen.

Der Zweck dieses Kapitels geht dahin, um mei. nen jungen Lesern ein Bild des Landes zu geben, von dem wir bisher gesprochen haben. Wir werden daher von der Gestalt des Landes, seinen Bergen und Ebenen einen Abrifs zu entwerfen, und in einigen Blättern dic Ideen zusammen zu fassen suchen, welche uns Herr von Humboldt in seinem grofsartigen Gemälde Amerika's niedergelegt hat.

Die Ausdehnung des Landes, welches wir bisher durchwandert haben, beträgt über 15,400 Geviertmeilen. Vor der Reise des Herrn von Humboldt war Südamerika beinahe ganz unbekannt, und die Richtung der Gebirge, die Lage derselben, die Höben der Berge, alles war noch verborgen. Durch diesen Reisenden ist man erst mit der wahren Gestalt dieses Welttheiles, seiner Beschaffenheit und Datur bekannt geworden. 


\section{$-\quad 252$}

Sïdamerika ist eines jener grofsen Dreiecke, welche die drei Landmassen in der südlichen Haldkugel bilden. Der äufsern Form nach ist das Dreieck, welches Südamerika bildet, Afrika noch ähnlicher, als Neu. Holland. Die Südspitzen dieser drei Dreiecke sind so geordnet, dafs das Cap der guten Hoffnung die nördlichste Spitze bildet, und wie man von diesem ostwärts segelt, so sicht man, dafs sich das Land in dieser Richtung bis zum Cap Horn dem Südpole immer mehr nähert, und also das feste Land unserer Erde, vom Vorgebirge der guten Hoffnung aus $33^{\circ}, 35^{\prime}$ his $43^{\circ}$, $38^{\prime}$ eine südöstliche Rich. tung nimmt. Südamerika befafst 571,000 Seegeviertmeilen; von diesen ist der vierte Theil mit Bergen bedeckt, die theils Gebirgsäste, theils abgesonderte Gruppen bilden. Das Übrige besteht aus Ebenen, velche lange, ununterbrochene, mit Wäldern und Gräsern bedeckte Streifen bilden, die eben ansteigen von der Mecresküste aus, so dafs sie in einer Entfernung von 300 Meilen vom Mecre eine Höhe von 30 bis 170 Toisen erreicht haben. Die gröfste Bergkette Südamerika's delnt sich von Süden nach Torden, in der gröfsten Länge des Festlandes aus. Dieses Gebirg ist aber keine Centralkette : wie die Alpen in Europa oder der Himalaya in Asien, d. i. es bildet nicht den Knoten des Landes, sondern es ist vielmehr beinahe an die Ýüste des stillen Oceans vorgeschoben. Man sieht, wie die Landschaft sich gegen Osten auf eine Ausdehnung von 600 Meilen bis zum atlantischen Meere verflächt, wo hingegen das 


\section{$-253$}

Gebirg gegen Westen sich gleiclisam unmittelbar in's Meer versenkt. Wofern in früheren Zeiten der atlantische Ocean jemals zu 1, 100 Fufs Hölıe über seinen gegenwärtigen Stand emporgestiegen ist, so mufsten sich seine Wellen in der Provinz Jaen de Bracamoros an den Felsenriffen brechen, die den östlichen Abhang der Anden - Cordilleren begrenzen. Die Höhe der Berge ist jedoch, im Vergleicbe mit der Breite des Festlandes, so gering, dafs diese vierzehnhundert Mal gröfser ist, als die mittlere Höhe des Andengebirges.

In dem bergigen Theile Südamerika's unterscheidet man eine Gebirgskette und drei Berggruppen, nämlich: die Anden-Cordillere, die sich ununterbrochen vom Cap Pilares, westlich der MagellansStrafse, bis zum Vorgebirge Paria erstreckt. Die drei Berggruppen sind: die Küstenkette von Venezuela oder die abgesonderte Gruppe der Siera Tevada von Santa Martha, die Gruppe der ParimeBerge, vom Orinoko umfangen, und die Berge von Brasilien. Die Berggruppe von Santa Martha steht ganz abgesondert da vor der Andeskette, mit der sie gar nicht zusammenhängt. Zwischen dem See Maracaibo und dem Magdalenenstrome ist die Wasserscheide in der Ebene selbst gelegen. Es ist vielmehr diese mit ewigem Schnee bedeclitc Sierra von Santa Martha mit der Küstenkette von Venezuela durch den Paramo de las Rosas verbunden. Von den drei Berggruppen, welche nicht Äste der Anden. Cordilleren sind, ist die erste die Sierra Ne- 
vada de Santa Martha nördlich gelegen, die beiden andern, die Parime - und Brasilienberge, liegen die erstere zwischen dem $4^{\circ}$ und $8^{\circ} \mathrm{N}$, Br. die letz. tere zwischen dem $15^{\circ}$ und $28^{\circ} \mathrm{S}$. Br. Aus dieser Vertbeilung der Berge entstehen drei Ebenen oder Becken, die zusammen $4 / 5$ von ganz Südamerika ausmachen, und ostwärts der Anden einen Flächen. raum von 420,600 Quadratmeilen, 20 auf cinen Grad, umfassen.

Zwischen der Küstenkette von Venezuela und der Gruppe der Parime-Berge dehnen sich aus: die Ebenen von Apure und Unter. Orinoko. Zwischen der Gruppe von Parime und Brasilien befinden sich die Ebenen vom Amazonenstrome, vom Rio Negro und Madeira. Zwischen der Gruppe von Brasilien und dem südlichen Endtheile des Festlandes liegen die Ebenen vom Rio de la Plata und von Patagonien. Weil nun alle diese Berggruppen weder unter einander, nóch mit der Andenkette zusammenhängen, so hängen alle die genannten Ebenen vom Unter - Orinoko, Amazonenstrome, Rio de la Plata und Patagonien durch bedeutend breite Landzungen mit einander zusammen, so dafs sich eine Linie denken läfst, auf welcher man ganz Südamerika, ohne einen Berg zu übersteigen, in einer beinalıe wagerechten Fläche durchwandern künnte.

Diese Ebenen werden wieder von Linien durchzogen, welche man Fíanten nennen könnte, und dic, obwohl sie sich dem Auge entziehen, doch die Wasserscheide (dirortia aquarum) in diesen unermefs- 


\section{$-255$}

lichen Ebenen bilden. Man könnte sie gleichsam unter der Oberfläche verborgene Kanten nennen, durch welche die Gebirge mit einander zusammenllängen. Diese Gräten oder Giebellinien befinden sich unter dem $2^{\circ}$ und $3^{\circ} \mathrm{N}$. Br. und dem $16^{\circ}$ und $18^{\circ} \mathrm{S}$. Br. Die e r ste Schwelle theilt die Gervässer, welche sich nordöstlich in den Unter-Orinoko, südlich und südöstlich aber in den Rio Negro und Ama. zonenstrom ergiefsen. Die $\mathrm{z}$ weite $\mathrm{S}$ chwelle sondert die Zuflüsse des recbten Ufers vom Ama. zonenstrome und vom Rio de la Plata. Die Richtung dieser Giebellinie ist so beschaffen, dafs wenn sie als Bergäste über den Boden hervorragten, so würde die Gruppe von Parime mit den Anden von Panama, und die Gruppe von Brasilien mit dem Vorgebirge der Anden von Santa Cruz de la Sierra, von Cochabanca und von Potosi vercinbart werden. Hieraus läfst sich einigermafsen das Gerippe des südamerikanischen Erdtheils zusammensetzen. Diese beiden Schwellen, welche sich nur durch die Trennung der Gewässer kund geben, laufen mit der Küstenkette von Venezuela parallel. Von den drei Ebenen, nämlich der zwischen der Küstenkette von Venezuela und der Parime, vom Amazonenstrome und Buenos - Ayres, dic durch Erdzungen zusammen. hängen, ist die erste und letzte mit Gras, die mittlere aber mit dichter Waldung hewachsen.

Ostwärts der Anden, auf einer Fläche von 480,00o Geviertmeilen, von denen 92,000 Bergland sind, findet sich kein Berg, der bis zur Grenze des ewi- 


\section{$-250$}

gen Schnees sich erhöbe, oder auch nur auf 1,400 Toisen Höhe reichte. Diese Senkung der Berge erstreckt sich bis zum $60^{\circ} \mathrm{N}$. Br., während im west. lichen Theile der Verlängerung der Andenkette in Mexiko unter $18^{\circ}, 59^{\prime}$ auf 2,770 Toisen, in den Fels. gebirgen $37^{\circ}$ bis $40^{\circ}$ auf 1,900 Toisen ansteigen. Die höchsten Berggipfel der Aleghanys in Nordame. rika, welche durch ihre Länge den brasilianischen Bergen entsprechen, übersteigen nicht 1,040 Toisen. Diejenigen Berggipfel also, welche den Montblanc an Höhe übertreffen, gehören der Längenkette der Anden an, welche das Becken des stillen Oceans einfafst. Die einzige isolirte Gruppe, welche mit den Andengipfeln wetteifert, ist die Sierra de St. Martha. Aber auch sie ist an der Westseite der Gruppe der Küustenkette von Venezuela.

Betrachtet man die östlichen Gebirge des Continents allein insbesondere, so sieht man die Berg. gipfel von Norden gegen Süden zu abnehmen. Die höchste Spitze der Küustenkette ist dic Silla von Ca. racas, 1,35o Toisen, der Pik von Duida 1,300 Toisen, in der Parime-Gruppe und in der brasiliani. schen Berggruppe den Itacolumi und der Itambe 900 Toisen.

Nun müssen wir aber auch wohl bemerken, dafs bei der Beurtheilung der Höhe eines ganzen Gre birges man sich nicht an die höchsten Spitzen halten und darnach die Höle beurtheilen dürfe. Der Dhawalaghiri im Himalaya Gebirge ist 676 Toisen höher als der Chimborazo, dieser goo Toisen höher 
als der Montblane, dieser wieder 636 Toisen höher als der Pik Nethou in den Pyrenäen. Hieraus ergibt sich aber keineswegs, dafs auch der Unterschied dieser verschiedenen Bergrücken derselbe sey, we!cher der der höclssten Spitzen ist. Das will sagen: der Bergrücken des Himalaya ist nicht auch um ${ }_{676}$ Toisen höher, als der Bergrücken der $A \mathrm{n}$ den. Bergrücken nennt man die Gebirgsfäche, auf welcher sich die abgesonderten Piks, Dome oder Nadeln erheben; derjenige Theil eines Bergrückens, wo dic Übergänge Statt finden, also ist es, der ein richtiges Mafs von dem Minimum der Höhe gibt, das die hohen Bergketten erreichen. Herr von Humboldt berechnet die mittlere Hühe des Himalaya, zwischen dem $75^{\circ}$ und $77^{\circ}$ üstlicher Länge, auf 2,450 Toisen, die der Anden in Peru, Quito und NeuGranada auf 1,850 Toisen, die des Grates der Al. pen und Pyrenäen auf 1,150 Toisen. Somit ist der Unterschied der IIölien der Cordilleren und der Schweizer-Alpen um 200 Toisen kleiner, als der ihrer höchsten Spitzen. Die eigentlichen Gebirgerücken der Alpen und der Pyrenäen sind von der. selben Höhe, obgleich der Montblanc um 600 Toi. sen höher als der Pik Nethou ist. Hingegen hatten das Himalaya- und das Anden-Gebirg dieselben Verhältnisse zu, cinander, d. h. um wie viel der Dhawalaghiri höher ist, als der Chimborazo, um so viel ist auch der Bergrücken des Ilimalaya höher, als der der Anden. Berechnet man nun auch die Höhe der Bergrücken, so ergibt sich für die Küstenkette 


\section{- 258}

von Venezuela eine IIöhe von 750 Toisen, für die von Parime 500 Toisen und die in Brasilien 400 Toisen. Hicraus erhellt, dafs die Erhöhung der südamerikanischen Berggruppen zur mittlern Erhöhung der Andeskette sich verhält wie $1: 3$. Um noch genauere Übersicht über den Bau der Berge zu erlangen, empfehlen wir beifolgende Tabelle.

\begin{tabular}{|c|c|c|c|}
\hline $\begin{array}{c}N \text { a me } \\
\text { der } \\
\text { Bergketten. }\end{array}$ & $\begin{array}{l}\text { Höchste } \\
\text { Gipfel. }\end{array}$ & $\begin{array}{l}\text { Mittlere } \\
\text { Höheder } \\
\text { Berg- } \\
\text { rücken, }\end{array}$ & $\begin{array}{l}\text { Verhältenifs } \\
\text { der mittlern } \\
\text { Höhe an } \\
\text { Bergrücken, } \\
\text { uur Höhe der } \\
\text { höchsten } \\
\text { Gipfel. }\end{array}$ \\
\hline $\begin{array}{l}\text { Himalaya (zwischen } 30^{\circ}, \\
18^{\prime} \text { und } 31^{\circ}, 53^{\prime} \mathrm{N} . \mathrm{Br} \text {. } \\
\text { und } 75^{\circ}, 23^{\prime} \text { his } 77^{\circ}, 38^{\prime} \\
\text { Ö. L.). . . . . }\end{array}$ & 4026 & 2450 & $1: 1,6$ \\
\hline $\begin{array}{l}\text { Anden-Cordilleren (zwi- } \\
\text { schen } 5^{\circ} \mathrm{N} \text {. und } 2^{\circ} \mathrm{S} \text {. } \\
\text { Br.) }\end{array}$ & 3350 & 1850 & $1: 1,8$ \\
\hline Schweizer-Alpen & 2450 & 1150 & $1: 2,1$ \\
\hline Pyrenäen . & 1787 & 1150 & $1: 1,5$ \\
\hline $\begin{array}{l}\text { Küstenkette von Vene- } \\
\text { zuela... } . . .\end{array}$ & 1350 & 750 & $1: 1,8$ \\
\hline $\begin{array}{l}\text { Berggruppe von Parime } \\
\text { Berggruppe von Brasi- } \\
\text { lien }\end{array}$ & 1300 & 500 & $1: 2,6$ \\
\hline
\end{tabular}




\section{- 250}

liieraus ergibt sich, dafs wenn man die einzeln erhabenen Piks von den eigentlichen Gebirgen unterscheidet, die höchsten Punkte des Erdballs den zwei Gebirgsketten der Cordilleren und des Himalaya angehören.

Toch ist eine Eigenheit bemerkbar. Die höchsten Gipfel der Anden sind Trachyt-Berge oder Glocken aus Trapp-Porpliyr, und man kann überall in dicser ganzen Kette als Regel annelımen, dafs da, wo die Piks der Anden die Grenze des ewigen Schnees erreichen, auch allezeit das Urgebirg ver. schwindet, und der Trachyt über denselben aufgelagert erscheint. Es sind nur wenig Ausnahmen, wie in den Cordilleren von Quito, wo die Schnee. berge von Condorasto und Cuvillan, dem Chimborazo gegenüber stehend, aus Glimmerschiefer ge. bildet sind, und Gänge von geschwefeltem Silber enthalten.

Desgleichen zeigen auch die vereinzelten Berggruppen, welche sich jählings mitten aus den Ebenen erheben, die höchsten Gipfel nur als vulkanisclse Gebirgsarten neuerer Entstehung, z. B. der Movna. Roa auf den Sandwichinseln, der Pik von Teneriffa, der Aetna, der Pik der Azoren u. a.m. In der beinahe isolirt stehenden Gruppe der Sierra Nevada von Neu-Granada bildet der Gneifs - und Glimmerschiefer den 1826 Toisen hohen Pik von Mulhacen, so wie aus dieser Gebirgsart die Alpen, Pyrenäen und wahrscheinlich auch das Himalaya-Ge. birg gebildet sind. Vielleicht sind alle diese Er. 


\section{- $200-$}

scheinungen, so verschieden sie scheinen, dennoch Wirkungen derselben Ursache. Vielleicht sind die Granit - und Gneifsgebirge und alle angeblich neptunischen Urgebirge nicht weniger Ergebnisse vulkanischer Kräfte, wie die Trachytgebirge es sind! Unter diesen vulkanischen Kräften werden jedoch solche verstanden, die ungleich gröfser sind, als welche sich jetzt unserer Erfahrung darbicten, und für welche wir innerhalb dieser Erfahrungen keinen Mafsstab besitzen. (So überraschend diese Ansicht ist, so sehr ist sie doch aus der Natur selbst ge. nommen, dafs man bei einigem Nachdenken gestehen mufs, Herr von Humboldt habe in dieser merkwür. digen Stelle das Geheimifs der Gebirgsbildung aus. gesprochen.)

Wir wollen nun über jede der bisher aufgeführten Gebirge noch Einiges im Einzelnen beifügen, und boffen, dafs unsere jungen Leser diesem Gegenstande, der so viel Stoff zum Nacbdenken gibt, gerne noch einige Aufmerksamkeit schenken werden.

1. Die Anden-Cordilleren; diese Hauptkette ist es, die wir zuerst betrachten wollen. Ich möchte sie gleichsam die Nath des Erdballs nennen, denn von allen diesen Gebirgsketten des Erdballs ist diese die am meisten zusammenhängende, die längste und von Süd nach Nord und Nord-Nord - West die beharrlichste. Sie nähert sich dem Nordpole bis zum $65^{\circ}$, indem sie im $52^{\circ} \mathrm{S}$. Br. ihren Anfang nimmt. Sie gehört beiden Amerika an, die sie durch den 
Felsendamm der Landenge von Panama und Guatimala mit einander verbindet; dort, wo ostwärts sich das niedere Land in's Meer versenkt hat, und jetzt das mittelländische Meer der neuen Welt bildet. In der sïdlichen Hälfte Amerika's sind die Berge dem stillen Meere ganz nahe zugeschoben, so dafs an mehreren Punkten der Fufs der Anden unmittelbar von den Wellen des grofsen Oceans bespült wird. In der nördlichen Hälfte entfernt sich die Bergkette etwas weiter von den Kï̈sten, ungefähr acht bis zehn Mal weiter, als in der südlichen Halbkugel. Als die zwei Endknoten des Andengebirgs nimmt Herr von Humboldt in Süden den Granitfels oder das kleine Eiland Diego Ramirez, dem Cap Horn gegenüber, den nördlichen Endpunkt aber: am Makenzieflusse jene Berge, welche unter dem Namen der Copper Mountains bekannt sind.

Die Breite der Cordillerenkette beträgt überall nicht mehr als 18 bis 22 Meilen. Davon sind jedoch ausgenommen die Bergknoten, wo die Cordillere sich durch jene hohen Strebepfeiler gleich. sam eine Verstärkung bildet, von hier aus eine Menge Seitenäste und Parallel-Ketten aussendet, und gleichsam eigene Giebirgsstöcke zu bilden scheint. An solchen Stellen zeigen sie eine Breite von 100 bis 120 Meilen. Wo diese Bergknoten durch die Arme, die sie gegen Osten aussenden, sich den Berggruppen des Osten nähern, da bilden sie alsdann die Landengen, d. h. jene breiten Bergpässe, 
wodurch die grofsen Ebenen mit einander zusammenhängen. Die Anden Südamerika's, vom Cap Pilares bis zu Choco auf der Landenge von Panama, bedecken einen Flächeninhalt von 58,90o Quadratmeilen.

Der Bau der Cordilleren besteht aus mehreren Knoten; ich kann dieses meinen jungen Lesern nicht besser versinnlichen, als durch das Gleichnifs eines ungeheuren Walles, der das Land von dem Eindringen der Mleerungeheuer schützen soll, und von Zeit zu Zeit durch einige Thürme mit auslaufenden Seitenwällen besetzt ist. Dieses sind die Bergknoten. Sie sind südwärts vom $48^{\circ} \mathrm{Br}$. niedriger, als die Pyrenäen, heben sich nordwärts dieser Breite und erreichen zwischen dem $25^{\circ}$ und $0^{\circ} \mathrm{S}$. Br. ihre höchste Höhe. Zwischen dem $20^{\circ}$ und $10^{\circ}$ süd. licher Breite bilden sie drei parallele Ketten, und hier ist cs, wo, nach neuern Reisenden, in der mittleren Parallelkette sich die Piks befinden, die bis zur Höhe von 4,900 Toisen ansteigen, und selbst das Himalaya-Gebirg an Höhe übertreffen sollen. Nordwärts vom Aequator senkt sich die Andeskette wieder, erhebt sich abermal in Mexiko, und erreicht hier die gröfste Höhe in ihrem nördlichen Laufe. Weiter gegen Norden sind die Nachrichten noch unvollständig; so viel ist jedoch gewifs, dafs sie in ihrer nördlichen Richtung die Höhe der Pyrenäen nicht übersteigen; denn der colossale St. Eliasberg in Neu-Nordfolk scheint nicht mehr den 
Anden-Cordilleren anzugehören. Die Andeskette erreicht an mehreren Orten in der heifsen Zone die Grenze des ewigen Sclinees, aber in Chili steigt die Schneelinie nicht über 2000 Toisen herab.

Um unsere jungen Leser nicht $z u$ ermüden, miissen wir uns schon hier enthalten, in die naturhistorische Beschreibung der Anden wicder einzugehen. Wir wollen daber nur die erwähnten Bergknoten aufzählen und hiezu dic folgende Tabelle cinfügen.

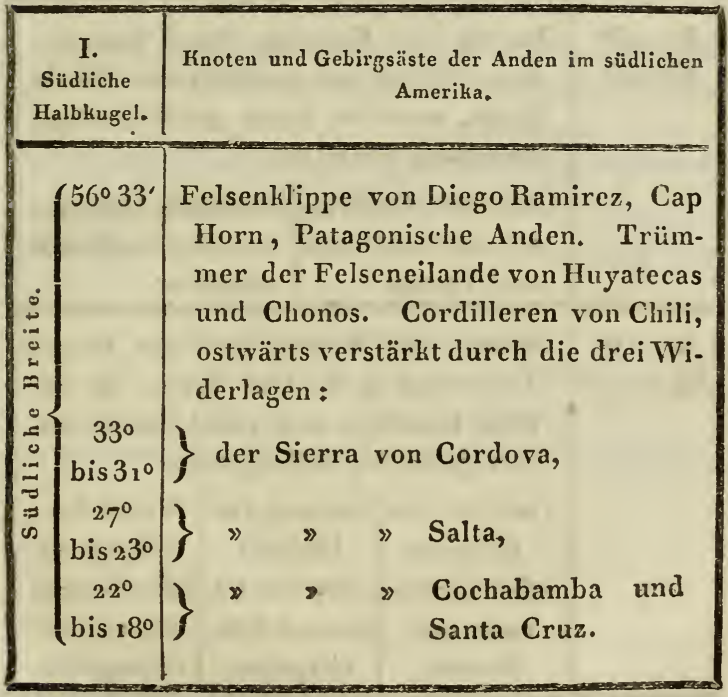




\begin{tabular}{|c|c|}
\hline $\begin{array}{c}\text { I. } \\
\text { Südliche } \\
\text { Halbkugel. }\end{array}$ & $\begin{array}{l}\text { Knoten und Gebirgsäste der Anden im südlichen } \\
\text { Amerika. }\end{array}$ \\
\hline $\begin{array}{l}\text { Br. } 20^{1} / 2^{0} \\
\text { bis } 19^{1 / 2^{0}}\end{array}$ & \begin{tabular}{r|l} 
Knoten von Porso und Potosi. Tren- \\
nung in zwei Gebirgsäste, östlich und \\
westlich vom Becken des Titicaca. \\
Östlicher Gebirgs- \\
$\begin{array}{l}\text { Westl. Gebirgsast von la Paz und } \\
\text { ader von Taaina } \\
\text { Palca. }\end{array}$
\end{tabular} \\
\hline $\begin{array}{l}\text { Br. } 15^{\circ} \\
\text { bis } 14^{\circ}\end{array}$ & 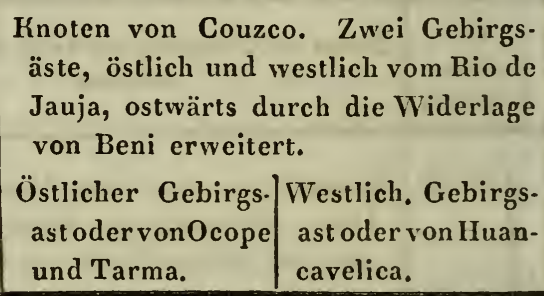 \\
\hline $\begin{array}{l}\text { Br. } 11^{\circ} \\
\text { bis } 10^{1 / 2} 2^{\circ}\end{array}$ & 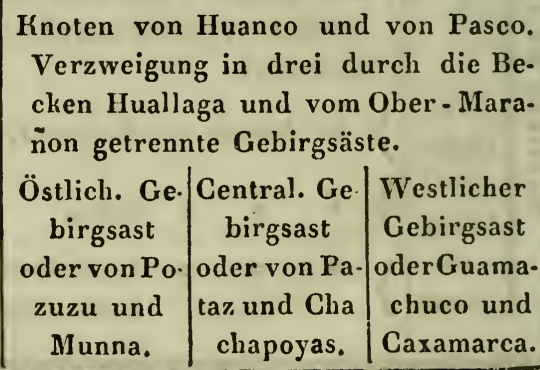 \\
\hline
\end{tabular}




\begin{tabular}{|c|c|}
\hline $\begin{array}{c}\text { I. } \\
\text { Südliche } \\
\text { Halbkugel. }\end{array}$ & $\begin{array}{l}\text { Knoten und Gebirgsäste der Anden im südlichen } \\
\text { Amerika. }\end{array}$ \\
\hline $\begin{array}{l}\mathrm{Br} .5^{1 / 4^{\circ}} \\
\text { bis } 31 / 4^{\circ}\end{array}$ & $\begin{array}{l}\text { Knoten von Loxa. Zwei Gebirgsäste, } \\
\text { östlich und westlich vom Becken von } \\
\text { Cuenza. }\end{array}$ \\
\hline $\begin{array}{l}\text { Br. } 2^{\circ} \\
\text { bis } 27^{\prime}\end{array}$ & 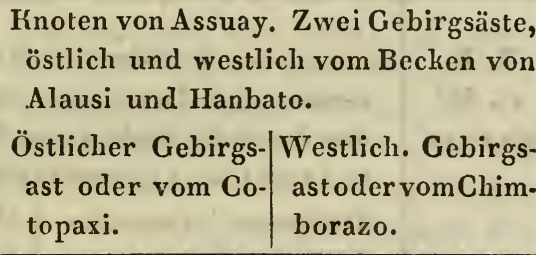 \\
\hline $\begin{array}{l}\mathrm{Br}, 0^{\circ} \\
\text { bis } 40^{\circ}\end{array}$ & $\begin{array}{l}\text { Gräte von Chisinche. Zwei Gebirgs- } \\
\text { äste, östlich und westlich vom Thale } \\
\text { Quito. } \\
\text { Östlicher Gebirgs- } \\
\begin{array}{ll}\text { ast oder vom An- } & \text { ast oder vom Pi- } \\
\text { tisana. } & \text { chincha. }\end{array}\end{array}$ \\
\hline
\end{tabular}




\section{- 200}

\begin{tabular}{|c|c|}
\hline $\begin{array}{l}\text { II. } \\
\text { Nördliche } \\
\text { Halbkugel. }\end{array}$ & $\begin{array}{l}\text { Der Aequator durchschneidet den Gipfel von } \\
\text { Cayambe (der dem Gebirgsaste von Antisana } \\
\text { angehört). }\end{array}$ \\
\hline $\begin{array}{l}\text { N. Br. } 12^{\circ} \\
\text { bis } 114^{\circ}\end{array}$ & $\begin{array}{l}\text { Knoten von los Pastos. Theilung in } \\
\text { zwei Gebirgsäste, östlich und west- } \\
\text { lich vom Plateau von Almaguer. }\end{array}$ \\
\hline $\begin{array}{l}\text { N. B. } \\
1^{\circ}, 55^{\prime} \\
\text { bis } 2^{\circ}, 20^{\prime}\end{array}$ & 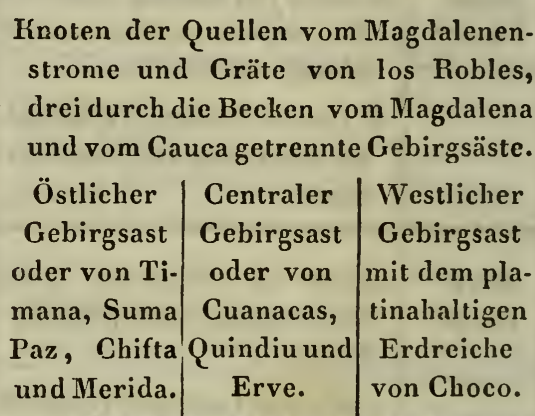 \\
\hline $\begin{array}{c}\mathrm{Br} .512^{\circ} \\
\text { bis } 7^{\circ}\end{array}$ & $\begin{array}{l}\text { Knoten der Provinz von Antioquia, } \\
\text { worin sich nur allein die Gebirgsäste } \\
\text { von Quindiu und Choco vereinigen. } \\
\text { Der centrale Gebirgsast verlängert } \\
\text { sich durch Wiederlagen gegen Honda. }\end{array}$ \\
\hline
\end{tabular}




\section{$-207$}

\begin{tabular}{|c|c|}
\hline $\begin{array}{c}\text { II. } \\
\text { Nördliche } \\
\text { Halbkugel. }\end{array}$ & $\begin{array}{c}\text { Der Aequator durchschueidet den Gipfel von } \\
\text { Cayambe (der dem Gebirgsaste von Antisana } \\
\text { angehört). }\end{array}$ \\
\hline $\begin{array}{c}\text { Br. } 7^{\circ} \\
\text { bis } 9^{\circ}\end{array}$ & $\begin{array}{l}\text { Trennung des Kinotens der Berge von } \\
\text { Antioquia in vier Äste : 1. von la Si- } \\
\text { mitarra, 2. von Caceres, Nechi und } \\
\text { Altos de Tolu, 3. zwischen dem Rio } \\
\text { St. Jorge und dem Atrato, 4. west- } \\
\text { lich vom Atrato. Dieser letzte sehr } \\
\text { niedrige Ast scheint höchstens dureh } \\
\text { cinen schwachen Ast oder Gräte mit } \\
\text { der Landenge von Panama verbunden } \\
\text { zu seyn. Der östliche Gebirgsast der } \\
\text { Anden von Neu - Granada, der von } \\
\text { Suma Paz und Sierra Nevada de Me- } \\
\text { rida bleibt von der Sierra Nevada } \\
\text { de Santa Marta durch die Ebene vom } \\
\text { Rio Cesar getrennt, er vereinbart sich } \\
\text { hingegen durch die Berge von Bar- } \\
\text { quisimento und von Nirgua, mit der } \\
\text { Küstenkette von Venezuela, dessen } \\
\text { culminirende Punkte sind : die Silla } \\
\text { von Caracas, der Brigantin, der } \\
\text { Turimiquiri und das Vorgebirg von } \\
\text { Paria. }\end{array}$ \\
\hline
\end{tabular}




\section{- 208}

Diese Tabelle kann einigermafsen die Gestalt der Anden des Continents von Südamerika versinnlichen. Man unterscheidet auf dieser Strecke zehn Ḱnoten, als eben so viele Verzweigungspunkte von dem Äste auslaufen, welche entweder Hochebenen, oder tiefe Becken, oder Thäler einschliefsen. Diese Thäler sind die Rinnsale der Quellen und Flüsse, oder auch Behälter von Gewässern, die man Bergseen nennt, welche aber so häufig nicht sind, als in den Alpen.

\section{Achtes Kapitel.}

Fortsetzung des Vorigen, - Becken und Thäler. - Höchste Spitzen. - Die übrigen Berggruppen.

Unter den Becken der Gebirge versteht man die Vertiefungen, welche von den einzelnen Bergen ciner Gebirgskette, wie von einer Mauer, einge. schlossen werden. Von den Becken, welche die südamerikanischen Anden einschliefsen, und die wahrscheinlich einst eben so viele Seen oder Binnenmeere gebildet haben, beträgt die Grundfläche des Sees von Titicaca allein 3500 Geviertmeilen, das Becken des Rio Jauja 1300 und das des Ober. Marañon 2400. Das Becken von Titicaca ist dermassen geschlossen, dafs kein Tropfen Wasser davon ausgehen mag, als durch Verdünstung. Es ist hier das geschlossene Thal von Mexiko gleichsam wiederholt, und man wird auf die Vermuthung geführt, dafs die vielen kreisförmigen Öffnungen im Monde 
wohl eben so viele Becken seyn müssen. Das Becken von Titicaca ist durch einen sehr grofsen Alpensee ausgezeichnet; die übrigen Becken ergiefsen ihre Gewässer durch natürliche Canäle, welche als so viele Spalten an den Wänden der Becken angesehen werden können. Noch kennt man die Höhe dieser drei Becken nicht, hingegen hat Herr von Humboldt ausgemittelt, dafs der Grund des Thales von Cuenza 135o, des von Alausi 1326 , des von Quito 13 q́o und in seinem westlichen Theile 1490, das Becken von Almagues 1160 , das von Cauca 500, das von Magdalena 200, und das Thal von Honda 100 Toisen über der Fläche des stillen Meeres erhaben sind. Die Höhe der Thäler zu erforschen ist schr vichtig, um über die Bildung der Thäler urtheilen zu können.

Üherschreitet man die Meerenge von Darien, so sieht man, wie sich die Anden nach ihrem Abfalle oder Einsenkung, die sich zwischen den Mündungen des Atrato und dem Golfe von Caupiza befindet, auf ihrem nordwestlichen Laufe wieder heben, sich in Veragua vergröfsern und wachsend durch Guate. mala bis Mexiko ausdehnen. Auch hier bilden sic wieder dieselben Grebirgsknoten und Verzweigungen, indem sie oberbalb Mexiko sich von der Westlüste des grofsen Oceans entfernen. Die Structur der Anden nordwestlich von Darien ist folgende.

N. Br. $8^{\circ}$ bis $11^{\circ}$. Berge der Landenge von $\mathrm{Pa}$ nama, von Veragua und von Costa Rica, in schwa. 
chem Zusammenhange mit dem Choco, dem wostlichen $\mathrm{Z}$ weige von Neu-Granada.

N. Br. $11^{\circ}$ bis $16^{\circ}$. Berge von Nicaragua und Guatemala; Vulkane, die in der Richtung von N. W. einander folgen; und meist noch thätig sind, vom Golfe von Nicoya bis zum Vulkane von So. conusco.

N. Br. $16^{\circ}$ bis $18^{\circ}$. Urgebirge der Provin Oaxaca.

N. Br. $18 \frac{1}{2^{\circ}}$ bis $19^{1} 2^{\circ}$. Trachytische Knoten von Anahuac; Parallele der Nevadas und der brennenden Vulkane von Mexiko.

N. Br. $19^{1} 2^{\circ}$ bis $20^{\circ}$. Knoten der metallhaltigen Berge von Guanaxuato und Zacatecas.

N. Br. $2134^{\circ}$ bis $22^{\circ}$. Trennung der Anden von Anahuac in drei Zweige.

Östlicher Zweig (von Potosi und von Texas), fortgesetzt durch die Berge Ozark und Wisconsan bis zum Obersee.

Central-Zweig (von Durango, Neu-Mexiko und von dem Felsengebirge) der einen Ast, der immer niedriger wird, bis zum Makenzie-Flufs aussendet.

Westlicher Zweig, der sich durch Widerlagen mit den Secalpen von Californien verbindet.

Was nun die Höhe der Anden anlangt, so sollen sie süđwärts des Bergknotens von Loxa die Himalaya-Gipfel selbst übertreffen, allein noch hat man nichts Gewisses hierüber. Hingegen wissen wir, 
dafs nördlich von den Bergen von Loxa die Cor. dilleren sich fünf Mal über die ansehnliche Höhe von 2600 Toisen erheben.

In der Gruppe von Quito, vom $0^{\circ}$ bis $2^{\circ} \mathrm{S} . \mathrm{Br}$. (Chimborazo, Antisana, Cayambe, Cotopaxi, Collannes, Yliniza, Sangai, Tunguragua).

In der Gruppe von Cundinamarca, vom $43 \% 4^{\circ}$ N. Br. (Pik von Tolima, nördlich der Anden von Quindiu).

In der Gruppe von Anahuac, vom $18^{\circ}, 59^{\circ}$ bis $19^{\circ}, 22^{\prime}$ (Popocatepetl oder der grofse Vulkan von Mexiko und der Pik von Orizava).

Betrachtet man die Kette des russischen Amerika als eine Fortsetzung des östlichen $\mathrm{Zweiges}$ von Mexiko, so kann man hinzufügen die Berggruppe des russischen Amerika, $60^{\circ}$ bis $70^{\circ} \mathrm{N}$. Br. (der St, Elias. berg).

Es sind zur Zeit nur noch die 12 Andengipfel, welche 2600 Toisen erreichen, bestimmt bekannt; und die also den Montblanc um 140 Toisen übersteigen. Von diesen 12 Kuppen sind nur drei nördlich von der Landenge von Panama.

2. Die isolirte Schneegruppe von Santa Martha. Sie ist eingeschlossen von zwei auslaufenden Zweigen der Anden, dem von Bogota und dem der Landenge von Panama.

Diese Berggruppe erhebt sich plötzlich, wie ein festes Schlofs, aus den Ebenen, die von dem Golfe von Darien durch die Mündung des Magdalenen. Flusses bis zum See von Maracaibo sich ausdehnt. 


\section{- 272}

- Noch hat man den höchsten Gipfel der Sierre de St. Martha nicht gemessen; Vermuthungen geben ihr eine Höhe von $\mathrm{mchr}$ als 3000 Toisen.

3. Die Küstenkette von Venczuela. Diese Kette, die wir schon öfter beschrieben haben, ist dicjenige, welche den grofsen Einflufs auf die Cultur von Venezuela hat. Keiner ihrer Gipfel erreicht die Schneelinie. So, wie die Anden, ist auch sie häufigen Erderschütterungen unterworfen, aber kein brennender Vulkan ist bis jetzt in ihr vorgckommen. Die höchste Spitze ist die Silla von Caracas. Diese Kette zeigt die gleichen Erscheinungen ihres Baues, wie dic Andenkctte, nämlich: Trennung in verschiedenen Parallelkreisen und die zahlreichen Bccken und Längenthäler. Da jedoch die Einbrüche des Antillenmeercs in einer unbekannten Vorzeit einen Theil der Küstenkette versenkt zu haben scheinen; so stellen sich dic Rcihen oder Zweige unterbrochen dar, und einige vormalige Becken sind occanische Golfe geworden.

4. Dic Gruppe der Parime-Berge trennt die Ebene des untern Orinoko von der des Amazonenstromes. Sie bedeckt das Land zwischen $3^{\circ}$ und $8^{\circ}$ $\mathrm{N}$. Br. und $60^{\circ}$ bis $70^{\circ} \mathrm{W}$. L. Sic bedeckt eine Fläche von 25,000 Geviertmeilen. Weil man in Amerika nur an die Anden denkt, so haben die Erdbeschreiber dicse Bcrggruppe beinahe ganz vergessen, was sie jedoch ihrer Wichtigkeit 


\section{- 273}

wegen nicht verdient. Sie ist neun Mal so grofs, als die Schweiz. Der Boden, auf dem sich die Berggruppe erhebt, scheint etwas gewölbt. Der höchste Gipfel dieser bis jetzt unerforschten Berglkette, den man kennt; hat 1300 Toisen Höhe.

5. Die Berge von Brasilien sind gemäfsigte Plateaus und wirkliche Bergketten. Der eigentliche Bergrücken hat 400 Toisen Höhe. Diese Berge entsprechen an Form, Lage und Richtung der Bergkette von Chili, die ihr gegenüber liegt; sie sind aber fünf Mal niedriger. Die culminirenden Punkte dieser Berggruppe sind; der Itambe 932 Toisen Höhe, die Sierra Piedade 910 und der Itacolumi 900 Toisen. Der Itabira 8,6 Toisen.

Wenn man nun einen Blick auf den Bau des ganzen Amerika wirft, so sieht man, dafs die höchste und beständigste Kette von Bergen die der Anden ist. Ihr gegenüber, am östlichen Rande des Continents, liegen einzelne Berggruppen (eine grofse, zerstörte Íette), dic allezeit gegenüber liegenden Theilen der Anden entsprechen, immer aber niedriger sind. Die Gegenüberstellung findet folgender Mafsen Statt:

Die Anden von Chili und Ober - Peru, Berg- Brasilien, niedriger, und knoten von Porco und zwar die gröfste Hölıe $9^{32}$ von Couzco, 2,500 Toisen Toisen. Höhe. 


\section{- 274}

Anden von Popayan und Cundinamarca, Ge. birgszweig von Guanacas, rom Quindiu und vom Antioquia, über 2,800 Toisen.

Isolirte Gruppe der Schneeberge von Santa Martha. Ihre Höhe 3,000 Toisen.

Vulkanische Anden von Guatemala und Primitiv. Anden von Oaxaca, von 1,700 bis 1,800 Toisen Höhe.

Anden von Neu. Mexiko und Ober-LuisianaFelsengebirg. Mehr westlich Seealpen von NeuAlbion, 1,600 bis 1,900 Kette des Küstenlandes von Venezuela, um 80 Toisen niedriger, als die skan. dinavischen Alpen, 1,350 Toisen.

Gruppe der Antillen. Die blauen Berge von Ja. maika, 1,140 Toisen. Toisen.

Ketten der Alegbanys, um 160 Toisen höber, als der Jura und der Gates von Malabar, 1,040 Toisen.

So sind die Berge des neuen Festlandes beschaffen und aufgesetzt. Die Gebirge schliefsen nun jene - Becken ein, die wir Ebenen nennen, und welche das bergfreie Land Amerika's einnehmen. Wir wol. len nun mit Aufzählung dieser Ebenen diese Abschweifungen schliefsen. Wir fangen von Norden her an: 


\section{$-\quad 275$}

1. Das Becken des Missisippi und von Canada. Dieses Becken ist zwischen den Anden und Ale. ghanys enthalten, und gegen Norden eben so, wie gegen Süden, geöffnet. Es enthält die Flưfsgebiete des Lorenzstromes, Missouri, Missisippi und Makenziestromes. Die Wasserscheiden sind auch hier in den Ebenen. selbst. Nirgend ist eine Querkette vorhanden, und die Ebenen werden sowohl gegen Norden als Süden, nur durch die noch flächern Meerebenen der Hudsonbai und des Antillenmeeres begrenzt. Diese Ebene begreift 2.70,000 Quadratmeilen, und ist beinahe so grofs, wie ganz Europa. Sie begreift mebrere Seen in sich, aber der höchste ist nur 100 Toisen erhaben. Diese Ebenen sind grasbewachsene Savanen, und in Canada wah. rer Wiesengrund. Doch sind auch grofse Strecken mit Urwald besetzt. Unter den Ebenen Amerika's ist in dieser Ebene die Civilisation am meisten vorgeschritten.

2. Das Becken des Antillenmeeres und des Golfes von Mexiko. Es ist eine Fortsetzung des Beckens vom Missisippi, man möchte sagen, er sey der unter Wasser liegende Theil des Beckens von Missisippi. Dieses Becken kann man mit Recht das Mittelmeer der neuen Welt nennen. Die Antillen bilden eben so viele Ausgänge desselben, und man kann sich nicht bergen, dafs dieses der Punkt seyn möchte, den viclleicht die Vorsehung zum einstigen Markte 


\section{$-270-$}

der Welt bestimmt hat. Es scheint, dafs hier den Gewässern durch einen Gewaltstreich der Natur der Eingang geöffnet worden sey, und die Antillen sind eben so viele Trümmer eines Riesendammes, den die Fluthen zertrümmert haben. Die kleinen Antillen haben noch bren. nende Vulkane, denen in der Andenkette eben. falls thätige Vulkanketten gegenüber stehen.

3. Das Becken des Unter-Orinoko und der Ebenen von Venezuela. Es wird im Westen durch die Ander, im Norden durch die Küstenkette, im Osten durch die Parime begrenzt. Im Süden begrenzt es das waldige Becken des Marañon. Diese Llannos sind die Wiesengründe, durch welche wir unsere Reisenden begleitet haben.

4. Das Becken vom Rio Negro und Amazonenstrome. Dieses ist das Centralbecken, und zwar das gröfste in Amerika. Der waldige Theil enthält 260,000 Quadratmeilen. Einen Theil davon haben wir auf dem Rio Negro durchschifft. Der waldlose Theil ist ein Grasmeer, und bildet die schon öfter erwähnte Enge, durch welche es mit dem letzten Becken

5. der Pampas von Buenos - Ayres und Patagonien zusammenhängt. Diese Ebenen erstrecken sich bis an die magellanische Meerenge, und bilden das Gegenstück zu den Ebenen des Missisippi. Dieses Becken entliält grasbewachsene Ebenen, vorzüglich im westlichen, und 


\section{$-277$}

dichte Waldungen im östlichen Theile; seine Gewässer sammeln sich in grofsen Strömen, die alle ihre Gewässer dem Rio de la Plata abgeben. Seine Oberfläche beträgt 135,00o Quadratmeilen.

Die ganze Oberfläche Süd.Amerika's beträgt 571 ,30o Quadratmeilen; davon bedecken 114,400 die Gebirge, und 456,900 nehmen die Ebenen ein. Ganz Amerika enthält auch fünf grofse Flufssysteme.

1. Das Wassersystem des Lorenzstromes; es erhält seine Nahrung aus dem Schnee und Eise des nördlichen Nord-Amerika und den vielfachen canadischen Seen.

2. Das Flufsgebiet des Missisippi. Seine Zuflüsse reichen bis an die Seen Canada's.

3. Das Flufsgebiet des Orinoko; seine Zuflüsse haben ihre Quellen in den Anden von NeuGranada und im Parime-Gebirge; es hängt zusammen durch den Cassiquiare mit

4. dem Flufsgebiete des Amazonenstromes oder Marañon. Dieses ist das prächtigste und gröfste Flufsgebiet der Erde. Es liegt unter dem Aequator, mit dem der Strom sich beinahe parallel von Jaen de Bracamoros, auf eine Strecke von 2,400 Meilen bewegt. Es erhält seine Nahrung durch die Aequatorial - Regen.

5. Das fünfte Flufsgebiet ist das des Rio de la Plata. Es entspricht dem des Missisippi. 
Von den fünf Flufsgebieten entleeren alle ihre Wassermassen in das atlantische Meer, und keines in den grofsen Ocean; in diesen fallen nur die Kïstenflüsse der Westseite der Cordilleren, welche aber bei der grofsen Annäherung derselben an das stille Meer von keiner Bedeutung sind. 
20 国 $\mathbb{N}$ 思 


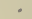

$-$

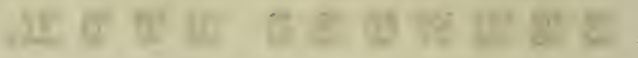

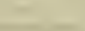




\section{Erstes Kapitel.}

Reise nach Cuba.

In neuerer Zeit ist die Schiffahrt so sehr vervollkommt, dafs eine Fahrt von den Küsten Venezuela's nach der Insel Cuba nur als eine Kleinigkeit erscheint. Die Bändigung des Meeres ist einer der schönsten Triumphe des menschlichen Geistes, man kann mit Recht behaupten, dafs die Menschen einander näher gerückt sind. Was in frühern Zeiten eine ungeheure Seefahrt hicf's, ist jetzt eine Spazierfahrt, und man kann sagen, dafs jetzt Cadix von Cuba nicht weiter entfernt ist, als es früher von London war.

Am:24. November um 9 Uhr Abends ging man unter Segel. Man verliefs die Rhede von Neu-Barcellona, fuhr im tiefen Fahrwasser zwischen den Borache-Inseln hin. Die Luft war kühl und angenehm, und die Fahrt daher viel reizender, als auf dem Orinoko, da sich hier keine Mosquitos einfanden. Die Tagestemperatur ist hier gewöhnlich $28^{\circ}$ bis $29^{\circ}$, die der Nacht $23^{\circ}$ bis $24^{\circ}$, welches eine sehr erquickende Veränderung der Wärme ist. Am folgenden Mittage befanden sie sich in der Nähe der Insel Tortuga, die von aller Vegetation entblöfst, nur sehr wenig über den Meeresspiegel erhaben ist. 


\section{- 282}

Da hier mit Anfang November die Ostwinde ge. wöhnlich sehr frisch wehen, so war die Windstille am 26. November auffallend. Auf dieser ganzen Kïste werden die Südwinde für sehr ungesund gebalten, weil sie die faulen Ausdünstungen der Wälder des Orinoko berbeiführen. Gegen 9 Uhr des Morgens bildete sich ein schöner Ring um die Sonne, im Augenblicke, wo die Temperatur dieser Gegenden plötzlich um $3 \frac{1}{2}$ sank. Herr von Humboldt vermuthet, dafs dieses die Wirkung einer ahsteigenden Strömung war. Diese Erscheinung war sehr schön. Der Ring um die Sonne hatte die Breite eines Grades, und war nicht weifs, sondern zeigte die schönsten Regenbogen-Farben, während das Innere des Ringes, wie auch das ganze Himmelsgewölbe, tief azurblau war, obne eine Spur sicht. barer Dünste.

Allmählich verliert man auch die Insel Margaretha aus dem Gesichte, und in der Entfernung stellt sich die Silla von Caracas den Blicken dar. Auf diesem Sattelberge verweilten die Blicke unserer Reisenden mit Liebe und Gefühl. Er war der böchste Berg Amerika's, den sie bis jetzt und nicht ohne einige Gefahr erstiegen hatten. Bei hellem Wetter ist die Silla, auch olne Luftspiegelung, auf 35 Meilen weit im Meere sichtbar. Das Meer war mit einer bläulichten Haut überzogen, welches das Leuchten desselbeni in der Nacht vermehrte. Sie bestand aus feinen Faserchen, und das Leuchten schien auf thierischen Ursprung hinzudeuten. 
Langsam näherten sie sich am 27. November der Insel Orchila. Wie alle dem Festlande nahe Insel. chen, ist auch diese unbewohnt geblieben. Ihr westlicher Theil liegt unter $11^{\circ}, 51^{\prime} 44^{\prime \prime} \mathrm{N}$. Br. und $68^{\circ}$, ${ }_{26}^{\prime} 5^{\prime \prime}$ W. L. Sie ist 8 Meilen lang und kaum 3 Meilen breit. Sie war damals mit berrlichem Pflan. zenwuchse bedeckt, und gewährte einen angenehmen Anblick. Sie ist aus zwei. Felsenreihen zusammengesetzt, die durch einen kleinen Isthmus verbunden, und nicht über 80 Toisen boch sind; auf ihren Gipfeln tragen sie Palmen mit Fächerblättern, wahrscheinlich Palma de Sombrero. Regen sind hier selten, aber es ist walirscheinlich, dafs auch auf dieser Insel süfse Quellen vorhanden sind. Es ist daher befremdlich, dafs, indem so viele lkleine Fel. sen-Inscln im Archipel der Antillen angebaut sind diese vielen Inseln in der Nähe des Festlandes un. bewohnt bleiben. Dieses rührt jedoch daher, weil sie derselben Regierung, wie das Festland, angehören, und Niemand gern auf beschränkten Inseln sich ansiedelt, wo er auf dem Festlande Platz genug hat, um sich auszubreiten.

Bei Sonnenuntergang nahmen sie zwei aus dem Wasser hervorragende Felsspitzen wahr, die sich wie Thürme erheben und Roca de afuere heifsen. Über der Insel Orchila sammelten sich Dünste und bildeten in beträchtlicher Höhe Wolken. Diese Erscheinung ist wohl bekannt. Die Wolken bleiben lange über solchen Inseln steben, und es zeigt sich, welche Kraft auch kłeine Erdmassen auf die Dünste 
der Atmosphäre ausüben. An diesen Wolken erkennt man von Weitem her die Lage der niedrigsten Inseln.

Am 29. November bei Sonnenaufgang sahen sie noch ganz deutlich die Silla von Caracas, aber mit dem Meerhorizont beinahe gleichlaufend. Sie befanden sich in einer Entfernung von 39 bis 40 HieiIen, welches eine etwas starke Stralılenbrechung anzeigt. Gegen Mittag kündete sich ein nördlicher Witterungs-Wechsel an. Die Luft erkältete sich plützlich bis auf $22^{\circ}, 8$, während die See auf der Oberfläche bis $25^{\circ}, 6$ beibehiclt. Der Wind ging auch am 3o. November wirklich in N. N. O. über, und die Wellen erhoben sich auf eine aufserordentliche Höhe. Gegen Norden zeigte der Himmel eine schwärzliche Färbung, und da die Wellen sich kreuzten, so verursachte dieses ein gervaltiges Schaukeln des Schiffes. Auf einer Mcile Entfernnng bildeten sich Wasserhosen, die sieh schnell von N.N.O. nach N. N. W. bewegten, und so oft eine Wasserhose sich näherte, war eine Erkältung des Windes spürbar. Gegen Abend brach durch Unvorsichtigkeit des Schiffkochs Feuer aus, welches leicht hätte gefährlich werden können, da die Schiffsladung aus gedörrtem, also leicht entzündbarem Fleische bestand, und der Wind heftige Stöfse aussendete. Es wurde jedoch schnell gedämpft.

In der Nacht vom ersten zum zweiten December stellte sich den Reisenden eine sehr merkwürdige Erscheinung dar. Es war eine halbe Stunde nach 
Mitternacht bei einem schwachen Ostwinde. Der Thermometer zeigte $23^{\circ}, 2$. Der Hygrometer aus Fischbein $57^{\circ}$. Herr von Humboldt stand auf dem Verdecke, um Sterne zu beobachten. Der Vollmond stand sehr hoch. Plötzlich bildete sich auf der Seite des Mondes 45' vor dem Durchgange durch den Meridian ein Bogen, der alle Farben des Regenbogens spielte, jedoch ein trauriges Aussehen hatte. Der Bogen überstieg seiner Höhe nach den Mond, war $2^{\circ}$ breit und sein Obertheil war $80^{\circ}$ bis $85^{\circ}$ über den Horizont des Meeres erhaben. Der Himmel war aufserordentlicl rein, es war nirgend cin Anschein von Regen vorhanden, und diese Erscheinung, die völlig einem Mondregenbogen glich, stellte sich doch nicht dem Monde gegenüber dar. Der Bogen sehien bis 10 Minuten lang still zu stehen, dann fing er an sich zu bewegen und zu senken, indem er über den Mond hinzog, und um 12 Uhr $54^{\prime}$ sich unter dem Horizonte mit dem Obertheile verbarg; Er bewegte sich sehr schnell, und Herr von Humboldt gesteht, diese Erscheinung nicht erklären zu können. Die Matrosen sind aber mit der Erklärung gleich bei der Hand, indem sie sagen: jedes aufserordentliche Meteor kündige Wind an.

Am 3. December gab es einen tüchtigen Schrecken, man sah nämlich ein kleines Fahrzeug, und glaubte nichts anders, als einen Corsaren zu sehen; was denn auf der See, wenn man sich auf einem Kauffarthei - Schiffe befindet, immer eine sehr ernstliche Sache ist, und mehr als Regenbogen und ent. 
fernte Wasserhosen frappirt. Als os jedoch näher kam, zeigte es sich, dafs es ein ganz unschuldiges Wesen sey, nämlich das Fahrzeug eines Franziskaner - Mönchs und eines sehr reichen Pfarrers eines indianischen Dorfes in den Savanen von Neu-Barcellona, das seit mehreren Jahren in Handelsangelegenheiten $z$ wisclien dem Festlande und den dänischen Inseln hin und her fuhr, und unter dem Na. men Balandra de Frayle bekannt war. In der Nacht bemerkte Herr Bonpland und mehrere Passagiere eine Viertelmeile entfernt eine Flamme auf dem Meere, die sich gegen S.W. bewegte, und die Luft erleuchtete. Man spürte weder ein Erdbeben noch eine Veränderung der Atmosphäre. Diese Flamme kann ein phosphorischer Glanz gewesen seyn, der aus der Fäulnifs von Weichthieren entstanden war, oder auch eine aus dem Meergrunde hervordringende vulkanische Flamme. Das letztere ist jedoch unwahrscheinlich, weil vulkanische Flammen nur dann aus dem Mecre emporsteigen mögen, wenn sich der Felsgrund des Oceans bereits so hoch gehoben hat, dafs Flammen und glühende Schlacken aus dem aufgeblähten Theile hervorkommen, nicht aber durch das Wasser selbst hindurch gehen müssen.

Da es in Kóriegszeiten nicht rathsam ist, sich lange im Angesichte des Landes aufuhalten, so wurde am vierten December die Überfahrt der Bank Pedro Shoals beschlossen. Die Bank ist 280 See-Quadratmeilen grofs, und der, bei der Insel Jamaika ähniich, sieht sie aus wio eine Erhebung des Meergrun- 
des, welcher die Oberfäche der See nicht zu erreichen vermochte, um eine eben so grofse Insel, wie Portorico, zu bilden. Die Milchfarbe des Wassers zeigte an, dafs man sich am östlichen Theile der Bank befinde; das Wasser, welches, wie wir im Anfange dieser Reise, im ersten Bändchen, bemerkt haben, auf Untiefen kälter ist, war auch hier um $1^{\circ}, 6$ erkältet. Vom 4. bis 6. December wurde die Witterung schlimm, und die Stofswinde von N. N. W. immer heftiger und in der Nacht war die Lage des Schiffs etwas gefährlich. Man befand sich in der Nähe von Klippen, die sich Jurch das Geräusch der Brandung ankündigten, und von denen ein Schiff, wenn es auf sie stöfst, leicht zerschmettert wird. An dieser Gefahr war weniger der Steuermann, als die Unrichtigkeit der See-Charten Ursache. Aus diesem Grunde ist die Richtigkeit der Charten so wichtig, d.h. alles Bestreben der Regierungen, die auf der See Geschäfte haben, müs. sen dahin gehen, dafs alle Örter des Meeres, be. sonders Inseln, Sandbänke und Klippen, auf das genaueste astronomisch bestimmt werden. Sind die Bestimmungen auf den See-Charten falsch, so laufen die Schiffe die gröfste Gefahr, an solchen Stellen, wo öfters die Charten das beste Fahrwasser angeben. Das Schiff jedoch, auf welchem unsere Reisenden waren, schien der Engel der Wissenschaften zu lenken, denn die Wendung des Fahrzeuges gelang vollkommen, und in einer Viertelstunde waren sie alle aufser Gefahr. Das Senkblei, 


\section{- 283}

welches im Anfange nur 9 Klafter zeigte, hatte 12 und hernach 15 gezeigt. Die Klippen, an denen sie so leicht scheitern konnten, liegen unter $16^{\circ}, 50^{\circ}$ Br. und $80^{\circ}, 43^{\prime} 49^{\prime \prime} \mathrm{L}$.

Am 9. December hatten sie sich den Caymas. Inseln genähert, und hier erhielt der Ostwind wieder seine vollkommene Stärke. Die grofse Caymas-Insel ist mit Cocospalmen bedeckt. Das Wetter war fortdauernd sehr schlecht und stürmisch und die Luft sogar kühl bei $19^{\circ}, 2$ bis $20^{\circ}$ des hundertheiligen Thermometers. Der üble Geruch des gedörrten Fleisches ersetzte hier die Mosquitos - Plage der Orinokofalirt. Der Himmel zeigte zwei Wolkenschichten, von denen die untere sehr dicht war; die obere schien unbeweglich und durch Streifen getheilt. Als sie an das Cap St.Anton kamen, legte sich der Wind. Dieses Vorgebirg liegt unter $87^{\circ}$, $17^{\prime} 22^{\prime \prime}$ W. L. und $2^{\circ}, 34^{\prime} 14^{\prime \prime}$ östlich voul Ilavannah.

Drei Meilen waren sie jetzt noch von der Insel Guba entfernt, dennoch kündigte sich dieselhe schon als nahe an, durch den lieblichenGeruch, welchen die gewürzrciche Vegetation dieser Insel aushaucht. Die Matrosen behaupten, dieser Geruch sey nicht spürbar, wenn man sich dem Cap Catoche auf den dürren Küsten von Mexiko nähert.

Wic das Wetter sich aufhellte, so stieg auch der Thermometer im Schatten nach und nach auf $27^{\circ}$. Durch eine Strömung von S. S. O. getrieben, rückte das Schiff schnell vorwärts. Diese Strömung gehört zur Wirkung des beschriebenen Golfstromes, 
von dem das erste Bändchen handelt. Am 19. Dccember 1800 landeten unsere Reisenden im Hafen von Havannah. Sie hatten auf der Überfahrt von Neu-Barcellona fünf und zwanzig Tage bei stets schlimmem Wetter zugebracht.

\section{$Z$ we ites Kapitel.}

Allgemeine Bemerkungen über die Antillen.

Die ganze Oberfläche der Antillen befafst nahe an 8300 Quadratmeilen (20 auf den Grad). Neun Zehntheile davon kommen auf die grofsen Inseln: Cuba, Haiti, Jamaika und Portorico, die einen Flächeninhalt von 7200 Quadratmeilen befassen. Die A rea dieses amerikanischen Archipels kommt daher der des preufsischen Staates gleich; die Bevölkerung ist jedoch noch keineswegs so grofs, als man von Inseln in der schönsten Gegend der Erde vermuthen sollte, und wohin Afrika seine unglücklichen Kin. der in so grofser Anzahl sendet. Die Bevölkerung der Antillen ist drei Mal geringer, als diejenige von Schottland.

Die Antillen sind es vorzüglich, wohin die armen afrikanischen Brüder gebracht werden, und wo man sicb schon gewöhnt hat, die schwarze Bevölkerung als die arbeitende Classe zu betrachten. Dieses grobe Vorurtheil, als ob die Colonial-Produkte nur durch Schwarze erzielt werden könnten, wir-

Sibl. naturh. Reison. IV. 


\section{- 2.0 .0}

Thet schr nachtheilig auf den Gewerbfleifs, und setzt die weifse Bevölkerung bei dem Übermafse schwap. zer Sclaven der gröfsten Gefahr aus. Wir wo!len daher jetzt in. einigen. Tabellen die Bevölkerung der Antillen beifügen, aus welchen das-Verhältnifs der Selaven zu den Freien, und der Schwarzen zu den Weifsen hervorgehen solk.

\begin{tabular}{|c|c|c|}
\hline Name der Inseln. & $\begin{array}{l}\text { Ganze Be-- } \\
\text { völkerung. }\end{array}$ & $\begin{array}{l}\text { Schwarze } \\
\text { Sclaven. }\end{array}$ \\
\hline I. Brittische Antillen . . & 776,500 & 626,800 \\
\hline a. Jamaika . . . . & 402,000 & 342,000 \\
\hline b. Barbados .. . .. . & 100,000 & 79,000 \\
\hline c. Antigua . . . . • & 40,000 & 31,000 \\
\hline d. St. Christoph .. . . & 23,000 & 19,500 \\
\hline e. Nevis.. • & $1: 1 ; 000$ & 9,500 \\
\hline f. Grenada. - * & $29 ; 000$ & $25,000$. \\
\hline $\begin{array}{l}\text { g. St. Vincent una Ure- } \\
\text { nadinen ....... }\end{array}$ & 28,000 & 24,000 \\
\hline h. Dominica .. . . . . & 20,000 & 16,000 \\
\hline $\begin{array}{l}i \text {. Montserat } . . . . \\
k \text {. Englische Jungfern- }\end{array}$ & 8,000 & $6,5 i 20$ \\
\hline $\begin{array}{c}k . \text { Englische Jungfern- } \\
\text { Inseln . . . . . }\end{array}$ & 8,500 & 6,000 \\
\hline l. Tabago . . . . & 16,000 & $2,4,000$ \\
\hline
\end{tabular}




\section{$-291$}

\begin{tabular}{|c|c|c|}
\hline Name der Inseln. & $\begin{array}{l}\text { Ganze Be- } \\
\text { völkerung. }\end{array}$ & $\begin{array}{l}\text { Schwarze } \\
\text { Sclaven. }\end{array}$ \\
\hline $\begin{array}{l}\text { m. Anguilla und Barbuda } \\
\text { n. Trinidad. . . . . } \\
\text { o. St. Lucie . . . . } \\
\text { p. Bahamas. . . . . } \\
\text { q. Bermudas . . . . }\end{array}$ & $\begin{array}{r}2,500 \\
4,1,500 \\
17,000 \\
15,500 \\
14,500\end{array}$ & $\begin{array}{r}1,800 \\
23,000 \\
13,000 \\
11,000 \\
5,000\end{array}$ \\
\hline II. Haiti $\cdot \cdots \cdot \cdot \cdot \cdot$ & $\begin{array}{c}820,000 \\
\text { alle } \\
\text { schwarz } \\
\text { aberfrei. }\end{array}$ & \\
\hline $\begin{array}{l}\text { III. Spanische Antillen . } \\
\begin{array}{l}\text { a. Cuba . . . . } \\
\text { b. Portorico . . . } \\
\text { c. Marguerita . . . . }\end{array}\end{array}$ & $\begin{array}{r}943,000 \\
700,00: \\
225,000 \\
18,000\end{array}$ & $\begin{array}{r}281,000 \\
256,000 \\
25,000 \\
400\end{array}$ \\
\hline $\begin{array}{l}\text { IV. Französische Antillen } \\
\text { a. Guadelupe mit der } \\
\text { Zubehör . } \\
\text { b. Martinique. }\end{array}$ & $\begin{array}{r}219,000 \\
120,000 \\
99,000\end{array}$ & $\begin{array}{r}178,000 \\
100,000 \\
78,000\end{array}$ \\
\hline
\end{tabular}




\begin{tabular}{|c|c|c|}
\hline Name der Inseln. & $\begin{array}{l}\text { Ganze Be- } \\
\text { völkerung. }\end{array}$ & $\begin{array}{l}\text { Schwarze } \\
\text { Sclaven. }\end{array}$ \\
\hline 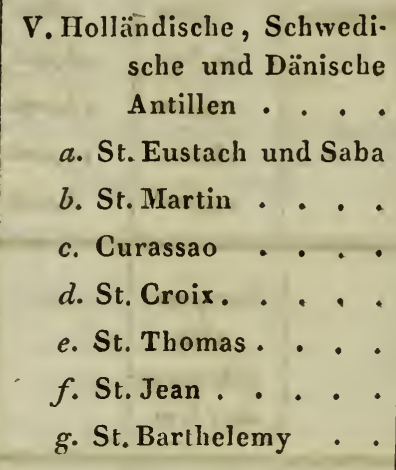 & $\begin{array}{r}84,500 \\
18,000 \\
6,000 \\
11,000 \\
32,000 \\
7,000 \\
2,500 \\
8,000\end{array}$ & $\begin{array}{r}61,300 \\
12,000 \\
4,000 \\
6,500 \\
27,000 \\
5,500 \\
2,300 \\
4,000\end{array}$ \\
\hline \multicolumn{3}{|c|}{ Wi e d e r holung. } \\
\hline $\begin{array}{l}\text { Englisch. . . . . . } \\
\text { St. Domingo . . . . } \\
\text { Spanisch. . . . . } \\
\text { Französisch. . . . . } \\
\text { Holländisch, Schwedisch } \\
\text { und Dänisch . . . }\end{array}$ & $\begin{array}{l}776,500 \\
820,000 \\
943,000 \\
219,000 \\
84,500\end{array}$ & $\begin{array}{l}626,800 \\
-- \\
281,400 \\
178,000 \\
61,300\end{array}$ \\
\hline Summa $\cdot . \cdot \cdot \cdot \cdot$ & $2,843,000$ & $1,147,500$ \\
\hline
\end{tabular}




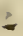

Aus dieser Tabelle können meine jungen Leser einige Schlüsse ziehen, wenn sie zuvor Folgendes bemerken. Diejenigen Einwolıner der Antillen, die lieine Sclaven sind, sind darum noch niclit alle weifse Leute. Es finden sich nämlich unter der Zahl von $1,686,500$ Nicht-Sclaven 870,000 freic Nege r, wo dann nur 816,50o Weifse überbleiben, aber auch unter diesen gibt es noch Mulatten und andere farbige Menschen. Hieraus folgt, dafs die Weifsen so sehr die Minderzahl ausmachen, dafs sie wirklich mit den Schwarzen sehr behutsam verfahren müssen, vvenn diese nicht einmal einen günstigen Augenblick benutzen und es den Negern von Haiti nachmachen sollen. Dann sieht man auch mit Erstaunen, dafs gerade diejenigen Nationen, welche am meisten gegen Sclavenhandel eifern, die meisten Sclaven besitzen, und es a!so zwischen schönen Reden und schönen Handlungen einen Unterschied gibt, und man sehr getäuscht wird, wenn man durch schöne Parlamentsreden sich nach fremdem Glück lüstern machen läfst. Um jedoch von lem Zustande der schwarzen Bevölkerung in Amerika unsern jungen Lesern einen Begriff zu geben, fügen wir Folgendes bei. In ganz Amerika gibt es 


\section{Fre i e Neger.}

Inseln

Vereinigte Staaten . . . .

Brasilien ........

Spanische Colonien des Festlandes

Brittisch, Holländisch und Fran-

zösisch Guiana . . • . • .

870,000

270,000

160,000

80,000

6,000

Summa .

$1,386,000$

\section{Neger.Sc 1 a ve n.}

'Inseln

Vereinigte Staaten . . . . .

Brasilien

Spanische Colonien des Festlandes

$1,0 y 0,000$

$1,650,000$

$1,800,000$

307,000

Brittisch, Holländisch und Französisch Guiana . . . • • .

200,000

Summa

$5,047,000$ 


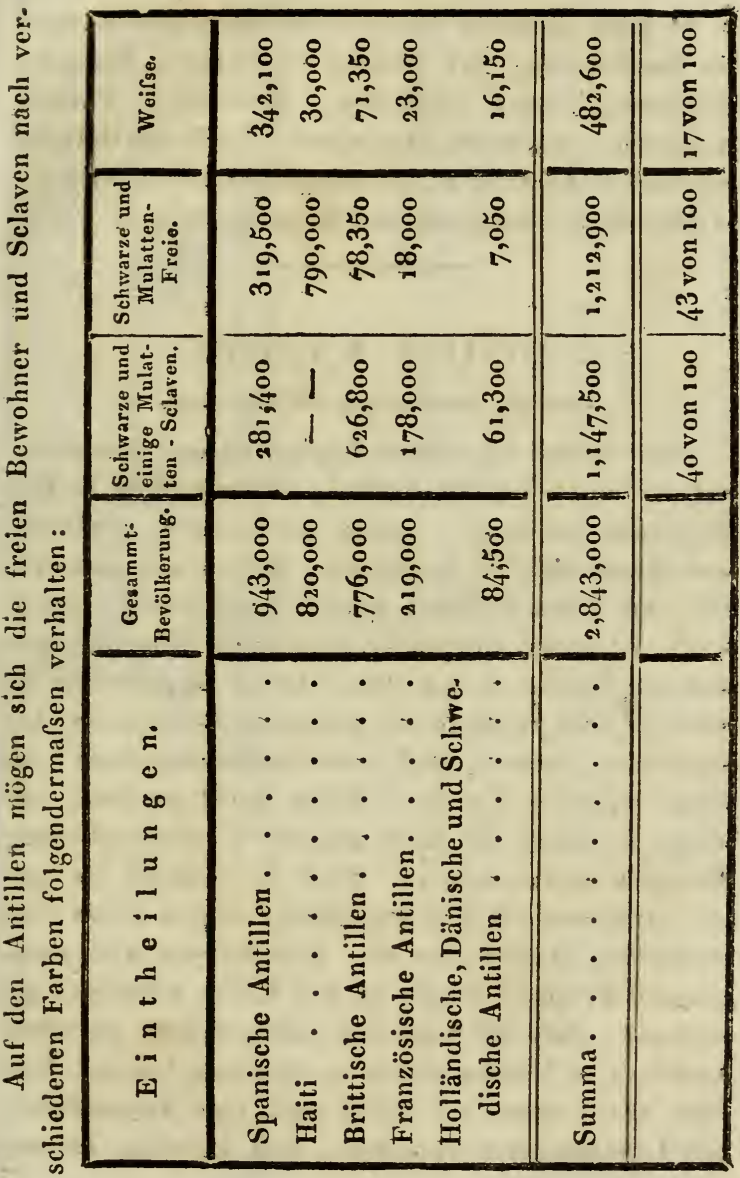




\section{$-290$}

In ganz Amerika verhält sich nach den Farben die Bevölkerung so: Weifse 13,471,000, Indianer $8,610,000$, Neger 6, 483,000 , vermischte Farben 6, 428,000 , zusammen 34,942,000. Nach den Religionen sind in Amerika 22,486,000 Römisch - katholische, 11,636,000 Protestanten und 820,000 Heiden.

\section{Drittes Kapitel.}

Politische Beschreihung der Insel Cuba.

Wir haben im ersten Kapitel unsere Reisenden auf der Insel Cuba verlassen, wie sie eben in der Havannah landeten. Bevor wir jedoch erzählen, was ihnen dảselbst begegnete, wollen wir diese Insel und ihren Zustand zuerst beschreiben. Diese Insel ist nebst Portorico der cinzige Überrest spanischer Gröfse in Amerika. Cuba ist aber cin so schönes und zugleich so wichtiges Besitztbum der spanischen Krone, dafs man behaupten kann, so lange Spanien die Insel Cuba nicht verliert, so lange ist auch die Hoffnung der Wiedereroberung Mexiko's nicht verloren. Hier ist nämlich die spaniscle Herrschaft fest gegründet; es gibt einen vor. trefflichen Waffenplatz ah. Hier können sich euro. päische Truppen so gut an das Klima Amerika's gewöhnen, dafs sie von den Ansteckungen bei einer Landung in Mexiko nichts zu fürchten haben. Von hier aus können sie daher auch eine Armee leicht mit Lebensmitteln versehen, und behalten immer, 


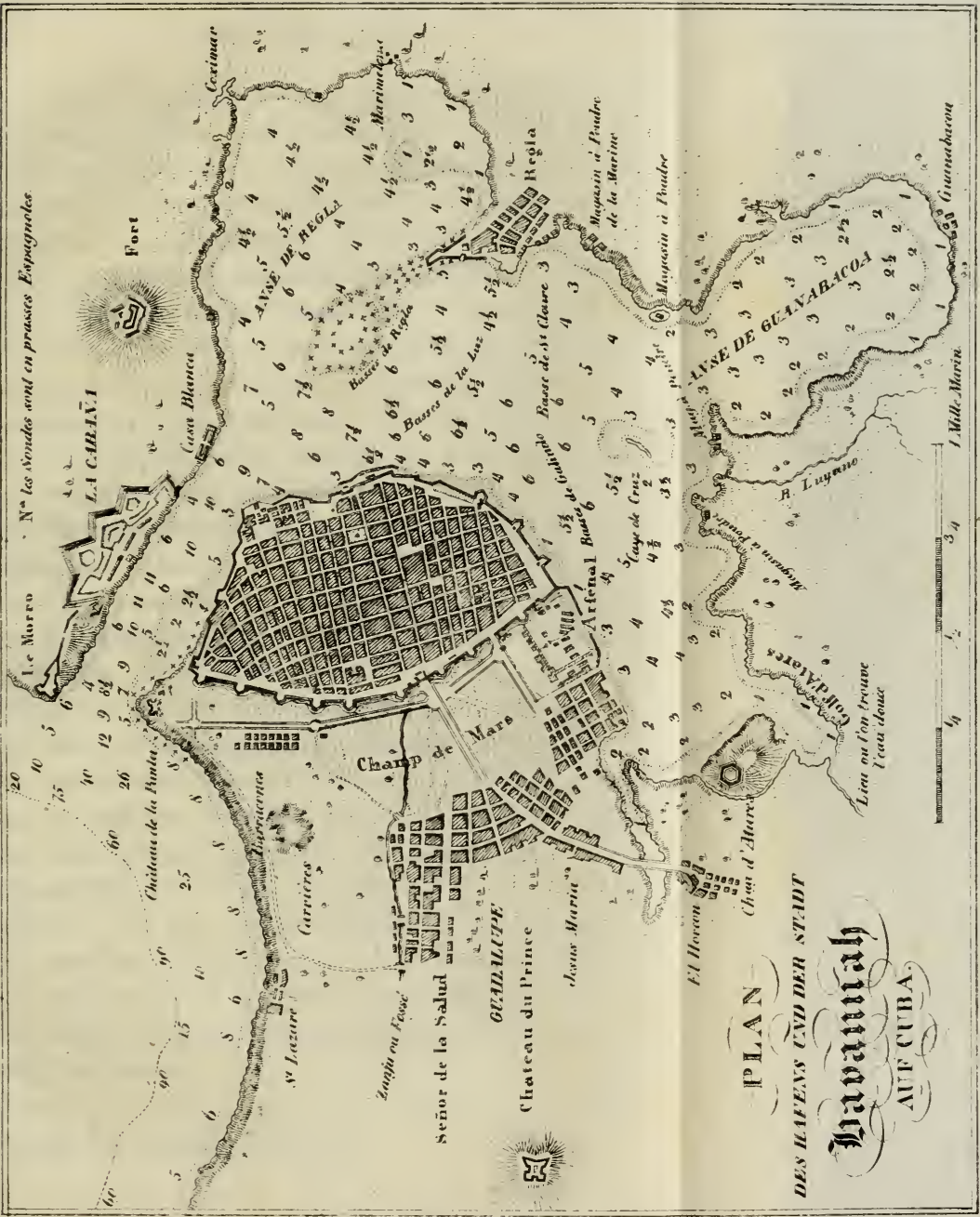



im schlimmsten Falle, einen Zufluchtsort, wenn sie genöthigt werden, sich einzuschiffen. Cuba ist also als Waffenplatz sehr wichtig für Spanien. Aber auch als Colonie, denn die grofse Insel Cuba bietet eine Menge Colonial Erzeugnisse dar, und alle Erzeugnisse der Tropenländer gelangen hier zur gröfsten Vollkommenheit. Cuba hat eine ausgedehnte Oberfläche, denn sie ist um die Hälfte grölser als Haiti, und so grofs als England ohne Wallis. Ihre Fruch tbarkeit ist aber grofs und bewundernswerth, und ihre Bevölkerung besteht zu drei Fünftheilen aus freien Mensehen. Über alle diese Vortheile geht aber ihre geographische Lage und die Lage der Stadt Havannah. Der Golf vom Mexiko bildet ein Mittelmeer von 250 Meilen Durchmesser, dessen Küsten den Bundesstaaten von Mexiko und Nord-Amerika angehören. Die Insel Cuba bildet gleichsam die Pforte zu diesem so wichtigen Meerbusen; durch die offen bleibenden Seiten dringt der Golfstrom ein und wieder heraus. Am nördliclien Ausgange, da, wo mehrere Strafsen des Welthandels kreuzen, liegt der schöne Hafen von Havannah, der sowohl von der Natur als Kíunst befestigt ist *). So wie die Flotten, die aus Cadix auslaufen, die Strafse in das Mittelmeer beherrschen, so können auch die aus Acajou- und Cedrela-Holz erbauten Flotten der Insel Cuba die gegenüberliegenden Kiüsten schlagfertig bedrohen.

*) Siehe den beigefügten Grundrifs. 


\section{- 208}

Auch die längliche, etwas scbmale Gestalt gibt der Insel Cuba eine solche Verlängerung, dafs sie sich zugleich der Insel Haiti und Jamaika nähert, wie auch der Küste Florida's und der mexilianischen Provinz Yucatan. Diese Verbindung, wo so viele Staaten so nahe an einander stehen, dafs cine zehn-bis zwölftägige Schiffahrt sie mit einander verbindet, verdient auch darum Rücksicht, weil gerade diese Staaten, die so schnell mit einander in Gemeinschaft treten können, die gröfste schwarze Bevölkerung enthalten.

Florida fängt an, seit es den vereinigten Staaten angehört, aufzublühen, und sein fruchtbarer Boden verspricht eines der schönsten Länder der Erde zu verden. Weiterhin blüht Neu-Orleans zum Hauptstapelplatz der Erde auf, und an sie reihen sich die mexikanischen Häfen Tampico, Veracruz und Alvarado bis zum Cap Catoche. Zwischen der Ilavannah und dem Hafen von Campeche ist der Handel überaus lebendig. Früher hat die Verwaltung dieser Insel viel gekostet, weil hier der stärkste Punkt der spanischen Seemacht ist; diese Colonie hat jedoch unter allen spanischen Besitzungen in fremden Welttheilen den gröfsten Wohlstand erlangt, so dafs sic aus dem Schatze Spaniens keines Zuflusses mehr bedarf. Die Einwohner sind klug, die Verwaltung ist gemälsigt, und dieses zusammen hat eine solche Lebendigkeit im Handel hervorgebracht, dafs der Ertrag der Zölle sich so ungeheuer vermehrt hat, 
dafs diese reiche Colonie sogar das Mutterland in Kampfe mit andern Colonien unterstützen konnte.

Unter die schönsten Ansichten der Erde, wie sie nur Neapel und Constantinopel aufzuzeigen haben, gehört auch die von Havannah. Es ist zwar hier der üppige Pflanzenwuchs keineswegs vorhanden, der die Flufs. Ufer des Guayaquil schmückt. Eben so wenig zeigt sich hier die wilde Gröfse, welche die Einfahrt in den Meerbusen von Rio Janeiro auszeichnet. Die Schönheit Havannah's besteht in dem Reize, den eine wohlangebaute Gegend, geschmückt mit den majestätischen Pflanzenformen der TropenJändcr, unter einem schönen Himmel entwickelt. Hingerissen von diesem erfreulichen Anblicke vergifst der Europäer die ihm hier drohende Gefahr; er sucht sich die Bestandtheile der ausgedehnten Land. schaft zu entwirren, und sein hetrachtendes Auge ruht auf jenen festen Schlössern, die sich auf der Ostseite des Hafens über den Felsenwänden dar. stellen. Sein Blick ergötzt sich an dem von Dörfern und Meierhöfen umzingelten Wasserbecken, an den zu aufserordentlicher Höhe aufsteigenden Palmbäumen und an den durch einen Wald von Masten zur Hälfte verdeckten Stadt. Die Einfahrt in den Hafen geschieht zwischen der Festung Morro und dem Schlosse San Salvador. Die Öffnung der Einfahrt ist auf eine Länge von $3 / 5$ Meilen nicht breiter als 170 bis 200 Toisen. Ist man durch den schmalen Eingang hindurch, und hat man das schöne Schlofs 


\section{$-300$}

San Carlos de la Cabanna nebst der Casa blanca hinter sich, so gelangt man in ein kreuzförmiges Becken, dessen grofse Axe von S. S. W. nach N. N. O. $2^{1 / 2}$ Meilen Länge hat. Dieses Wasserbecken steht wieder mit drei Buchten in Verbindung, nämlich mit der von la Regla, von Guanavacoa und von Atares, wovon die letzte einige Süfswasserquellen enthält. Die mit Mauern umgebene Stadt Havannah bildet ein Vorgebirge, das südwärts vom $\mathbf{A r}$ senal (Magazin für Schiffsgeräth) und nordwärts vom Schlosse de la Punta begrenzt wird. Jenseits der Überreste einiger versenkter Schiffe auf der Untiefe von la Luz trifft man nur noch fünf bis sechs Klafter Wasser an. Westwärts wird die Stadt von den Schlössern Santa Domingo de Atarés und San Carlos del Principe vertheidigt; diese liegen von der innern Mauer landeinwärts, das eine 669 , das andere 12 q́o Toisen entfernt. Zwischen der Stadt und den Schlössern liegen die Vorstädte (Arrebales oder barrias extra mures) von Horcon, von Jesus Maria, von Guadalupe und Sennora la Salud. Durch die Vorstädte wird das Mlarsfeld immer enger zusammengedrä̉ngt. Nicht sowohl durch Schönbeit, als durch Festigkeit und Gröfse sind ausgezeichnet die Gebäude: die Katbedralkirche, das Gouvernementshaus, die Wohnung des Marine-Commandanten, das Arsenal, der Correo oder das Posthaus, die Tabak-Faktorei. Die Strafsen sind eng, und die meisten derselben ungepflastert. Weil die Steine von 
Veracruz hergebracht werden müssen, so war man auf den Einfall gerathen, sich statt der Steine zum Strafsenpflaster grofser Bäume zu bedienen. Die Reisenden waren daher nicht wenig erstaunt, die schönen Calıoba-Stämme in den Koth von Havannah versenkt zu sehen. Zur Zeit des fferrn von Humboldt hatten wenige Städte Spanien's ein so häfsliches Aussehen, als die reiche Havannah. Man wanderte im Kothe bis an die Kniee; die Menge der Caleschen oder Volanten, die das eigenthüm. liche Fuhrwerk der Havannah bilden, die mit $\mathrm{Zu}$ ckerkisten beladenen Karren, die Stöfse der zahllosen Träger machen das Fufsgehen eben so beschwerlich als das Fahren. Die Häuser und engen Gassen wurden durch das gedörrte Fleisch oder Tassaio, welches einen widrigen Geruch von sich gab, verpestet. Es ist hauptsächlich die Nahrung der armen Schwarzen. Jedoch soll die Polizei in neuerer Zeit diesen Übeln in etwas abgeholfen haben.

Havannah hat ein Theater, welches 1803 durch einen italienischen Künstler sehr schön und geschmackvoll ausgeschmückt wurde. Kunstwerke sind in einem Lande noch selten, wo der Mensch sich erst einheimisch macht, und nur darauf bedacht ist, seinen Wohlstand zu gründen, und sich mit dem Nothdürftigsten zu versorgen. Desgleichen hat auch Haxannah zwei sehr schöne Promenaden, deren eine zwischen der Almada, zwischen dem Hospitale Paula und dem Theater gelegen ist; die andere liegt 


\section{- 302}

zwischen dem Castello de la Punta und der Pucrta de la Mluralla, und führt den Namen: Spaziergang aufser den Mauern. Sie gewährt die angenehmste Kühlung, und wird nach Sonnenuntergang von den Spazierfahrern viel besucht. Ihre erste Anlage rührt von dem Marquis de la Torre her. Sie besteht aus prächtigen Palmen. In der Nähe des Marsfeldes befindet sich der Pflanzengarten, welcher äufserst wichtig ist. Darneben ist der Platz des Fluches, wo die unglücklichen Sclaven ausgeboten werlen.

Auf der Promenade aulser den Mauern ist in der neuesten Zeit die Bildsäule Carls III. aufgestellt worden. Der Platz war früher zu einem Denkmale des Christoph Columbus bestimmt. Seine Asche ruht nämlich hier, indem sie nach der Abtretung des spanischen Antheils von St. Domingo hieher gebracht worden war. In demselben Jalrre wurde auch die Asche des Ferdinand Cortez aus einer Kirche in dic andere versetzt, und so geschah es, dafs gleichzeitig am Schlusse des achtzehnten Jahrhunderts die zwei gröfsten Männer, welche die Eroberung Amerika's auszeichnet, ein neues Begräbnifs erhielten.

Die prachtvolle Königspalme (Palma real) ertheilt der Umgebung von Havannah einen besondern Reiz. Ihr schlanker, in der Mitte etwas aufgetriebener Schaft erreicht dic Höhe von 70 bis 80 Fufs. Sein Obertheil ist glänzend, von zartem Grün, und bildet mit dem übrigen weifslichen und zerrissenen 
Schafte cinen Gegensatz, so dafs der Obertheil mit dem Untertheile zwei auf einander gesetzten Säulen gleichen. Die gefiederten Blätter steben senkrecht empor, und sind gegen die Spitze etwas eingebogen. Hier, wie überall, wo die Menschenmenge sich zusammendrängt, leidet der Pflanzenwuchs, und man siehet in der Ungegend der Stadt die Palmen jährlich schwinden, die Sümpfe werden ausgerottet und angebaut, und wie der Anbau des Bodens vorwärts schreitet, zeigt der Boden laum noch Spuren seines vormaligen wilden Überflusses an Pflanzenreichthum. Man sieht die Zwvischenräume von einer Bucht bis zur andern mit Häusern sich bedecken, die zum Theil angenehm und zierlich gebaut sind. Die Häuser werden meistens in den ver. einigten Staaten verfertigt. Man zeichnet einen Plan dazu, und bestellt sie, wie man bei uns ein Hausgeräth bestellt. Es sind nämlich aus Holz gezimmerte Landhäuser. Wenn in Havannah? das gelbe Fieber herrscht, so bezieht man diese Landhäuser am La Regla_und Guanavacoa, wo die Luft reiner ist. Bei der Kühle der Nacht streichen die Böte durch das Wasser hin, und lassen bei der Phos. phorescenz des Meeres lange, licbte Streifen hinter sich, was einen schönen $\Lambda$ nblick gewährt, und eine reizende Zufluchtsstätte der Einwohner ist, die das Getümmel der Stadt fliehen. Um die Fortschritte der Cultur noch genauer zu würdigen, müssen die Reisenden die kleinen Charcas besuchen, voll Mais 


\section{- $304-$}

und Maniocplanzen, so wie in den Feldern von la Cruz de Piedra die nach der Schnur gepflanzten Ananas und den bischöflichen Garten, welcher in der neuesten Zeit ein besonders angenehmer Ort geworden ist.

Die eigentliche mit Mauern umgebene Stadt Havannah ist nicht über 900 Toisen lang und 5oo breit, und auf diesem engen Raume wohnen 44,000 Menschen, unter denen 26,00o Neger und Mulatten sind. Die Bevölkerung der Vorstädte ist um nichts geringer, besonders in der von Jesus Maria und la Salud, die jedoch, ihrer engen Gássen wegen, die. sen schönen Namen gar nicht verdient, obgleich die Lufttemperatur etwas milder, als in der Stadt selbst ist. Die Ingenieure beweisen der Regierung beständig, dafs die Vorstädte zu nahe bei den Festungswerken liegen, und der Feind sich da einquartiren hönne, ohne von dem Geschütze der Festung er. reicht zu werden. Allein wer hätte den Muth, eine Bevölkerung von 28,000 Menschen zu vertreiben? Havannah ist übrigens sehr fest, und nicht leicht würde es einem Feinde gelingen, sich der Stadt zu bemächtigen, die von der Natur und Kunst so sehr befestigt ist. Der bedenklichste Feind der Havannah ist in der Stadt selbst. Es sind dieses die Neger und Mulatten. Folgende Tabelle wird die Be: völkerung Havannah's ausweisen. 


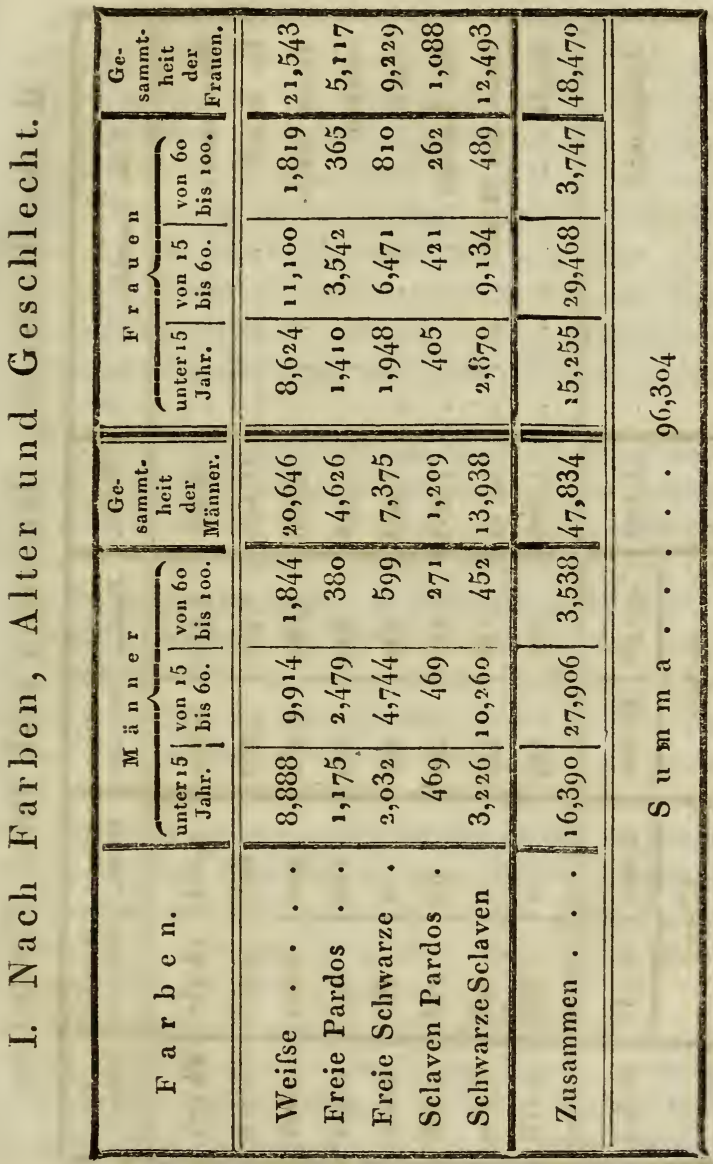




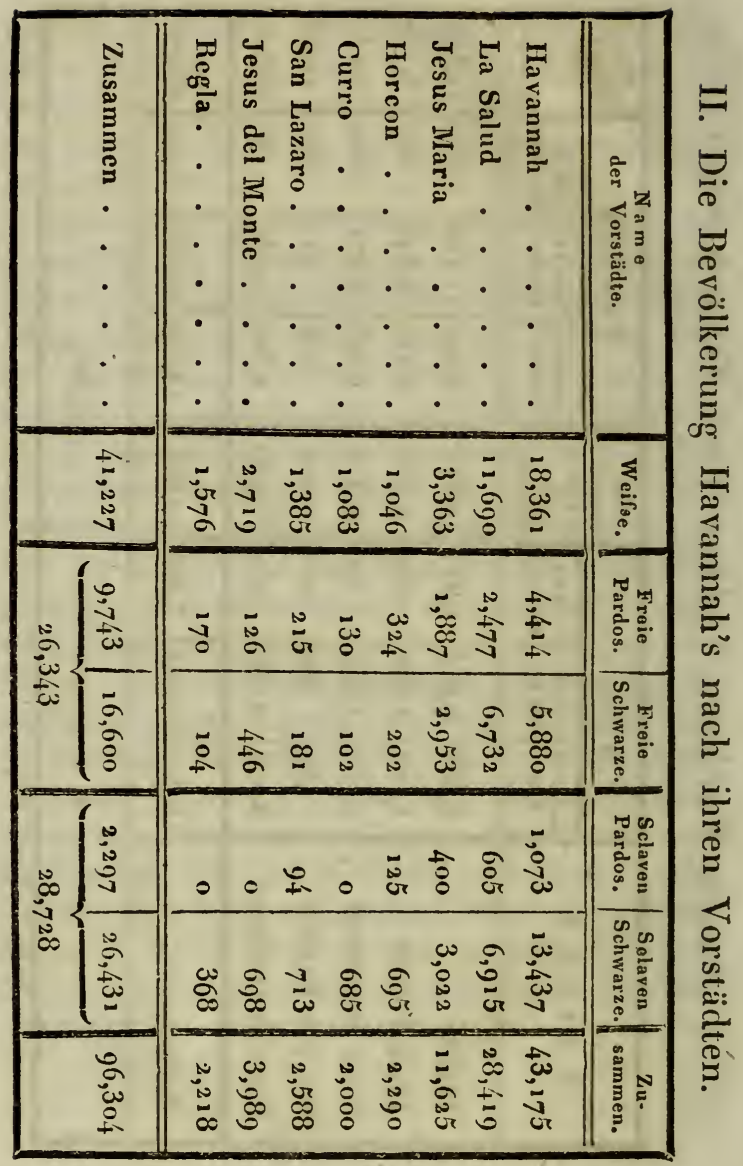


Hieraus ergeben sich 41,227 Weifse auf 55,071 Farbige und Schwarze, welche allerdings als diejenige Classe, die am meisten zu klagen Ursache hat, den Festungsiverken am gefährlichsten werden könnte. Pardos heifsen alle, die weder weifs noch schwarz sind. In dieser Zählung sind die Soldaten, Mönche und Ausländer nicht mit begriffen. Die Garnison beträgt gewöhnlich 6,000 Mann; die Zahl der Ausländer beläuft sich auf 20,000 , so dafs man die Gesammtbevölkerung auf 130,000 Seelen berechnen kann.

Da die Stadt Havannah eben nicht das gesundeste Klima hat, auch viele nicht eingewohnte Fremde sich hier befinden, so ist wohl natürich, dafs die Zahl der Gestorbenen jährlich sehr bedeutend ist, und dieses um so mehr, als hier das gelbe Fieber herrscht; dennoch ist die Sterblichkeit nicht grösser, als in andern grofsen Städten, und bei weitem nicht so grofs, als man glaubt. Nicht für die Eingebornen, wohl aber für die aus Europa kommenden Fremden ist das Ḱlima gefährlich, und das um so mchr, je kühler und gemälsigter der Himmelsstrich ist, aus dem man kommt. Dieses svird auch dann noch der Fall seyn, wenn eine gute Polizei hinsichtlich der Reinigung der Stadt nichts mehr zu wünschen übrig lassen wird.

Der Markt der Stadt wird sehr reichlich versehen mit allen Bedürfnissen des Lebens. Alltäglich werden 2,00o Lastthiere mit Mais, Manioc, Hülsenfrüchten, Branntwein, Fleisch, Milch, Eiern, 


\section{- 308}

Käse und haucb tabak beladen nach der Stadt gebracht. Ihre Ladungen wurden 1819 das Jahr hindurch zu dem Gesamintbetrage von $4,480,000$ Piastern berechnet. Havannah ist eine der fünf Städte Amerika's, deren Bevölkerung 100,000 Menschen übersteigt, und gehört daher zu den gröfsten der neuen Welt. Mexiko zählt 170,000, Neu-York 140,000, Rio Janeiro 135,000, darunter 105,000 Schivarze; Philadelphia, Havannab und Bahia, jede 120 bis 130,000 .

\section{Viertes Kapitel.}

Fortsetzung der Beschreibung der Insel Cuba, - Gröfse, - Be. schaffenheit. - Bevölkerung. - Sclaven.

Der Monat Jantiar und Hornung wurde von unsern lieisenden dazu verwendet, um in der Um. gegend von Havannah Bemerkungen über das Land zu sammeln. Die Gestalt wie die Gröfse der Insel Cuba ist lange Zeit unbekannt geblieben. Nach sorgfältigen Untersuchungen gibt Herr von Hum. boldt die Grundfäche dieser Insel auf 3,520 SecGeviertmeilen ohne die Insel Pinos, und mit derselben auf 3,615 an. Sie ist daher um ein Siebentheil kleiner, als man bisher geglaubt hatte, und um 0, 24 gröfser, als St. Domingo. Ihre gröfste Länge beträgt 227 Meilen. Ihre gröfste Breite, von der Spitze Maternille zur Ausmündung des Magdalena nahe beim Pik Tarquino beträgt 37 Meilen, zwischen Havannah aber und dem Prinzenhafen nur 


\section{- 300}

15 Meilen. In dem bestcultivirten Theile aber, zwischen Havannah und dem Batabano, hat sie nur 81/3 Scemeilen. Diese Landenge zwischen zwei Hafen ist für die Vertheidigung der Havannah äufserst wichtig. Unter allen grofsen Inseln der Erde ist keine der Insel Cuba in Bezug auf Gestalt und Grölse ähnlicher, als die Insel Java, deren Area 4,170 Qua. dratmeilen beträgt. Die Insel Cuba enthält daher beinahe die Hälfte des Areal oder der Gesammtfläche des ganzen Antillen.Archipels, welche 7,787 Quadratmeilen, 20 auf einen Grad, beträgt. Die Insel Cuba hat auf vier Fünftheile ihrer Oberfläche nur tiefe Niederungen; am südöstlichen Endtheile hebt sich das Land zu einer Berggruppe, deren höclister Punkt sich nordwestlich der Stadt Santiago der Insel Cuba unter dem Namen Motanna del Cobre bis auf ,200 Toisen absolute Höhe erhebt. Zur nämlichen Berggruppe gehört die Sierra de Tarquino mit den Kupferbergen. Eben so wird die Insel von O.S. O. nach W. N. W. von einer Hügelkette durchzogen, die ibre Richtung nach der Nordküste nimmt. Auf dem Wege nach der Stadt Trinidad hat Herr von Humboldt Nadeln gesehen, die sich in isolirten Spitzen auf mehr als 300 Toisen erheben. Dieses Kalk. gebirg stellt sich sehrimposant dar, wenn man beim Cayo de Piedras vor Anker liegt. Im Innern der Insel ist das Erdreich sanft wellenförmig, wie in England, und erhebt sich nirgend über 40 bis 60 Toisen. In den hohen Gebirgen Montanno's del Cobre will man Gneifs und Glimmerschiefer erkannt ha- 
ben, und aus diesem Urgebirge sind walirschein. lich die goldhaltigen Anschwemmungen hergekom. men, die in den ersten Zeiten der Eroberung, zum Unglücke der Eingebornen, so reiclie Ausbeute gcliefert haben. Heut zu Tage ist der Reichtlum des goldhaltigen Sandes erschöpft, und wenn der Golddurst die Bewrohner Cuba's zum Wühlen nach Schätzen verleiten sollte, so würden sie unstreitig sicherer in den Gängen des Urgebirges selbst, als in von den Vorfahren verlassenen Goldwäschen ihren $Z_{w}$ eck erreichen.

Der mittlere und westliche Theil der Insel enthält zwei Formationen von dichtem Kalksteine und Gyps, welche dieselben Erscheinungen, wie alle ähnlichen Formationen in Europa darbieten. Auf der Insel Cuba sind noch keine vulkanische Pro. dukte neuerer Formation gefunden worden, und es scheint überhaupt zu den glücklichen Vorzügen der Insel Cuba zu gehören, von den Erdstörsen nicht so sehr heimgesucht und zerstört zu werden, wie Haiti und Portorico. Die Erdstöfse werden meistens nur in den östlichen Theilen verspürt, und sind nicht so zerstörend. Vielleicht ist es der Fall, dafs gegen diese Region hin sich seitwärts die Wirkung einer Spalte ausdehnt, von der man glaubt, sie durchziebe die Granitfelsenzunge, zwischen Port au Prince und Cap Tiburon, über welcher auch im Jahre $177^{\circ}$ ganze Berge eingestürzt sind.

Der westliche Theil der Insel hat Mangel an Flüssen, welches man der Zerstörung der Kalkberge 


\section{$-311$}

und dem Mangel an Waldung zuschreibt. Haiti und Jamaika sind in dieser. Hinsicht von der Natur sehr begünstigt, indem sie vulkanische, mit Waldung bedeckte Spitzberge haben, welche die Feuchtigkeit an sich ziehen, erhalten, und den Quellen Nahrung verschaffen.

Die fruchtbarsten Landschaften der Insel Cuba sind die Bezirke von Matanzas, Mariel, Trinidad und Xagua. Das Thal von Guinos wird künstlich bewässert, und diesem Umstande verdankt es seine ausnehmende Fruchtbarkeit. Des Mangels an grossen Flüssen, und der ungleichen Fruchtbarkeit des Bodens ungeachtet, gewährt die Insel Cuba durch ihre wellenförmige Oberfläche, ihr stets sich erneuendes frisches Grün, und die Vertheilung ihrer Pflanzenformen bei jedem Schritte, den man, so zu sagen, thun kann, die mannigfaltigste und lieblichste Landschaft. Zwei Bäume mit grofsen, lederzähen, glän. zenden Blättern, der Mummea und das Calophyllum:Calaba, verschönern die Fluren. Fünf Arten von Palmen : die Königspalme (Oreodoxa regia), die gemeine Cocospalme, die gekrauste Cocospalme (Co. cos crispa), die Corypha miraguama und maritima nebst klein an einander blühenden Sträuchen dienen den Hügeln und Savanen zum Schmucke. Die feuchten Stellen des Bodens werden durch die Cecropia peltata bezeichnet. Man möchte glauben, die ganze Insel sey ursprünglich ein Wald von Palmen -, Citronen- und wilden Orangen - Bäumen gewesen. Die wilden Orangen mit ganz lleinen. Früchten waren 
vermuthlich vorhanden, ehe noch die Europäer landeten, welche die Orange der Gärten dahin brachten. Sie werden selten höher als 10 bis 15 Fufs. Meistens kommt der Citronen- und Orangenbaum jedem unvermischt vor. Wenn die Colonisten den Boden durch Feuer urbar machen, so unterscheiden sie die Eigenschaften des Bodens, je nachdem derselbe mit der einen oder der andern Art der gesellschaftlichen Pflanzen hewachsen war, und ziehen den Boden, auf welchem der edle Orangenbaum wächst, demjenigen vor, der kleine Citronen trug. Diese letztern hält man in Amerika für einlıeimisch, und behauptet mit Recht, dafs die aus Asien herübergebrachten auch in der Verwilderung nicht ausarten. Da jedoch hier zu Lande die Zuckersiedereien noch nicht genug vervollkommnet sind, und man keinen andern Brennstoff dazu hat, als das ausgequetschte Rohr (bagasse), so ist die Zerstörung des Holzes selbst eine wahre Landplage. Es gibt wohl mehrere kleine Küstenflüsse, die zur Bcwässerung des Landes dienen können, aber alle sind nur ein paar Meilen oberhalb ihrer Mündung schiffbar. Viele dieser Flüsse verlieren sich in Sümpfe oder stürzen sich in Felsenschlünde. Das Verschwinden der Gewässer ist so häufig, dafs in Folge des dadurch verursachten Druckes das süfse Wasser mitten aus dem Salzwasser in beträchthicher Entfernung von der Küste hervorquillt.

Der Bezirk von Havannah gehört nicht zu den fruchtbarsten der Insel, darum sind auch die 
'Luckerpflanzungen, welche früher in der Nähe der Hauptstadt gefunden wurden, durch Meierlöfe mit Viehstand, durch Maisfelder und Futterwiesen verdrängt worden, welehe wegen der Nähe derHauptstadt grölsere Vortheile gewähren. Auf der Insel Cuba unterscheiden die Pflanzer zweierlei Erdreich; das eine, schwarze, enthält mehr vegetabilische Stoffe; das andere, rothe, entlält Eisenoxyd. Beide Arten wechseln mit einander $a b$, wie die Felder im Damenbrete. Man hält die schwarze Erde, weil sie die Feuchtigkeit besser an sich hält, für den Zuckerbau, die rotbe der Caffeestaude zuträglicher. Dennoch findet man auch auf dem rothen Erdreiche Zuckerrohrpflanzungen.

Das Klima der Insel Cuba ist dasjenige, welches der gemäfsigten Zone näher liegt, und schon jene bedeutendern Unterschiede zwischen Wärme und Kälte darbietet, die die gemälsigte $Z$ one bezeichnen. Calcutta, Canton, Macao, Havannah und Rio Janeiro sind Orte, denen ihre Lage, ihre gleiche Höbe mit der Meeresfläçhe und die Nähe der.Wendekreise eine ziemlich gleiche Temperatur geben, und für das Studium der Meteorologie sehr geeignet sind. Man hat ${ }_{1}$ sich gewölunt, die Ḱlimate zwischen den Wendelireisen sich überall gleichförmig zu denken. Dieses ist aber nicht der Fall, und jeder Grad Entfernung bringt auch andere Verhältnisse in die Er. scheinungen der Temperatur

Herr von Humboldt hat für dię Meteorologie des Antillen-Archipels sehr, viele und wichtige That-

Bibl. waturh. Reisen. IV. 
sachen gesammelt, von denen wir unsern jungen Lesern so viel mittheilen wollen, als wir glauben, dafs hinreichend sey, um ihnen einen Begriff von dem Ḱlima der Insel Cuba beizubringen. Die mittlere Temperatur der Havannah beträgt im Jahres. Durchsclinitte $25^{\circ}, 7$ des hundertheiligen Thermometers, also nur um $2^{\circ}$ weniger, als in Cumana, welches doch dem Aequator um 12 ${ }^{\circ}, 42^{\prime} \mathrm{Br}$. näher liegt. Allein der Unterschied zwischen den kälte. sten und wärmsten Tagen ist auf Cuba viel gröfser. Die wärmsten Monate zeigen, wie unter dem Aequator, eine mittlere Temperatur von $28^{\circ}, 8$, sogar $29^{\circ}, 5$; die kältesten Monate, im December und Januar, geben eine mittlere Temperatur von $17^{\circ}$, in der Havannah $21^{\circ}$, d. l. einen um $5^{\circ}$ bis $8^{\circ}$ gröfsern Unterschicd, als unterm Aequator. Man sah sogar den Thermometer auf $4^{\circ}, 5$ herabsinken, und bei dieser Temperatur, was noch merkwürdiger ist, eine mehrere Linien dicke Eiskruste frieren, ohne dafs der Thermometer auf $0^{\circ}$ gesunken wäre. Dieses geschieht, wenn im Winter ein lange anhaltender Wind die kalten Luftschichten aus Canada herabführt durch das Becken des Missisippi. Herr Wells und Wilson nahmen das Entstehen der Eis. liruste wahr, während der Thermometer noch auf $5^{\circ}$ und selbst $9^{\circ}$ über $0^{\circ}$ stand.

Diese Bildung des Eises, in einer mit der Meeres. fläche gleichen Ebene in der heifsen Zone mufs urn so mehr auffallen, als in Caracas bei $10^{\circ}, 31^{\prime}$ Breite und 477 Toisen Erhöhung über der Meeresfläche, der Ther. 
mometernie unter $11^{\circ} \sin k t$, und man unterm Aequator 1400 Toisen hoch steigen rnufs, um Eis sich bilden zu sehen. Ja man trift in Quito in einem engen Thale von 1490 Toisen Erböhung noch kein Eis an, und in den umliegenden Antillen sah man den Thermometer nie unter $18^{\circ}, 5$ sinken. Der Tenperaturwechsel erfolgt auf der Insel Cuba schnell. Der Frost schadet jedoch niemals den Pflanzungen. Auch sind die zerstörenden Orkane nicht so häufig, als auf Jamaika und Haiti.

Cuba besitzt zwei Bischöfe, wovon der cine Bi. schof von Havannah ist, dessen Bisthum 40 Kirchsprengel begreift; der andere ist der von Santiago de Cuba mit 22 Kirchspiclen.

Die Insel Cuba öffnet durch den überall anbau. fähigen Boden der Industrie und Gewerbsamkeit ein weites Feld. Sie scheint zur Königin unter den Antillen bestimmt zu seyn. Ihre 3600 Geviertmeilen kön. nen einst 6 Millionen Menschen Nahrung und Wolıl. stand verleilien. Auch befindet sich die Bevölkerung in starker Zunahme. 1775 zählte man 170,862 Ein. wohner auf der ganzen Insel, 1791: 272,140; im Jahre 1817: 630,980. Nach der letzten Zählung fanden sich: 29c,021 Wcifse, 175,691 freic farbige Menschen und 225,268 Sclaven. Wir sehen, dafs Cuba das Glück hat, dafs daselbst die weifse Bevölkerung der schwarzen das Gleichgewicht bält, und die freie Bevölkerung die der Sclaven übertrifft. In den brittischen und französischen Antillen wird die freic Bevölkerung von der der Sclaven drei- und selbst sechs. 


\section{0}

fach übertroffen, und es steht für alle das Schicksal Haiti's zu fürchten. Cuba allein hat das Wenigste zu fürchten, um so mehr, als man da eine mildere Behandlung der Sclaven wahrnimmt, und ihre Freilassung selır begünstigt wird. Die freien Neger erlangen Eigenthum und Wohlstand, und geniefsen alle Vortheile der Gesetze, wodurch ihr Interesse mit dem der Weifsen erhalten wird. Zudem sind die Sclaven begünstigt, und ihrem Fleifse und ihrer Sparsamkeit ist es anheimgegeben, sich ihre Freiheit durch Loskaufung zu verschaffen, die derHerr nicht verhindern' darf. So wird die Geduld 'der schwarzen Bevölkerung nie auf die äufserste Probe gestellt.

Anders verbält es sich auf den übrigen Antillen, und menschenfreundliche Gesinnungen, wie sie sich in England und Frankreich über die Afrikaner aussprechen, scheinen keineswegs die französischen und englischen Pfanzerzu leiten. Man glaubt der Gefahr durch Mifshandlung der Sclaven zu entgeben. Auf Cuba ist es anders. In keinem Lande, wo Sclaverei angetroffen wird, sind die Freilassungen so häufig, als auf der Insel Cuba. Die Gesétzgebung erleichtert sie, und dic einmal freien Neger werden nimmer Sclaven. Jeder Sclave hat das Recht seinen Herrn zu wechseln oder durch Rückgabe des Kaufpreises sich frei zu maclien. Das religiöse Gefühl flöfst vielen Herren den Gedanken ein, in ihrem Testamente eine Anzahl Selaven frei zu machen. Auch kann sich der Sclave leicht etwas verdienen, 
wenn er dem Herrn täglich eine bestimmte Summe bezalilt, und dann für eigne Reclinung arbeitet. Alle diese Umstände begünstigen den Übergang der Sclaven in die Classe der freien Farbigen. Herr vón Humboldt sagt: die Lage der, freien Farbigen ist glücklicher in der Havannah, als unter solchen Nationen, die sich seit Jahrhunderten einer weit vorgerücktern Civilisirung rühmen. Es sind dort jene barbarischen Geset\%e unbekannt, die noch beut zu Tage angerufen werden, und denen zu Folge die Freigelassenen unfälig sind, von Weifsen Schenkungen anzunehmen, hingegen aber ihrer Freiheit beraubt, zum Vortleile des Fiscus verkauft werden können, wenn sie überwiesen sind, Marronsnegern Zuflucht gestattet zu haben. Übrigens ist das Loos der Sclaven immer schrecklich, besonders wenn man bedenkt, dafs es unter den Pflanzern ernsthaft erörtert wurde, ob es besser sey, die Sclaven zu schonen, um sie länger am Leben zu crhalten, oder ihnen durch möglichste starke Arbeit den gröfsten Nutzen abzugewinnen, und sie schnell aufzureiben? - Grausamkeiten werden genug begangen. Hiezu kommt noch das Klima, welches viele der neuangekommenen Neger aufreibt. Man weifs, dafs nach Cuba allein bis $1820,413,500$ Afrikaner eingeführt wurden. Anstatt, dafs sich nun ilıre Zahl auf der Insel hätte' sehr vermehren sollen, sind daselbst nur 390,000 farbige Menschen, freie und Sclaven vorhanden." Immer jedoch noch mehr im Verhältnisse, als in den Colonien anderer Nationen. 


\section{$-318$ \\ Fünftes Kapitel.}

Geistige Bildung auf der Insel Cuba. - Öffentliche Anstalten, Produlte.

Was die geistige Bildung anbelangt, so ist dicselbe beinahe ganz auf die weifse Bevölkerung beschränkt, aber auch hier sehr unglcich vertheilt. Die vornehme Gesellsehaft in Havannah gleicht durch feine Sitte ganz der feinen Gesellsehaft in Cadix und den übrigen reichen Handelsstädten in Europa. Der grofse Wohlstand maeht, dafs sie sogar einen etwas indischen Ansirich erhält. Aufser der Hauptstadt hingegen trift man bei den Pflanzern und Landgutbesitzern jene Sitteneinfalt an, die sich dureh rauhe, aber herzliche Tugenden zu Tage legt. Die Havannesen waren unter den spanischen Colonisten die ersten, welche Italien, Frankreich und Spanien be. sucht haben. Hier batte man auch immer die genauesten Nachrichten von den Häíen, und man war von der Politik sehr gut unterrichtet, welches für den Handelsstand eben so wichtig als vortheilhaft ist.

Für literärisehe Anstalten besitzt Cuba jene gros. sen und kostbaren Anstalten nicht, welche seit alter Zcit Mexiko auszeichnen; hingegen finden sicl in der Havannah Einrichtungen, welehe der Patriotis. mus der Bewohner gründete, und wenn anders die Ruhe nicht gestört wird, auch vervollkommnen wird. Die patriotisehe Gesellsehaft in Havannah ward 1793 gegründet. Sie hat von ihr unabhängige Vereine zu Espiritu-Santo, von Puerta-Principe und von 
Trinidad. Im Ḱloster der Padres Predicadores ist eine seit 1728 gestiftete Universitä, diese hat Lehrstühle der Theologie, der Jurisprudenz, der Medicin und der Mathematik, und seit 1818 einen Lehrstuhl der Staatswissenschaft und der ökonomischen Botanik. Ferner hat Havannah ein Museum, eine Scliule der beschreibenden Anatomie, eine öffentliche Biblio. thek, eine unentgeldliche Schule für die Zeichenkunst und Malerei, eine nautische Schule. Die Lancaster'schen Schulen und der Pflanzengarten sind noch junge Anstalten, aber im Fortschreiten begriffen.

Man zählt hier auf der Insel 1100 Geistliche. Der Bischof von Havannah hat 110,000 Piaster, der Erz. bischof von Cuba 40,000, ein Chorherr 3000 Piaster Einkünfte. 1825 befanden sich in Havannah über 500 praktische Ärzte, vor denen sich doch weder der Tod noch das gelbe Fieber sehr zu fürchten sclien; unter diesen waren 61 medicos, 333 cirujanos latinos $\mathrm{y}$ romancistos und 100 farmaceuticos, dann 312 Advokaten! und 9// Escribanos. Die Zahl der Advokaten nahm aufserordentlich $z u$, was eben kein Beweis für die Verträglichkeit der Havannesen ist. 1814 waren auf der ganzen Insel nur 160 vorhanden.

Was den Anbau anlangt, so war zur Zeit, als die Spanier in Amerika sich ansiedelten, ihre ganze Mühe auf Erzeugung der Pflanzen gerichtet, welche Nahrung gewähren, und in Mexiko, Peru und den gëmäfsigten Gegenden von Gundinamarca hat sich 
dieser allentbalber crhatión, wo die Weifsen ausgedehnte Ländereien besitzen, ¿ Diese Pflanzén: der Pisang, der Mais, der Manioc, die európäischen Cerealien, die Kartoffeln und der Quinoah, áls Nah. rungspflanzen, sind der Hauptgegeristánd des Landbaues in den gemäfsigten Hochebénen des ContinentalAmerika geblieben. "Den Indigo, die Baumwolle, der Caffeestrauch und das Zuckerrohr erscheinen in diesen Gegenden als untergeordnete Zweige. Seit dritthalbhundert Jahren hat Cuba und die übrigen Antillen keinen Wechsel erlitten. Auch wares Cuba, dessen Ausfuhr bis in's achtzehnte Jahrbundert aut Leder und Häute beschränkt blieb. Der Viehzucht folgte der Tabakbau und die Vermehrung der Bicnen, wozu die ersten Bienen aus Florida eingebractit wurden. Bald waren Wachs und Tabak bedeuterdere Gegenstände des Handels, als Häute; doch wurde Wachs und Tabak gar bald durch Zucker und Caffee verdrängt. Gegenwärtig sind Wachs, Tabak, Zucker und Caffee die Ausfuhrartikel.

1760 wurden an Zucker ausgeführt: 13,000 Kisten. Diese Ausfuhr steigerte sich von Jahr zu Jahr bis 1824 : $\mathrm{zu} 300,211$ Kisten. Man kann daher annelımen, dafs, des Schleichhandels ungeachtet, jetzt jähr. lich 330,0oo Kisten Zucker ausgeführt werden. Den Verbrauch auf Cuba selbst nimmt Herr von Hü. boldt auf 8o,00o Kisten an, welches einen Gesammtertrag der jährlichen Zuckerernte von 440,000 Kisten darbietet.

Vielleicht haben meine jungen Leser eine Freude 


\section{$-\quad 321$}

daran, zu sehen und zu erfahren, wie viel Zucker überhaupt in Amerika erzeugt wird; damit jedoch die Freude auch ein Gegengewicht habe, so will ich überall auch die Zahl der schvarzen Sclaven, die dazu verwendet werden, beisetzen.

Die Antillen führen an Zucker aus : 62,000,000 Zentner, zu denen 1,147,500 Sclaven gebraucht werden. Brasilien 27,000,000 Zentner mit 2,000,000 Sclaven. Guiana 9,000,000 Zentner mit 206,000 Sclaven. Mithin liefert ganz Aequinoctial-Amerika für Europa 98,000,0oo Zentner Zucker, zu deren Erzeugung $3,3,1,000$ unglückliche Sclaven verwendet werden... Ein Drittheil dieses Zuckers verbraucht Grofsbrittanien allein. Die Zuckerpflanzung ist gegeniwärtig auf dem Erdballe dermafsen verbreitet, dafs, eine solche Veränderung des Preises des $\mathrm{Zu}$ ckers nicht zu fürchten steht, wie zu der 'Leit, als der Anbau desselben noch auf einen engen Raum beschränkt war.

Die Insel Cuba hat gegenwärtig eine Ausfuhr von 1/5 alles Zuckers der Antillen und von 1/8 alles des Zuckers, der aus dem Aequinoctial-Amerika nach Europa komnit." Man unterscheidet auf der Insel Cuba drei Sorten von Zucker, nach dem Grade der Reinheit, den er durch das Raffiniren erhält.: Der Zucker wird nämlich in sehr grofse Hüte oder umgestürzte Kegel geformt, von diesem enthält der obere Theil den, weifsen, der mittlere den gelben und der untere Theil die geringste Sorte, Cucurucho genannt. ., Aller Zucker auf Cuba wird so raffinirt, 
und nur sehr wenig roh ausgefïhrt. Die Hüte wie. gen gewölnlich eine Arobe, und man rechnet $5 /$ weifs, $3 / 9$ gelb und $1 / 9$ Cucurucho in einem Hute. Wird der reine weifse allein verkauft, so geht er gewöhnlich um zwei bis drei Realen theurer ab, als gemischt. Die Preise des Zuckers sind nicltt fest, und waren besonders zur Zeit der europäischen Ḱriege und den Unruhen aufSt. Domingo sehr schwanliend, und zwar so sehr, dafs sie zwischen 30 und 13o schwankten. Seit 1826 sind sie wieder sehr niedrig. Ein Eigenthümer, der eine mittelmäfsig grofse Zuckerpflanzung besitzt, und auf ihr achthundert Kisten Zucker erzeugt, erhält dafür 19,300 Piaster, zu 2 fl. 4 kr. C. M. Vor zwölf Jahren erhielt er dafür 28,00o Piaster. Damals, zwischen 1811 und 1815 , kostete die Kiste 36 Piaster, jetzt aber nur 24. Dieser niedrige Preis kommt uns Europäern wieder zu gut, indem wir wohlfeilern $\mathrm{Zu}$ cker haben.

Auf der Insel Cuba sind nur wenig Pflanzungen, welche 40,000 Aroben Zucker ertragen. Die Pflanzungen lieifsen Ingenio. Eine solche grofse Yngenio hat gewöhnlich eine Ausdehnung von 50 Caballerias oder Morgen Landes von 65,000 Quadratklaftern, was ungefähr $5 \frac{1}{2}$ Joch oder Morgen nach unserm Mafse beträgt, so dafs man für eine der gröfsten Pflan. zungen auf Cuba ungefähr 250 Joch Landes nach unserm Mafse rechnen liann. Von einem solchen Stück Land, das die Gröfse von einem Zehntheile Quadratmeile hat, ist der eigentlichen Zuckerrohr. 


\section{- $\quad 323$}

Pflanzung nur die Hälfte gewidmet, die andcre Hälfte wird dagegen zum Anbaue der Nahrungspflanzen und der Viehweiden benutzt. Der Preis des Landes ist nach der Beschaffenheit des Bodens verschieden, so wie auch nachdem es Mavannah oder einem andern Hafen näher liegt. In der Nähe Havannah's wird eine Caballeria zu zwei oder dreitausend Pia. ster gewerthet. Um 32,00o Aroben Zucker zu erzeugen, mufs man wenigstens 300 Neger haben. Ein acclimatisirter Neger kostet 450 bis 500 Piaster (1000 fl. C. M.); ein erwachsener, aber noch nicht an das Klima gewohnter Bozaneger kostet nur $37^{\circ}$ bis 400 Piaster. An Nahrung, Kleidung und Arznei mag ein Neger jährlich 45 bis 50 Piaster kosten, mit den Zinsen vom Capital mag ein Neger täglich auf 30 bis 34 Kreuzen C. M. oder 9 Groschen sächsisch kommen. Die Nahrung des Sclaven besteht in Tas. sajo, an der Sonne gedörrtes Fleisch, aus Buenos. Ayres und Caracas. Ist das Tassajo zu theuer, so erhält der Sclave gesalznen Kabeljau oder Stockfisch; als Gemüse empfängt er Kürrbis, Munnatos, Pataten und Mais. Eine so grofse Pflanzung, wie wir oben erwähnt haben, braucht aufser den 300 Sclaven noch drei Walzenwerke, die durch Ochsen in Bewegung gesetzt werden, werin dieses nicht durch Wasserräder geschehen kann; ferner 18 Sied. kessel, die nach der alten spanischen Methode sehr viel Holz erheischen. Wo sehr viel Branntwein oder vielmehr Rhum Absatz findet, decken die Melassen (Abfall, aus dem der reine Zucker bereits gezogen 


\section{- 324}

ist), die zu Rlum gebrannt werden, die Kosten der Fabrikation. 32,000 Aroben 'Zucker liefern einen zu Branntwein tauglichen Abfall von 30,000 Aroben, aus denen 500 Pipen Rhum, zu 25 Piaster, gebrannt werden. Es ergibt sich bei Berechnung der Zuckerbereitung folgendes Resultat.

$\therefore$ Der Werth von 32,00o Aroben Zucker (weifs und gelb) zu 24 Piaster, die Kiste zu 16 Aroben geben . . . . . . . . 48,000 Piaster, Werth von 500 Pipen Rhum . . 12,000 i

60,000 Piaster.

Die Kosten belaufen sich bei einer solchen Pflan. zung. jährlich auf 30,000 Piaster. Das Kapital, welches in einer Pflanzung steckt, besteht in 50 Caballeros Land, zu dem Mittelpreise von 2,500 Piaster in . . . . . . . . . 125,000 Piaster 30 Stück Neger, zu 450 Piaster. 135,000 " Gebäude und Mühlen . . . . 80,000 ॥ Kufen, Cylinder und übriges Ge-

räthe . . . . . . . . 130,000 ,

\section{Summe 470,000 Piaster.}

Aus dieser Berechnung ergibt sich für einen $\mathrm{Ca}$ pitalisten, der eine Zuckerpflanzung auf Cuba unternelimen wollte, ein Ertrag für sein Capital von. $6 \frac{1}{8}$ vom Hundert. Nimmt man hinzu, dafs Mifsjahre eintreten, INeger sterben, Gebäude und Maschinen der Ausbesserung bedürfen, und die Auslagen jähr rlich die: nämlichen bleiben, so ergibt sich, 


\section{- 325}

dafs der Vortheil der Zuckerpflanzungen keineswegs so grofs ist, als man glaubt. "Der Vortheil, der seit länger angesiedeltén Pflanzer besteht darin, dafs sic ihre Einrichtungskosten noch vor 20 bis 30 Jahren macliten, und damals ein bedeutendes Capital ersparten. Zu jener Zeit kostete ein Caballeros Land der besten Sorte nur 1,200 bis 1,600 Piaster, jetzt aber das Doppelte. Sie hatten die Zeiten der bohen $\mathrm{Zu}$. ckerpreise zu ihrem Vortheile. Man sah daher in neuerer Zeit, als die Zuckerpreise so gewaltig wichen, mehrere Zuckerpflanzungen in Reispflanzungen sicb verwandeln. Solche Berechnungen sind bo sonders für unsere jungen Leser von Nutzen, sie können hieraus. Unternehmungen berechnen lernen.

Herr von Humboldt fand, dafs der ausgeprelste Saft des Zuckerrohrs, je nachdem dasselbe auf bes. screm oder schlechterem Lande gewachsen ist, 12 bis 16 vom Hundert reinen Zucker liefert, d. h. 100 Pfund Zuckerrolirsaft geben 12 bis 16 Pfund Zucker. Der Saft des Zuckers im Ahorn in Nord. Amerika liefert auf gutem Boden $2 \frac{2}{2}$ vom Hundert. Eben so viel gibt auch der Saft der Runkelrübe. Hieraus ergibt sich, dafs 100 Pfund Zuckerrohrsaft sechs Mal so viel Zucker geben, als 100 Pfund Ahornoder Runkelrübensaft. Aber Runkelrüben wachsen mit weniger Kosten und Mühe, und ohne Sclavenhände, und trotz der Verminderung der Zucher. preise treiben in Frankreich 15 Runkelrüben Zuckerfabriken ihr Geschäft mit Vortheil. Der Saft des Zuckerrohrs ist seinen chemischen Bestandtheilen 


\section{$-320$}

nach sehr verschieden, je nachdem der Boden, auf dem es gewachsen, verschieden ist; nachdem mehr oder weniger Regen gefallen, die Wärme mehr oder weniger 2 wischen verschiedenen Jahreszeiten vertheilt war, und die Pflanzen Neigung zur Blüthe zeigten. Die Blüthe macht das Rohr untauglich. Auch hängt von dem zweckmäfsigen Verfahren bei der Fabrikation des Zuckers sebr viel von den chemischen und technischen Ḱenntnissen ab, welche die Werkführer besitzen, und ein fehlerhaftes Verfahren macht den Ertrag des krystallisirten Zuckers um vieles geringer. Viele europäiscbe Chemiker haben in Hinsicht auf Zuckerbereitung grofse Entdeckungen gemacht, welche jedoch auf den Antillen noch eine geraume Zeit olne Anwendung bleiben werden.

In Ländereien, die bewässert werden können, oder worin Knollengewächse vor dem Zuckerrohre gepflanzt worden sind, erhält man aus einer Cabal. lerie fruchtbaren Bodens 3 bis 4,000 Aroben. Der gewöhnliche Ertrag jedoch, zu 1,500 Aroben angenomrnen, nach den jetzigen Preisen berecbnet, würde ein solches Grundstüek, das mit Zuckerrohr be. pflanzt $348 \mathrm{fl}$. C. M. einträgt, mit Getreide bepflanzt nur $115 \mathrm{fl}$. eintragen. Allein Zuckerpflanzungen fordern ein grofses Capital, so dafs zu einer Pflanzung von 32,000 Aroben 400,000 Piaster Capital, ohne die Auslagen des ersten Jahres, erfordert werden. In Bengalen trägt der Boden doppelt so viel auf gleicher Ausdehnung, als das beste Land der An. 


\section{$-327$}

tillen. Der Tagelohn des freien Indiers ist drei Mal geringer, als der eines Negersclaven auf Cuba, sein Leben fordert kein Capital und sein Tod bringt dem Pflanzer keinen Verlust von 1,ooo fl. Darum ist auch der indische Zucker so wohlfeil, und darum ist es auch gewifs, dafs die Arbeit freier Hände sicherer und wohlfeiler ist, als die der Sclaven, abgesehen davon, dafs die freie Hand besser und melh arbeitet. In Jamaika ist der Ertrag ungefähr derselbe, vie auf der Insel Cuba, und gibt dieselben Preise.

Übrigens ist durch Berechnungen erwiesen, dafs nicht ganz 20 Seegeviertmeilen Landes hinreichen würden, so viel Zucker zu erzeugen, als jetzt Cuba selbst verbraucht und ausführt, nämlich 440,000 Kisten im Werthe von 20,800,00o Gulden. Um ganz Frankreich, nämlich 3o,0oo,ooo Menschen, mit $\mathrm{Zu}$ cker zu versorgen, bedarf man in den Tropenländern $9 \%$ Seegeviertmeilen Land mit otaheitischem Zuckerrohre bepflanzt. Bei uns würden $37^{2} \%$ SeeQuadratmeilen mit Runkelrüben bepflanzt eben so viel Zucker liefern!

Zur Zeit der Anwesenheit des Herrn von Humboldt auf Cuba hatte man aus Frankreich Runkelrüben.Zucker kommen lassen, und man erschrack nicht wenig, als es sich zeigte, dafs es wirklich Zucker war, was man aus Rüben zog, und dals er dem Rolirzucker ganz vollkommen gleich war. Es hiefs, der Rohrzucker werde in Europa entbehrlich werden. Wie sehr die Franzosen für diese Erfin. dung von den Colonisten verehrt wurden, läfst sich 
denken. Ein Trost blicb noch. Man dachte, die hohen Arbeitspreise in Europa würden es verbin. dern ; dafs die Runkelrüben-Zuckerfabrikation mit der des Rohrzuckers in die Schranken trete. Seitdem ist cs aber der französischen Chemie gelungen, die Arbeit so sehr zu erleichtern, dafs trotz den seither geöffneten Colonien der Runkelrüben-Zucker sieh neben dem Rohrzucker erhält. Bei alle dem ist jetzt nicht mehr zu fürchten; dals die. Colonisten durch europäisclie Zuckerfabrikation zu Grunde gehen werden, wenn es auch für jeden, der die fortschreitende Menschleit betrachtet, eine Freude seyn mufs, zu sehen, wie die Industrie dem kalten Norden abtrotzt, was nur die Gegenden der Erde freiwillig geben, denen die Sonne im Scheitel steht.

Bis in das Jahr 1762 hat die Insel Cuba nur wenig Erzeugnisse in den Handel geliefert. Ein unglückliches Ereignifs weckte den schlummernden Geist der Cubaner. ${ }^{1} 762$ ward Havannah durch die Engländer erobert, und von ihnen am 6.Juli 1764 wieder geräumt, und von diesem Augenblicke an scheint es, als hätten die Engländer die Havannesen mit ihrem Geiste für die Unbill entschädigt. Dic Aufführung, neuer Festungswerke brachte Geld in Umlauf, und der freigegebene. Sclavenhandel bot den Colonisten arbeitsame Hände. Das Glück wollte ihnen auch wohl, indem es ihnen einen tüchtigen Gouverneur in Don Luis de las Casas gab. Dieser Name, an dem so viele schöne Erinnerungen kleben, 


\section{- 329}

gab allem Guten mächtigen Antrieb. Patriotische Gesellschaften und die Zerstörung der französischen Colonie auf St. Domingo, von 179 t bis 1803 , steigerten die Zuckerpreise, und waren kräftige Ermunterungen für die Pflanzer auf Cuba. Die gröfsten Veränderungen, welche in den Zuckerpflanzun. gen Statt gefunden baben, fallen in den Zeitraum von 1796 bis 1803 . Anfangs wurden an die Stelle der von Ochsen getriebenen Mühlen, solche mit Maulthieren gesetzt, dann wurden Wasserräder eingefülirt und endlich der Gebrauch von Dampfmaschinen versucht. Von diesen sind jetzt 25, vorhanden. Zugleich wurde auch der Anbau des Zuckerrohrs von Otaheiti allgemeiner. Neue Siedkeśsel und Reverberiröfen wurden eingeführt, und man dachte auch sogar án die bessere Verpflegung der Neger. In sehr vielen Pflanzungen trägt man sehr edelmüthige Sorgfalt für die Pflege der Ḱranken, für Einbringung der Negerinnen und die Erziehung der Negerkinder. Im Jahre 1777 waren 473 Zuckersiedereien vorhanden, 1817 waren deren 780 , von denen jede das Viarfache liefert vón dem, was sie früher lieferten. Vom Zucker wird an die Regierung nur ein halber Zehent, d. h. der zwanzigste Theil abgeliefert, dennoch beträgt er einen Durchschnittertrag von 2,30o, ooo Franken.

Das bare Geld ist jedoch in Havannah sehr rar, und das macht, dafs die Capitalien nur zu sehr hohen Zinsen $z u$ haben sind, $z$. B. nur zu 12 bis 15 vom Hundert. Um den Zinsfufs zu steigern, hat der Sclavenhandel sehr vicl dazu beigetragen. Dieser 
Handel ist cben so schädlich als einträglich. Die Schurken, welche sich mit diesem Handel heschmu. tzen, gewinnen oft auf eincr einzigen Reise 100 bis 125 vom Hundert. Sie nchmen daher zu diesem Ilandel Capitalien zu 18 bis 20 p.C. auf.

Auf frisch urbar gemachtem Lande gewährt das gut und sorgfältig gepflanzte Zuckerrohr durch 20 bis 23 Jahre gute Ernten, dann mufs es alle drei Jahre frisch gepflanzt werden. Das Zuckerrohr von Otaheite gewährt den Vortheil, auf demselben Lande um ein Viertheil mehr Saft und ein dichteres, zum Brennen tauglicheres Rohr, als das creolische zu liefern. Die Raffinirer helhaupten, es sey der Saft vom otaheitischen Rohre Jeichter zu behandeln, und gebe bei geringerem Zusatze von Kalk und Potasche krystallisirten Zucker. Dieses Zuckerrohr erhält nach fünf bis sechs Jahren Anbau ein dünneres Strob; dic Ínoten bleiben allezeit weiter von einander entfernt, als bei dem Creolischen. Dic anfängliche Besorgnifs, es möchte dieses Rolır in gemeines Zuckerrohr ausarten, ist nicht erfüllt worden, Das $\mathrm{Zu}$ ckerrohr wird auf der Insel Cuba in der Regenzeit, vom Julius bis October, gepflanzt, und die Ernte findet vom Hornung bis Mai Statt.

In demselben Verhälınisse, als die Insel entholzt war, nahm auch der Brennstoff $a b$, und man fing an, am Holze Mangel zu leiden. Es wurde Orangenholz verwendet, und jetzt meistens Bagasse oder das ausgeprefste Rohr, welches gedörrt ein schr gutes Brennmaterial abgibt. Durch neue Reverbe- 
rirüfen wird viel erspart, und Herr ron Itumboldt hat während seines Aufenthalts auf Cuba verschiedene Versuche gemacht, um den Bedarf des Brennstoffs zu vermindern, und den Sclaven ihr Gresehäft weniger peinlich zu machen. Da er bci Salzsiedereien von Jugend auf sich Erfahrungen gesammelt hatte, so kamen ihm hier seine Kenntnisse trefflich zu statten. Überhaupt, wozu wäre nicht alles, was Kenntnifs heifst, zu gebrauchen? Seine Versuche wurden häufig nachgeahmt, und cr hat das Verdienst, die Arbeiten in den Zuckersiedereien auf Cuba erleichtert und sparsamer eingerichtet zu haben.

In Havannah kostet der Zucker ungefähr ein Drittheil des Preises, um welchen er in Europa zu haben ist, und ungefähr ein Vierttheil von dem, zu welchen wir ihn von den Krämern zu unscrm Gebrauche abnehmen. Die Fracht bis zu uns beträgt wohl auch ein Viertheil mit der Assekuranz, dann müssen die Zölle berechnet werden, dann das Raffiniren und die Procente derer, durch die der Betrieb gesehieht. Es ist merkwürdig zu bedenken und zu überlegen, was es bedarf, bis eine Tasse Caffee unsern Gaumen kitzelt ! 


\section{$-\quad 332$}

\section{Sechstes Kapitel.}

Die Verwendang der Sclaven, - Caffee. - Tabak. - Wachs. Handelsverkehr.

Es ist ein in Europa allgemein verbreiteter, und für das Aufhören des Sclavenhandels nachtheiliger Irrthum, dafs man glaubt, ;s in den Antillen, welche Zuckercolonien heifsen; w werde der gröfste Theil der Sclaven in den Zuckerpflanzungen verwendet, Der Anbau des Zuckerrohrs ist cines der mächtigsten Hindernisse der Auflebung des Sclavenhandels. "Ohne Sclaven kein Zucker, \& das ist das Mährchen, womit man die europäische Humanität hintergeht. Eine einfache Berechnung zeigt jedoch, dafs die Gesammtzahl der Sclaven auf den Antillen dreifach gröfser ist, als zur Erzeugung des Zuckers nöthig sind. Um die 4 jo,000 Kisten Zucker auf Cuba zú erzeugen, sind 30,000 Sclaven vollkommen hinreichend. Es lastet daher der Druck der Sclaverei auf einer weit gröfseru Anzahl von Individuen; als der Landbau dieser Länder heischt, : wofern man auch annehmen wollte'; wa's jedoch nicht wahr ist; dafs Zucker, Caffee, Indigo und Baumwolle nur durch Sclavenhände erzeugt werden könnten. Auf der In. sel Cuba rechnet man zur Erzeugung von 1,000 Kisten 150 Neger, diesemnách würden 440,000 Histen 66,00o Sclaven erbeischen. Rechnet man zu dieser Zahl noch 30,00o andere zur Erzeugung des Caffees und Tabaks, so ergibt sich, dafs von den 260,000 Sclaven 100,000 vollkommen hinreiehen würden, für 


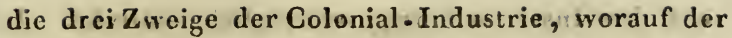
Wohlstand der Insel berult. Der Tabak wird jedoch meist durch weifse freie Menschen gepflanzt. Ein Drittheil der Sclaven . lebt in Städten, denen aller Landbau fremd bleibt. Der Sclavenhandel ist nicht blos barbarisch, er ist auch unverständig, weil er seinen Zweck verfehlt... Die den Sclavenhandel durch die Erzeugung der Colonial - Produkte beschönigen, bedenken nicht, dafs von den $1,1,48,000$ Sclaven, welche die Antillen enthalten, sich nur die Hälfte mit dem Ackerbaue beschäftigen, und die andern blos dem Stolze des Nabobs in den Pflanzungen dienen. Un'd gesetzt, sie baueten alle dic Colonial.Produkte, wo, steht denn geschrieben, dafs der liebe Gott die armen A frikaner nur darum geschaffen habe, damit wir in Europa / Caffee trinken und Zuckerbrot in den Wein tauchen können ? Bs ist Gotteslästerung zu ságeñ, der Sclavenhandel sey ein unvermeidliches Übel! : Liest man nun noch dazu die Behandlung der Sclaven, die übermäfsigen Arbeiten, die schlechte Kost, Jdie grausamen Strafen, unter denen Herr Bolingbroke als die gelindern an. führt: das Z Zwingén siedend heifse und stark gepfefferte Suppe zu' essen, oder eine Aúfösung von Glaubersalz, in einem gant heifsen Löffel essen zu lassen; wenn man s, sage ich, alles dieses zusam. men bedenkt, so wird jedem fühlenden Herzen, selbst;der suifseste Zucker zúr Galle. is

Aufser dem Zucker ist eines der wichtigsten Produkte Cuba's für den Handel der Caffee. Er wird 


\section{$-\quad 334$}

auf der Insel seit 1797 vorzüglich cultivirt. Im Jahre 1817 zählte man in der Provinz Havannalı 779 Cafetales (Caffeepflanzungen). Da der Caffee. strauch erst im vierten Jabre gute Ernten liefert, so betrug die Ausfuhr im Jahre 1804 nicht mehr als 5o,000 Aroben, hingegen 1823 betrug sie schon 895,924 Aroben. Jedoch sind die Jahre sich un. gleich, aber zwischen 1809 und 1824 war die geringste Jahres - Ausfuhr 3zo,00o Aroben, die gröfste 918,263. Im Jahre 18,5 war der Preis des Caffecs 15 Piaster der Zentner, und die Ausfuhr überstieg in eben diesem Jahre 3,443,000 Piaster. Die Caffecausfuhr Cuba's übersteigt diejenige von Java, so wie auch die von Jamaika, die 1823 nur 169,734 Zentner betrug. Die Gesammtausfuhr des Caffecs vom Archipel der Antillen scheint gegenwärtig auf 800,000 Zentner anzusteigen. Ungefähr das Fünffache des jährlichen Bedarfs in Frankreich, wo Paris allein 5,117,190 Pfund verbraucht, ganz Frankreich aber 167,803 Zentner. England verbraucht ungefähr lıalb so viel Caffee, als Frankreich, aber drei Mal so viel Zucker. Der Caffee kostet in Havannah 12 Piaster. Früher sah man ihn zwischen 13 und ${ }_{17}$ Piaster schwanken. Die Cultur des Caffees beschäftigt auf der Insel Cuba kaum 28,00o Sclaven, die im Durchschnitte jälırlich 305,000 Zentner produciren. Hieraus ergibt sich, dafs gegenwärtig ein Sclave für den Werth von 13o Piaster Caffee und 160 Piaster Zucker hervorbringt.

Aufser diesen beiden Produkten ist auch noch 
der Tabak der Insel Cuba berühmt in allen Ländern, wo man die Wilden der Insel Haiti nachgeäft hat, bei welchen man das erste Tabakrauchen wahrnahm. Man hatte geglaubt, dafs wenn das Tabakmonopol aufhören würde, dieser Culturzweig sich schnell verbreiten werde. Obgleich die Regierung diesem Wunsche vollends genug gethan, und die Factoria de Tabacos abgeschafft hat, so ist doch die gehoffte Wirkung nicht sichtbar. Den Pflanzern mangeln Capitalien; die Landpacht ist sehr theuer gervorden, und die Vorliebe für den Caffeestrauch wirkt dem Tabakbaue entgegen. Von ${ }_{1789}$ bis 1794 betrug der Ertrag des Tabaks auf der Insel jährlich 250,000 Aroben. Seitdem hat sich der Ertrag um die Hälfte vermindert, aber von 1822 bis 1825 glaubt man, dafs sich derselbe neuerdings auf 400,000 Aroben vermehrt habe. Der innere Verbrauch des Tabaks auf der Insel beträgt 200,00o Aroben. Die andern 200,000 Aroben werden zu einem Preise von 2,000,00o Piaster ausgeführt.

Es werden auf der Insel Cuba auch Baumwolle, Indigo und Weizen gebaut, allein diese Produkte werden nur in geringer Quantität erzeugt, weil sie nicht concurriren können mit den benachbarten Ländern, und der Anbau des Zuckers, Caffees und Tabaks gröfsere Vortheile gewährt. Der Staat von Salvador in Guatemala gibt dem Handel allein 1,800,00o Pfund Indigo, im Werthe von mehr als zwei Millionen Piaster. Baumwolle wird sowohl in den vereinigten Staaten, als auch im spanischen 
Amerika in grofser Menge erzeugt. Es wird zwar auf Cuba Weizen auf geringer Höhe über der Meeresfï̈che angebaut, allein dieser $\mathrm{Z}_{w}$ eig des Landbaues ist nur wenig verbreitet. Das Mehl ist zwar schön und gut, aber nicht hinreichend, und die benachbarten vereinigten Staaten Nord - Amerika's liefern, zu reiche und zu wohlfeile Ernten, als dafs es möglich wäre, bei den hohen Preisen des Landes auf Cuba um denselben Preis Weizen zu erzielen, als ihn der Ausländer in die Havannah führt. Ähńdiche Schwierigkeiten stehen dém Anbaue des Flach. ses, Hanfes und der Weinrebe entgegen. Die Cù. baner; wissen es vielleicht selbst nicht, dafs die Spanier in den ersten Jabren der Eroberung auf der Insel Cuba Wein aus wilden Trauben geprefst haben. Diese einheimische Rebe ist aber nicht unsere Weinrebe. . Die! amerikanische Rebe, , die den etwas : sauren Wein derInsel Cuba geliefert hat, wár die Vitis liliaefoliá. In der nördlichen Halbkugel sind bis jetzt nirgend Weingärten gepflanzt worden, südwärts vom $27^{\circ}, 68^{\prime} \mathrm{S}$. Bris in Europa und $29^{\circ}, 2$

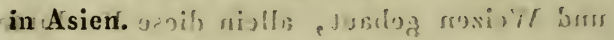

(i) Beträchtlicher, als die eben genannten Erzeugnisse Cuba"s, ist das Wachs if Es tommt nicht vön einheimischen, I sondern von europäischen Bienen, die über Florida eingebracht wurden, und nicht, Iwie ilire Landsleute; dem gelben Fieber un. terworfen sind, sondern sịch schnell, und fröhlich

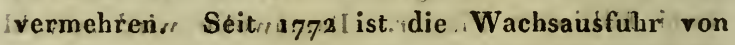
grofser, Bedeutung geworden, indem sie bis 2779 


\section{$-337$}

jährlich auf 2,700 Aroben betrug. Im Jahre 1803 schlug man die Ausfulır schon auf 42,700 Aroben an. Das Wachs von Cuba wird in den Kirchen Mexiko's in grofser Menge verbraucht. Die Preise schwanken zwischen 16 und 20 Piaster die Arohe. 1825 wurden aus Havannah allein ausgeführt 16,505 Arobas. Die Bienen gehen jedoch in dem Mafse zu Grunde, als dic Zuckerpflanzungen zunchmen. Die Bienen übersättigen sich nämlich in den Zuckersiedereien mit Melasse, nach dem sic sehr lecker sind, und gehen zu Grunde. Die Ausfuhr des Waclises von Cuba wird jährlich auf eine halbe Million Piaster geschätzt.

Der Reichthum Cuba's hat zwei unversiegbare Quellen, und schon in der Kindheit der Cultur hat ein verständiger Franzose gesagt: die Insel Cuba sey allein schon für Spanien einem Königreiche gleich zu achten. Seitdem für das Mutterland alle Colonien des Festlandes verloren sind, ist Cuba um so wichtiger. Nicht blos seine Erzeugnisse machen es reich, sondern auch seine Lage am Eingange in den Meerbusen von Mexiko, und es müfste selbst olne den Reichthum seines Bodens Cuba ein reicher Handelspunkt werden, indem sich in seinen Häfen die Handelsstrafsen der reichsten Nationen der Erde durchschneiden. Die Insel Cuba, welcher vom Hofe zu Madrid sehr weislich eine grolse Handeisfreileit eingeräumt worden ist, führt aus seinen Häfen an Zucker, Tabak, Wachs, Caffee und Häuten für einen Werth von 14,000,000 Piaster oder 28 Millio. Bibl, naturh. Reiseu. IV. 


\section{- 338}

nen Gulden aus. Diese machen 1,000 bis 1,200 Schiffs. ladungen aus. Eine Schiffsladung mit Produkten der Tropenländer ist mehr werth, als eine Ladung mit Produkten der gemäfsigten Zone. Zucker, Indigo, Caftee, Cochenille haben den Vorzug im Handel, dafs sie bei grofsem Werthe nur wenig Raum einnehmen. Aufser den 1,200 Kauffartheischiffen, die jälırlich in den Häfen Cuba's landen, sieht man daselbst sogar in Friedenszeiten jährlich 120 bis 150 Triegsschiffe verschiedener Gröfse und Nationen anlommen und abgehen. Eine unzählige Menge Barken und Küstenfahrer beleben die Gewässer um die Insel, und alles zusammen macht diese Gegend zu einem der belebtesten Punkte der Erde. Die Einfubr auf erlaubien und unerlaubten Wegen beträgt sehr wahrscheinlich 15 bis 16 Millionen Piaster, von denen jedoch 3 bis 4 Millionen wieder ausgeführt werden. Die Havannah kauft vom Auslande mehr als ihr Bedürfnifs fordert; sie tauscht ihre Erzeug nisse gegen europäisclie Manufaktur-Produkte aus, um diese wieder nach Veracruz, Truxillo, la Guayra und Carthagena zu verkaufen.

Unter den eingeführten Waaren bemerkte man 1826 Getreide - Mehl um 718,921 Piaster, europäische Weine und Liqueure 463,067 Piaster, Pökelfleisch, Efswaaren und Gewürze 1,096,791 Piaster, verschic. dene Kleiderwaaren 127,681 Piaster, Seidenstoffe 282,382 Piaster, Tücher und andere Wollenstoffe 103,224 Piaster, Mobilien, Krystalle und GalanterieWaaren 967,312 Piaster, Papier 61,486 Piaster, be- 


\section{- 330}

arbeitetes Eisen 33o,368 Piaster, Felle und Häute 135,103 Piaster, Breter und anderes bearbeitetes Bauholz 235, 217 Piaster, Leinen - und Baumwollentücher 3,226,859 Piaster.

Ausfulhr von demselben Jahre: Getreide-Mehl 145,254 Piaster, Weine und Liqueure 111,466 Piaster, Pökelfleisch und Efswaaren 227,274 Piaster, verschiedene Kleiderwaaren 4,825 Piaster, Scidenwaaren 47,872 Piaster, Leinen - und Baumwollentücher 1,529,610 Piaster, Mobilien, Krystalle und Galanterie - Waaren 29,000 Piaster, Papier 20,497 Piaster, bearbeitetes Eisen 99,581 Piaster, Zucker 3,962,709 Piaster, Caffee 847,729 Piaster, Wachs 169,683 Piaster, gegärbte Häute 19,978 Piaster. Seit 1816 ist jedoch Einfuhr und Ausfuhr beständig im Zunehinen, so wie auch der Verbrauch auf der Insel selbst. Über das, was auf der Insel selbst verbraucht wird, mufs man erstaunen. Cuba zählt nur 325,000 Weifse und 130,000 freie Farbige, und man sieht aus dem Bedarfe der Luxuswaaren, dafs sich dort allmählich eine Üppigkeit einheimisch macht, die in Europa nur in England ihres gleichen haben mag.

Unter den eingeführten Waaren befinden sich sehr grofse Quantitäten Mundvorräthe, woraus her. vorgeht, dafs die Leitung der Landwirtbschaft auf dicser Insel so beschaffen ist, dafs ohne Freiheit und Thätigkeit des äufsern Handels, die Bevölkerung auf dem glücklichsten Boden der Erde an den notl. dürftigsten Nahrungsmitteln Mangel leiden würde. Die europäische Industrie hat hier die Ordnung der 


\section{- 340}

Natur umgekehrt. Die Länder, welche die herrlichsten und edelsten Nahrungsmittel dem Menschen fast ohne Arbeit im Überflusse darbieten würden, inüssen, um ihr tägliches Brot zu haben, von dem kältern und kargern Norden sich abhängig machen. In den kleinern Inseln ist es die engherzige Politik des Pflanzers, der nur hingeht, um sich zu berei. chern, und alsdann den erworbenen Reichthum in seiner Heimath verzehrt. Cuba ist jedoch ein Land, welches ausgedehnt und grofs genug ist, das Vaterland einer zahlreichen Bevölkerung zu werden, die es nach und nach einsehen wird, dafs ihr neues Vaterland so freigiebig ausgestattet ist, dafs es Leben und Freude dem Fremden gewähren kann, ohne sein Brot vom Auslande betteln zu müssen.

Schon im Jahre 1800 machte ein wohlunterrichteter Mann folgende Schilderung Havannah's: In der Havannah beginnt man alle Wirkungen des sich anhäufendem Reichthumes zu verspüren. Binnen we. niger Monate hat sich der Preis der Lebensmittel verdoppelt. Der Arbeitslohn ist so theuer, dafs ein kürzlich von der afrikanischen Küste eingebrachter Bozal-Neger mittelst seiner Handarbeit allein 4 bis 5 Realen (1 fl. C.M.) täglich verdient. Treibt er oin mechanisches Gewerbe, sey es auch noch so roh, so verdient er 5 bis 6 Franken ( $2 \mathrm{fl}$. bis $2 \mathrm{fl}$. 3o kr. C. M.). Die Familien bleiben hier fest an. gesiedelt; wer sich bereichert hat, kehrt mit seinen Vermögen nicht nach Europa zurück. Es gibt dermafsen reiche und mächtige Familien, daf's Don 
Matheo de Pedroso, welcher vor kurzem gestorben ist, an Grundstïcken über 2 Millionen Piaster hinterlassen hat. Mẹhere Handelshäuser in der Havannah kaufen jährlich zehn- bis zwölftausend hí. sten Zucker, die sie mit 35o, oco bis 420,000 Piaster bezahlen. Die Geschäfte, welche jährlich auf diesem Platze gemaclit werden, betragen über $20,000,000$ Piaster. So war es 1800 . Seitdem hat sich der Wohlstand verdoppelt, ja vervierfacht, und ist noch immer im Steigen begriffen. Der Caffecstrauch ist seither hinzugekommen, und eine Menge Quellen des Wohlıstandes haben sich geöffnet.

\section{Siebentes Kapitel.}

Wünsche für die Industrie und das Loos der Sclaven

Je leichter die Verbindung der Insel Cuba mit der ganzen Erde ist, desto schwieriger ist die Verbindung im Innern. Sie gleicht hicrin gar vielen Menschen, die alles, was aufser ihnen ist, gar wolał kennen, und von der Ceder bis zum Ysop alles be. greifen, in sich selbst aber Fremdlinge bleiben. So ist es leichter 1,00o Zentner Caffec von Cuba nach Cadix zu schaffen, als 100 Zentner aus dem Innern der Insel an das Meeresufer. Die Ursache dieses Übels ist der gänzliche Mangel an Strafsen und Ca. nälen. Die Insel ist sehr schmal, und nirgends ist nan sehr weit von der Küste entfernt, dennoch sind die Transportkosten nach irgend einem Hafen 


\section{$-342$}

sehr grofs. Man hat vor länger als einem halben Jahrhunderte schon den Entwurf gemacht, Canäle zu graben, aber bis jetzt ist noch keiner zu Stande gekommen. Der zunehmende Reichthum der Insel wird, wenn einst der Friede in den spanischen Besitzungen auf irgend eine Weise hergestellt seyn wird, auch hier Werke der Kunst schaffen, wie sie die Lage der Insel und der Vortheil ihrer Bewol. ner fordert. Von vorzüglich grof'sem Nutzen würde ein Canal von der Havannah nach Batabano seyn. Die Insel ist hier nur $8 \frac{1}{5}$ Seemeilen breit. Er würde durch die sogenannten Guinen führen, und daher auch für die kleinere Schiffahrt von unermefslichem Nutzen seyn, weil die am besten angebauten Land. striche sich in sciner Nähe befänden. Nirgend sind dic Strafsen schlechter, als in diesem Theile der Insel, wo in dem aus zerreiblichem Kalksteine bestehenden Boden der Schlamm zur Regenzeit grundlos ist. Um den Zucker aus den Guinen nach der IIavannah zu bringen, kommt jetzt der Zentner auf einen Piaster. In der schlimmen Jąhreszeit und in H́riegszeiten lönnten die Fahrzeuge, welche mit Pökelfeisch beladen aus Venczuela kommen, in Batabano cinlaufen und der Gefalir entgehen. Im Jahre 1796 hat man den Bau des Canals auf cine Million \%weihunderttausend Piaster berechnet; gegenwärtig würde er wohl auf anderthalb Millionen ansteigen. Man hat jetzt den Canal aufgegeben, aber Herr von $H_{L^{\prime}}$ mboldt ist von der Nutzbarkeit und Möglichkeit 
desselben überzcugt, wenn man auf den Theilungspunlt genug Wasser bringen lönnte.

In der Ilavannah klagt man eben so, wie überall, wo die Gesellschaft vom Ackerbaue zum Handel übergegangen ist, über den Verfall der Sitten und den Verlust ursprünglicher Einfachleit und Tugend. Wenn wir auch hier die Offenheit und Reinheit der Sitten mit dem Zustande vorgerückter Civilisirung nicht vergleichen können, so ist so viel gewifs, dafs auch Cuba, als die Insel noch Vieh- und Ackerbauern nährte, der patriarchalischen Einfachleit weit näher stand, als seitdem Ilavannah die Hauptstadt der Antillen geworden ist. Der Handelsgeist schätzt und wiegt alles nach dem Werthe des Celdes, und gering wird alles geachtet, was nicht um Geld zu haben oder für Geld zu verhandeln ist. Im Allgemeinen war in grofsen Handelstaaten von Alters her nur der Vortheil und nie die Moralität das leitende Princip. Es sind jedoch glücklicher Weise dic Verhältnisse der Mensehen so beschaffen, dafs das Wünschenswertheste, Schönste und Edelste im IIenschen selbst ist, einzig nur ais scinem Gemüthe hervorgeht, und aus der Vervollkommnung und Entwickelung seiner Geisteskräfte. Würde jemals unglücklicher Weise die Übcrschätzung des Reichthums unbedingt alle Classen der Gesellschaft ergreifen, so mülste dieses die Zertrümmerung alles Ileiligen nach sich ziehen, und alle jene Übel müfsten die Gesellschaft heimsuchen, welche der Eigennutz seinen Verehrern droht. England scheint auf diesem 


\section{- 344}

Wege zu seyn. Zum Glücke ist jedoch dic Natur mächtiger, als die Verkünstlung, und mitten in den Handelsstaaten sehen wir, wie der Geist der IIumanität waltet, und auch der Krämergeist den hohen Zwecken der Vorsehung dienstbar wird. Auch hicr kann England als ein lebendes Muster gelten, wo auf dem moralischen Düngerhaufen englischer Laster auch die grofsartigsten Blumen der Humanität gedeihen. Auch in Cuba wird mit dem Wohlstande Laster und Eigennutz, Verweichlichung und Betrug zunchmen; aber auch dic edleren Blumen des mensch. lichen Geistes werden sich entfalten, und Vaterland und Menschenliebe werden dem Reiche der Morali. tät Ersatz leisten, und den Kaufinannsgeist mit der Tugend versöhnen.

Man blickt mit Vergnügen auf das Schicksal der Völker, und sieht mit Theilnahme auf ihre Entvickelung. In der Freude, welche man iiber den Wohlstand einer uns auch noch so fremden Gesellschaft empfindet, thut sich das Gefülil der Verwandt. schaft und das Bewufsiseyn des gemeinsamen Bandes, welches uns alle umschliefst, kund. Der Schmerz, der die feinsten Fasern unsers Herzens bei dem Gedanken an die Leiden der armen Sclaven durchzuckt, chrt die Menschheit, und ist das Zeichen zugleich, dafs unser Blut von demselben Stoffe ist, wie dasjenige, welches aus der Geifselwunde des armen Negers fliefst. Dasselbe Mitgefühl war es auch, welches die Monarchen Europa's 7.u dem gemeinsamen Willen für die Abscbaffung der Sclaverei verbunden 


\section{- 345}

hat. Alle haben Verorinungen gegen den Sclaven. handel erlassen, und die angehorne Liche zu unserm Monarchen mufs sich allezeit auf's neue entflammen, wenn wir bedenken, dafs er es ist, der in seinem Lande und auf seinen Schiffen keinen Sclaven duldet. Der Sclave, welcher sei. nen $F u \int s$ a u ein österreichisches Bret set $\%$, ist frei! Im ganzen Umfange der grofsen Besitzungen unsers Vaters ist kein leibeigener Sclave!

Wir schliefsen diese Beschreibung Cuba's mit den eben so weisen als schönen Bemerkungen des Herrn von Humboldt über die Sclaven und ihr Schicksal. Das Schicksal San Domingo's hat die merkwürdigen Worte Schillers: 》 vor dem Sclaven, wenn er die Kette briclt ", leider erfüllt, und Herr von Humboldt, der die Antillen genau kennt, und mit den Gefahren wolıl bekannt ist, kann sich nicht verbergen, dafs die mit so schauerlichem Erfolge gekrönte Empörung Domingo's allerdings sich wiederholen künnte. Er wünscht die Ḱlagen der unglücklichen Sclaven zu den Ohren derer zu bringen, die ilınen abhelfen können, durch eben so weise als gemäfsigte Verordnungen, wie auch vor allem durch kräftige Erfüllung und Befolgung derselben. Vermöge des Fürstenbeschlusses auf dem Congresse z.u Wien sollte mit dem Jahre 1820 der Sclavenliandel aufhören. Leider weifs der gewissenlose Eigennutz sich Mittel zu verschaffen, die Gesetze zu umgehen, und der Sclavenhandel dauert noch fort. Ich habe, sagt der edle Humboldt, den Zustand der schwar- 


\section{$-\quad 340$}

zen Menschen in den Ländern beobachtet, wo die Gesetze, die Feligion und die National-Gewohnheiten das Schicksal der Sclaven zu erleichtern be. strebt sind; dessen ungeachtet hat sich bei der $\mathrm{Ab}$ reise aus Amerika mein Abscheu vor dem Sclaven. thum, den ich aus Europa mitgebraclit hatte, nicht vermindert. Geistreiche Schriftsteller haben vergebens versucht, die Barbarei dieser Verhältnisse durch täuschende Worte zu verbüllen, indem sie die Namen von Negerbauern auf den Antillen, von schwarzer Lehnspflichtigkeit und von patriarchalischem Schutze erfanden. Es heifst die edlen Künste des Geistes und den Beruf des Schriftstellers entweihen, wenn man solche Hüllen schaffen will, um die schändlichste Wahrheit zu verhüllen. Es heifst die Throne entchren, wenn man die unter ilrem Schutze lebenden Bauern mit den Sclaven roher I'flanzer oder wollüstiger Nabobs vergleicht. Selbst der leibeigene Russe, der sich als Eigenthum tausendweis verschenken lassen mufs, ist noch auf der lö̈chsten Stufe des Glüclis gegen den Neger; denn iln schützen Gesetze, ihm steht der Weg zu seinem Monarchen offen, er lebt in seinem Vaterlande, im Schoofse seiner Familie, geniefst des bäuslichen Glückes, dessen sich der arme Neger beraubt sicht. Die einsichtigen und edlen Bewohner der Antillen. Zucker-Inseln sind überzeugt, dafs die über ihnen schwebende Gefahr nur durch allmähliche Abschaffung der Sclaverei abgewendet werden könne. Besonders hat Havannah sich zu rühmen, von jeher 


\section{- 347}

für die Abschaffung der Sclaverei weder ein verschlossenes Ohr, noch ein hartes Herz gehabt zu haben.

Unter allen Übeln, unter allem Jammer, der je die Menschheit belastet hat, ist der erbarmungswürdigste das der Sclaverei. Der freie Neger wird mit Gewalt seinem leimathlichen Boden entrissen, und aus der Mitte sciner Familie auf das Sclavenschiff geworfen, wo man mit grausamer Industric für seine Verpackung gesorgt hat. Hier werden die armen Opfer mit Peitsclenhieben gezwungen, fröhlich zu seyn, und zu tanzen, damit sie gesund bleiben. Sie müssen im Chore singen: messe, messe makeriba (lustig, lustig ist's unter den Weifsen)! Sie werden heerdenweise auf die Antillen gebracht und sind Waare, Ebenholz von dem Kaufmanne genannt. Allein auch hier ist sein Loos verschieden. Der Abstand zwischen dem Sclaven im Hause des reichen Mannes in der Havannah ist von den in den Zuckerpflanzungen arbeitenden unermefsich verschieden. Man bedient sich Drohungen, welche den Zustand der Schwarzen in verschiedenen Lagen bezeichnen. Der Calessero wird mit der Cafetal und dieser mit Zuckerpflanzung geschreckt, den letztern aber schreckt man mit nichts mehr. In der Zuckerpflanzung lebt jedoch der, welcher ein Weib hat, und Abends im Schoofse seiner armen Familie aus. ruht, glücklicher als der vereinzelte, unter der Menge sich verlierende Sclave.

Zum Glücke für die Neger Cuba's hat der Luxus 


\section{- 348}

und der Reichthum der Einwohner Havannal's 80,000 Sclaven in die Städte gezogen, wo sie sich allerdings besser befinden. Die Gesetze begünstigen, wie schon oben bemerkt wurde, dic Freilassung aufserordentlich, und erzeugen sich so wirksam, dafs es bereits 130,000 Farbige gibt, welche frei sind. Herr von Humboldt glaubt jedoch, alle Gesetze zur Abschaffung der Sclaverei werden an dem, was man in den Colonien erworbene Rechte nennt, sclieitern, bis man sich mit den Colonial-Behörden verstanden laben wird, und der Mitwirkung der Colonial-Versammlungen versichert ist. Auf ein Mal kann man die Sclaven nicht frei lassen, weil diese Entfef'slung einer rohen und ungebildeten Menge nur das gröfste Unheil bringen könnte. Man sollte dafür sorgen, dafs nicht, wie es bis $18{ }_{2} 6$ geschehen ist, die Ihinder der Sclaven von den Eltern getrennt, verkauft werden dürften. Man solite untersagen das Zeichnen der Neger mit glüliendem Eisen, welches nur geschieht, um das Menschenvich desto bequemer crkennen zu liönen. Man sollte wenigstens solche abscheuliche Barbareien durch Gesetze auf das strengste verbieten. Man sollte ihnen Weiber zugesellen, damit sie der Pflege in Krankheit und Alter nicht entbehrten. Jedem Sclaven sollte nach fünfzehnjähriger Arbeit und jeder Sclavinn nach Er. zichung von vier Kindern die Freilieit geschenkt werden. Man sollte dem Selaven bestimmte Arbeits. tage frei Jassen, damit ihm die ïbrigen bezahlt würden. Auch sollte die Verwaltung jährlich eine 


\section{- 349}

Anzahl solcher, die sich besonders durch Fleifs und Treue ausgezeichnet haben, auf öffentliche Kíosten los liaufen, und bei dem Tode des Eigenthümers sollte jeder durch's Loos bestimmte zehnte Sclave frei werden. Unter solchen Umständen, meimt Herr von Humboldt, würde nach und nach das Schicksal der Sclaven erleichtert werden, und eine allmäh!iche Abschaffung der Sclaverei aufser Zweifel seyn. Und gewifs werden meine jungen Leser nicht verfehlen zu wünschen, dafs Güte bald alle Herzen derer, die dazu beitragen können, lenken möchte, damit diese Wünsche erfüllt würden. Viel. leiclit werden unsere Kinder es erleben, dafs dieser Schandfleck von der Menschheit abgewischt seyn wird. Noch eine Bemerkung des Herrn von Hum. boldt kann ich nicht übergehen. Wenn, sagt er, dic Civilisation, statt sich auszudehnen, ibren Sitz ändern würde, wenn das zwischen Cap Hatteras und dem Missouri befindliche Amerila der Hauptsitz der Aufklärung der Christenheit werden sollte, welchen Anblick würde dieser Mittelpunkt der Civilisation darbieten, wo in der Mitte des Heiligthums der Freiheit, man einer Negerversteigerung aus dem Nachlasse eines Verstorbenen beiwohnen, und das Schluchzen der von ihren Eltern getrennten Hinder hören könnte?! Wie sollte sich auch Christenthum und Sclaventhum vereinigen lassen? Wie traurig sich \%u denken, dafs in das: Herr Gott dich loben wir, der Gläubigen, der Peitschenknall auf dem Rücken des Negers, und das Gewinsel verkaufter 
Jinder gräfslich einfällt. Mit Freuden hoffen wir daher, dafs die sowohl unkluge als schändliche Sitte des Sclavenhandels allmählich aufhören, und nach und nach die ganze Sclaverei aus den Colonien verschwinden werde! Mian weifs mit Gewifsheit, dafs die brittischen Antillen seit 106 Jahren allein 2, 30,000 Neger aus Afrika bezogen haben; der ganze Archipel hat mehr als 5,000,00o erhalten, und doch sind gegenwärtig nicht mehr als 1,147,50o Sclaven und \$,212,900 freie Farbige übrig. Wie schrecklich hat lier die Barbarei Menschenblut vergossen? Nun rechne man zu den fünf Millionen noch diejenigen, welche auf der See zu Grunde gingen, und als un. nütze Waare über den Bord geworfen wurden!

Man mufs übrigens mit Vergnügen gestehen, dafs die reichen Pflanzer von Cuba, besonders die Ein. wolner von Havannab sehr günstige Gesinnungen fïr die Sclaven hegen, und gerne die Hand dazu bieten, ilıren Zustand zu verbessern. Die Humanität der Gesetzgebung räumt dem Sclaven auf Cuba vier Begünstigungen ein, welche der der Antillen anderer Nationen entbehrt. Er darf sich einen gelindern Herrn suchen, und wenn dieser den Kaufpreis bezahlt, mufs er entlassen werden. Er darf nach freier Wahl heirathen. Er darf sich nach und nach durch Arbeitsverdienst frei kaufen. Er hat das Recht, Eigenthum zubesitzen, und mittelst seines Erwerbs Weib und Kinder frei zu kaufen. Das Recht, sich einen Herrn zu suchen, der den Kaufpreis, das Gesetz sagt, den geringsten für den Scla- 


\section{$-\quad 351$}

ven erlȩ̣̂t, hat läufig zur Folge, dafs der Fremde von dem Sclaven mit der Frage begrüfst wird: Wollen Sie mich nicht kaufen? Der niedrigste Preis cines Sclaven ist zwischen 200 bis 280 Piaster. Bei den Griechen kostete ein Sclave 54 bis 108 Piaster. Während jedoch die spanischen Gesetze auf alle Weise die Freilassung begünstigen, so besteht auf andern Antillen das abscheuliche Gesetz, dafs der Herr für jeden Sclaven, den er frei läfst, dem Fiskus fünf- bis siebenhundert Piaster zahlen mufs. Es ist daher ein gräfslicher Unterschied zwischen den alten spanischen Gesetzen, und den barbarischen Bestimmungen, welche auf jeder Seite des schwarzen Gesetzbuches (code noir), wie in den Gesetzen der brittischen Antillen, sieh finden. Die ${ }_{17} 30$ erlassenen Gesetze der Bermuden.Inseln verordnen: es dürfe gegen den Sclavenherrn, der seinen Neger durch Züchtigung tödtet, keine Anklage Statt finden; der jedoch, welcher ihn aus Bosheit tödtet, solle an den Schatz 10 Pfund Sterling bezahlen! - Ein Gesetz von St. Christoph vom 11. März 1784 fängt mit den Worten an: Wir verordnen und befehlen, dafs wer dem Sclaven ein Auge zerstört, die Zunge ausgerissen oder ein $\mathrm{Ohr}$ abgehauen hat, soll 500 Pfund Sterling zahlen und zu sechs Monat Gefängnifs verurtheilt werden. Die englischen Gesetze sind jedoch jetzt aufgehoben, und durch humanere ersetzt worden, und eine Veränderung der französischen ist so eben im Werke. Leider wurden auf den französischen Antillen 1805 sechs jungen Sclaven, die im 


\section{- 352}

Verdachte waren, die Fiucht beabsichtigt zu haben, nach Urtheilsspruch die Koniesehnen zerschnitten!

Ob nun gleich die Weisheit und Milde der spanischen Gesetzgebung die Sclaven vor solcher empörenden Grausamkeit schützt, so bleibt demungeachtet ihr Loos in der Einsamkeit des Pachthofes und der Zuckerpflanzungen der Willkür des Herrn preisgegeben, wo denn die scharfe Geifsel und selbst auch die Machette unumschränkte Gervalt übt. Die Gesetze erlauben dem Sclaven, sich an den Mragistrat 7u wenden; allein der Sclave darf sich nicht aus der Pflanzung entfernen, und der reiche Pflanzer bleibt gegen seinen Scỉaven immer im Vortheile. Es haben jedoch die Colonisten selbst schon einschen gelernt, dafs eine mildere Behandlung nothwendig wird, und dafs die Weisheit der Gesetzgebung sich dahin beschäftigen müsse, sowohl Mifsbräuche als Gefahren zu verhindern.

Von dieser Weisheit der Gesetzgebung in Hinsieht der Negersclaven hängt dieSicherheit von 875,000 freien Menschen, weifsen und farbigen ab. Es hängt aber auch die Milderung des Schicksals von 1,150,000 Sclaven ab. Durclt Mitwirkung der Colonial-Be. lıörden und der Pflanzer selbst, kaun dieses auf ruhigem Wege geschehen. Unthätig jedoch dürften dieselben nicht bleiben, weil sonst leicht Ercignisse, die weder zu berechnen noch zu beherrschen sind, diejenigen traurigen Folgen der Sclaverei herbeiführen könnten, welche alle Völker und Länder erfabren haben, wo Sclaverei cingeführt war und 
langen Bestand batte. Selbst Rom war mehr als cin Mral an den Rand des Verderbens geführt durch scine Sclaven, und diese waren auch zuletzt nicht die kleinste Ursache, dafs es den einbrechenden Barbaren so leicht unterlag.

Die Sclaverei steht mit der Civilisation im grellsten Widerspruche, und es ist unmöglich an die Humanität des Volkes zu glauben, wo der arbeitende Theil verkäuflicher Sclave ist, olıne Eigenthum, ohne Recht, olne Freilıeit. Er hat beide Übel, sowohl die der Wildheit als die der Civilisa. tion zu ertragen. Wie im wilden Zustande ist er fremder Willkür überlassen, und mufs doch die Arbciten tragen, welche die Sitlignng von ibren Theilnebmern fordert. Er sicht die Wohlthaten schützender Gesetze, ohne an denseiben Theil zu nelimen, und je mehr sich die Bildung und der Woblstand der Civilisation um ihn herum entwickelt, desto sclireiender ist sein Elend. Man kann nicht anders, als von Herzen wünschen, dafs jene Gegenden ohne Zuckungen in einen Zustand übergehen möchten, den die christliche Religion fordert. Dafs die Sclaven schwarz und ilire Gebicter weifs sind, ist ein Umstand, welcher dic Gefalır der bürgerlichen Ordnung in den Antillen nur noch mehr stcigert. 


\section{$-\quad 354$}

\section{Achtes Kapitel.}

Rüstung zur Abreise. - Falsche Nachrichten.

Gegen Ende April liatten die Herren von Humboldt und Bonpland ihre Beobachtungen vollendet, welche sie an der Grenze der nördlichen heifsen Zone zu machen beabsichtigt latten. Sic standen nun im Begrife, mit der kleinen Flotte des Admirals Arisabal nach Veracruz abzureisen. Alle Vorbe. reitungen wurden gemacht, als plötzlich eine Zeitungs-Nachricht allen ihren Vorsätzen eine andere liichtung gab. Sie verzichteten in Folge ciner Zeitungsnachricht von der Reise des im ersten Bande erwähnten französischen Capitän Baudin auf die Reise durch Mexilıo nach den Philippinen. Verschiedene Tagesblätter, besonders aus den vereinigten Staaten, meldeten nämlich, es seyen zwei Corvetten Franlireich's: der Geographe und der Naturaliste, nach dem Cap Horn unter Segel gegangen; sie soll. ten ihre Fahrt längs den Kü̈sten von Peru und Chili nelımen, um von da sich nach Neu-Holland zu begeben. Diese Nachricht war es, welche Herrn von Humboldt in dic lebhafteste Bervegung setzte, und ihm das reizende Bild einer Reise um die Welt vorspiegelte. Es lamen ihm wieder alle Entwürfe in den Sinn, welche er gemacht hatte, als er noch in Paris war, und die Regierung zur Absendung die. ser Expedition zu bewegen gesucht hatte. Als Herr von Humboldt aus Spanien abgereist war, hatte er 


\section{$-\quad 355$}

das Versprechen gethan, sich dem Capitäne Bauảin überall anzuschliefsen, wo er iln treffen würde. $\mathrm{Er}$ beredete sich nun, es sey seine Pflicht, sich in den Stand zu setzen, um sein Versprechen zu lösen. Herr Bo:zpland, der immer Muth und Entschlossenheit zeigte, war sogleich bereit. Es ward nun vor allem der grofse Vorrath von Pflanzen, die gesam. melt waren, in drei Theile getheilt. Diese Abtheilung geschah darum, damit dasjenige, was man mit so vieler Mühe an den Ufern des Orinolio, Atabapo und des Rio Negro zusammengebracht hatte, nicht dem ungewissen Schicksale einer langen Seereise ausgesetzt bleibe. Eine dieser Sammlungen sollte durchi England nach Deutschland gehen, eine andere ïber Cadix nach Frankreich, die dritte sollte fïr alle Fälle in der Havannah aufbewahrt bleiben. Diese kluge Mafsregel war ein äufserst glücklicher Gedanke; denn ohne denselben wäre leicht die ganze Frucht der Reise mit allen Tagebüchern und allen Arbeiten verloren gegangen. Eine jede der drei Sendungen enthielt die nämlichen Artcn, und alle Vorsicht war getroffen, damit selbst im Falle das Schiff von Franzosen oder Engländern genornmen würde, die Kisten entwerler den Professoren der Naturgeschichte im Museum zu Paris oder dem Sir Joseph Bank's in London übergeben würden. Ein glücklicher Zufall war es, dafs die Ilandschriften und Tagebücher nicht derjenigen Abtheilung beigelegt wurden, welche mit dem oben schon öfter er- 


\section{- 350}

wähnten Ordensmanne nach Spanien abging, denn wir haben schon oben gehört, wie dieses Schiff nit Mann und Maus und also auch mit den Sammiungen zu Grunde ging. Es war schon ein Unglück, dafs bei dieser Sendung sich die ganze Sammlung von Insekten befand, die Herr Bonpland am Orinoko unter den schwierigsten Umständen veranstaltet hatte. Durch ein Mifsgeschick hatten sie schon zwei Jahre keine Briefe aus Europa erhalten, und die Briefe der drei folgenden Jahre meldeten nichts vom Schicksale der Sammlungen, so dafs unsere Freunde in der gröfsten Unrube waren, was aus ihren Tagebüchern geworden seyn möchte. Dic Angst war daher nicht gering, besonders da auch die mit so gros. ser Beschwerde gemachten astronomisclien Beobachtungen dabci waren. Erst im Augenblicke, da sie Amerika zu verlassen im Begriffe waren, erlblickte Iferr von Humboldt zufällig auf der öffentlichen Bibliothek zu Philadelphia, bei Durchgehung cines Registers der wissenschaftlichen Übersichten, die Worle: Ankunft der Handschriften des Herrn von Humboldt bei seinem Bruder in Paris über Spanien. Beinahe laut jubelte er vor Freude.

Während Herr Bonpland Tag und Nacht beschäftigt war, die Sammlungen zu ordnen, quälten Herrn von Humboldt die Hindernisse, welche sich einer so unvermutheten Abreise entgegensetzten. Im Hafen der Havannah war kein Schiff zu finden, welches sie nacb Porto Cabello oder nach Carthagena 


\section{- 357}

überführen wollte. Diejenigen Personen, welche zu Rathe gezogen wurden, gaben sich alle Mühe, die Beschwerlichkeiten übertrieben zu vergröfsern, welche der Übergang über den Isthmus von Panama und eine Scliiffahrt von Süd nach Nord, von Panama nach Guayaquil, von da nach Lima und Valparaiso darbicten. Sie machten Herrn von Humboldt gegründete Vorvürfe darüber, dafs er nicht fortfahre, dic grofsen und reichen Besitzurgen des spanischen Amcrika zu untersuchen, wclches seit einem halben Jahrhunderte allen fremden Reisenden verschlossen geblicben war, besonders da so ausgedchnte Bewilligungen, als Herr von Humboldt erbalten hatte, nicht lcichtJemanden wieder zu Theil werden könn. ten. Sie stellten vor, wie vicl dankbarer dic innere Untersuchung eines grofsen, reichen und unbekannten Landes sey, als eine ungewisse Reise um die Welt, wo man nur hie und da Küsten berührt, und auch diese nicht nach eigener Wahl. Wie viel interessanter müfste die Untersuchung cines Landes seyn, welches allein für sich $5 / 8$ der Silbermasse liefert, welche aus den gesammten Bergwerken der ganzen Erde gewonnen wird? Je mehr jedoch Herr von Humboldt in der Ausführung seiner Plane gehindert war, desto eifriger betrieb er ihre Ausfüh. rung. Er hatte nämlich dic Hoffnung, auf einer so grofsen Reise, die wichtigsten und bisher auf solchen Reisen vernachläfsigten Beobachtungen über die Beschaffenheit der Luft, des Wassers, der Wär- 
mevertheilung und des Magnetismus der Érde zu machen, und so die physikalische Beschaffenbeit der Erde zu erforschen.

Da die Überfahrt auf einem neutralen Schiffe, d.h. auf einem solchen, das einer Nation zugehörte, welche mit allen Seefahrern im Frieden lebte, unmöglich war, so miethete Herr von Humboldt eine catalonische Goelette, die sich aut der Rbede von Batabano befand, und bereit seyn wollte, ihn entweder nach Porto Cabello oder nach Carthagena des Indes za bringen, je nachdem es die Winde gestatteten, welche in dieser Jahreszeit hier noch heftig weben. Es war Herrn von Humboldt hier leicht, sich die nöthigen Gelder zu verschaffen, so wie sich Freunde bereit fanden, alles zu befördern, was die Abreise nöthig machte. Am 6. Mtai ward ihnen gemeldet, dafs die gemiethete Goelette bereit sey, die Reisenden aufzunehmen.

Der WVeg von Batabano führte sie nochmals durch die Guines zur Pflanzung vom Rio Blanca, deren Besitzer, der Graf von Monpox, daselbst auf alle Weise, die durch ein grofses Vermögen möglich ist, ihren Aufenthalt verschönerte. Die Gastfreundschaft, welche Menschen mit einander so sehr verbindet, und die bei fortschreitender $\mathrm{Ci}$ vilisation gewöhnlich abnimmt, ist auf der Insel Cuba noch in voller Ausdehnung und wird mit licbenswürdigem Fleifse geübt.

Vom Rio Blanca nach Batabano fübrt der Weg 


\section{$-\quad 350$}

durch ein unangebautes, zur Hälfte mit Waldung bedecktes Land. Auf dem unangebauten Boden wachsen Indigo und Baumwolle verwildert. Die Baumwolle, welche auf Cuba gebaut wird, gehört zu der schönsten; da aber die Kapseln sich gerade zu der Zeit öffnen, wo die Nordstürme am heftigsten wehen, so wird der feine Flaum zerstreut und die Ernte leidet gewöhnlich Schaden. Weiter südwärts fanden sie beim Herborisiren eine Palmenart mit Fächerblättern, die zwischen den Nebenblättern einen freien Faden zeigt. Diese Corypha bedeckt einen Theil der Südküste der Insel, und tritt an die Stelle der prächtigen Königspalme und der gekrausten Cocospalme der Nordküsten. Hin und wieder kommt der löcherige Kalkstein zum Vorschein, der dem Jurakalk gleicht.

Batabano liegt unter $22^{\circ}, 43^{\prime} 24^{\prime \prime} \mathrm{N}$. Br., und war zur Zeit des Herrn von Humboldt nur ein elendes Dorf, dessen Kirche erst vor kurzem erbaut worden war. In der Entfernung einer halben Meile von Batabano nimmt die Sienga, eine sehr sumpfige Landschaft, ihren Anfang, und erstreckt sich von der Laguna de Cortes bis zur Ausmündung des Rio Xagua, in einer Ausdehnung von 60 Meilen von West nach Ost. Man glaubte hier, dafs das Meer landeinwärts Fortschritte mache, vorzüglich sey dieses zur Zeit des grofsen Einsturzes fühlbar gewesen, als im Anfange des achtzehnten Jahrbunderts die Tabakstampfen verschwanden und der Flufs 


\section{- 300}

Chorrera seinen Lauf änderte. Dieses Sumpfland gewährt einen äufserst traurigen Anblick. Nicht ein cinziger Baum verschönert den Sumpf, wo nur einige verkrüppelte Palmen, wie zerbrochene Masten, aus den Gräsern hervorragen. Sie verweilten nur eine einzige Nacht in Batabano, und konnten daher sich nicht selbst belehren über die zwei Arten des Kro. kodills, dic in der Sienga hausen.

Von diesen zwei Arten wird die eine von den Einwohnern Cayman, die andere Crocodilo, d. h. Krokodill genannt. Letzteres ist hochbeiniger, lebendiger und seine Schnautze zugespitzter, als die des Caymans, ron welchem es sich immer gesondert hält. Es ist sehr muthig, und man bebauptet, es erklimme sogar Schiffe, wenn es für seinen Schwanz cinen Stützpunkt erhalten kann. Die ausnehmende Kühnbeit dieses Thieres ist schon von dem ersten Reisenden, Diego Velasquez, bemerkt worden. Das Ḱrokodill pflegt sich bis auf cine Meile weit vom Rio Carlo und der sumpfigen Küste von Xagua zu entfernen, um sich im Innern des Landes Schweine zur Beute zu holen. Es gibt solche, die bis fünfzehn Fufs lang sind, und die also in ihrem Bauche Platz genug hätten, um meine jungen Leser einzuquartieren. Es gibt sogar solche unter ihnen, die sich gar nicht scheuen, selbst einen Reiter zu verfolgen, wie unsere Wölfe in Europa tliun. Es wäre überhaupt der Mühe werth, zu untersuchen, ob die Sage von den Drachen nicht diesen grofsen 


\section{$-361$}

Eidechsen ihren Ursprung $z u$ verdanken hat? Dic Caymans sind hingegen sehr furchtsam, und zwar so sehr, dafs man selbst an solchen Stellen ohne Furcht baden liann, wo sie haufenweise vorzukommen pflegen. Wir rathen jedoch unsern jungen Lesern, bevor sie sich unter Caymans baden, solche von den Kírokodillen ja recht wohl unterscheiden zu lernen, mafsen sich gar leicht eine spitzige Schnautze darunter finden möchte, und die Erfahrung lehrt, dafs spitze Physiognomien immer etwas besonders zu Fürchtendes an sich haben. Die Caymans sind hingegen vorne platt, und also, wie alles Platte, wenig zu fürchten.

Herr von Humboldt vermuthete nach dieser Beschreibuug, dafs die fleischfressenden Saurier - Kro. kodille zu den grofsen Thieren, die im Orinoko und Rio Magdalena so häufig sind, verschieden seyen. Sonst glauben die Amerikaner, irre geführt durch die übertriebenen Beschreibungen der Nil-Kŕrokodille, dafs die echten Krokodille einzig nur im Nile vorhanden seyen. Die Zoologen haben jedoch erkannt, dafs in Amerika sowohl Caymans oder Alligators mit abgestumpfter Schnautze und Füfsen ohne Zackeneinschnitte, als auch wirkliche Krokodille mit spitziger Schnautze und gezackten Füfsen vorkommen. Hinwieder kommen auf dem alten Festlande sowohl Irolodille als Gaviale (Ganges - Krokodille) mit langen runden Rüsseln, den Menschen unschädlich, vor. Der Crocodilus acutus von St. Domingo hat mit dem Bibl. natarh. Reiocn. IV. 
Nil-Krokodille eine solche Ähnlichkeit, dafs man selbst nach Prüfung einzelner Theile ihn kaum von demselben unterscheiden kann.

Da Herr von Humbóldt bei der zweiten Reise nach Havannah im Jahre 1804 nicht nach Batabano kain, so liefs er mit grofsen Kosten die zwei Arten, welche dic Einwohner Cayman und Crocodilo nen. uen, nach der Havannah bringen. Von der letztern erhielt er zwei lebendige Thiere, wovon das ältere vier Fufs und drei Zoll Länge batte. Ihr Fang war sehr schwierig gewesen, und man hatte sie knebeln und binden müssen, um sie auf Maulthieren fort. bringen zu können. Sie waren kräftig und ziemlich wild. Um ihre Bewegungen und Gewohnheiten beobachten zu können, wurden sie in einen grofsen Saal gebracht, wo Herr von Humboldt sie von einer hohen Geräthschaft herab beobachtete. Es wurden Hunde über sie gelassen, von der grofsen Art, die jedoch von den Krokodillen muthig ange. griffen wurden. Nachdem sie am Orinoko, am Rio Apure und am Magdalenenstrome sechs Monate hindurch Krokodille beobachtet hatten, war es. ihnen sehr angenehm, vor ihrer Rückreise diese Thiere nochmals beobachten $z u$ können. Sie gingen von der ruhigsten Trägheit zu den schnellsten Bewegun. gen über, und zeigten eine grofse Biegsamkeit. Herr von Humboldt sah hier, was auch Descourtilz und Dampier beobachtet haben, wie sie öfter dieSchnautze und den Schwanz einander näherten. Diese Thiere 


\section{-303 -}

hatten eben so zugespitzte Schnautzen, wie die Krokodille am Orinoko und Magdalena. Ihre Farbe war etwas dunkler, auf dem Rücken braunschwärzlich und am Bauche weifs. Die Seitentheile waren gelb gefleckt. Er zählte, wie bei allen echten Kírokodillen, 38 Zähne in der obern Kínnlade und 3 o in der untern. In der obern Kinnlade waren der zehnte und neunte, in der untern der erste und der vierte die gröfsten. Der vierte untere Zahn umfafste frei die obere Kinnlade. Die hintern Extremitäten waren palmfülsig. Sie hielten daher das Krokodill von Batabano für ganz gleich dem des Orinoko. Allerdings trafen die Erzählungen von der wilden Lebensart nicht mit den Beobachtungen am Orinoko überein; allein man weifs, dafs diese fleischfressenden Eidechsen in demselben Strome bald wilder, bald zahmer sind.

Das in Batabano mit dem Namen Cayman belegte Thier starb auf dem Transporte, und man war so unvorsichtig, dasselbe nicht zu überbringen, so dafs es unmöglich war, beide Arten zu vergleichen. Was jedoch die Colonisten von Batabano erzählen, ist es beinahe ganz aufser Zweifel, dafs sich hier echte Caymans mit stumpfer Schnautze finden, deren vierter Zahn in die obere Kinnlade eintritt, den Alligators von Florida gleich. Es hätte also auf Cuba das Volk zwischen Cayman und Iŕrokodill eben so richtig unterschieden, wie die Gelehrten, was nicht das erste Mal wäre. Bei den Krokodillen fanden 
sich die vier Taschen, welche Moschus enthalteu, genau eben so unter der Unterkinnlade und beim After gelegen, wic bei denen am Rio Magdalena; hingegen war es sehr auffallend, dafs in der Havannah drei Tage nach dem Tode der Thiere, und bei einer Temperatur von $30^{\circ}$, jener Geruch nicht spürbar war, während in Monpox am Magdalenenstrome die lebendigen Krokodille ibr Zimmer verpesteten. Auch Dampier bemerkt die völlige Abwesenheit des Geruclıs beim Krokodille auf Cuba, wäbrend jedocb dic Caymanc cinen sehr starken Geruch verbreiteten. Eben dieser so geschickte Seefahrer als Naturbeob. achter hatte schon vor hundert Jahren den Unter. schied wahrgenommen, der zwischen dem Alligator oder Cayman und dem spitzrüsseligen Krokodille Statt findet. Dampier sagt auch über die geographische Vertheilung dieser Eidechsen Folgendes : $v$ in der Campeche-Bucht habe ich nur Caymans oder Alligators gesehen, auf der Insel Grofs-Cayman nur Krokodille, aber keine Alligators; auf der Insel de Pinos und in den unzählbaren Lachen und schlammigen Flüfschen der Insel Cuba werden gleíchmäfsig Krokodille und Caymans getroffen." Die echten Krokodille finden sich auch auf den Antillen unter dem Winde, welche dem Festlande zunächst liegen. Auf Trinidad, auf der Margaretha.Insel und wahrscheinlich auch, trotz dem Mangel an süfsem Wasser, auf Curacao. Südlicher trift man dasselbe in Guiana, im Rio Neveri, im Orinoko, 


\section{- 305}

Rio Apure und dem Cassiquiare, so auch im Magdalenenstrome, also auf eine Entfernung von 400 Meilen von Cuba, und zwar ohne Beimischung von Alligators. Mithin scheint der Hafen von Batabano eine Art Grenzscheide zu seyn, denn in Florida und im Missisippi sind nur Alligators, ohne Beimischung von Ḱrokodillen.

Ich kann nich jedoch nicht enthalten, hier eine Art Verwunderung auszudrücken, über die Unvollkommenheit unserer Kenntnisse über diese Art von Eidechsen. Und obgleich sich dasselbe von allen grofsen Thieren behaupten läfst, so mufs es doch auffallend seyn, die fleischfressenden Saurier nicht genauer beschrieben und erforscht zu finden, da sich dieselben doch so sehr der Wifsbegierde darbieten. Es wird kein Schritt in die Tropenregion beschrieben, wo nicht der Krokodille erwähnt würde. Alle Welttheile, dic sich in die heifse Zone erstre. cken, wimmeln von diesen an Sitten und Neigung so verschiedenen Thieren, und dennoch klingen noch alle Beschreibungen wie Mäbrchen. Ist es das Staunen, die unwillkürliche Furcht, der Schauder, welcher sich unserer Phantasie beim Anblicke eines so fremdartigen Thieres bemächtigt, was von der genauen Erforschung abhält? Es ist gewifs, dafs selbst im Nile nicht alle Krokodille derselben Art angehören, und schon die alten Egypter haben schädliche und unschädliche unterschicden. Welche Be wandtnifs hat es aber mit den indischen Eidechsen, 
mit denen in Neu-Holland, Paraguay, im südlichen und nördlichen Amerika? Was ist die Lebensweise dieser Thiere? Verfolgen sie einander selbst? Vermischen sie sich niemals unter einander? Sind die zahmen, unter denen man furchtlos badet, und die sich mit Fischen begnügen, wirklich eben dieselben, die man anderwärts so wild und blutgierig schildert? Man hat sich mit dem kleinsten und unbe. deutendsten Ungeziefer so viel Mühe gegeben, seine Lebensweise und Natur zu erforschen, sind es denn die grofsen Thiere weniger werth? Selbst die grossen Ḱatzen, die grofsen Grasfresser, die Schlangen, ja selbst unser Pferd hat sich noch keiner solchen Aufmerksamkeit unserer Naturforscher zu erfreuen gehabt, als z. B. nur unsere Spinnen!

\section{mancominomensos \\ Neuntes Kapitel.}

Abreise ron Batabano, - Seefahrt 2 wischen den Inseln.

Am 9. März wurde vor Sonnenaufgang die Goelette gelichtet. Dieses Schiff war ungewöhnlich klein, und man konnte nur auf dem Verdecke schlafen, was eben so unbequem als für die Gesundheit nach. theilig ist. Die Schiffskammer erhielt ihr Licht nur von oben, und war so klein, dafs es kaum anging, die Instrumente darin unterzubringen; es war früher eine Vorrathskammer gewesen, und sie war so dumpfig, dafs der Thermometer sich stets auf $3_{2}$ und 
33 Centesimalgraden erhielt. Zum Glücke dauerte diese Unbequemlichkeit nur zwanzig Tage, und die Fahrt in einem offenen Kahne auf den mit Mosquitos bedeckten Orinoko und dem stinkenden Fleisclschiffe des Amerikaners hatte sie für solche Unbequemlichkeiten schon hinlänglich abgehärtet.

Der Golf von Batabano ist von selir niedrigen und sumpfigen Küsten eingefafst, und stellt sich als eine weitläufige Wüste dar. Die Fischer-Vögel, welche früher als die Landvögel und faulen Zamuros-Geier erwachen, zeigten sich nur in geringer Zahl. Das Meerwasser hatte hier eine braungrüne Farbe, wie sie verschiedene Gebirgsseen in den Alpen und Karpathen zeigen, während die Luft in dem Augenblicke, wo die Sonne sich am Horizonte zeigte, trotz ihrer Reinheit, jene blafsblạue Färbung zeigte, die der Darstellung landschaftlicher Umrisse so besonders günstig ist. Der Hafen von Batabano wird beinahe nur von Schmugglern besucht, weil kein Canal ihn mit der Ilavannah verbindet. Wäre dieses der Fall, und würde der Ha. fen gereinigt, so würde er bald einerder besuchtesten werden. Der Golf, in dessen Grunde der Hafen sich befindet, bietet ein grofses, fünfzig Ileilen breites und vierzehn Meilen tiefes Becken dar, das durch eine zahillose Menge von Untiefen und Cayen geschlossen wird. Mitten unter diesen Cayen hebt sich eine grofse Insel hervor, deren Ausdehnung vier Mal gröfser ist, als die Insel Martinique, und 


\section{- 368}

deren dürre Berge mit prächtigen Coniferen bewacksen sind. Es ist dieses die Insel del Pinos, die Columbus El Evangelista, und die spätern Schiffer Isla de Santa Maria genannt haben. Sie ist berühmt durch das prachtvolle Acajou oder Mabagony-Holz, welches sie dem Handel liefert. Wir haben schon im ersten Bande eines 36 Fuls langen und 9 Fufs breiten Mahagony-Pfosten auf der Insel Cuba erwähnt.

Unsere Freunde segelten in ihrer unbequemen Lage in der Richtung von $\mathbf{O}$. N. O. durch die Strafse von Christoval, um die Insel Cajo del Padres zu erreichen, und diesen Archipel zu verlassen. Die zahllosen Inselgruppen haben die Eroberer in der ersten Zeit der Entdeckung mit dem Namen der Gärten und Bosquets belegt (Jardines y Jardinillos). Die wirklichen Gärten der Königin (Jardines de la Reyne) liegen dem Cap Cruz näher, und sind von diesen Inselchen, die wir hier beschrieben, durch eine offene See von 35 Meilen Breite getrennt. Columbus selbst bat ilınen diesen Namen gegeben, als er im Mai 1494 auf sciner zweiten Reise 58 Tage lang zwischen der Pinos. Insel und dem Ostcap ron Cuba mit Stürmen und Strömungen zu kämpfen hatte. Er beschreibt die Inselchen dieses Archipels als anmuthig, grün, vollreizender, schlanker Bäume. Ein Theil dieser sogenannten Gärten ist auch wirklich sehr angenehm, mit jedem Augenblicke wechseln dem Seefahrer die Ansichten, und das Grün 


\section{- 360}

mchrerer dieser Inselchen erscheint um so freund. licher, als dasselbe gegen andere Cayen absticht, welche nur weifsen dürren Sand zeigen. Diese Sandbänke, wenn sie von der Sonne bescheint werden, haben das Ansehen eines wellenförmigen Wasserspiegels. Die Sonne belebt auch hier die Landschaft, und durch die Luftspiegelung scheint sich diese todte Gegend zu beleben. Sobald die Sonne aufgegangen ist, scheinen diese todten Massen sich wie in der Luft zu bewegen und zu schweben, und am benachbarten sandigen Ufer hat man den täuschenden Anblick eines nicht vom Winde bewegten Wasser. beckens. So erscheint ein Zauberbild von schwebenden Gärten und bewegten Wasserflächen. Jetzt zieht eine Wolke vor das Bild der Sonne, und so. gleich ist der ganze Zauber zerstört. Die schwebenden Felsen und Baumstämme senken sich wieder auf den Boden nieder, die Wasserfächen stehen stille, und zeigen ihre wahre Beschaffenheit als dürrer Sand. Der von den Arabern besungene süfse Zauber der Einsamkeit der Wüste beruht auf eben dieser Erscheinung der Luftspiegelung.

Die Fahrt geht in dieser Gegend äufserst langsam vor sich, woran theils die vielen Untiefen, theils die durch viele Inseln geschützte Ruhe des Wassers Ursache ist, welches hier beinahe einem Süfswasser. see gleicht. Die Zeit vertrieben sich unsere Reisenden auf dieser Fahrt mit Beobachtungen, die auf Luft und Wasser Bezug hatten. Sie bestanden 
darin, den Einflufs zu beobachten, welchen die Veränderung der Grundfächen auf die Temperatur des Meerwassers äufsert. Wir haben schon im ersten Bande gesehen, dafs auf Untiefen die Temperatur immer niedriger ist, weil daselbst die untern Wasserschichten sich der Oberfläche nähern, und diese immer kälter sind, als die Oberschichten. Herr von Humboldt fand diese interessante Bemerkung auch hier durch viele Versuche' bestätigt. Auffallend war es Herrn von Humboldt, zu bemerten, dafs die seichten Wasser hier die weifse Milch. farbe nicht zeigten, wie dieses auf der Bank von Vibora, südwärts von Jamaika, und an vielen andern Orten mehr der Fall ist. Der Grund der Rhede von Batabano ist ein aus zerbröckelten Corallen bestehender Sand, der Fucusarten ernährt, die nur selten auf der Oberfäche des Wassers sicht. bar werden.

Der Kleinheit des Fahrzeugs und der Sorgfalt des Steuermanns ungeachtet, blieb das Fabrzeug öfters auf dem Grunde fest sitzen. Bei weichem Seegrunde war keine Gefahr vorhanden, Schiffbruch zu leiden, man zog jedoch vor, bei Sonnenunter. gang Anker zu werfen, als sich den Gefahren nächtlicher Schiffahrt Preis zu geben. Die Nacht war -ausnehmend hell. Landeinwärts beobachteten sie eine Menge Sternschuppen, dic alle eine Richtung , nabmen, welche der des Windes in der untern Atmosphäre entgegengesetzt war. Diese Gegend, die 


\section{$-\quad 371$}

zur Zeit des Columbus bewohnt und von Fischern häufig besucht ward, ist jetzt öde und still, wie das Grab. Damals gebrauchten die Einwohner von Cuba einen kleinen Fisch als Köder, um grofse Seeschildkröten damit zu fangen; sie befestigten ein langes Seil an den Schwanz des Revés (so hiefs der Fisch bei ihnen). Dieser Fischer - Fisch bediente sich aber des flachen mit Saugröhren besetzten Schildes, den er auf dem Kópfe trägt, um sich an die Schale der Schildkröten anzusaugen, die in den Canälen der Jardinillos häufig vorkommen. Der Revés, sagt Columbus, liefse sich eher zerreifsen, als dafs er sich unfreiwillig von dem Körper trennen möchte, an dem er sich einmal angesauget hat. Am näm. lichen Seile also holen sich die Indianer den FischerFisch und die Schildkröte. Als Gomara und Peter Martyr diese Thatsache von den Reisegefährten des Columbus vernommen hatten, und in Europa bekannt machten, glaubte man darin ohne Zweifel ein Reisemährchen zu finden. Aus den Beobachtungen des Capitän Rogers, von Dampier und Comerson wissen wir nunmehr, dafs eben dieses in den Jardinillos wahrgenommene Jagdverfahren auf Schild. kröten auch von den Bewohnern der Ostküste Afrika's, in Mozarmbique und Madagascar angewendet wird. Menschen, mit grofsen durchlöcherten Flaschenkürbissen auf dem Kopfe, haben in Egypten, San Domingo und in den Seen des Thales von Mexiko sich im Wasser verborgen, um die Vögel 
bei den Füfsen zu fangen. Die Chinesen gebrauchen von den ältesten Zeiten her die Cormorane, einen der Pelikan-Familie angehörigen Vogel, zum Fiscb. fange an den Küsten; sie legen ilım einen Ring um den Hals, damit er seine Beute nicht verschlingen könne, sondern für sie Fische fange. Selbst bei den rohesten Völkern entwickelt sich List und Scharfsinn der Menschen, um Fischerei und Jagd zu betreiben. Völker, die nie in Verbindung mit einander waren, zeigen in der Auswahl der Mittel, um ihre Herrschaft über die Thiere geltend zu machen, die auffallendste Älınlichkeit.

Erst nach drei Tagen war es möglich die Jardines und Jardinillos zu verlassen. Sie besuchten cinige dieser Inseln, da alle Tage zur Nachtzeit die Anker geworfen wurden. Eine der ersten, die sie besuchten, war die Cayo Bonito (Hübsch), die ihren Namen dem Reichthume ihres Pflanzenwuchses verdankt. Alles zeigt an, dafs sie schon seit langer Zeit über dem Oceane emporsteht. Auf ihr erhebt sich ein ganzer Wald von Wurzelträgern oder Rhizophoren, die man, von ferne gesehen, für Lorbeer zu halten geneigt seyn könnte. Die Avicennia nitida, die Batis, kleine Euphorbien und einige Grasarten sind bemüht durch ihr Wurzelgeflechte den lockern Sand zu befestigen. Was jedoch dieses Corallen - Eiland vorzüglich schmückt, ist die prächtige Tournefortia Gnaphalioides (kann man sich einen gárstigern und barbarischern Namen denken?), 
von Jaquin mit silberfarbnen Blättern, welche sie hier zum ersten Male antrafen. Es ist eine gesellig lcbende Pflanze, ein Strauch von fünfthalb bis fünf Fufs Höhe, dessen Blüthen einen sehr angeneìmen Geruch verbreiten. Mehrere Eiländchen werden damit geschmückt, als : der Cayo Flamenio, der Cayo de Piedras und vielleicht die meisten Niederungen der Jardinillos. Sic fanden lier auch Parthenium Hysterophorum, eine Pflanze, die sowohl auf allen Feldern Cubas, als auch in Caracas und Mexiko zwischen 470 und 900 Toisen Erhöhung angetroffen wird. Die Einwohner gebrauchen sie sowohl für aromatische Bäder, als auch zur Vertreibung der im tropischen Klima so häufigen und lästigen Flöhe.

Wälrend unsere Reisenden botanisirten, suchten die Matrosen nach Langousten. Unwillig, dafs sie keine fanden, stiegen sie auf die Wurzelbäume, und richteten da unter den Alcatraz, die hier paarweise in den Nestern safsen, eine gewaltige Niederlage an. Die Alcatraz sind eine Art Pelikan, welche die Gestalt eines Schwans haben. Mit der den Meervögeln eigenen dummen Zuversicht und Sorglosig. keit verfertigt der Alcatraz sein Nest nur aus etlichen Baumästen. Man zählt vier bis fünf Nester auf einem einzigen Wurzelbauıne. Die jungen Vögel vertheidigten sich mit ihren 6 bis 7 Zoll langen Schnäbeln sehr tapfer. Die Alten flogen schwebend über ihren Köpfen und stiefsen lautes Klaggeschrei 


\section{$-374$}

aus. Das balf ilinen jedoch sehr wenig, und bald sah man das Blut von den Bäumen herabträufeln, denn die Matrosen waren mit Stöcken und Manchetten bewaffnet. Der Matrose, der auf einsamen Seefahrten zu andauerndem Gehorsame gezwungen ist, übt gerne eine grausame Herrschaft gegen Thiere aus, sobald sich dazu Gelegenheit darbictet. Der Boden lag bald voll verwundeter im Todeskampfe zappelnder Vögel, Bei der Landung hatte vollkommene Ruhe und Friede auf diesem Erdwinkel geherrscht, jetzt schien alles zu ver. künden: die Menschen sind hier gewesen - mit ihrer Qual!

\section{mononomanos \\ Zehntes Kapitel.}

Geschichtliche Erinnerungen, - Fahrt nach Trinidad. - Libeise nach dem Festlande.

Der Himmel war mit röthlichen Dünsten überzogen, die sich gegen Südwest allmählich zertheil. ten. Diese Gegenden besitzen für denkende Reisende einen Reiz, welcher der neuen Welt meistens fehlt. In der alten Welt verleiht die Erinnerung an die Vergangenheit unaussprechlichen Reiz. Die neue Welt ist selbst in ihren herrlichsten Theilen ohne geschichtliche Sagen. Hier jedoch ist der clas. sische Boden geschichtlicher Erinnerungen. An diese Stelle wird sich einstens die Geschichte Ame. 
rika's knüpfen. Hier fallen dem Reisenden die Punkte in die Augen, an die die berühmtesten Namen der spanischen Monarchie erinnern. Hier befuhren Christoph Columbus und Ferdinand Cortez den Ocean. Auf der Südküste Cuba's, zwischen der Xagua-Bucht und der Pinos - oder Fichteninsel, hatte der Admiral auf seiner zweiten Reise mit Erstaunen v jenen geheimnifsvollen König gesehen, der nur durch Zeichen mit seinen Unterthanen sprach, und jene Menschen-Gruppe, die, mit langen, weifsen Hemdröcken bekleidet, Mönchen de la Merced glich, während das übrige Volk nackt war." Auf seiner vierten Reise traf Columbus in den Jardinillos grofse Piroguen mexikanischer Indianer an, die mit reichen Erzeugnissen und Waaren von Yucatan beladen waren. Durch seine Phantasie verführt, glaubte er aus dem eignen Munde dieser Seefahrer zu hören : "Sie kämen aus einem Lande her, wo die Männer auf Pferden reiten und Goldkronen tragen.» Schon bildete er sich ein, $v$ es wären Catayo, das Reich vom Grofs - Chan, die Mündungen des Ganges « einander so nabe gelegen, dafs er sich bald zweier arabischer Dolmetscher würde bedienen können, die er für seine Reise nach Amerika in Cadix eingeschifft hatte. Hier war es auch, wo der grofse Mann himmlische Erscheinungen zu sehen und mitten im Sturme tröstende Worte zu vernehmen glaubte. Naiv und rührend lautet der Brief, den Columbus von hier aus an die Königinn ron Spanien schrieb; 


\section{$-\quad 370$}

× Eure Hoheit darf mir glauben, sagt Columbus, dafs der Erdball lange nicht so grofs ist, als man gewöhnlich glaubt. Sieben Jahre verweilte ich an Ihrem böniglichen Hoflager, und sieben Jahre lang ward mir gesagt: mein Vorhaben sey eine Thorheit. Jetzt, nachdem ich den Weg gebahnt, verlangen nun Schneider und Schuster sogar Privilegien, um neue Länder zu entdecken. Verfolgt und vergessen, wie ich bin, kann ich nie an Hispaniola oder Paria denken, ohne dafs Thränen meine Augen füllen. Zwanzig Jahre stand ich im Dienste Ihrer Hoheit; meine Haare sind alle grau, und mein Körper ist schwach, ich kann keine Thräne melır vergiefsen. Bejammere mich jetzt, o Himmel! wie ich durchjammere die Erde ! Bedaure mich, wer Liebe, Wabrheit und Gerechtigkeit ehrt! So bejammert bier der Entdecker Amerika's sein Loos und die Undanla barkeit der Welt!

Die Pinos-Insel und die sie umgebenden Gärten sind aueh in der Eroberung Mexiko's merkwürdig. Als Ferdinand Cortez sich zu seiner grofsen Unternehmung rüstete, erlitt er während der Überfahrt vom Hafen der Trinidad zum Cap St. Anton mit seiner Nave Capitana auf einer der Jardinillos Schiffbruch. Fünf Tage lang hielt man ihn für verloren. Der wackere Pedro de Alvarado sandte aus dem Hafen von Carennas (Havannah) drei Schiffe, um ihn aufzusuchen. Später, im Jahre 1519, sammelte Cortez seine ganze Flotte, in der Nähe des Cap St. 


\section{$-\quad 376$}

Anton, vermuthlich an derselben Stelle, welche auch jetzt noch den Namen Enseriada de Cortez führt, westlich von Batabano der Pinos-Insel gegenüber. Von hier war es, dafs er in der Hoffnung den Schlingen des Gouverneurs Velasquez desto eher zu entgeben, beinahe heimlich nach der mexikanischen Küste abging. Hier zeigt sich der seltsame Wechsel menschlicher Schicksale! Eine Handvoll Menschen, die von Westen der Insel Cuba auf den Küsten vou Yucatan gelandet hatte, war hinrcichend, um die Grundfesten von Montezuma's Reich zu crschüttern, und jetzt nach drei Jahrhunderten ist dieses nämliche Yucatan ein Theil des mexikanischen Staates, der auf's neue von Cuba aus bedrolit wird, indem er sclbst eben diesem Cuba drohend gegenüber steht.

Vormittag den 11 , besuchten die Reisenden den Cayo Flamenco unter $21^{\circ}, 59^{\prime} 39^{\prime \prime}$. Der mittlere Theil dieses Eilandes ist sehr niedrig und hat nicht mehr als 14 Zoll Erhöhung über die Mecresfläche. Diese Niederung enthält Wasser von geringem Salzgehalte. Andere Cayos oder Eilande haben Becken von völlig süfsem Wasser. Die Sceleute von Cuba, so wie die Venezianer der Lagunen und selbst einige Naturforscher, erklären die Süfsigkeit dieses Wassers aus der Wirkung des Sandes, durch welchen das Wasser einfiltrirt würde. Herr von Ifumboldt widerspricht dieser Meinung, um so mehr, als diese Cayen aus Felsengrund, und nicht aus Sand gebilBibl. naturh. Reisen. IV. 


\section{- 378}

det sind, und auch ihre Kleinlseit nicht zuläfst, dafs das Regenwasser hier dauernde Pfützen bilden könnte. Es scheint Herrn von Humboldt nicht unmöglich, dafs diese süfsen Wasser der Cayen von cubanischen Gebirgen durch hydrostatischen Druck herrühren. Es ist dieses um so wahrscheinlicher, als nach neuern Beobachtungen einen halben Grad östlich von den Jardinillos, mitten in offner See dritthalb Meilen von der Küste, Süfswasserquellen sprudelnd aus dem Meere hervortreten. Die Kraft, mit wel. cher diese süfsen Wasser aus dem Meere hervorsprudeln, ist so grofs, dafs sie für kleine Kähne cinen oft gefährlichen Wellenschlag verursacht. Auch holen, Schiffe, die nicht in Xagua einlaufen wollen, zuweilen ihren Süfswasser-Vorrath daselbst. Das Wasser ist um so süfser, je tiefer es geschöpft wird. Auch die Lamartins oder Mannati haben die süfsen Wasser entdeckt, und werden daselbst von den Fischern häufig gefangen.

Eine halbe Meile östlich vom Cayo Flamenco trafen sie zwei zu Tage stehende Felsengründe an, an denen sich die Wellen gewaltsam zerschlagen, es sind dieses die Felsen Diego Perez unter $21^{\circ}$, $51^{\prime} 10^{\prime \prime} \mathrm{N}$. Br. Abends landeten sie bei zwei an. dern Felsen, dem Cayo de Piedras. Sie stehen vereinzelt am Ende der Jardinillos und werden den Schiffen oft gefährlich. Der Cayo de Piedras ist vom Holzwuchse beinahe ganz entblöfst, weil bei den öfter hier stattfindenden Schiffbrüchen die 


\section{$-\quad 370$}

Verunglückten alles Strauchwerk, um damit Fcuer. Signale zu machen, umhauen. Von hier aus sahen sie zuerst hohe Gebirge, die sich in der Richtung von O.N. O. jenseits der Bucht von Xagua erheben. Diese Nacht blicben sie noch ein Mal vor Anker liegen, und traten den folgenden Tag in dic offne See ein.

Sogleich erhöhte sich die Temperatur des Wassers, als sie sich von den Untiefen entfernten. Die See wurde indigoblau, und der Thermometer, wel. cher früher bei $6 \frac{1}{2}$ bis $8 \mathrm{Fufs}$ Tiefe $22^{\circ}, 6$ zeigte, erbielt sich jetzt auf $26^{\circ}, 2$, bei einer Luftemperatur von $25^{\circ}$ bis $27^{\circ}$. Sie versuchten in den Hafen von Trinidad einzufahren, weil von da aus, bei dem herrschenden Nordostwinde, die Überfahrt nach Carthagena leicht bewerkstelligt werden konnte, dessen Meridian zwischen Santiago de Cuba und die Bucht von Guantanamo fällt. Sie kamen vor der sumpfigen Küste der Camareos vorbei, welche durch den edelmüthigen und humanen las Casas berühmt ist.

Der Hafen von Xagua ist einer der schönsten auf der Insel Cuba, aber am wenigsten besucht; schon Herera sagt von ihm: er sey der schönste, so dafs es keinen andern auf Erden gebe. In der neuern Zeit wurde dieser Ruhm bestätigt, allein bis jetzt gibt es nur eine kleine Häusergruppe daselbst, und eine kleine Festung zur Vertheidigung, weil ihn früher in Kriegszeiten die Engländer benutzten, um 


\section{- 380}

daselbst ihre Schiffe zu kielholen. Östlich von Xa. gua gewimnen die Küsten ein majestätischeres Ansehen, indem sich die Berge den Küsten nähern. Thre Höhe beträgt zwar nicht über 300 Toisen, aber sic imponiren durch ihre steile Abschichtung und die zackige Gestaltung der ganzen Gruppe. Dic Küste ist hier dermafsen steil (accore), dafs Schiffe ganz nahe an sie hinankommen, und zwar selbst Fregatten sich ihr überall bis zur Ausmündung des Rio Guaurabo nähern können. Als nächtlicher Wcile die Luft bis auf $23^{\circ}$ sich abgekühlt hatte, und der Wind vom Lande her wehete, brachte er wieder jenen herrlichen Geruch von Blüthen und Honig, der die Luft um Cuba so herrlich auszeichnet. Das Wachs von Cuba ist ein Erzeugnifs europäischer Bienen, und macht, wie wir oben gezeigt haben, einen bedeutenden Handelsartikel der Insel aus. $T^{\top}$ or der Ankunft der Spanier ward auf Cuba kein Wachs gesammelt, wie Christoph Columbus aus. drücklich erwähnt. Er fand daselbst zwar einen grofsen Wachskucben, welchen er auch in einer Audienz dem Könige Ferdinand überreichte, es wies sich jedoch nachher aus, dafs dieses Wachs als Handelswaare von Mexiko eingeführt worden war. Bedeutsam war das erste mexikanische Pro dukt, welches im November 1492 den Spaniern in die Hände fiel, nicht Gold, sondern cin Erzeugnifs der Landwirthschaft, zum richtigen Zeichen, dafs dieses der wahre Reichthum des Landes sey. Här. 
ten die Spanier mchr nach Wachs als nach Gold getrachtet, so wären jetzt wahrscheinlich Mutter und Töchter g! ̈̈cklicher. Sie fuhren nun bei drei Mlei. len der Kiüste cntlang, und befanden sich am folgenden Morgen der Ausmündung des Rio St. Juan gegenüber. Hier ist ein Landungsplatz, der aber allen Sefahrern, aufser Schmugglern und Piraten, zuwider ist, weil dic Luft von Mosquitos und Zacundos wimmelt, wie auf dem Cassiquiare. Dieser Hafen liegt unter $23^{\circ}, 40^{\prime} 50^{\prime \prime}$ Länge. Die Berge, welche den Hafen beberrschen, erreichen hier kaum 23o Toisen Höhe. Herr von Humboldt brachte einen Theil der Nacht auf dem Verdeclie zu. Er erstaunte über die öden küsten, wo nicht ein cinziger Lichtfunke das Dascyn auch nur einer Fischerhütte andeutete. Von Batabano bis Trinidad ist nicht ein einziges Dorf vorhanden, und kaum findet man zwci oder drei Coralcs für Kiühe oder Schweine. Zur Zeit des Columbus war diese Küste bewohnt. Wenn man hier Brunnen gräbt, oder wenn bei grossen Wasscrn der Boden ausgespült wird, so kommen nicht sclten stcincrne Äxte nnd Kupfergeräthe zum Vorscheine, welche von den vormaligen Bewohnern herrühren. Auf Cuba und Haiti kommt allerdings vicl Kupfer vor, und die Menge mufste die Einwohner zur Schmelzung desselben vcranlas. sen. Columbus meldet: in Haiti würden Massen von gediegcnem Kupfer, 6 Aroben schwer, gefun: den, und die Piroguen von Yucatan, denen er an 


\section{$-\quad 382$}

den Ostlüsten von Cuba begegnete, führten unter andern Handelswaaren aus Mexiko auch Tiegel zum Sclimelzen des Kupfers.

Sie fuhren nun in einem Wasser von 60 Toisen Tiefe; die Temperatur desselben war $4^{\circ}, 2$ höher, als die der seichten Wasser bei Batabano. Am 14. liefen sie in den Rio Guaurabo, cinen der zwei Häfen der Stadt Trinidad de Cuba, ein. Hier hoff. tcn sie nun mit einem Paquetboote nach Carthagena segeln zu künnen. Sie landeten gegen Abend, und wurden nun von einigen catalonischen Kírämern lu. stig und munter eingeladen, sie nach der Stadt zu begleiten. Die Fahrt nach der Stadt glich der der alten Johannisritterfahrt. Sie safsen nämlich alle yu zwei und zwei auf einem Pferde, und Herr von Humbolat und Bonplund zögerten nicht, das naive Anerbieten anzunehmen. Die Entfernung der Stadt beträgt ungefälbr vier Meilen auf einer beinahe wa. gerechten Ebene, die mit dem schönsten Pflanzen. wuchse bedeclit ist. Einen besondern Reiz derselben bildet die Corypha Mliraguama, ein Palmbaum mit silberfarbnen Blättern, den unsere Freunde hier zum ersten Male sahen, und welcher der Ge. gend einen eigenthümlichen Reiz verleiht. Dieser schöne und fruchtbare Erdstrich wartet noch auf Menschenhände, um sehr reiche Ernten zu liefern. Gegen Westen wird die Aussicht malerisch, da sie sich nach den Kalkgebirgen der Lomas de St. Juan öfnet, welche 1800 bis 2000 Fufs Höhe hat, und 
sïdwärts steil abgestutzt ist. Die nackten Gipfel stcllen theils Kuppen, theils wirkliche Nadeln und eigentliche Hörner dar. Obwohl die Temperatur zur Zeit der Nordwinde niedrig ist, so erfolgen doch niemals Schneenicderschläge, wiewohl öfter Reif sowohl auf diesen, als auch auf den Bergen von Santiago angetroffen wird. Beim Austritte aus dem Walde erblickt man eine Reihe von Hügeln, deren südlicher Abhang mit Häusern bedeclit ist. Dieses ist die Stadt Trinidad, welche der Gouver. neur Velasquez 1514, aus Veranlassung der reichen Goldminen, weiche im Thale des Rio Ariamo soll. ten entdeckt worden seyn, gegründet hat. Die Strafsen sind alle auf steilen Abhängen befindlicb, und es herrscht, wie überall im spanischen Amerika, die Klage über die schlechte Auswall des Bodens zur Gründung der Städte. Am nördlicben Ende stebt die Kirche von Nuestra Sennora de la Papa, welche ein berühmter Wallfalırtsort ist, und 7oo Fufs über der Meeresfläche erhaben liegt. Man geniefst hier eine prachtvolle Aussicht über den Ocean, über beide Häfen, über einen Wald von Palmbäumen und nach der Gruppe der hohen Gebirge St. Juan.

Sie gelangten glücklich nach Trinidad, und wurden daselbst bei dem Verwalter der königlichen Pflanzung, Herrn Munnoz, mit der liebenswürdigsten Gastfreundschaft empfangen. Trinidad liegt nach der Beobachtung des Herrn von Humbodlt un- 


\section{$-\quad 384$}

ter $21^{\circ}, 48^{\prime} 20^{\prime \prime} \mathrm{N}$. Br. und $82^{\circ}, 21^{\prime} 7^{\prime \prime} \mathrm{W}$. L. Der Stattbalter von Trinidad, dessen Gerichtsbarkeit sich über einen bedeutenden Theil der Insel erstreckte, war ein Neffe des berübmten Astronomen Antonio Ulloa. Er gab unsern Reisenden ein grofses Fest, zu welchem auch mehrere ausgewanderte Franzosen von San Domingo geladen waren, die ibren Fleifs und ihre Einsichten nach Cuba übergebracht hatten.

Die Ausfuhr von Trinidad ist keineswegs so bedeutend, als man denken sollte. Die Stadt fülurt noch keine vollen 400 Kisten Zucker aus. Trinidad hat $z$ wei Häfen, von denen jedoch keiner noch diejenigen Verbesserungen erhalten hat, deren sic von Natur aus fähig sind. Die Bocca de Rio Guaurabo gewährt, seit sie durch eine Batterie vertheidigt wird, einen sichern Landungsplatz, der jedoch von Winden keineswegs geschützt ist. Solche Fahrzeuge, die nicht tief gehen, oder die zum Theil ausgeladen werden, können sich stromaufwärts bis auf eine Meile der Stadt nähern. Die Paquetboote ziehen diesen Hafen vor, da sie sicher lan. den künnen, olne eines Piloten zu bedürfen. Der Hafen von Cisilda ist ein mehr geschlossener, tief landeinwärts gelegener Ort; man bedarf jedoch hier der Piloten, weil er mit einer Menge Klippen verschlossen ist. Der Leuchtthurm war durch das Abfeuern der Kanonen völlig zerfallen; auch leidet der Hafen von Cisilda Mangel an süfsem 
Wasser, welches auf eine Meile weit hergeholt werden muls.

Die Bevölkerung von Trinidad mit den umliegenden Pacbtböfen, in einem Umkreise von 2000 Toisen, beträgt 19,000 Seelen. Die Zucker- und Caffeepflanzungen sind von grofser Ausdehnung, und europäische Brotfrüchte werden nur weiter gegen Villa Clara lin angebaut.

Einen sehr angenehmen Abend brachten sie noch im Hause eines sehr reichen Einwohners, des Don Antonio Padron zu, wo die ganze vornehme Gesellschaft von la Trinidad versammelt war. Auch hier war der muntere und lebhafte Geist der Be. wohner von Cuba, besonders der Frauen, sehr auffallend, und dieser Geist läfst eine einstige selır holie Stufe der Cultur ahnen. In der Naclit vom 15. verliefsen sie la Trinidad. Es widerfuhr ihnen die Ehre, dals sie der Stadtmagistrat in einem mit carmesinrothem Damast ausgeschlagenen Staatswagen nach dem Hafen führen liefs, und ein Geist. licher hatte in einem Sonnette ibre Reise nach dem Orinoko besungen. Dieser Auszug war freilich feicrlicher, als der Einzug, wo zwei auf einem Pferde safsen.

Auf dem Wege nach dem Hafen hatten sie eine entzückend schöne Erscheinung, mit der sie nac ziveijährigem Aufenthalte in der heifsen Zone schon liätten vertraut seyn sollen. Nirgends anderswo, versichert jedoch Herr von Humboldt, hatte er eine 


\section{- 380}

solche Menge leuchtender Inseliten geseben (elater noctilucus). Das Gras am Boden, die Äste und Blätter der Bäume, alles glänzte von röthlichem be. weglichem Lichte, dessen stärkerer oder schwäche. rer Glanz vom Willen der Thiere, die ihn hervorbringen, abhängt. Es war, als hätte das Sternfirmament des Himmels sich auf die Savane niedergesenkt. In den Hütten armer Landleute dienen ein Dutzend solcher Insekten in einer durchlöcherten Kürbisflasche als Nachtlampe, bei der man alles Benöthigte finden kann. Man darf die Flasche nur rütteln, um das Insekt zu reizen, und den leuchtenden Scheiben, die sich zu jeder Seite seines Bruststückes befinden, einen erhöhten Glanz zu geben. Das Volk nennt sie ewig brennende Laternen. Sie erlöschen auch in der That nur durch Krankheit oder den Tod der Insekten, welche sich durch etwas Zuckerrohr leicht ernähren lassen.

Da die Brise in nordöstlicher Richtung immer heftiger wehte, so wollte man die Caymas.Inseln vermeiden, die Strömung trieb sie dennoch dureh diesclben hin. Allmählich verloren sie nun Trinidad, die Palmenwälder und endlich die Insel aus dem Gesicbte. Sie verliefsen die Antillen in dem Augenblicke, wo der Sturm der Sclavenempörung auf St. Domingo den gesammten Archipel zu ergreifen und zu verschlingen drobte. Glücklicher Weise ist diese Drohung nicht in Erfüllung gegangen. Wo der Sturm entstand, hat er sich wieder gelegt. Eine 
freie Negerrepublik hat sich auf Haiti gebildet, und gibt der Weltgeschichte das erste Beispiel cines civilisirten Negerstaates. Ackerbau, aber nicht der Anbau der Colonialerzeugnisse, ist der Gegenstand der Beschäftigung bei diesem schwarzen Volke. Möchten nur die Antillen, durch dieses Beispiel gewarnt, immer solche Mafsregeln ergreifen, welche ihre Sicherheit befestigen. Da jedoch die sichersten Anstalten jederzeit auch die menschlichsten sind, so ist zu wünschen, dafs eine allmählige Auflösung der Sclavenbande jedem gewaltsamen Sprengen derselben zuvorkomme. Selbst die Freiheit wird zu theuer, wenn sie durch gewaltsames Vergiefsen von Menschenblut und durch! die Gräucl einer Revolution erkauft werden soll.

Und so hätte ich denn meinen jungen Lesern das Wesentlichste des Reiseberichtes des Herrn von Humboldt wieder erzählt, so weit es ihm bisher gefallen hat, uns davon zu unterrichten. Er geht nun hin, um eine Rise un die Welt zu machen; allein er bleibt in Amerika, besucht Neu-Granada, Peru, Guatemala und Mexiko, um gleichsam durch höhern Willen gezwungen, sein Vorhaben: die spanischen Colonien in Amerika zu durchforschen, auch auszuführen. Ich habe nichts von dem verschwiegen, was ich für meine jungen Leser passend hielt, und nur das übergangen, was ihnen unverständlich, und eben darum langweilig geworden wäre. 
Würden dadurch meine jungen Freunde auch Freunde der Natur, fühlten sie sich für ihre Mlajestät begeistert und angetricben, der Erkenntnifs derselben diejenige Zeit zu widmen, welche man gewöhnlich dem Mürsiggange und gefährlichen Zerstreuungen weibt, so hättc ich meine $\mathrm{Absicht}$ erreicht. -

Ende des vierten Bändchens. 


\title{
Inhalt des vierten Bändchens.
}

\author{
S i e b e n t e s B u ch.
}

Seito

Eilf tos K a pitel. Töpfer-Waare der Indiaver. - Die Landschaft bis zu den schwarzen Wassern . . . . 5 Z wölftes Kapitel. Die schwarzen Gewässer. - San Fernando de Atabapo . . . . . . . . . . . 14 D s e ize-hntes $\mathrm{K}$ a p.itel. Nouer Reiseplan, - San Fernando de Atabapo. - Fahrt auf dem Guaviare in den Atabapo, - St. Balthasar . . . . . . . . . 20 Vierzehntes Ka itel. Fahrt auf dem Rio Temi. -

Der Fels der Mutter. - Reise nach Javita - . . . 34 Fün fohntes Kapitel. Javita. - Reise an den Rio Negro. . . . . . . . . . . . . . 44

\section{A c h t e s B c li.}

Erates Hapitol. Fahrt auf. dem Rio Negro. - Der

Teufelstanz. - Meise bis zur Mission Franzesco Solano $\mathrm{Z}$ weites Kapite 1. Die Menschenfresser. - Fahrt bis

Mandavaca. . . . . . . . . . . 76

Drittes Kapitel. Fahrt bis zur Gabeltheilung. - Nacht.

Besuch rom Jaguar. . . . . . . . . 86

Viertes $\mathrm{K}$ a pite l. Die Gabeltheilung des Orinoko . . 96 Fiu $\mathrm{n}$ f tes $\mathrm{K}$ a $\mathrm{p}$ it el. Der Ober. Orinoko. - Esmeralda. -

Das Curare. - Das Juviafest. - Juvia. - Schilf und

Bast . . . . . . . . . . . . . . 108

Sechstes Ka pitel. Der Iauf des Orinolio oberhalb Esmeralda, - Abreise von Esmeralda, - Tiger . . . 123

Si c be $n$ tes Ka pit e l. Die Höhle ron Ataruipe- Reise nach Carichana. . . . . . . . . . . . 138 Hibl. naturh, Neisen. IV. 
A chtes Kapitel. Mission von Carichana. - Mission

Uruana. - Die Otomalien oder Erdfresser . . . . 1/8 Neuntes Kap ite I. Reise nach Angostura . . . . 157 $\mathrm{Z}$ ehntes $\mathrm{K}$ a pite 1 . Umgebungen von Angostura, - Die

Krokodille. - Die Müvdung des Orinoko. - Das Steigen und Fallen der Ströme . . . . . . . . . 168

Eilftes $K$ apitel. Das rechte Ufer des Orinoko. Die Mission von Carony. - El-Dorado. - Der Parime. See . . . . . . . . . . . . ${ }_{178}$ N e u n t e s $B$ u c h.

Erstes $K$ a pite 1. Abreise von Angostura. - Die Mission der Cariben. - Historischo Benerkungen über die Völker Amerika's . . . . . . . . . . . . . 191 Z we it es $K$ a p it e l. Bemerkungen über die Cariben . 199 Drittes If a p ite l. Abreise von Cari. - Villa del Pao. Reise nach $\mathbb{N} \in u$ - Barcellona. - Betrachtungen über dic Steppen . . . . . . . . . . . . . 211

$\mathrm{V}$ iertes Kapitel. Erscheinungen in den Llannos. Keu-Barcellona. - Aufenthalt daselbst. - Ausfüge . . 220 Fü ü $\mathrm{f}$ e 9 K a itel. Reise nach Cumana. - Aufenthalt daselbst. - Abreise nach der Havannah . . . . 23́o

$\mathrm{S}$ e c lis $\mathrm{t}$ e $\mathrm{s}$ a p ite l. Allgemeine statistische Bemerkungen über Venezuela... . . . . . . . . . 240 Si e be utes Kapitel. Gestaltung des Landes. - Unebenheiten des Bodens. - Bergknoten. - Ebenen - . 25 s $\Delta$ chtes Kapitel. Fortsetzung des Vorigeu. - Beckeu uud Thäler. - Höchste Spitzen. - Die übrigen Berg. gruppen . . . . . . . . . . . . 268 $\mathrm{Z}$ e $\mathrm{h} n \mathrm{t}$ e $\mathrm{s}$ B c b.

Erstes Kapitel. Reise nach Cuba. . . . . . 28 s $\mathrm{Z}$ we ites $K$ a p itel. Allgemeine Bemerkungen über die Antillen . . . . . . . . . . . . 289 Drittes $K$ apite 1. Politische Beschreibungder Insel Cuba zy 6 
Seite

Viertes Kapitel. Fortsetzung der Beschreibung der Insel Cuba, - Grörse. - Beschaffenheit. - Bevölkerung. - Sclaven . . . . . . . . . . 308 Fü $\mathrm{n}$ f te $\mathrm{s}$ I a p i t e l. Geistige Bildung auf der Insel Cuba. Öffentliche Anstalten. - Produkte . . . . . . 318 Sechstes Ka pitel. Die Verwendung der Sclaven. Caffee. - Tabak, - Wachs, - Handelsverkehr - . 332 $S$ i ebentes K apitel. Wünsche für die Industric und das Loos der Sclaven... . . . . . . . 341 A c h t e $\mathbf{s}$ a pite1. Rüstung zur Abreise, - Falsche Nachrichten . . . . . . . . . . . . . 354

N e un tes Ka pitel. Abreise ron Batabano. - Seefahrt zwischen den Inseln . . . . . . . . . 366

$\mathrm{Z}$ ehnte $\mathrm{s}$ a p it e l. Geschichtliche Erinnerungeu, - Fahrt nach Trinidad, - Abrcise nach dem Festlande . . . 374 





$$
y_{\varepsilon}
$$


